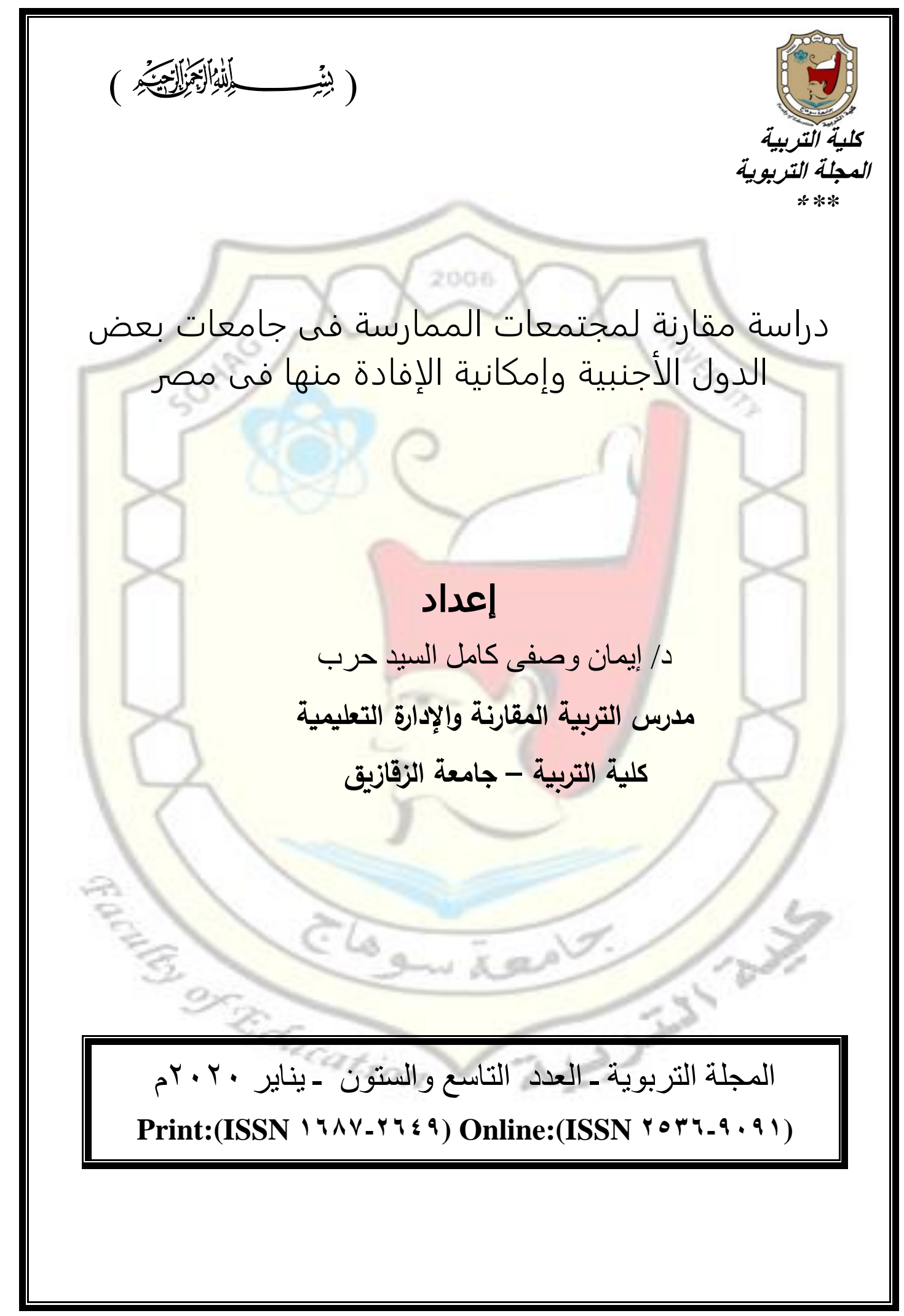


يهاف البحث بصورة أساسية إلى الاستفادة من أبرز ملامسح تطبيقات مجتمعات الممارسة فى جامعات بعض الاول الأجنبية فى وضع إجراءات مقترحة لتطبيق مجتمعات الممارسة بالجامعات المصرية، وبما يتماشى مع طبيعة المجتمع المصرى. وفى سبيل تحقيق هذا الهدف استخدم البحث المنهج المقارن، وسـار البحث وفق هذا المنهج فى مجموعة من الخطوات بدأت بالإطار العام للدراسـة، ثم توضيح الأسـاس الفكرى لمجتمعات الممارسة، ثم تناول البحث طبيعة علاقة مجتمعات الممارسـة بتطوير الجامعات من خلال توضيح دورها فى التنمية المهنية، والتعلُّم الإلكترونى، وإدارة المعرفة فى الجامعات، تـلا ذلك عرض أبرز ملامـح تطبيقات مجتمعات الممارسـة في جامعات بعض الـدول الأجنبيـة، والتحليل المقـارن، ثـم عرض وتحليل واقـع الجهود المصرية المبذولـة فى تطوير الجامعات فى ضوء مفهوم مجتمعات الممارسـة، وتضمنت الخطوة الأخيرة الإجراءات المقترحة لتطبيق مجتمعات الممارسة فى الجامعات المصرية فى ضوء الاستفادة من الإطار الفكرى وخبرات جامعات بعض الاول الأجنبية.

communities of practice: مجتمعات الممارسة professional development: التنمية المهنية e-learning التعلُّم الإكترونى إدارة المعرفة: knowledge management 


\begin{abstract}
The main objective of this research is to develop proposed procedures for the Implementation of the communities of practice in Egyptian universities

To achieve this purpose, the research used the comparative approach. The research proceeded according to this approach in a series of steps, starting with the general framework of the study, then clarifying the theoretical basis of communities of practice. The research clarified the nature of the relationship between the communities of practice and the development of universities by clarifying their role in professional development, e-learning, and knowledge management in universities. The research presented the most prominent features of the Implementation of communities of practice in the universities of some foreign countries, and then comparative analysis. Analyzing the reality of Egyptian efforts in developing universities in the light of the concept of communities of practice. The last step included the proposed procedures for the Implementation of communities of practice in Egyptian universities in light of the theoretical framework and the experiences of universities of some foreign countries.
\end{abstract}


أصبح تطوير الجامعات يمثل موضوعًا حيويَّا لأقلام المفكرين والباحثين خاصـة فى هذا العصر الذى يتميز بـالتفير السـريع والتقـدم العلمس والتكنولـوجى. ولقـد حاولت العديــ مـن

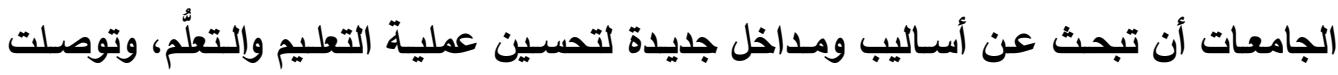

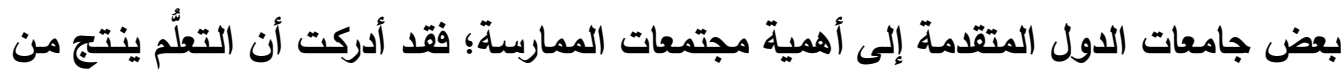
مشـاركة الأفراد في السياق الاجتمـاعى، وأن تكوين المجتمعات داخل الجامعات يـوفر البيئة الآمنة للأفراد للتعلُّم من خلال التفاعل مع الآخرين. وتعتمد مجتمعات الممارسة على التغييرات المؤسسية التى ثُيِِّر عملية التنمية، وتشبيع الابتكـارات فـى المجـال التقنـى، والمشـاركة المفتوحـة والعمـل الجمـاعى، والتتسـيق المـنظم الهـادف، ومشــاركة الخبـراء، ووضــع الأهـداف والتوجيهـات المشــركة فـى العمـل، وهياكـل

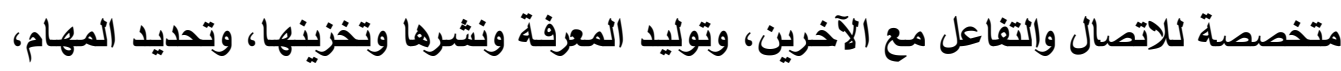

والاستخدام الجيد للتكنولوجيا"(')

وتتضمن مجتمعات الممارسة ثلاثة عناصر أساسية وهى (ץ): المجتمـع: ويشير إلى مجموعة من الممارسين يتفـاعلون مـع بعضهم، وهذا التفاعل يكون من خلال المقابلات وجهًا لوجه أو من خلال البيئة الافتراضية.

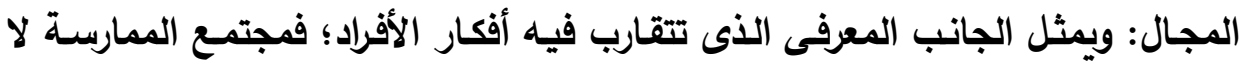
ينشأ من تجمعات عثوائية ولكنه يُبنَى من خلال مجموعة من الأفراد لهم اهتمامـات وقضـايا وأهداف مشتركة.

الممارسـة: إذ يثـارك الأفراد فـى ممارسـات معينـة وتصبح للديهم موارد وأدوات محددة ويتبادلون الخطط والأنشطة كما يتبادلون خبراتهم ومهاراتهم والتغذية الراجعة. وأعضاء مجتمعات الممارسة فى الجامعات لايهم اهتمامـات مشتركة وقضـايا ومشكلات واقعية، ولايهم الرغبة فى مواجهة هذه المشكلات؛ لذا فإن " مجتمعات الممارسـة تقوم على افلى

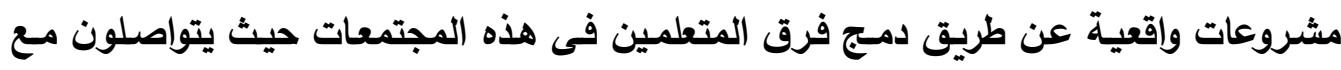

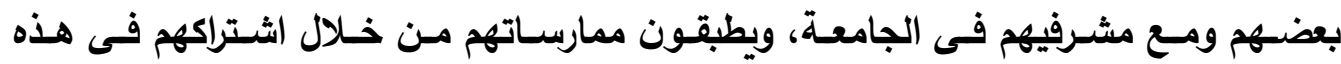

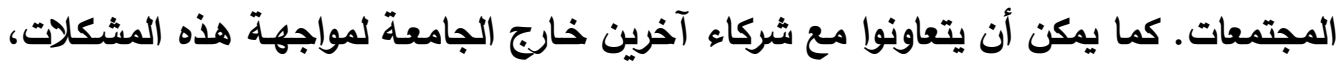

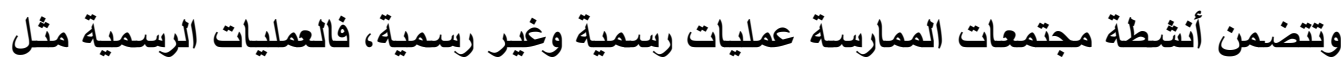




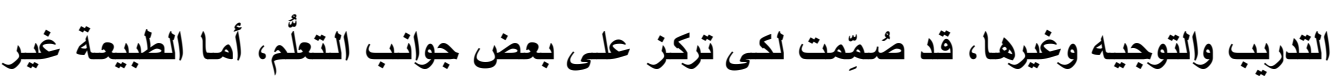
الرسمية لمجتمعات الممارسة فإنها تتضمن الأنثطة التى تحدث خلال العياة الداريسية والتى لعضى

تساعد على تنمية المعارف والمهارات العملية"(().

وتتعدد وتتنوع فوائد المشاركة فى مجتمعات الممارسة؛ فهى تعمل على زيادة الدافعية

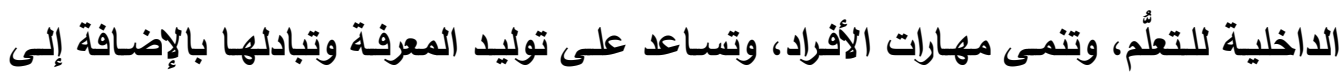

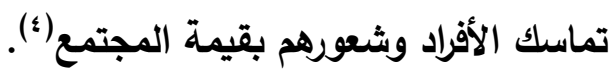

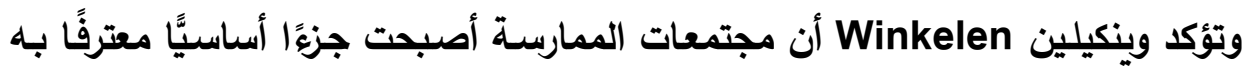

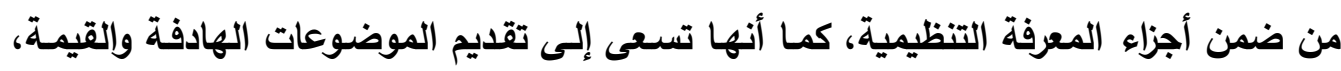

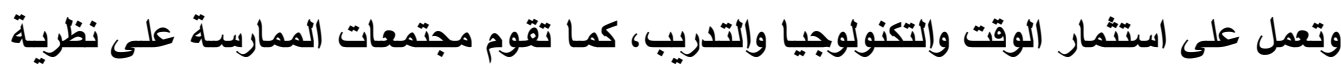

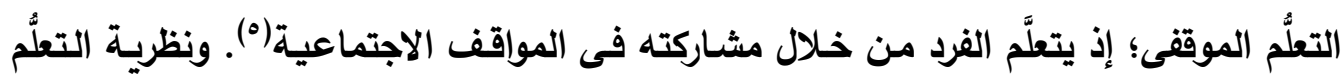

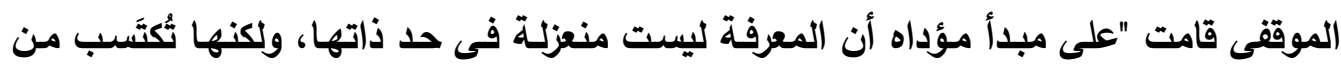

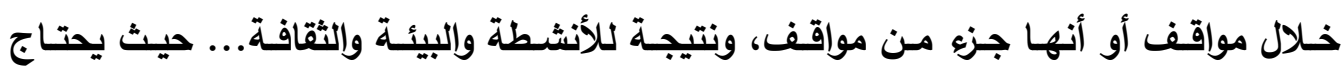

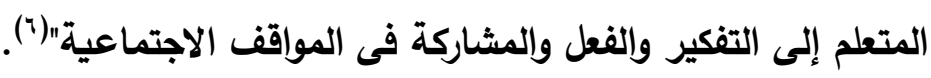
وتقوم مجتمعات الممارسـة بدور بارز فى التنمية المهنية، وإدارة المعرفة، وتحسين

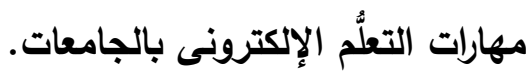

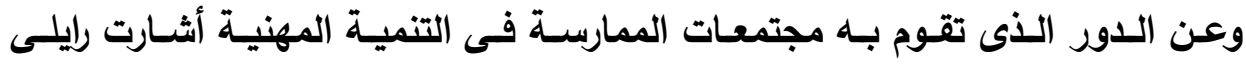

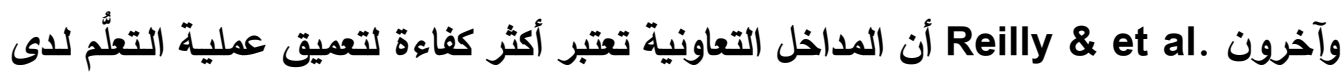

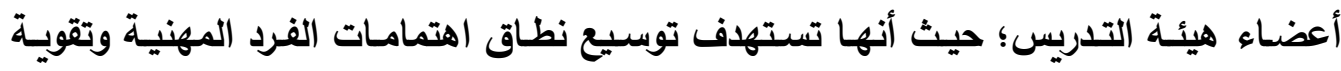

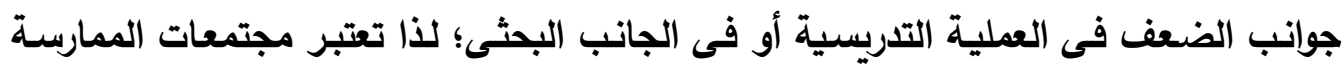

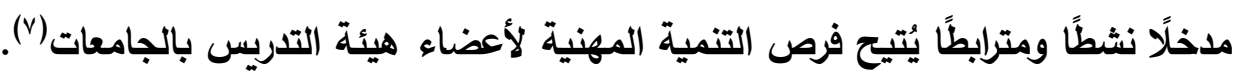

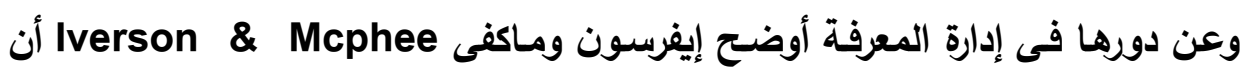
مجتمعات الممارسة تقدم آلية عملية لإدارة المعرفة، فهى تقدام نمونجَا لفهم المعرفة وإِ إدارتها

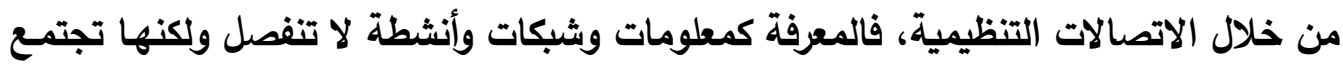
فى مفهوم أساسى وهو الممارسة الاجتماعية كسبيل للمعرفة؛ أى أن المعرفة تتولا من خلانلال الممارسات الاجتماعية وهو ما يسعى نموذج مجتمع الممارسة إلى تحقيقه (^). 


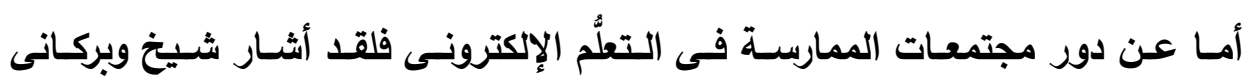
Chikh \& Berkani

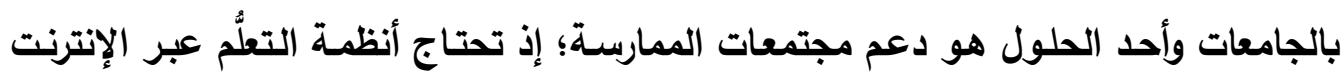
إلى جها وتكاتف فى مراحلها المختلفة من تحليل وتصميم وتنفيذ ومشاركة، وهو ما تقدمـه

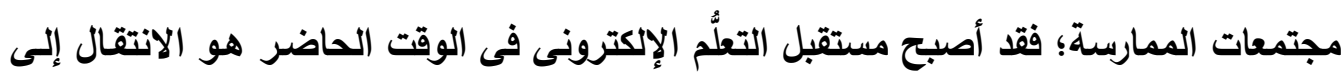

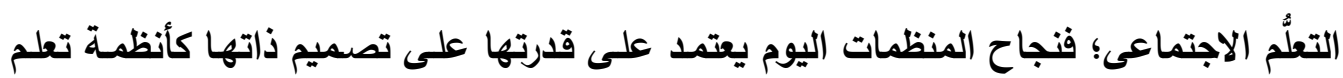

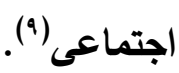

ولقد أدركت العديد من الدول المتقدمة أهمية مجتمعات الممارسة، وسعت جامعات هذه الدول إلى تصميم وبنـاء هذه المجتمعات لتطوير جامعاتها ومواجهة المشكلات التى تتعلق

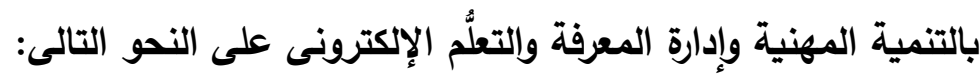

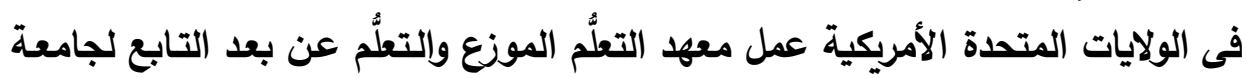
فرجينيا Virginia Tech على الاستفادة من مجتمع الممارسـة لمواجهة المشكلات المتعلقة

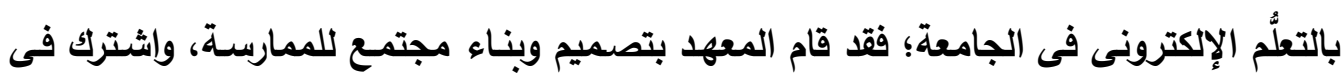

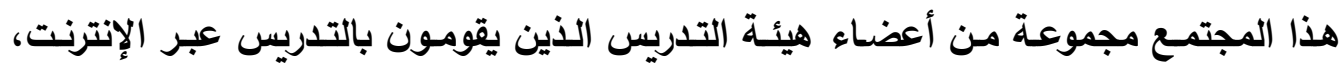

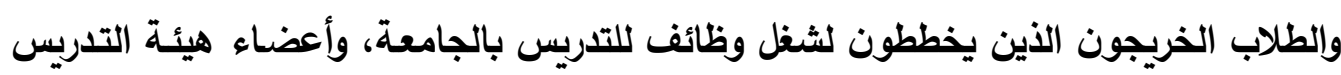

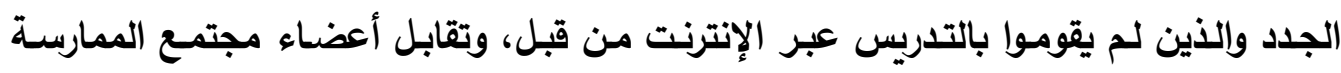

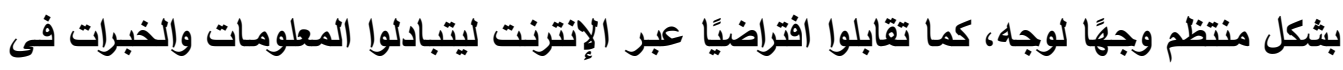

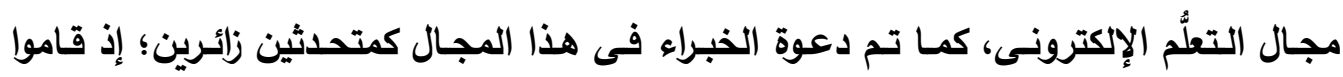

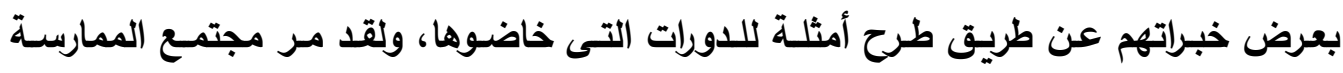

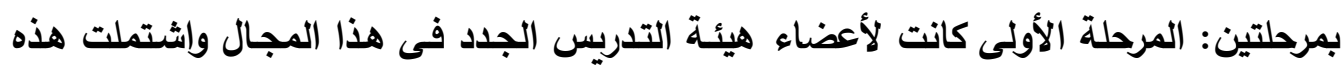

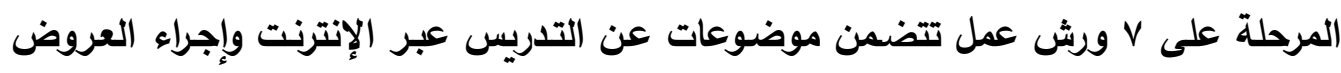

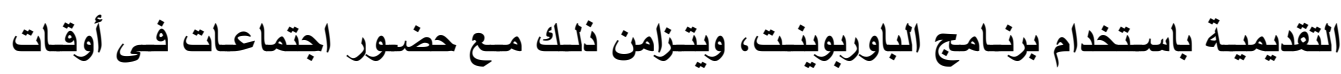

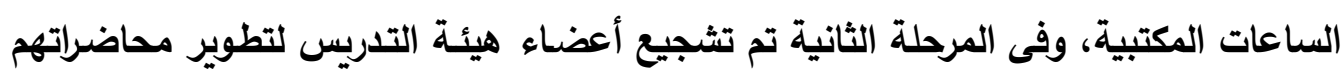
التى تقدم عبر الإنترنت عن طريق حضور 7 ورش عمل يتم فيها التعرف على الاستراتيجيات

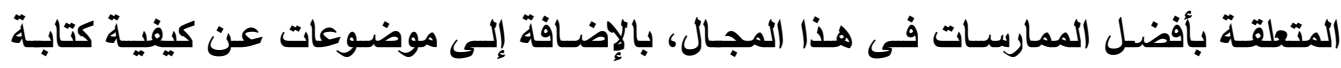
الأهداف، والاتصـال الفعّال، والتقييم عبر الإنترنت وضمان الجمان الجودة، كما كان هناك مجموعة 
من الجلسات التعاونية يقوم فيها الأعضساء بالتطبيق الفعلى لمحاضراتهم عبر الإنترنت، وتم تقييمها من الأعضاء الخبراء فى مجتمع الممارسة (·'). وفى جنوب أفريقيا قامت جامعة رودس Rohodes University بتطوير نموذج لمجتمـع الممارسـة لتطبيق المعرفة ونقلها وتقاسمها مـع المجتمع المحلى من خـلال مشروع جمـع بين الجهود التعاونية لأعضـاء هيئة التدربس والطلاب بكليـة علوم الكومبيوتر وكليـة التربية من أجل نقل المعرفة وتقاسـها فى مجال تكنولوجيا المعلومـات والاتصـالات بمنطقة جراهامستاون Grahamstown حيث قام أعضـاء مجتمع الممارسـة بالجامعة بتقديم الدعم لمدارس المنطقة ومعلميها فى مجال التكنولوجيا، كمـا قام مجتمع الممارسـة بالجامعة بتنظيم اجتماعات مع معلمى المدارس لتنمية مهاراتهم الفنية والتقنية، وتصميم موقع إلكترونسى يثمل كافـة المعلومـات عن المعلمين وبيانًا بالموارد الماديـة والتكنولوجيـة بمدارس المنطقة، وكـان هناك دعم خارجى لمجتمع الممارسة من مجموعة من الثركات مثل شركة ديل Dell، وشركة تليكوم Telkom، ومؤسسـة شـاتلوورث Shuttleworth، الذين قدموا دعمًا إلى مجتمـع الممارسـة مـن خـلال تـوفير خدمـة الاتصـال بالإنترنت عبر الاتصـال اللاسلكى، وتقديم أجهزة الحاسب الآلى إلى المدارس، واستطاع أعضاء مجتمع الممارسة تدربب المعلمين والطلاب فى بلى مجال تكنولوجيا المعلومـات والاتصـالات، كمـا تم تحفيزهم لرؤيـة أنفسهم مشـاركين فى بنـاء

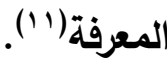

وفى أسـتراليا تـم تأسـيس مجتمـع الممارسـة للتعليم مـن أجـل الاســـامة بجامعـة تسمانيا University of Tasmania عام II ب ولقعد هدف مجتمع الممارسـة إلى دعم التنمية المهنية لأعضاء هيئة التدريس من خلال تبادل خبراتهم فى تحديث التعليم فى إطار

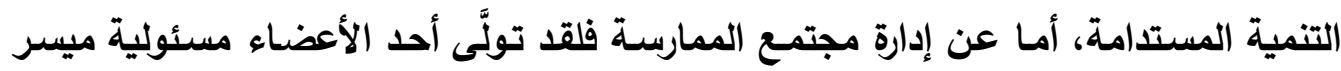

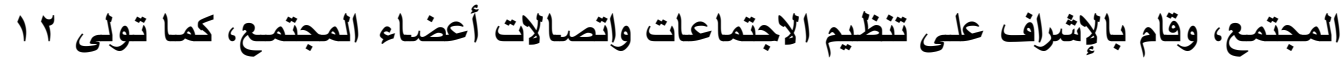
عضوًا من الأعضاء الناشطين مسئولية الإدارة من خلال نموذج القيادة الموزعة، وكان هؤلاء الأعضاء من تخصصات مختلفة فى (الطب والسياسـة والجغرافية والفلسفة والدراسـات البيئية وعلوم الصحة وغيرها)، وانضم إلى المجتمع ؟ عضوًا من جميع أنحاء الجامعة سـاهموا فى ألى مجموعة متنوعة من الأنثطة على مختلف المستويات، وتناول أعضاء المجتمع مجموعة من 
الموضوعات مثل البحث والتعليم والثراكة المجتمعية فى إطار التنمية المستـامة، وتم تمويل

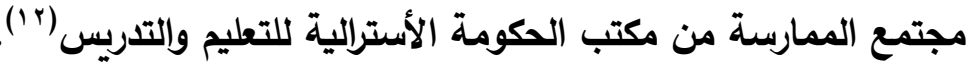
وعلى الصعيد المحلى تبذل جمهورية مصر العربية العديد من الجهود من أجل تطوير

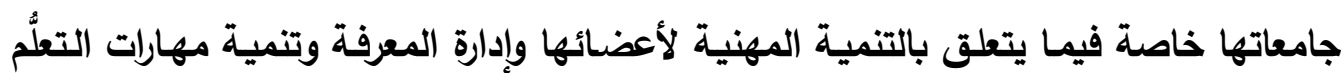
الإكترونى، وظهر ذلك فى تنفيذ العديد من المشروعات على النحو التالى (ז'ا'): -مشروع تطوير كليات التربية FOEP. - مشروع توكيد الجودة والاعتماد QAAP.

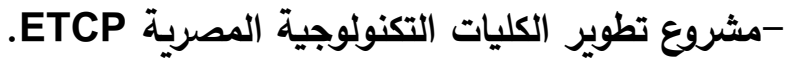
-مشروع تكنولوجيا المعلومات والاتصالات ICTP-مشروع تنمية قدرات أعضاء هيئة التدريس والقيادات FLDP. -مشروع صندوق تطوير التعليم العالى مEEPF. "ويعد ظهور مشروعات تطوير التعليم العالى فى بداية العقد الأول من القرن الحادى والعشرين، الحدث الأهم فى مجال التعليم العالى فى جمهوريـة مصر العربية فى هذه الحقبة

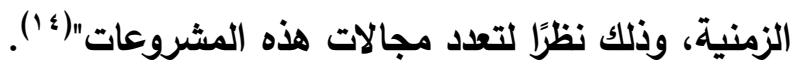

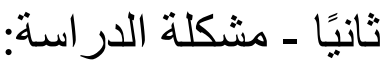
على الرغم من الجهود السابقة التى قامت بها الدولة لتطوير الجامعات المصرية إلا أن جامعاتنا ما زالت تعانى من العديد من المشكلات وأوجه القصور التى تقف عائقًا أمسام تحقيق أهدافها، ومن أوجه القصور هذه على سبيل المثال:

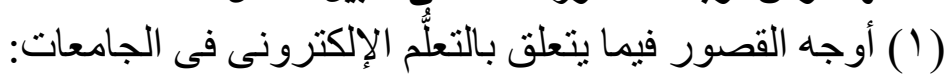

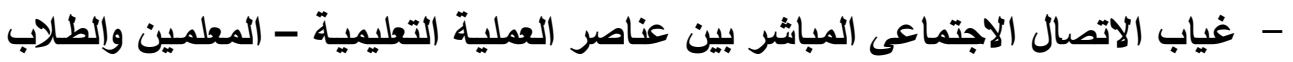
والإدارة - مما يؤثر سلبًا على مهارات الاتصال الاجتماعى لاى المتعلمين(ه (1).

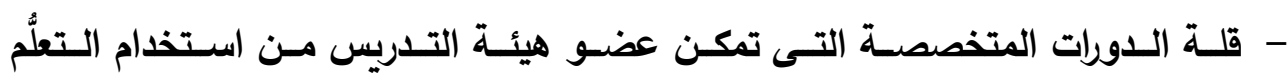
الإكترونى بكفاءة، بالإضافة إلى ضعف مهارات تكنولوجيا المعلومات التى تساعد على هلى

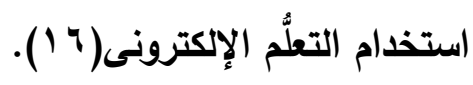
- تَخؤف أعضاء هيئة التدريس من تكنولوجيا التعليم واتجاهاتهم السلبية نحوها، وعدم توفر المهارات اللازمة لاستخدامها لديهم خاصة المهارات الفنية الجديدة(IV) . (Y) أوجه الضعف و القصور فيما يتعلق بالتنمية المهنية فى الجامعات: 
- إهمـال الأسـاليب التدريبية المعتمدة على الجوانب التطبيقيـة وأسـاليب الأداء العملى، واقتصـار أسـاليب التدريب على المحاضرات وورش العمل فقط، وتجاهل الاحتياجـات التدريبية الفعلية لأعضاء هيئة التدريس حسب تخصصاتهم المختلفة(1 ا). - الإجبار على حضور الدورات كشرط للترقية وليس لسد الفجوة لدى المتدرب، وقصور المواد التدريبية، ومقاومة بعض أعضاء هيئة التدريس لعملية التنمية المهنية للقصور فى نشر هذه الثقافة( 9 (1). (T) أوجه الضعف و القصور فيما يتعلق بإدارة المعرفة فى الجامعات: - قلة الوعى بأهمية تثـاطر المعارف وإلخبرات والعمليات المعرفة بصفة عامـة، وفقدان مهارات الحوار والتفاعل ومهارات الاتصـال عامـة، وفقدان الدفء والتعلاقات الإنسانية

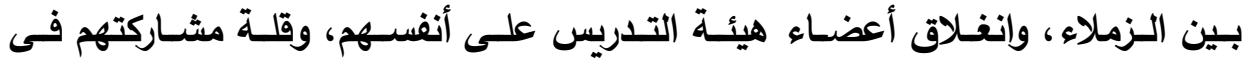

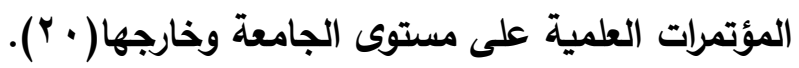
- قلة مواكبة الجامعات للتقدم التقنى والمعرفى، وتضاؤل جهودها فى عملية المشاركة فى التطوير والابتكار( ( ') . - إن المشكلات السابقة تجعلنا نفكر فى مداخل وأسـاليب جديدة لمواجهتها، وربمـا يكون

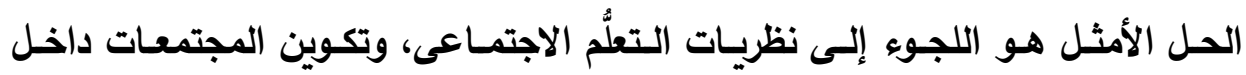
الجامعـة للتشـجيع على تبـادُل المعلومـات والمعـارف، ورؤيسة المعرفـة مـن منظورهـا

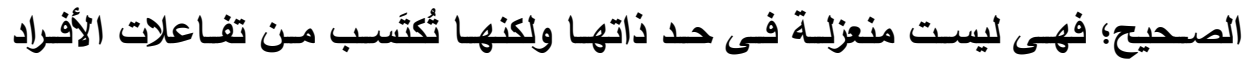
ومشـاركتهم فى المواقف المختلفة، إن كل ذلك يمكن تلخيصسه في مفهوم وإحد وهو "مفهوم مجتمع الممارسـة" الذى انتشر فى العديد من جامعات الدول المتقدمـة لتعزيز التنافسية ومواجهة العديد من المشكلات. وفى ضوء ما سبق يحاول البحث الحالي الإجابة عن السؤل الرئيس التالي : - كيف يمكن الاستفادة من الاراسـة المقارنـة لمجتمعات الممارسـة فى جامعات بعض الاول الأجنبية فى تطوير الجامعات المصريةٌ؟ - وينبثق من هذا السؤال الرئيس عدة أسئلة فرعية على النحو التالى:

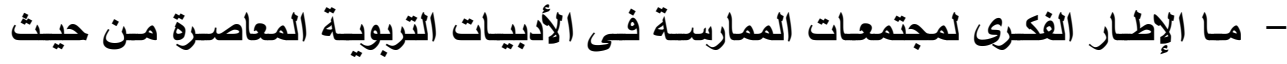
(مفهومها، ونشأتها، وعناصرها، وأهميتها، وخصائصها، ....)؟ 
- مـا طبيعة علاقـة مجتمعـات الممارسـة بتطوير الجامعـات مـن حيث علاقـة مجتمعـات

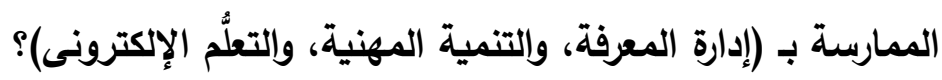

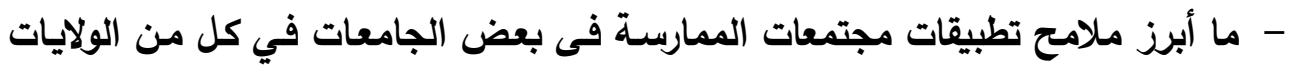
المتحدة الأمريكية و إستراليا و جنوب أفريقيا من حيث إبراز دور مجتمعات الممارسـة

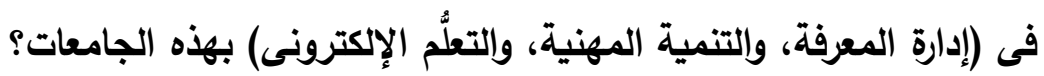
- ما أوجه الثبه والاختلاف بين تطبيقات مجتمعات الممارسة فى جامعات المقارنة؟ - مـا واقع الجهود المصرية المبذولـة فى تطوير الجامعات خاصسة فيمـا يتعلق بـ (إدارة

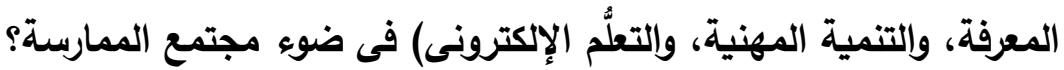

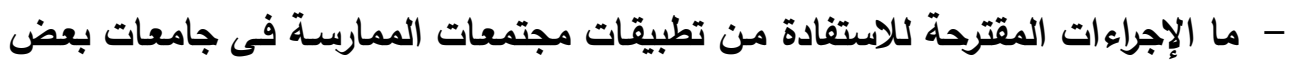
الدول الأجنبية فى جمهورية مصر العربية؟

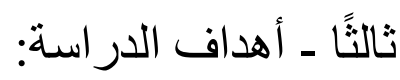

- التعرُف على الإطار الفكرى لمجتمعات الممارسة فى الأدبيات التربوية المعاصرة. - التعرُّف على طبيعة العلاقة بين مجتمعات الممارسة وتطوير الجامعات.

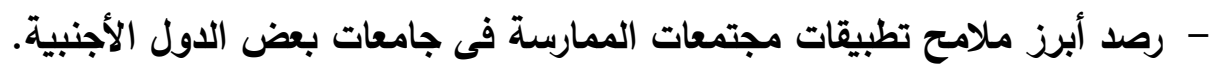
- رصد أوجه الثبه والاختلاف بين تطبيقات مجتمعات الممارسة فى جامعات المقارنة. - الوقوف على واقع الجهود المصرية المبذولـة فى تطوير الجامعات فى ضوء مجتمعات الممارسة.

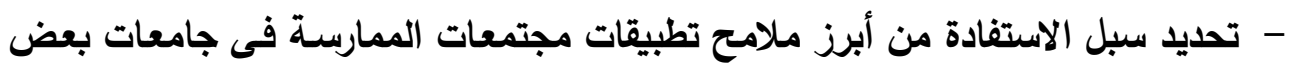

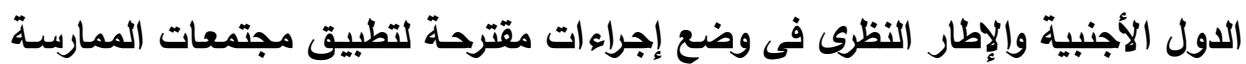
بالجامعات المصرية، بما يتماشى مع طبيعة المجتمع المصرى. 


$$
\text { رابعًا ــ أهمية الدر اسة: }
$$

- قد تعالج الدراسـة الحاليـة بعض المشكلات التى تعانى منها الجامعات المصرية عن طريق تَبِّى فكرة مجتمعات الممارسة مما يساعد على تطوير الجامعة بحيث تكون قادرة على أداء رسالتها وتحقيق أهدافها. - قلة الاراسـات المصرية فحى مجال مجتمعات الممارسـة، ولهذا قد تسهم الدراسـة الحالية فى توفير خلفية نظرية وخبرات جديدة تساهم فى لفت نظر صناع القرار إلى أهمية نشر ثقافة مجتمعات الممارسة بالجامعات المصرية.

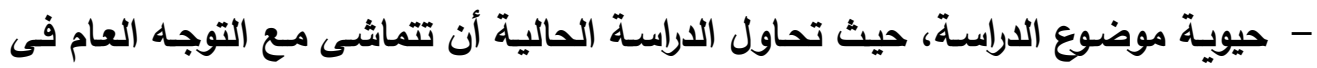

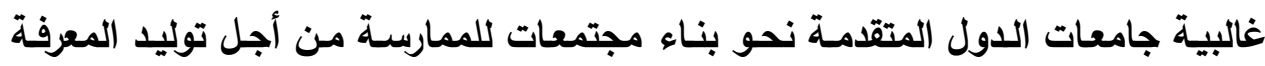
ونقلها وتقاسـها مـع الآخرين ومـع المجتمـع المحلى، وإحداث التنمية المهنية، وتنمية

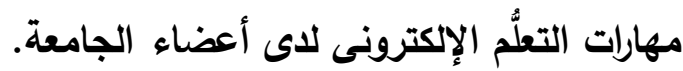

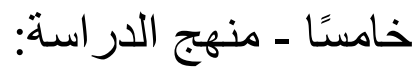

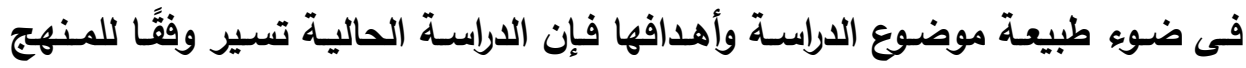
المقارن الأى لا يقتصر على "مجرد تجميع معلومات أو بيانات وصفية أو إحصائية عن نظام

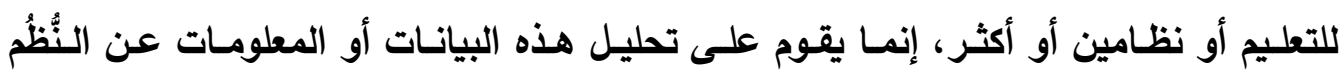

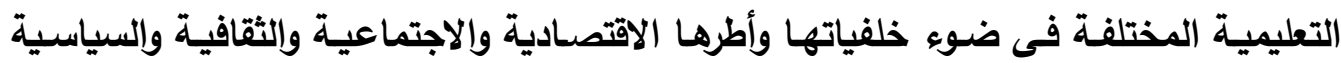

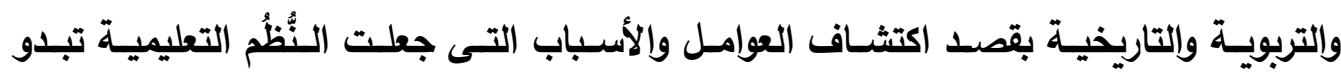
بالصورة التى هى عليها والتى فرضت حلولًا معينة لمشكلات تربويـة واحدة"(Y Y)، وفى ضوي

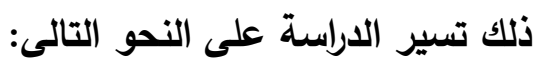
- جمع المعلومات والمعطيات التربويـة المتعلقة بمجتمعات الممارسـة من حيث مفهومها ونشأتها وعناصرها وأهميتها وخصائصها وأبعادها وأنواعها.

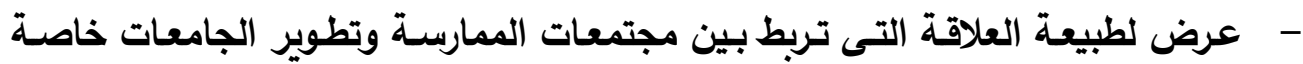
فيما يتعلق (بالتعلُّم الإكترونى والتنمية المهنية وإدارة المعرفة).

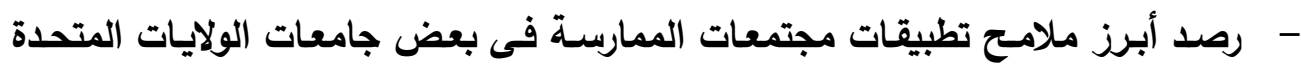
الأمريكية وأستراليا وجنوب أفريقيا. 
- - تحليـل مقـارن لإبـراز أوجـه الثـبه والاختلاف بين تطبيقـات مجتمعـات الممارسـة فيى

$$
\text { جامعات المقارنة. }
$$

- الوصول إلى إجراءات مقترحة لتطبيق مجتمعات الممارسـة فى الجامعات المصرية بما

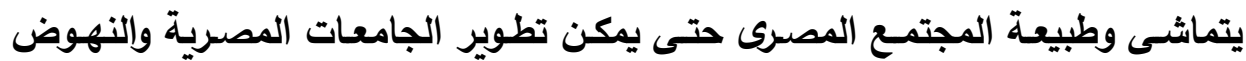

$$
\text { سادسًا ـ ـدوراتها. }
$$

تقتصر الدراسة الراهنة على الحدود التالية:

ا - الحدود الموضـوعية: فيمـا يتعلق بالإطـار الفكرى لمجتمعـات الممارسـة تقتصر الدراسـة

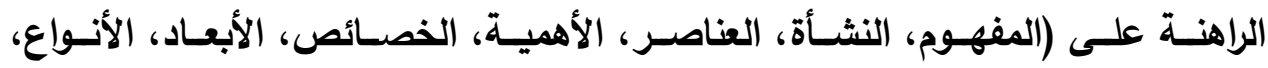
الاعتبارات الواجب مراعاتها عند تصميم مجتمعات الممارسـة بالجامعات والعقبات والقيود

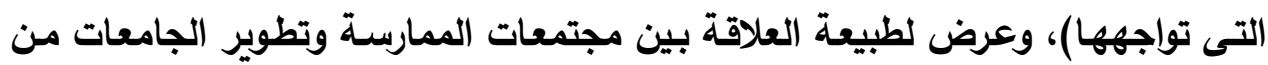

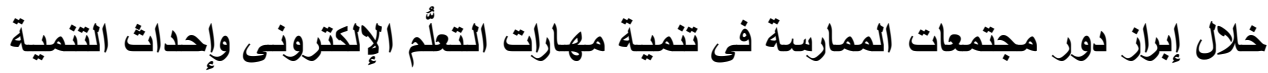
المهنية للأعضاء وإدارة المعرفة بالجامعات.

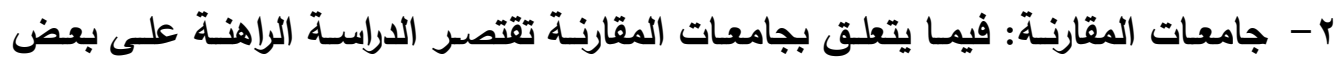

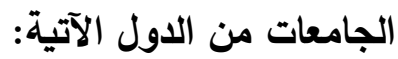
أ- الولايات المتحدة الأمريكية: ومبررات ذلك: اشتهرت الجامعـات الأمريكيـة على مستوى العـالم بجـودة مرافقها ومواردهـا وهيئـات

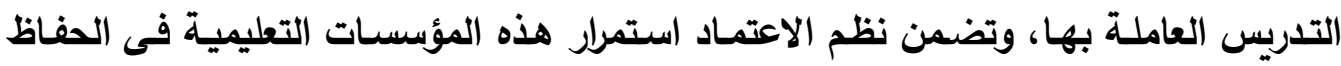

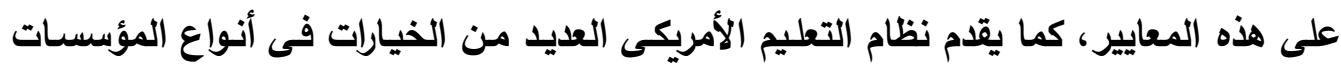

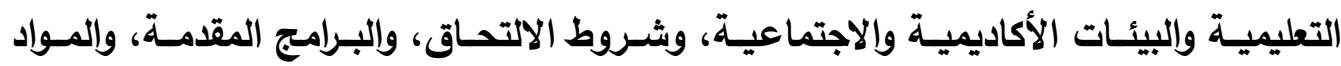
الاراسية التى يتم التخصص فيها(ب Y) ب- أستراليا: ومبررات ذلك:

تتمتـع الجامعات الأسترالية بثـهرة عالميسة فى العديد مـن فروع المعرفة، وبفضل مـا

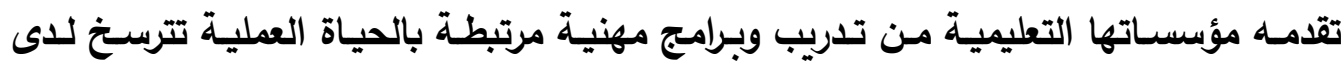

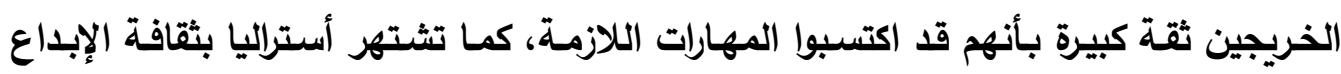
والبحث العلمى المكثف وتعمل على جذب الطلاب والباحثين من جميع دول العالم(؟ ؟). 
ج- جنوب أفريقيا: ومبررات ذلك:

سعى حكومة جنوب أفريقيا فى العقود الأخيرة إلى الاهتمـام بالتعليم الجامعى وتحقيق جودته، وذلك من خلال تبنّى بعض المداخل والآليات الحديثة للتطوير والتحسين المستمر ،

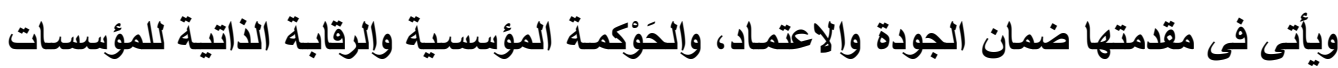

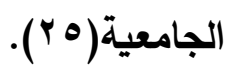

\section{Communities of Practice}

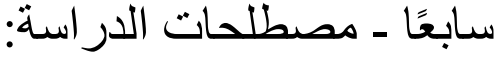

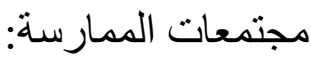
تعرف مجتمعات الممارسة بأنها: مجموعة من الأفراد يتشاركون الاهتمام حول شىع مـا يفعلونه ويتعلمون كيفية فعله بصورة أفضل لأنهم يتفاعلون معًا بانتظام(؟ Y).

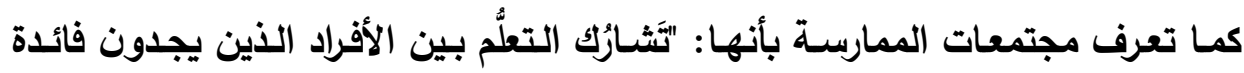

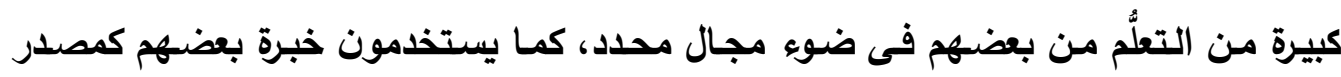

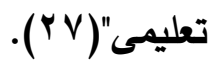
وأنها: مجموعة من الأفراد الذين يشتركون فى الاهتمـام أو الثـفف بثـع مـا يفعلونه،

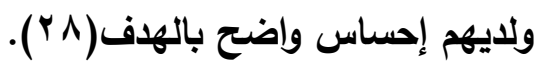
ويمكن تعريف مجتمعات الممارسـة بالجامعة إجرائيًا بأنها: مجموعة من الأفراد الذين

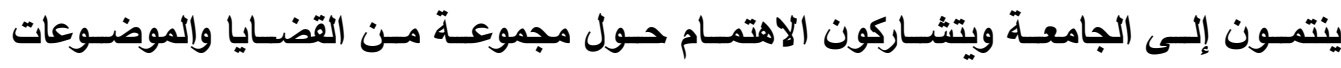

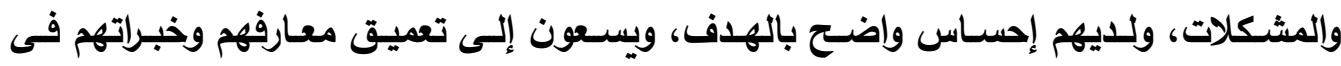
مجالات اهتمامهم من خلال التفاعل المستمر بينهم حتى تحقق الجامعة أهدافها المرجوة. Knowledge Management

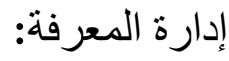
تعرف إدارة المعرفة بأنها: "العمليات التى تهدف إلى إدارة الرصيد الفكرى للمؤسسـة من خلال تطوير المعرفة، وتخزينها، واستخدامها، وتقاسمها، وبذلك تتضمن إدارة المعرفة تحديد

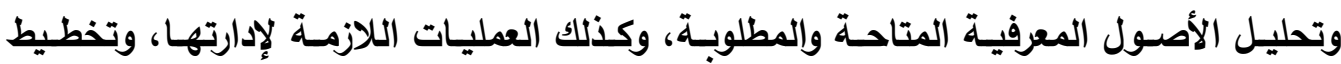
ومراقبة هذه العمليات بحيث تساعد فى تطوير وتحسين المعرفة لدى المؤسسـة، وتسـاهم فى ولى ولهي

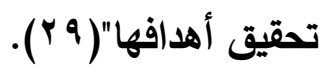




\section{Professional Development}

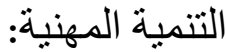

تعرف التنميـة المهنيـة بأنها: "تلـك الجهود المقصـودة التـى تقـوم بهـا المؤسســات

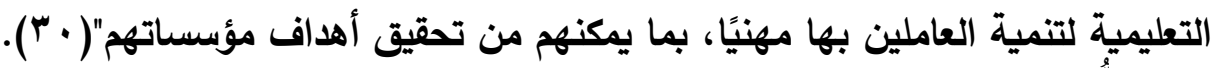
E-

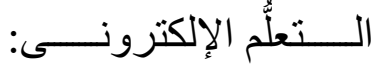

\section{Learning}

يعرف التقلُم الإكترونسى بأنسه: "نمط من التعليم يوظف التقنيات الإكترونيـة المتاحة لذدمة العملية التعليمية لكل فرد يرغب فى التعليم فى أى وقت وفى ألى زئى زمان وفى أى مكان وفى أى مستوى تعليمى" ( آل).

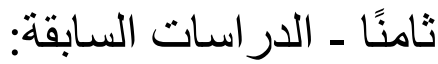

يتم عرض الدراسات السابقة التى تتصل بموضوع الدارسة طبقًا للترتيب الزمنى لها من القديم إلى الحديث، بداية بالدراسات العربية ثم الدارسات الأجنبية، على النحو الآتى:

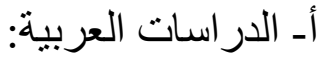

1 - أكرم فتحى مصطفى وإبراهيم سفر الغامدى: المعايير التربويـة والتقنيـة لتصميم

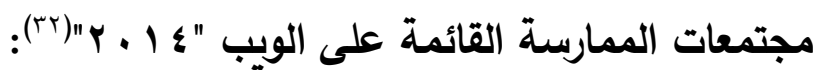
هدفت الاراسـة إلى تحديد المعايير التربويـة اللازمـة لبناء شبكة الممارسة المجتمعية المابة

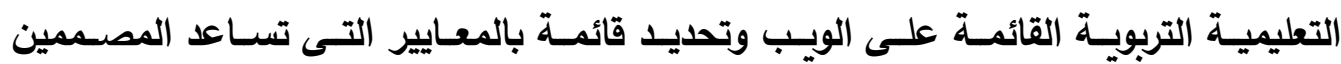

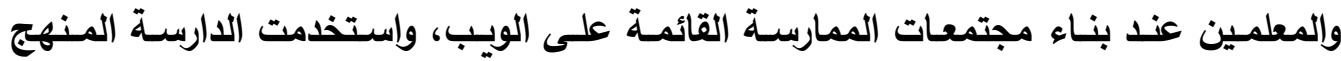
الوصفى التحليلى، وتوصلت الدراسة إلى مجموعة من النتائج أهمها: أن هناك معايير تتعلق بالمجال فى مجتمعات الممارسـة مثل أن يكون المجال محددًا،

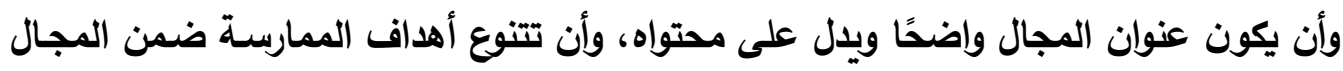

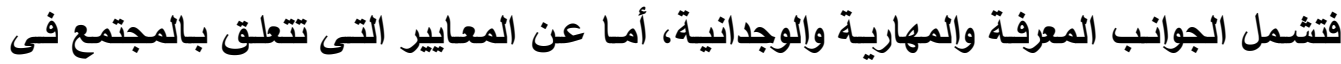
مجتمعات الممارسة عبر الويب فإنها تثمل صياغة ميثاق للمجتمع يتضمن الأهداف والرسالة

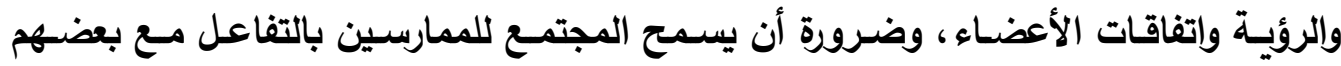

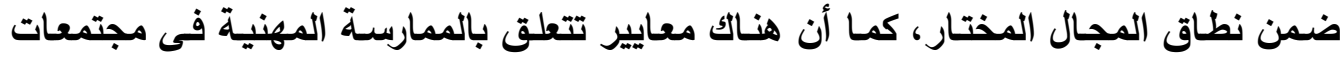

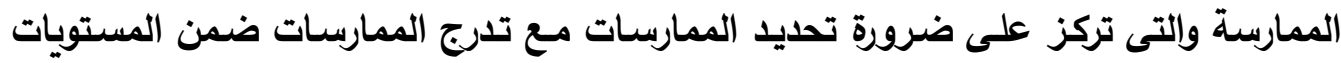

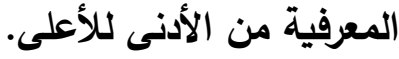


r - نهلة سيد أبو عليوة: دراسـة مقارنـة لبعض تطبيقات نظريـة مجتمـع الممارسـة فى التنميـة المهنيـة لمعلمـ STEM فـى كـل مـن الولايـات المتحدة الأمريكيـة وكوريـا الجنوبية وإمكانية الإفادة منها فى جمهورية مصر العربية "ه 1 ـ ץ"(r)". هدفت الاراسة إلى التعرف على نظريـة مجتمع الممارسـة وتطبيقاتها فى مجال التنمية المهنية للمعلمين المتخصصين فى تعليم STEM، واستخدمت الاراسـة المنهج المقارن على مانى

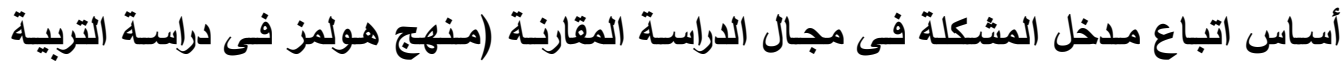
المقارنة)، وتوصلت الدراسة إلى مجموعة من النتائج أهمها: أن هناك اهتمامًا من قبل الدولية بالتنمية المهنية لمعلمى STEM، وغياب دور كليات التربية فى إعداد معلمى STEM، وعدم إنهام استمرارية المعلمين بالعمل فى المدرسـة بعد تدريبهم على طريقة المشروعات مما يؤدى إلى إلى الهـدر فى الوقت والجهد، وقلة الاهتمام بالتوعية المجتمعية على المستوى القومى بتجربـة

.STEM

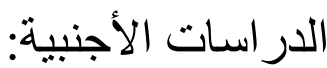

ا - ديفيد كارول David M. Carroll: التعلُّم المهنحى التعاونى: تكوين مجتمع الممارسة بين المدرسة وشركاء الجامعة فى مجال تعليم المعلمين " ا ـ . ץ"( ع ب):

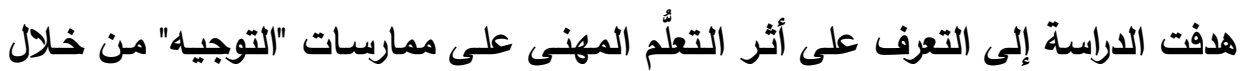
مجتمعات الممارسة وكيفية تأثير التعاون بين المعلمين فى مجتمعات الممارسـة على التعلُّم وبنـاء المعرفة حول عملية التوجيه فى سياق البرنـامج التعليمى الذيى تقدمسه جامعة ولايـة ميتشيجان بالاشتراكك مـع مدرسـة الكابيتول الابتدائية، واستخدمت الدراسـة المـذخل التحليلى واعتمــت فـى جمـع البيانـات علـى المقابلـة وإلملاحظـة والاسـتعانة بالتسـجيلات الصـوتية وتسـجيلات الفيـايو، وتوصـلت الدراسـة إلـى مجموعـة مـن النتـائج أهمهـا: أن التعـاون فـى مجتمعات الممارسـة قد سـاعد على تبادل الخبرات فى مجال التوجيه بين المعلمين وتعزيز ممارسـات التوجيه التربوى، كما سـاعد المعلمين المبتدئين؛ فقد استفادوا من خبرة المعلمين والموجهين فى تطوير ممارساتهم فى ضوء معايير محددة وأصبح لديهم القدرة على التخطيط الجيد للاروس والتنوع فى عملية التقويم.

Calherine H. Monahan \& Norina كاثرين موناغان ونورينا كولومبارو (Y) L. Columbaro 
هدفت الدارسة إلى التعرُّف على أثر مجتمعات الممارسة على التنمية المهنية لطلاب

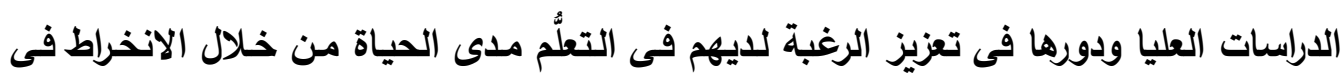

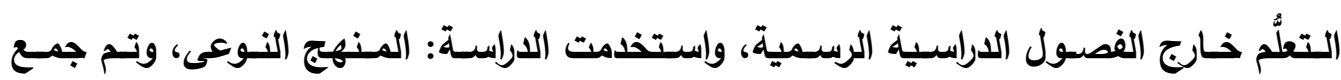
البيانات من خلال المقابلة والملاحظة، وتوصلت الدراسة إلى مجموعة من النتائج أهمها:

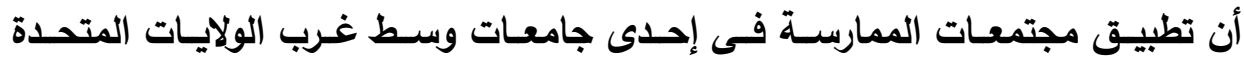

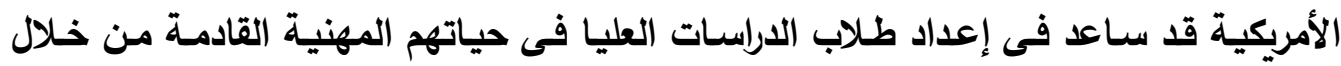

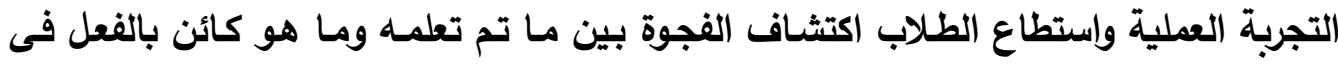

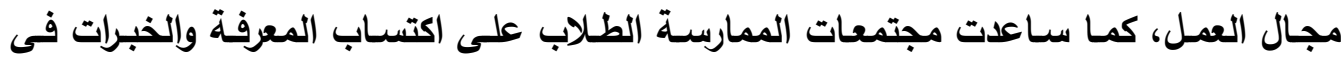
الججال المهنى والقدرة على تطبيق ما تعلموه من خلال تجارب واقعية.

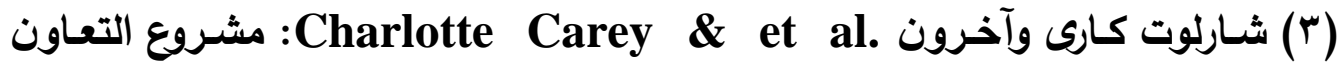

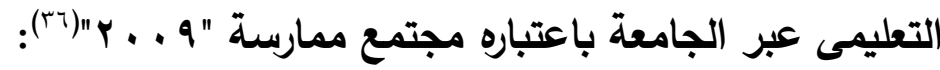
هدفت الدراسة إلى تقييم المشروع التعليمى للتكنولوجيا المتطورة فى جامعة برمنجهام

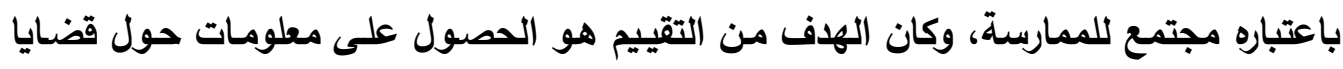

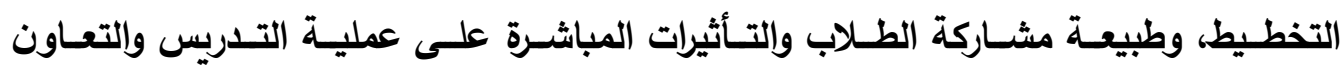

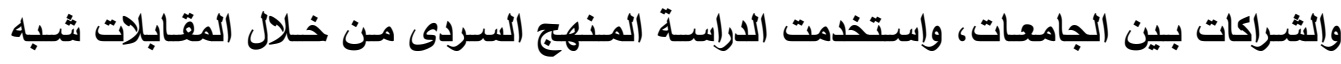

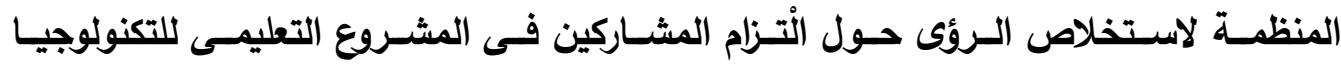
المتطورة، واشتملت عينة الدراسة على 1 ا عضوًا من أعضاء المشروع باعتبارهم المسئولين

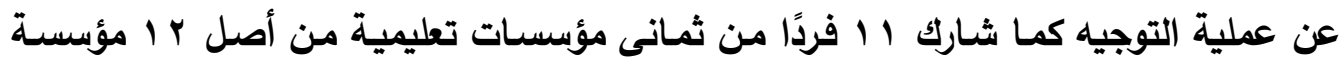
فى إجراء المقابلات، وتوصلت الدراسة إلى مجموعة من النتائج أهها: أن المشروع التعليمى

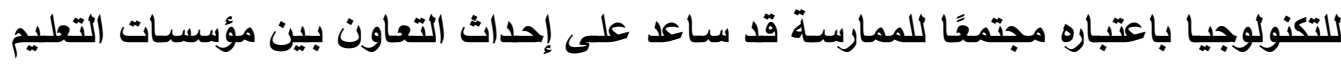

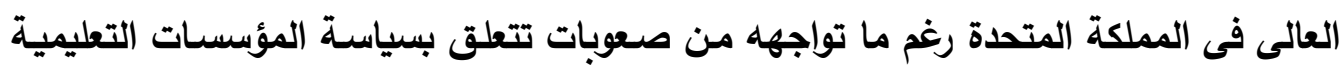

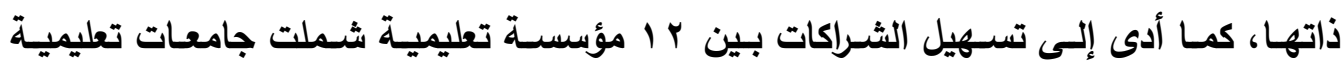
وبحثة، واستفاد الأعضاء المشاركون فى المشروع فى تطوير مهاراتهم فى المجال التدريسى من خلال تنمية مهاراتهم التكنولوجية، وساعد التعاون بين الأعضاء على التوصل فئل إلى أفكار 
(؛) إسمى عارف إسماعيل وآخرون Ismi Arif Ismail \& et al.

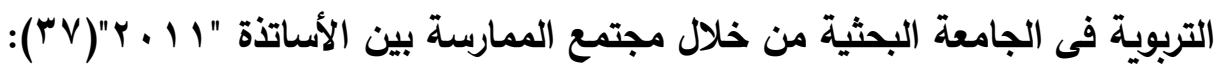

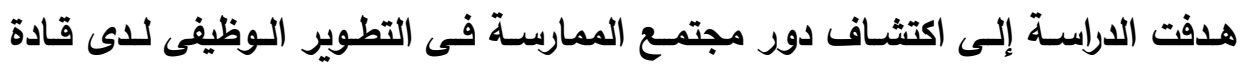
الجامعات المحلية والخارجية، واستخدمت الداراسة المنهج النوعى من خلال إجراء المقابلات

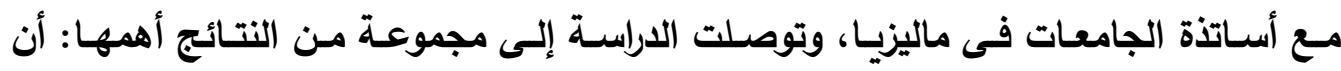
الجامعات الماليزيـة تحتـاج إلى نوع جديد مـن القيادة التى تتماشـى مـع التغييرات العالميـة

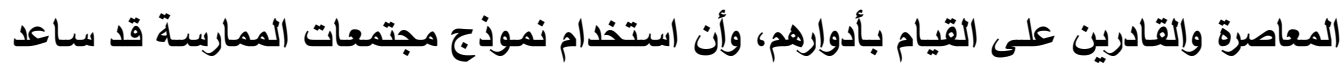
على اكتثـاف تجارب هؤلاء القادة وخبراتهم فى مختلف المراحل المهنية، كما كان القادية قادين على تحديد واجباتهم وأهدافهم والصفات التى يحتاج لها القائد مثل: الإبداع والنزاهة والمثابرة والطموح. (0) إيمى لين ديثـامبو Aimée Lynn deChambeau: دعم نجـاح الطلاب:

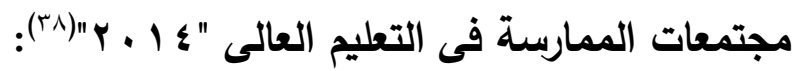
هدفت الدراسـة إلى التعرف على درجة تطور أداء طلاب الدكتوراه فى كلية بريسكوت

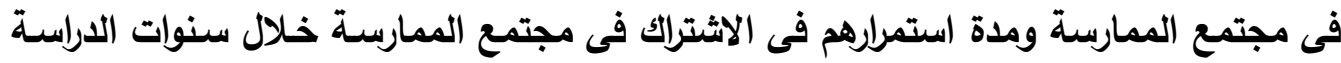

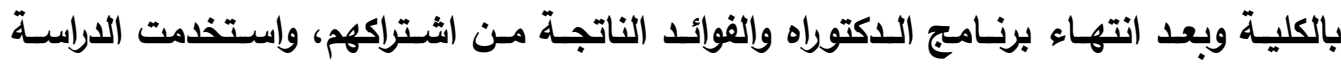

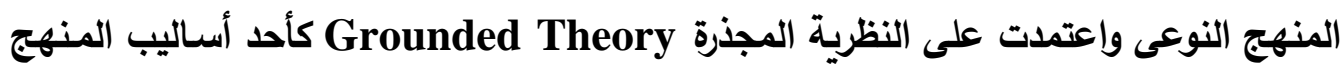
النوعى، واستخذمت الدراسة الاستبيانات والمقابلات لجميع البيانات من المشاركين، وتوصلت

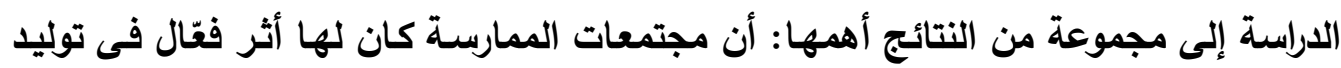

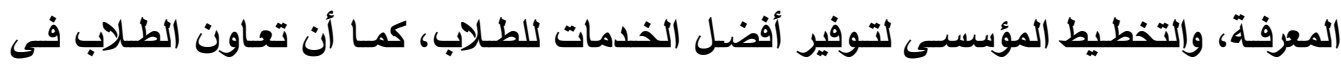

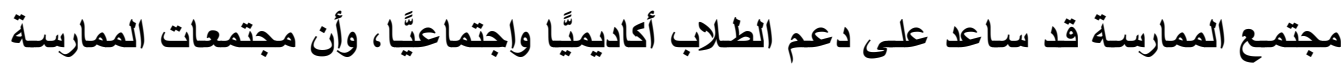

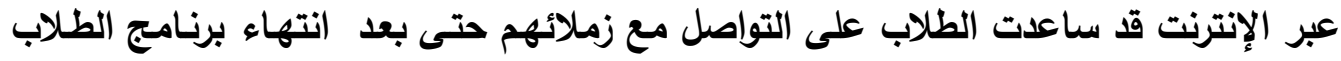
مما أدى إلى ترابط الطلاب وتوفير الفرصة لتبادل المعلومات والمعارف بينهم. 
التعليق على الدر اسات السابقة:

- تشـابهت الدراسـات السـابقة العربيـة والأجنبيـة مـع الدراســة الحاليـة؛ مـن حيـث الاهتمـام

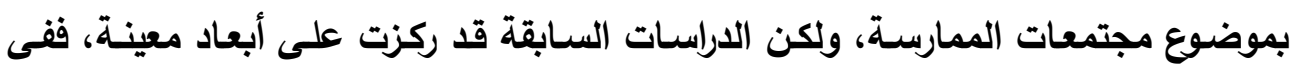

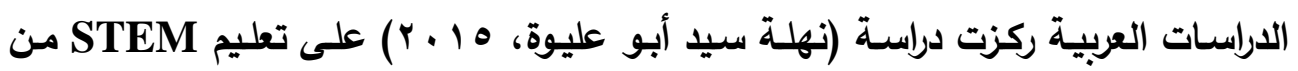

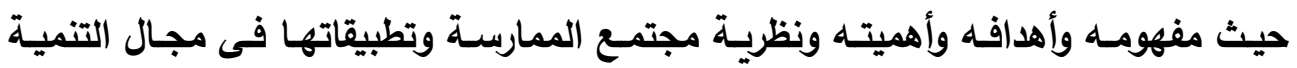

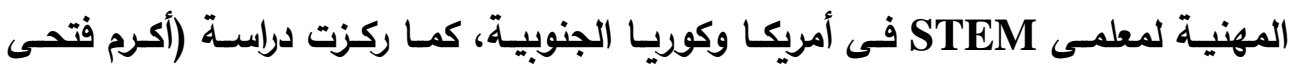

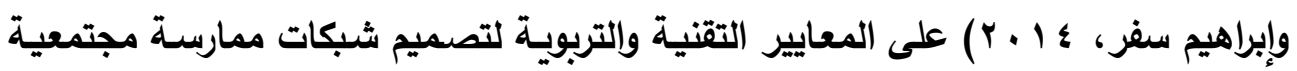
عبر الويب لمساعدة المعلمين وإلطلاب على تحسين أدائهم، بينما ركزت الدراسـة الحالية على مجتمعات الممارسة فى الجامعات ووضع إطار تنظيرى يوضـح (مفهومها، ونشأتها، وعناصرها، وأهميتها، وخصائصها، وأبعادها، وأنواعها، والاعتبارات الواجب مراعاتها عند إندات

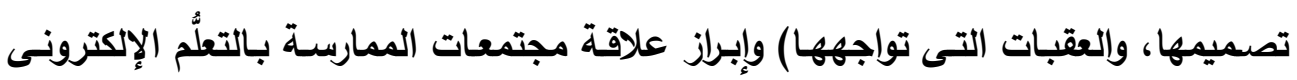
والتنمية المهنية وإدارة المعرفة بالجامعات.

- أما الدراسات الأجنبية فقد اهتمت بمجتمعات الممارسة من حيث دورها فى التنمية المهنية

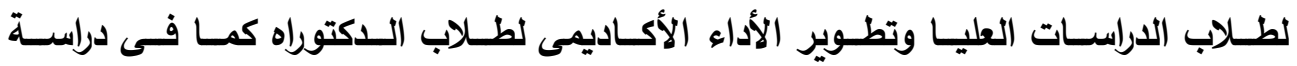
(Catherine \& Norina, Y...q)

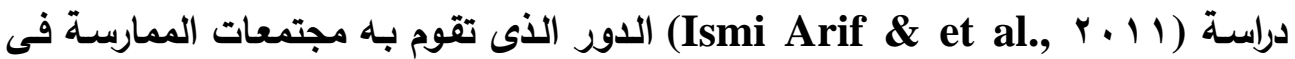
تنمية القيادة التربوية بالجامعات، بينما تحاول الدراسـة الحالية رصد الواقع المصرى على وجه التحديد والاستفادة من خبرات جامعات الدول المتقدمة للوصول إلى إجراءات مقترحة لتطبيق مجتمعات الممارسـة فى الجامعات المصرية لمواجهة قضايا معينة تتعلق بالتعلُّم الإكترونى والتنمية المهنية وإدارة المعرفة بالجامعات؛ لذا فإن هذه الدراسـات سوف تسهرح بثكل فقّال فى تدعيم الإطار التظيرى والخبرات الأجنبية بالاراسة الحالية.

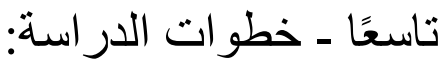

فى ضوء أهداف الدراسة ومنهجها تسير الدراسة الحالية وفق الخطوات الآتية:

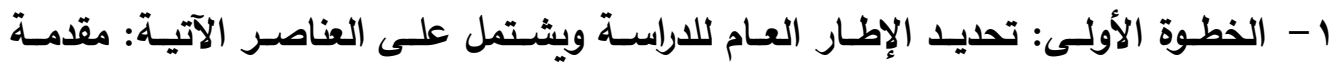

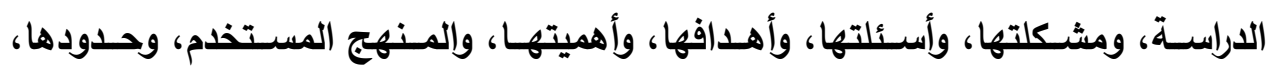
ومصطلحات الدراسة، والدراسات السابقة ذات العلاقة، ثم خطوات الدراسة. 
r- الخطوة الثانيـة: وتتضـمن الأسـاس الفكرى لمجتمعـات الممارسـة مـن حيث: مفهومها،

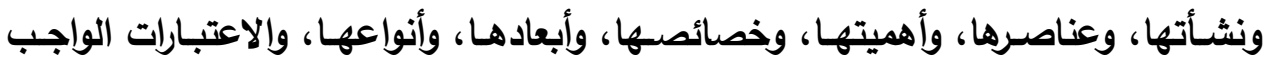

مراعاتها عند تصميمها، والعقبات التى تواجهها.

r- الخطوة الثالثة: تناولت طبيعة علاقة مجتمعات الممارسـة بتطوير الجامعات من خـلال

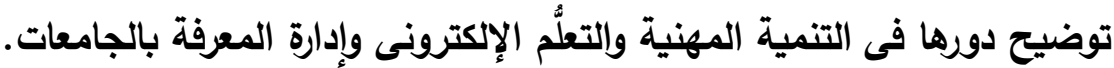

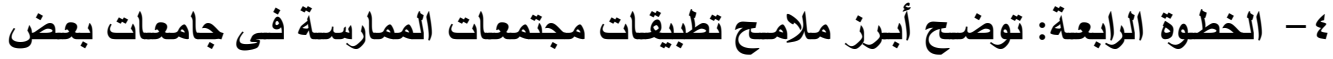

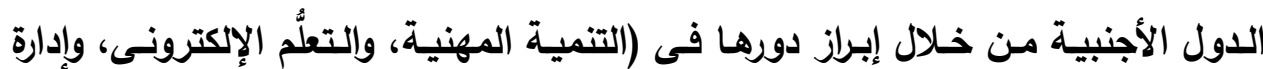
المعرفة) بالجامعات الأجنبية. ه- الخطوة الخامسـة: دراســة تحليليـة مقارنـة لتطبيقـات مجتمعـات الممارسـة فـى جامعـات

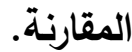
צ- الخطوة السادسـة: تتضمن عرضًّا وتحليلًا لواقِع الجهود المصرية المبذولـة فى تطوير

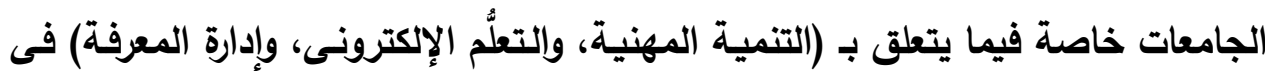
ضوء مجتمع الممارسة. V - الخطوة السـابعة: تثمل الإجراءات المقترحة لتطبيق مجتمعات الممارسـة فى الجامعات المصرية على ضوء الاستفادة من الإطار النظرى وخبرات جامعات بعض الدول الأجنبية وبما يتماشى مع طبيعة الواقع المصرى. الخطوة الثانية: الإطار الفكرى لمجتمعات الممارسة:

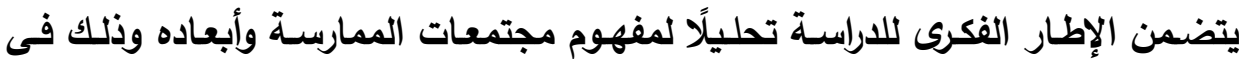

الصفحات التالية: - الصات أو لاً - مفهوم مجتمعات الممارسة: انتثر مفهوم مجتمع الممارسة فى الآونة الأخيرة فى العديد من المجالات الأكاديمية، وعلى الرغم من ظهور هذا المصطلح فى الآونـة الأخيرة إلا أن هذا المفهوم يشير إلى فكرة

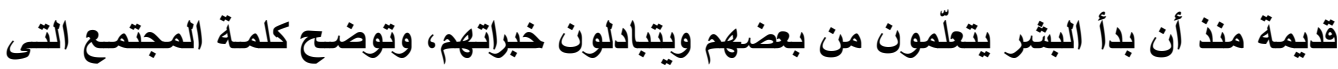
تظهر فى بدايـة المصطلح هذا المعنى الذى يؤكد تعـاون الأفراد وارتباطهم معًا مـن خـلال تفاعلاتهم وعلاقاتهم مع بعضهم. ولقد أشارت برادبورى وميدليمس Bradbury \& Middlemiss أن استخدام مفهوم المجتمع فحى بداية مفهوم مجتمع الممارسـة لـه دلالـة تميزه عن غيره نظرًا لتركيزه على فهم 


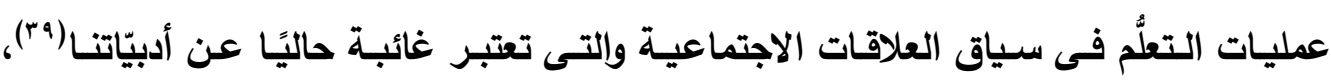

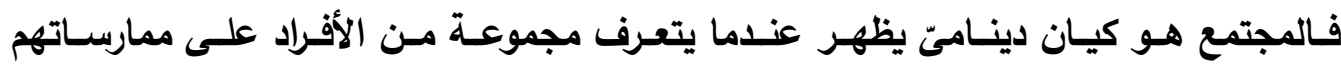
ويتشاركونها ويعتمدون على بعضهم ويصنعون قراراتهم معًا ويعرفون أنهم جزء من شىء أكبر بكثير من علاقاتهم الفردية، ويُلزمون أنفسهم بالتزامات طويلـة المدى لصالح أنفسهم ولصـالح

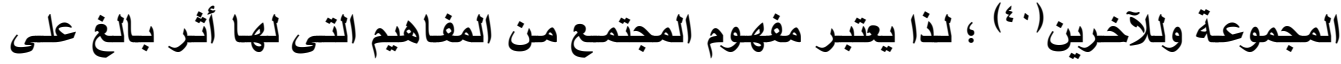

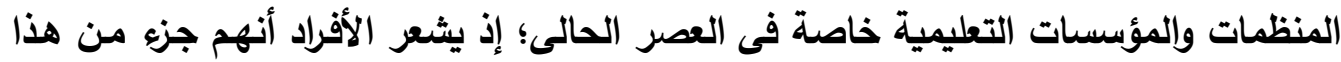
المجتمع، وأن ممارساتهم التى تتم داخل العمل يمكن أن تتم فى إطار من التعاون والعلاقات الاجتماعية.

وبهذا ثُعَّف مجتمعات الممارسة بأنها: "مجموعة من الأفراد الذين يتثـاركون الأهداف،

والأنثطة، والمعرفة فى سياق ممارسة معينة"( ( \&). ويُعرِفها فينجر Wenger وسنايدر Snyder بأنها: مجموعة من الأفراد ملتزمون معًا

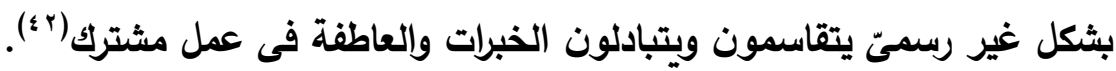
ويعرفها فينجر Wenger وآخرون بأنها: "مجموعة من الأثخاص يتثـاركون القلق والاهتمام بمجموعة من المشكلات أو الشغف حول موضوع محدد ويعمقون معرفتهم وخبراتهم فى هذا المجال من خلال التفاعل المستمر، ويوضح فينجر وزملاؤه أن هؤلاء الأفراد ليس من الضرورى أن يتقابلوا يوميَّا فى العمل، ولكن عليهم أن يجدوا القيمـة الحقيقية من مقابلاتهم وتفاعلهم مع بعضهم حيث يتبادلون المعارف والرؤى وتقديم النصـح والإرشـاد ويسـاعد بعضهم بعضًا فى حل المشكلات، ويتناقشـون المواقف التى تعرضوا لها وطموحساتهم وإحتياجـاتهم، ويتفكرون فـى القضـايا المشـتركة، ويستكشفون الأفكار الجديـدة، وبمـرور الوقت يطورون منظـورًا فربـًا لموضـوعاتهم وتصـبح لــيهم مجموعـة مسن المعـارف المشـتركة والممارســات والأساليب مما يؤدى إلى تطوير علاقاتهم الثخصية، وبناء سبل للتفاعل فيما بينهم، وتنمية

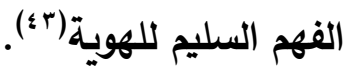
ويتضـح من خـلال التعريفات السـابقة أهمية مفهوم مجتمع الممارسـة داخل المجتمع الجامعى؛ فهو مفهوم يرفض العمل الفردى ويؤكد على العمل الجماعى، يفضل التركيز على

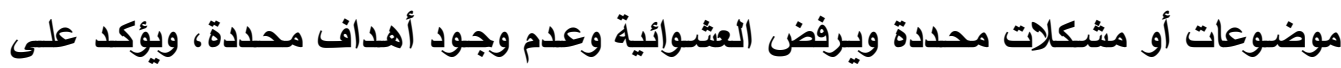

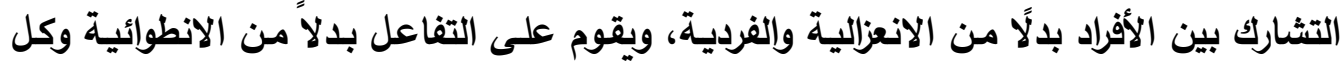


هذه الأمور سوف تساعد أعضاء المجتمع الجامعى على معالجـة المشكلات ومواجهة العديد من القضايا وتوليد المعرفة ونشرها، واكتساب العديد من المهارات والقدرات.

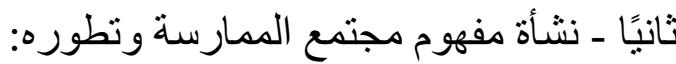

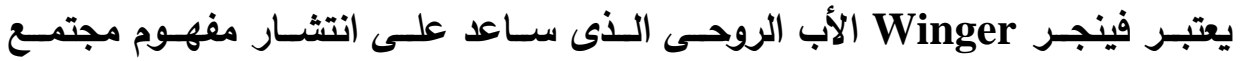

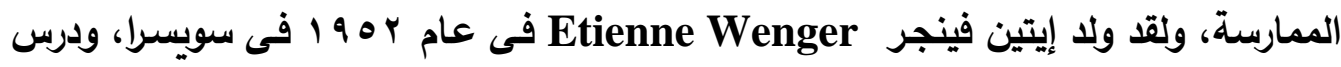
فينجر فى عدة دول هى: سويسرا، والمملكة المتحدة، والولايات المتحدة الأمريكية، وفى عام . 99 ا كانت بداية عمله مـع جين ليف Jean Lave عالم الأنثروبولوجيا الاجتماعية وألفا

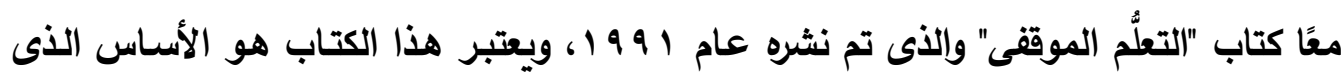

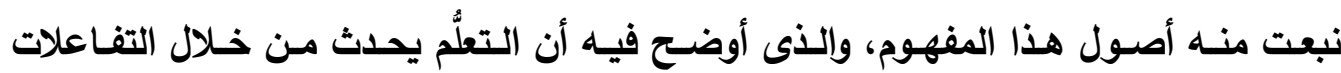

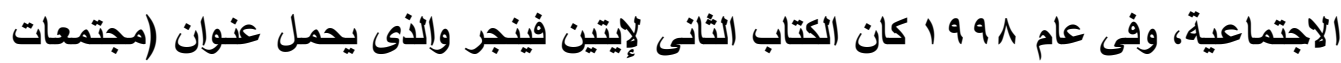

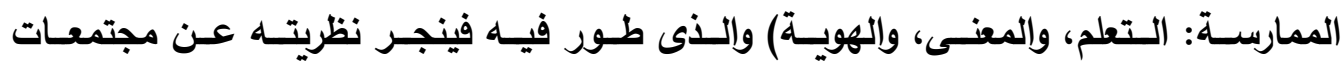
الممارسة(؛ ؛)، ثم توالت مؤلفات إيتين فينجر وغيره فى مجال مجتمع الممارسـة، ولقد استطاع فينجر بمؤلفاته بمساعدة الآخرين أن يطوروا مفهوم مجتمع الممارسـة ويضعوا منظورًا فريدًا له، لذا لا يمكن أن نتجاهل هذه الأعمال نظرًا لأهميتها فى تطوُّر هذا المفهوم وإنتشاره، ومن هن أهم هذه المؤلفات ما يلى:

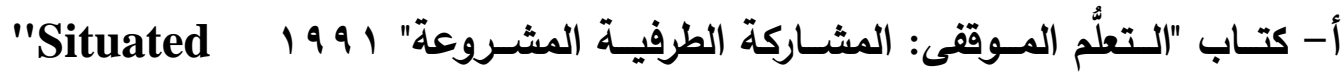
:Learning: Legitimate Peripheral Participation" 1991 ركزت العديــ مـن الأدبيات علـى تحليـل أعمـال فينجر وزملائسه فـى مجـال مجتمعـات

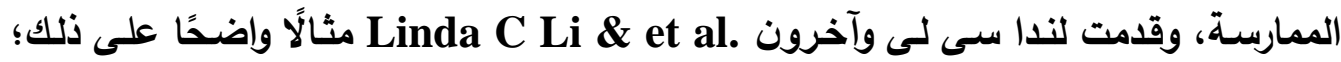
فقد أوضحت أن كتاب (التعلُّم الموقفى: المشـاركة الطرفية المشروعة) هو البدايـة الحقيقية لمفهوم مجتمع الممارسـة ولقد عرف ليف وفينجر مجتمعات الممارسـة فى هذا الكتاب بأنها مجموعة من الأفراد من نفس التخصص المعرفى يعملون على تحسين مهاراتهم عن طريق العمل لفترة طويلـة مـع الخبراء والمشـاركة فى أداء المهام، وفى البداية يكون الوافد الجديد على هامش المجتمع حيث يتعرف على المهام والمعايير والقيم والمبادئ التى يقوم عليها

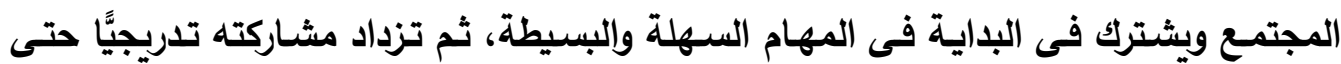

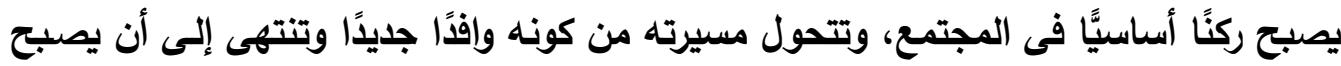


وفى هذا الكتاب ظهرت نظرية ليف وفينجر فى سياق وعى متنامٍ بالطبيعة الاجتماعية

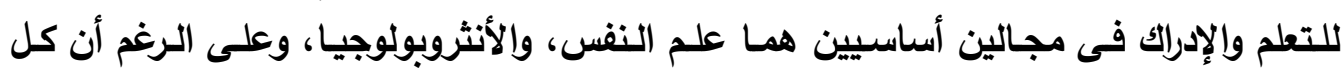

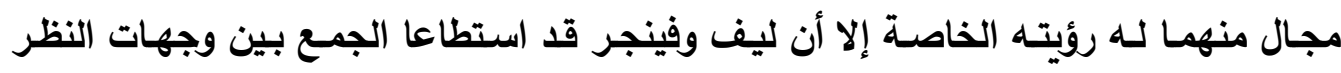

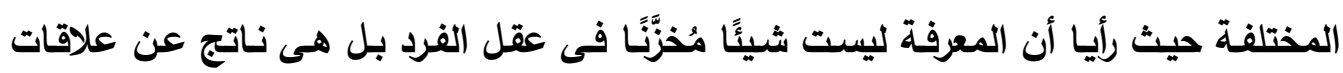

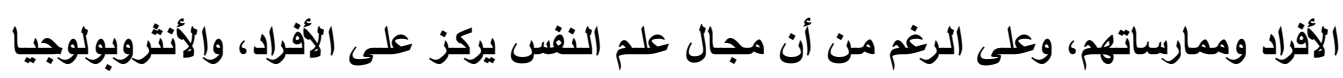

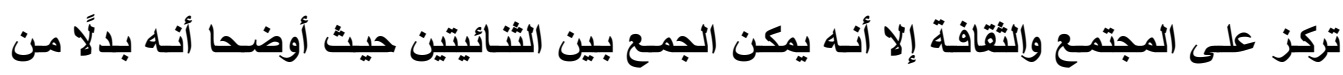

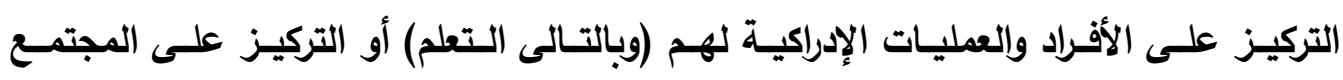

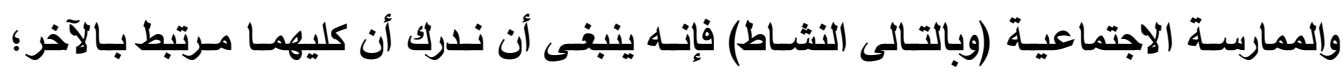

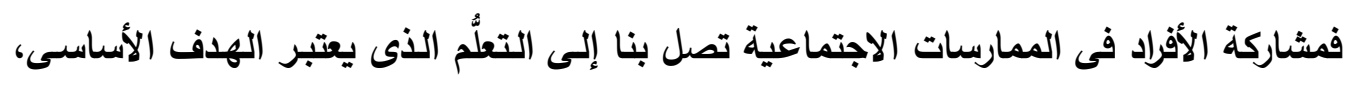

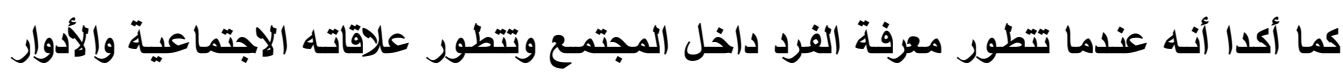

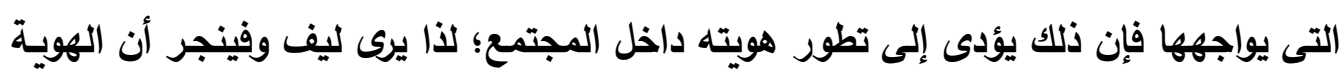

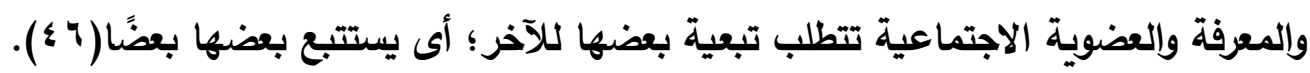

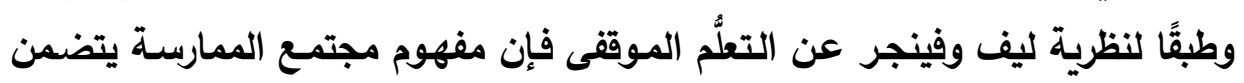

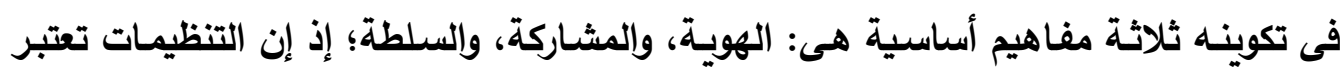

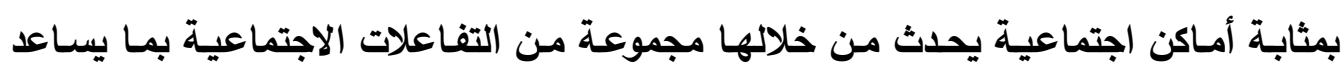

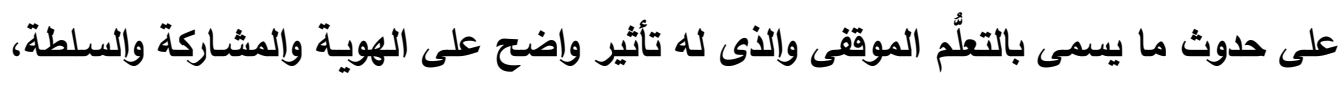

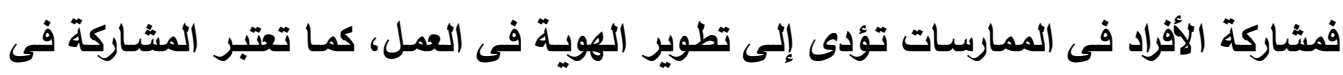

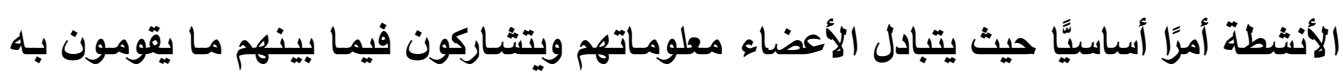

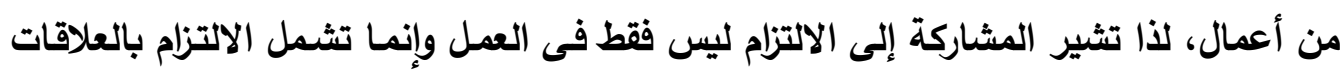

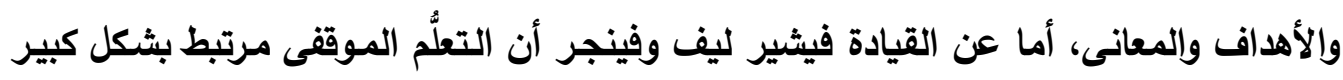

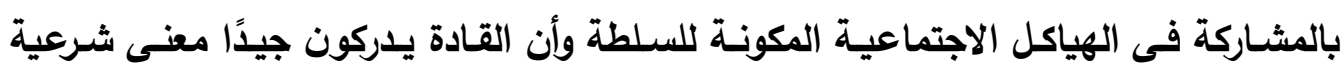

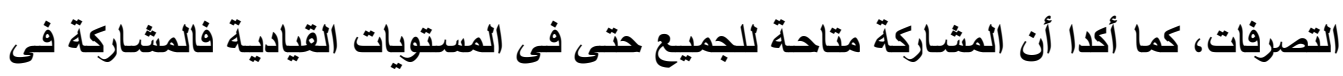
المسئوليات هو جانب مهم للغاية للوصول إلى التعلم(V \& ).

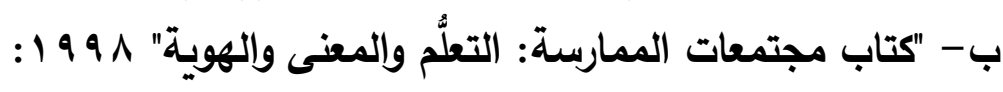
"Communities of Practice: Learning, Meaning, and Identity" 1994: 
ركز فينجر فى كتابه على الكيفية التى تعمل بها المنظمات ودور الأفراد داخل هذه المنظمـات وعلاقات بعضهم ببعض، كمـا درس كيفية تثكيل هويـة الفرد من خـلال عضويته

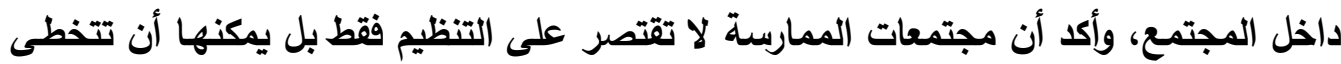
الحدود التنظيمية(^ \&). ولقد استطاع فينجر فى كتابه عام 991 أن يستفيد من الجوانب النظريـة فى التعليم وعلم الاجتماع ونظريات التعلُّم الاجتماعى لتنقيح وتطوير مفهوم مجتمع الممارسـة مـع التركيز

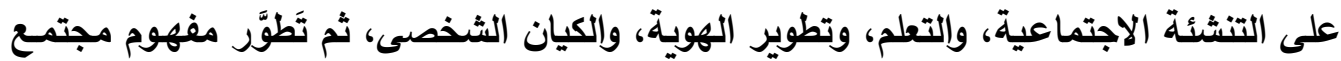
الممارسة من مجرد مفهوم قائم على العلاقة بين الوافدين الجدد والخبراء إلى كونه كيانًا يرتبط

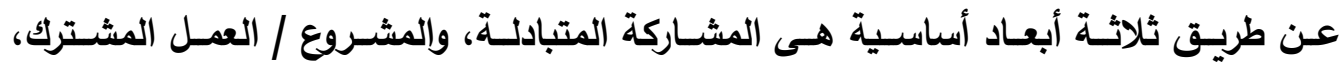
والمخزون المشترك، وتعمل الأبعاد الثلاثة على تحديد العملية المتعلقة بتفاعل الأفراد داخل مجتمع الممارسة، واقترح فينجر أربعة عشر مؤشرًا للكثف عن مجتمعات الممارسة، واستطاع تقسيم هذه المؤشرات فى ضوء الأبعاد الثلاثة السابقة، كما تتضمن كتاب فينجر مجموعة من المناقشات حول الاضطرابات التى يتعرض لها الأفراد الذين ينتمسون إلى مجموعات متعددة سواء كانت قائمة على التعاون أو التنافس(9 ؛ ؛ ). ولقد حدد فينجر فى كتابه أربعة مكونات لنظريته الاجتماعية عن التعلُّم وهى( •(ه):

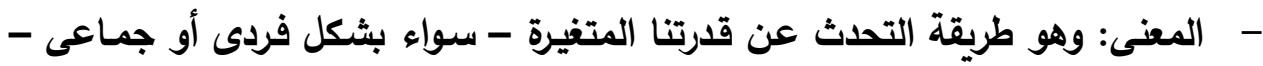
عن طريق تجريب واختبار الحياة حتى يكون هناك مغزى للحياة بأسرها.

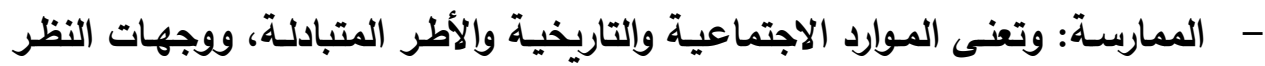
التى يمكن أن تسهم فى استدامة المشاركة المتبادلة والتفاعُل مع الأهداف.

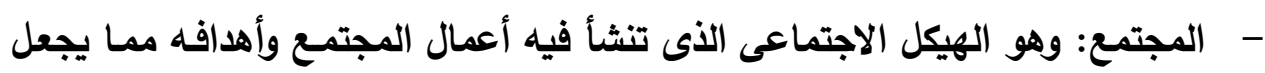
لمشاركة الأعضاء مكانتها المتميزة، ويجعلها مشهودًا لها بالكفاءة.

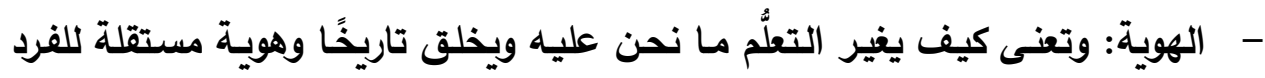
تدرج ضمن سياق المجتمع الأى ينتمى إليه. 
ج- كتاب "صقل مجتمعات الممارسة: دليل لإدارة المعرفة" ب . . ؟ : "Cultivating Communities of Practice: A Guide to Managing Knowledge" ${ }^{\prime}$... r:

فـى هذا الكتـاب أوضـح "فينجر وآخرون" أن المنظمـات يمكن أن تعمل على تطوير مجتمعات الممارسة كى تعزز من التنافسية، ولقد صور الكتاب مجتمع الممارسـة بأنها أحد

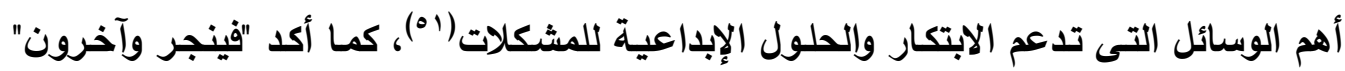

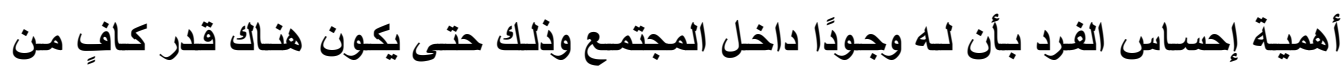

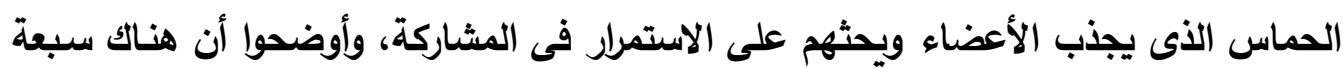

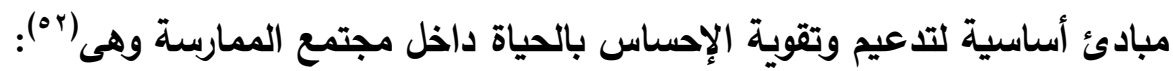

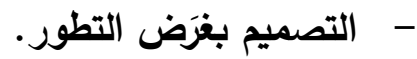
- - إيجاد حوار مفتوح يقرب بين وجهات النظر الداخلية والخارجية. - - الدعوة للمشاركة على كافة المستويات. - تطوير المجالات العامة والخاصة بالمجتمع. - - التركيز على القيمة. - - الجمع بين الألفة والحماس. - - خلق إيقاع أو وتيرة وإحدة للمجتمع.

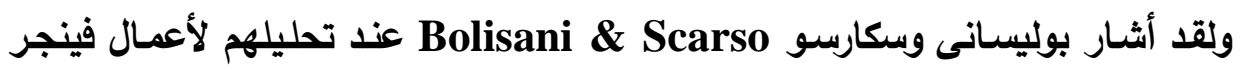
أن هذا الكتاب قد قدم منظورًا فريدًا لمفهوم مجتمـع الممارسـة حيث تحول التركيز من النظرة إلى مجتمعات الممارسة كسبيل للتعلم الاجتماعى إلى كونها أداة تنظيمية يمكن أن تستخدمها

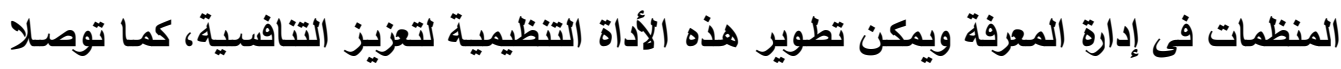
عند تحليلهم لمؤلفات فينجر إلى ثلاث نقاط أساسية وهى: أن مجتمعات الممارسـة عبارة عن هياكل اجتماعية خاصـة يمكن تحديدها والتعرف عليها داخل التنظيمات والمجتمعات، وأنها بيئات منظمـة ذاتيًا ولـديها القدرة على الاستـامة من خـلال إرادة الأفراد ورغبتهم فى تبادل الخبرة، وأخيرًا أنها نسق قائم على الأفراد حيث تتكون من خلال بذل جهود مشتركة من قبل الأل

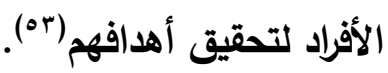




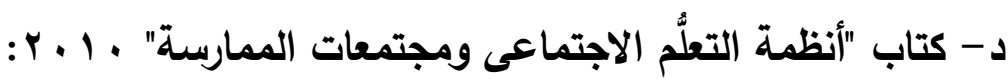
"Social Learning Systems and Communities of Practice" r • 1 . : شارك فينجر فى تأليف بعض فصول هذا الكتاب، وفى الفصل الثامن منه انتقل فينجر

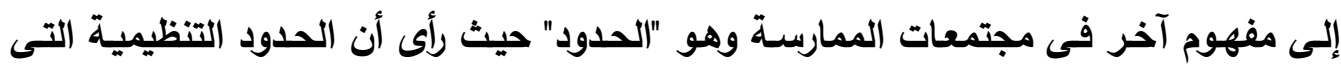
تُنثِئهها المنظمـة تكون واضحة للغايـة، أمسا الحدود بين مجتمعات الممارسـة فعـادة مـا تكون

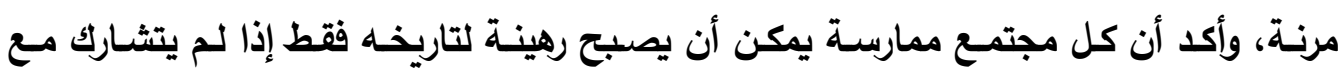

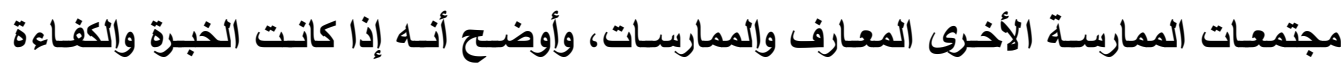

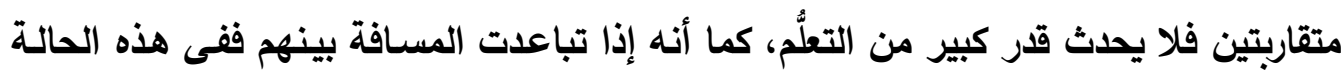

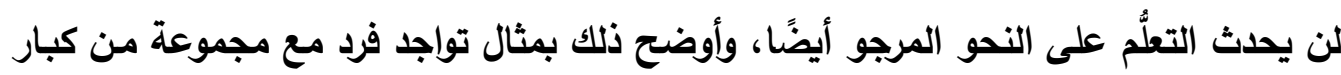

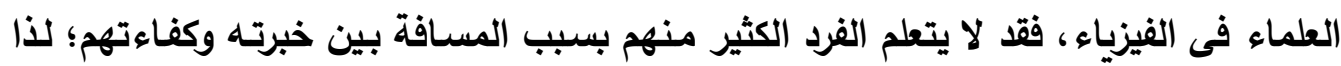
ينبفى أن تكون الخبرة والكفاءة متقاربتين بقدر معين حتى يحدث التعلم، وأكد أنـه على الرغم

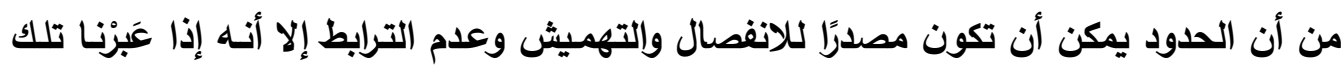

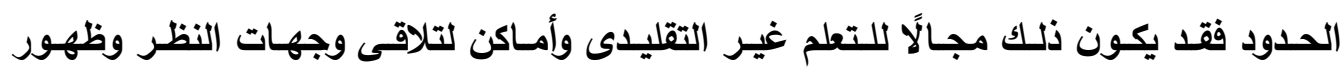
الاحتمـالات، وأن الرؤى الجديدة قد تظهر عبر الحدود فظهور تخصص مثل تخصص علم المناعة النفسية والعصبية يدل على تلاقى مجموعة من الممارسات المتعددة وترابطها(؛).

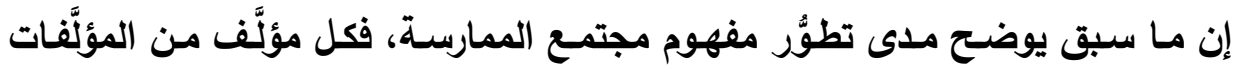

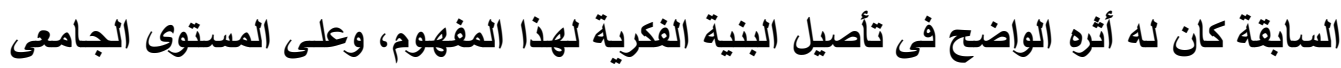
نجد الجامعات فـى العصر الحالى بحاجـة إلى بناء وتصميم مثل هذا النوع من المجتمعات والتـى تعتبر بمثابـة أداة تنظيمية يمكن أن تستخدمها الجامعات فـى تعزيز التنافسية وإدارة

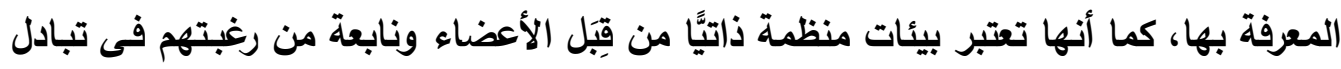
خبراتهم بما يسهم فى تنمية الإبداع والابتكار وتطوير الأداء الجامعى. لون.

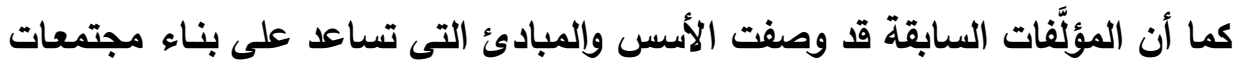
الممارسـة بالجامعـات؛ فلقد أوضـح كوكس "Cox" أن العمل الذَى قدمـه فينجر هو عمل

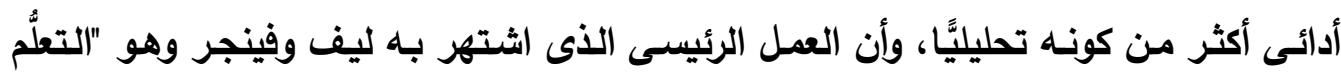

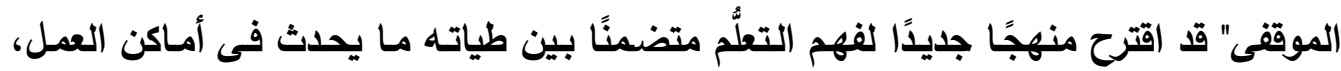

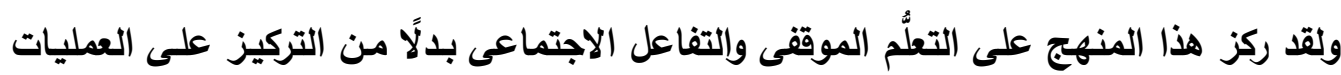


المخططة لنقل المعرفة، فهذا التفاعل ينتج عنه فى النهاية مـا يُسمَّى بالتعلُم الواقعى، وهذا

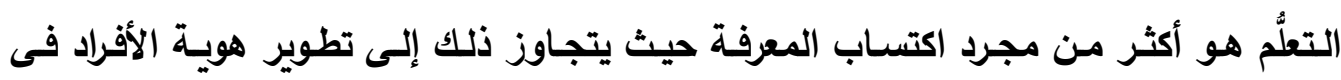

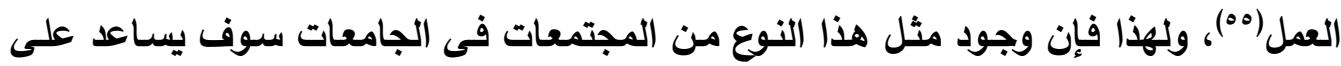

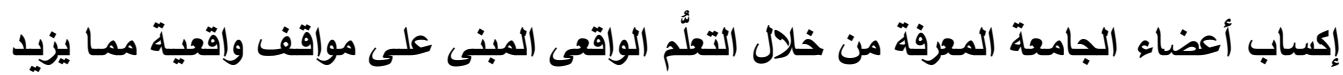
من ثقة الأعضاء وقدرتهم على الاستمرارية فى عملية التعلم.

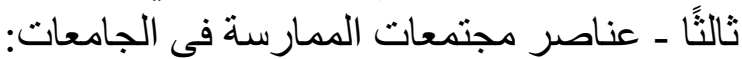

تشتمل مجتمعات الممارسة فى الجامعات على ثلاثة عناصر أساسية هى( آه): Domain 1 ـ المجال: المجـال هـ نطـاق المعرفـة الذـى يجمـع أعضـاء المجتمـع معًا ويحدد مجموعـة مـن

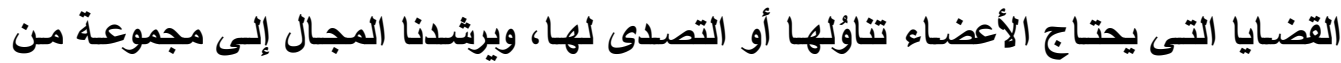
التسـاؤلات ويسـى الأعضـاء إلى الإجابـة عن هذه التسـاؤلات، ويطرحون أفكارهم ويتبادلون معلومـاتهم وبـذلك يخلق المجـال مـا يســى بـ "الأرضـية المشـتركة"، ويرسـم الحدود ويجعل

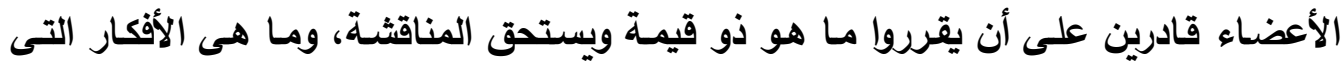

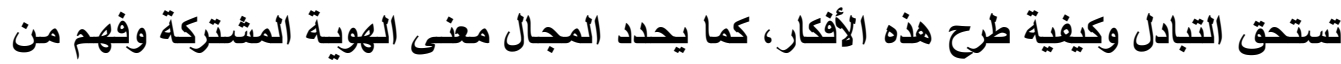
نكون وإلى أى مجتمع ننتمى، فعندما يصبح الفرد ممثلًا لمجتمع ما يُطوّرِ هذا الفرد من نفسـه

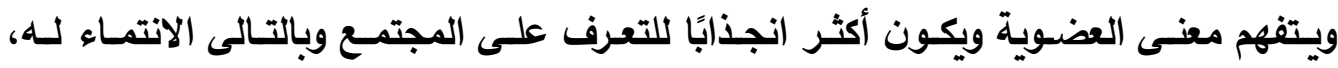
وبتشارك مع الآخرين أفكارهم وممارساتهم حتى يصل إلى الثعور بالالتزام إزاء هذا المجتمع. Community

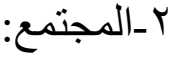
إن المجتمع يشير إلى الهياكل الاجتماعية التى تُشجِّع على التعلُّم من خلال علاقات

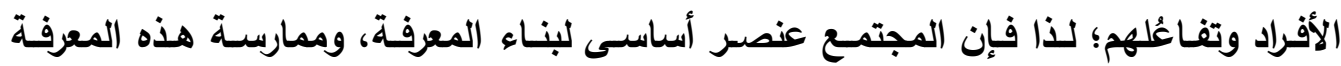

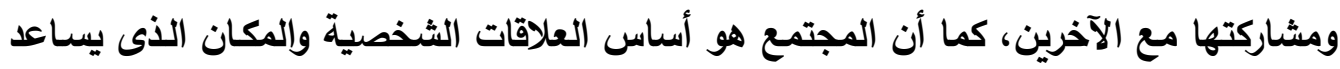

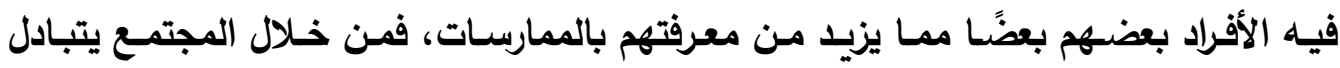

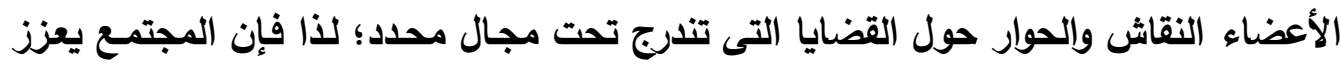

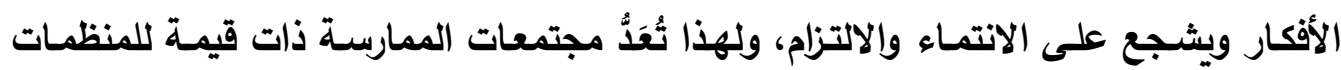

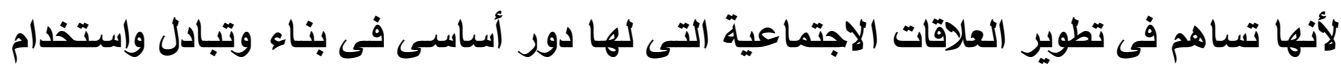


Practice

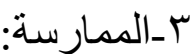

يُطلَق على أعضاء مجتمع الممارسـة مصطلح (الممارسون) لأنهم ينمون مواردهم

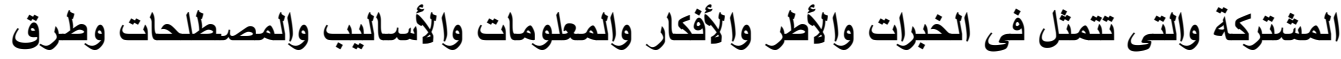
معالجة المشكلات، وتثير الممارسة إلى التعلُم من خلال العمل؛ لذا يرى العلماء العاء أن الممارسة

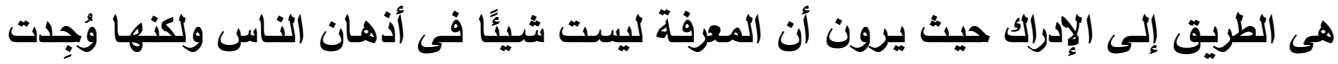
من خلال الممارسة وفى سياق من التفاعل.

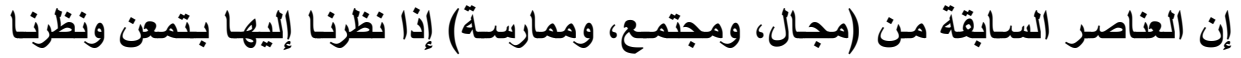
نظرة أخرى إلى الجامعات سوف نجد أن الجامعات بها العديد مـن المجـالات نظرًا لكونها

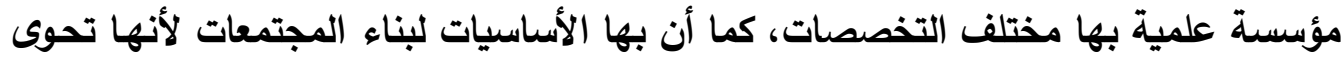
بداخلها العديد من التفاعلات والعلاقات الاجتماعية بين أعضائها وأخيرًا، فهى تحتوى على العياء

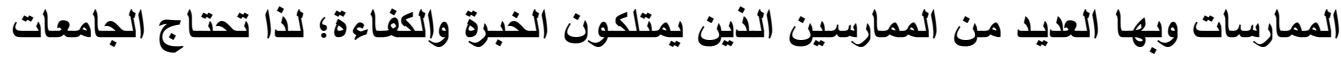

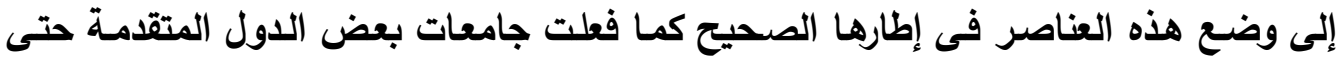

$$
\text { رابعًا ـ أهمية مجتمعات الهمات الممارسة فى الجامعات: }
$$
أوضحت العديد من الدراسـات أهيـة وفوائد مجتمعات الممارسـة سواء على مستوى الهمات

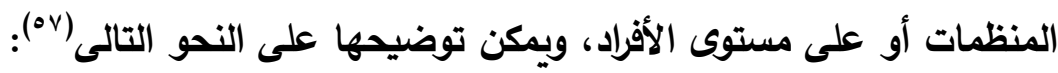
- - ت تصسين أداء المنظمات. - مساعدة المنظمات على الإبداع وتطوير أفكار جليدة. - تعزيز الابتكار فى المنظمات حيث يتم تبادل المعرفة وربطها بطرق جديدة. - - تثجيع وتيسير التعلُم والتعاؤن وتقاسُم المعرفة داخل المنظمات. - - زيادة وتنمية رأس المال الاجتماعى فيما بين الأفراد. - - زيادة المهارات الفردية وطريقة الوصول للكيفية التى يتم بها تحقيق ذلكاتك. - - تحسين عملية تبادل وتدفق المعرفة فى المنظمة. - - تنمية شعور الفرد بالانتماء تجاه المنظمة. - - تبادُل الخبرات والمعارف فيما بين الأعضاء. 
ولقد أظهرت إجابة سيرات Serrat عن أسئلة محددة فى دراسته حول: مـاذا تفعل

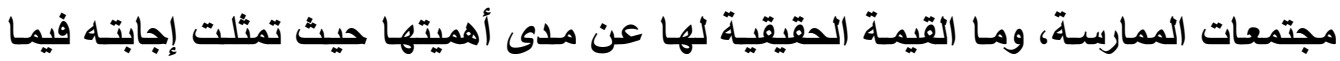
يلى (م)

- - تُوفِّرِ مجتمعات الممارسة وسيلة لتبادل المعارف والبيانات والمعلومات بحرية تامة.

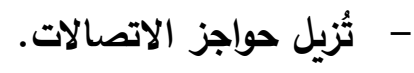
- تُوفِّرِ بيئة ترحيب اجتماعية غير رسمية. - - تعتبر وسيلة لبناء العلاقات والاتصالات.

- - يقوم أعضاؤها بتعبئة المساحة الخاصة بثبكة المعرفة الخاصة بهم ومراجعتها. - تعمل على تحديد المعرفة وإنتاجها وتثارُكها واستخدامها.

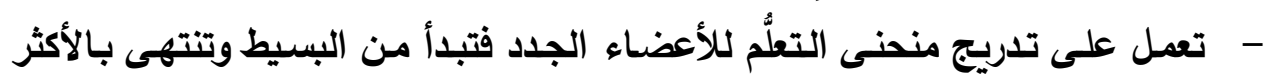
تعقيدًا.

- - تساعد على التنمية المهنية لأعضائها. - - تعطى حلًّ سريعًا للمشكلات وقدرة على الاستجابة للاحتياجات. - - تساعد على إنتاج أفكار جديدة. - ميتصف أعضاؤها بسرعة التعلُم كما أنهم قادرون على ربط التعلُم بالعمل. وأثشار بشورى ودنكان Bashouri \& Duncan أن مجتمعات الممارسة أداة مهمة

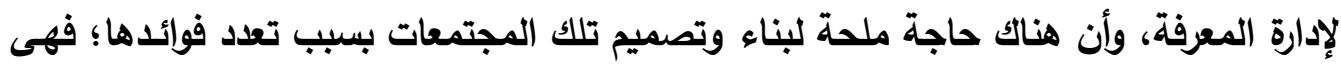

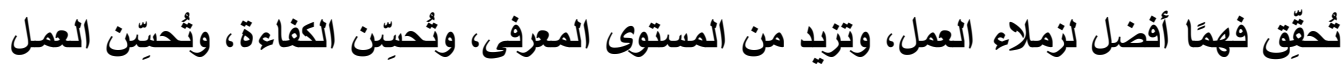

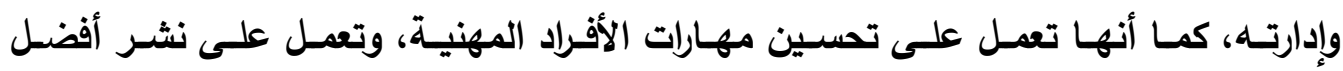
الممارسات، وتقوم على حل المشكلات، وتسـاعد على اكتشـاف مسـارات جديدة فى العمل،

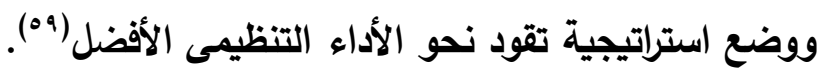
إن ما سبق يؤكد على مدى أهمية مجتمعات الممارسة للجامعات ليس فقط لكونها

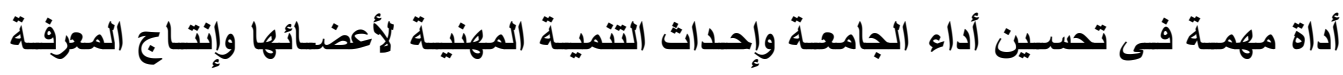

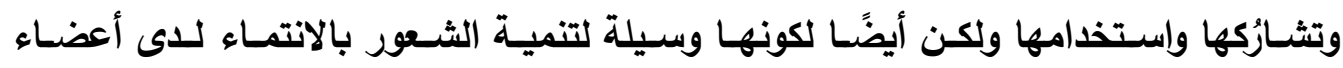

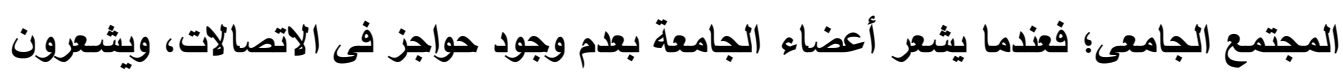

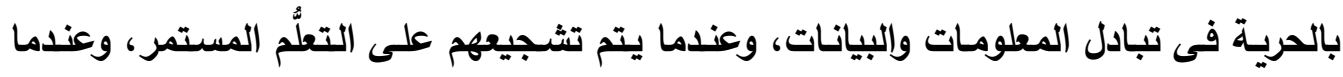


تصل المعرفة إلى الأعضاء الجدد تدريجيَّا حتى يصبحوا خبراء ويتم تقدير إسهاماتهم حينها يتولد الثعور لايهم بالانتماء والولاء إلى الجامعة.

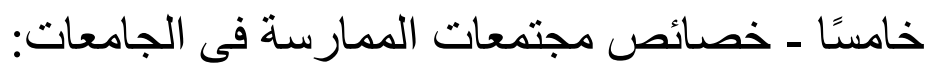
مع ظهور مفهوم مجتمع الممارسـة وانتشـاره فـى العديد من المجالات خاصة المجال الأكاديمى اهتمت بعض الدراسـات بالبحث حول خصائص هذا المفهوم مثل دراسـة موناغان فonaghan - - التكوين الذاتى والحَوْكمة الذاتية. - - - يتشارك الأعضاء فى الاهتمامات أو الاهتمام بموضوع معين. - - يشارك الأعضاء فى بناء المعرفة الجديدة.

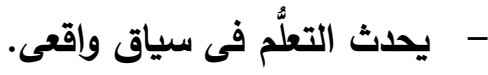
- - مجتمعات الممارسة يمكن أن تتناول أى مجال من مجالات الحياة. - - يساعد مجتمع الممارسة على تنمية وتطوير المعانى المشتركة وتثكيل هويـة الأفراد فى العمل.

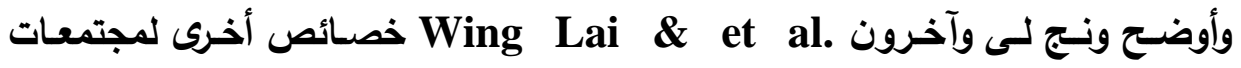
الممارسة تمثلت فى الآتى (1"): - - ترتبط مجتمعات الممارسة بإنجاز مشروع أو عمل مشترك. - - - تعمل من خلال المشاركة المتبادلة.

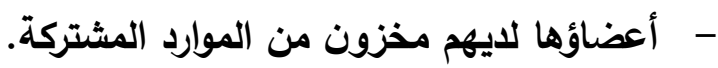

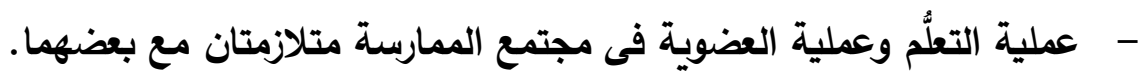
- - تعتبر الممارسة هى السمة الأساسية للمجتمع. - علاقات المجتمع تتأصل من خلال تبادل المعلومات وبناء المعرفة. - - تثمل العضوية كلَّا من الأعضاء الجدد والقدامى معًا.

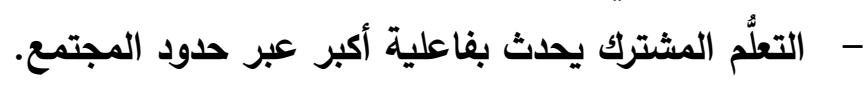
كما أشـارت أوبرتحى وبيريز Oberty \& Pérez إلحى أن مجتمعات الممارسـة تتسم

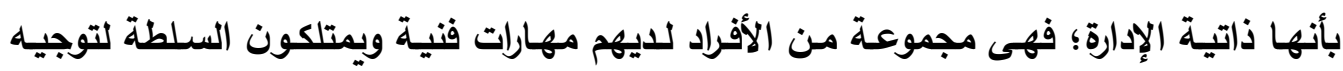

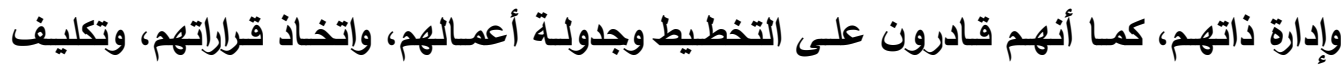

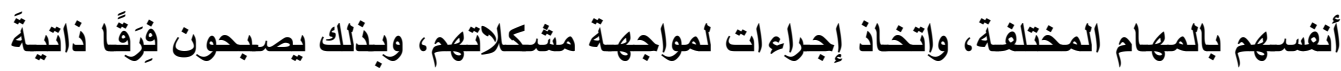


الإدارة وهذا النوع من الفرق تظمح إليه العديد من المنظمات فى العصر الحالى، كمـا أوضحتا

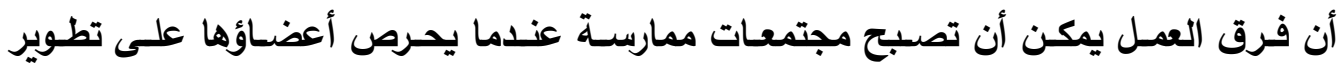
علاقاتهم، وتغيير مصـادر التشريع، ففى الفريق يحدث التشريع مـن خـلال التكليف بالقيام بأدوار رسمية، بينما أعضاء مجتمعات الممارسـة يضعون تشريعاتهم من خلال التفاعل فيمـا بينهم أثناء القيام بممارسـاتهم، لذا فإن فرق العمل المُتكوِّنة بثكل رسمى يمكن أن تصبح مجتمعًا للممارسة عندما يطور أعضاؤها علاقات اجتماعية ويطبقون المعرفة التى يملكونها ويعملون معًا لتحقيق هدف مشترك(rיi). إن ما سبق من خصائص لمجتمعات الممارسـة يوضـح أن المنظمـات تتجه فى العصر الحسالى إلـى العمل الجمـاعى فى إطـار مـن العلاقـات الاجتماعيـة؛ لـذا أصسبحت مجتمعـات الممارسة فى الجامعات أمرًا حتميًّا فلم تعد الأساليب الإداريـة الملزمـة وقوانين العمل وتعقيداتهـ تحقق أهداف الجامعة، وأصبح من الضرورى أن تتحول الجامعـات فـى العصر الحسالى إلى الجى وعاء يحوى جميع العلاقات الاجتماعية بين أعضساء الجامعـة فى إطـار محدد يتشـارك فيـه الأعضـاء الاهتمامـات، ويتعلمون فى سياق واقعى ويتثـاركون المعلومـات وإلمعارف ويستفيد فيـه الأعضـاء الجـدد مـن خبـرات الأعضـاء القـامى ويصـبحون قـادرين علـى إدارة أنفسـهم يخططون أعمالهم ويتخذون قراراتهم فى إطار من الثقة والاحترام والتعاون.

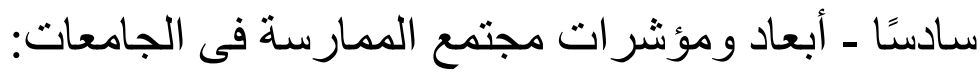

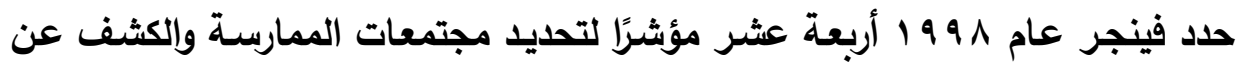
وجودها داخل التظيم، واستطاع تقسيم هذه المؤشرات فى ضوء ثلاثتة أبعاد أساسية، ولقد تناولت العديد من الدراسات هذه الأبعاد والمؤشرات وإستطاعت تحليلها للكشف عن مجتمعات الممارسة داخل المنظمات كما فى دراسة روجرز Rogers والذى استطاع تفسير أبعاد فينجر

Mutual Engagement كما يلـى( T T):

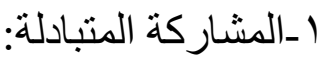
وتثـير إلى تفـاعلات أعضساء المجتمـع حيث يثـارك أعضـاء المجتمـع فى قضـية أو مشكلة مشتركة يتفكرون فيها ويتناقش بعضهم مـع بعض بثأنها، ويشتركون فى الأنشطة

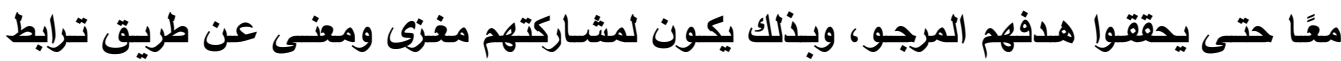
أعضاء المجتمع فى كيان اجتماعى واحد.

Joint Enterprise ب ـالمشروع / العمل المشترك: 


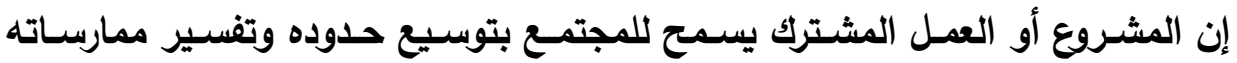

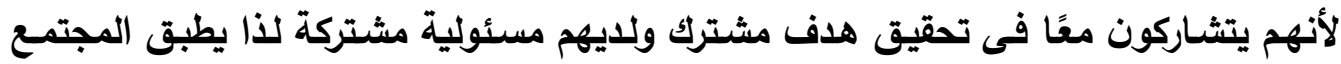

Shared Repertoire مبدأ المحاسبية والمساءلة. إن أعضاء المجتمع لايهم مواردهم الخاصة، وهذه الموارد يمكن أن تكون مادية مثل

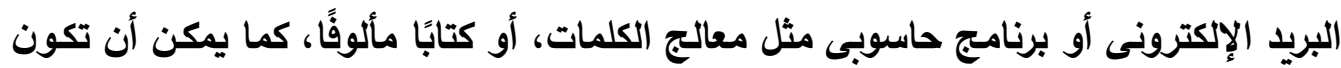

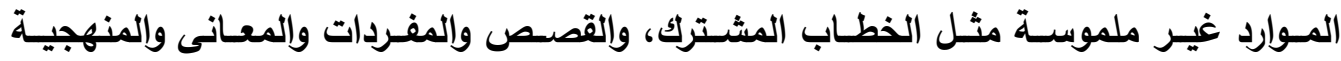

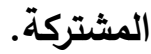

أما عن مؤشرات مجتمع الممارسة فهى على النحو التالى( ؟ج):

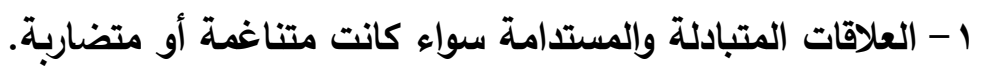
r - العبل المتبادلة للمشاركة فى عمل الأثشياء معًا. ب- ب- التدقق السريع للمعلومات واللوصول إلى الإبداع. ؛ - غياب الديباجات (المقدمات) التمهيدية. ه - تحديد المشكلة ودراستها جيدًا وتحضيرها للنقاش. צ- التشابك والتداخل فى مواصفات المشاركين وإلى من ينتمون.

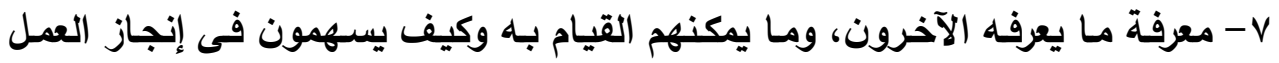

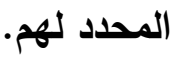
1- التعرف على الهويات بثكل تبادلى. 9- القدرة على تقييم مدى ملاءمة الإجراءات والنتائج. ـ - الأدوات المحدة والبيانات والملاحظات. 11- المعرفة المحلية، والقصص المتبادلة وروح العمل. r r - المصطلحات والاختصارات التى ثُيَيَّر عملية الاتصال. r آ أساليب مُعِينة مُتعارَف عليها مثل العضوية. ؛ ا- - الخطاب المشترك الأى يعكس منظورًا معينًا حول العالم. والجدول التالى يوضح كيفية تقسيم المؤشرات فى ضوء الأبعاد الثلاثة السابقة.

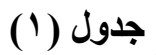
طريقة تقسيم مؤشرات فينجر الـ ؛ أ فى ضوء الأبعاد الثلاثة 
دراسة مقارنة لجمتمعات الممارسة فى جامعات بعض الدول الأجنبية ....

\begin{tabular}{|c|c|c|}
\hline أبعاد مجتمع الممارسة & & مؤشرات وينجر \\
\hline المشّاركة المتبادلة & - & 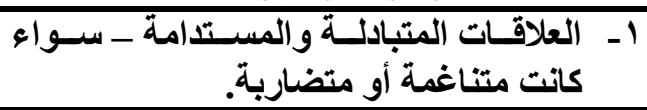 \\
\hline المشروع / العقل المشرك & - & 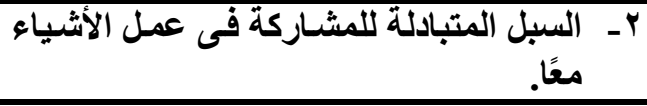 \\
\hline المشاركة المتبادلة & - & 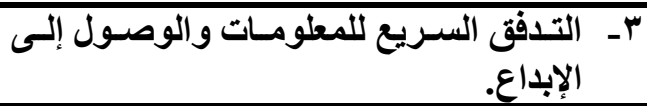 \\
\hline المخزاركة المثتبادلة & - & ـ - غياب الديباجات (المقدمات) التمهيدية. \\
\hline المخزون المشتبرك & $\begin{array}{l}- \\
-\end{array}$ & هـ تلتقاشيد المشكلة ودراستها جيدًا وتحضيرها \\
\hline المشاركة المتبادلة & - & 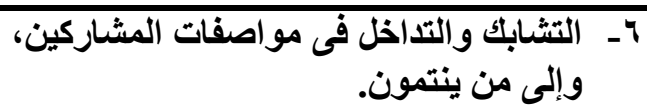 \\
\hline المشروع / العثبل المشترك & $\begin{array}{l}- \\
-\end{array}$ & 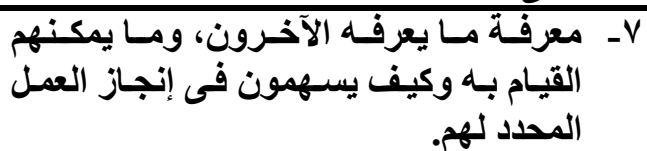 \\
\hline المشاركة المتبادلة & - & ^-ـ التعرُف على الهويات بشكل تبادلى. \\
\hline المخزون المشترك & - & 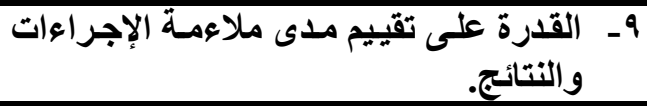 \\
\hline المخزون المشترك & - & • ـ ـالأدوات المحددة و البيانات و الملاحظات. \\
\hline المخزون المشترك & - & 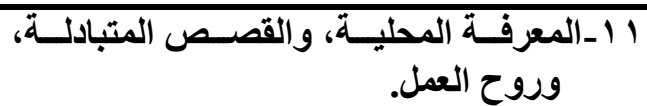 \\
\hline المشزاركة المتبادلة & $\begin{array}{l}- \\
-\end{array}$ & 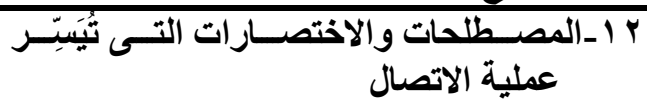 \\
\hline المشاركة لمتبادلة & - & r ا ـ أساليب معينة متعارف عليها مثل العضوية. \\
\hline المشـاركة المتبادلة & - & ـ ا ـالخطاب المشترك الذى يعكس منظورًا معينًا \\
\hline
\end{tabular}

المصدر: (Rocco Agrifoglio, r. 10, p. rq )

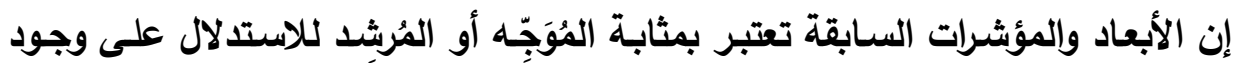

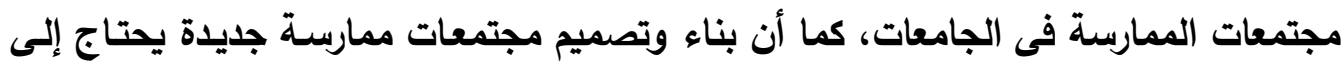

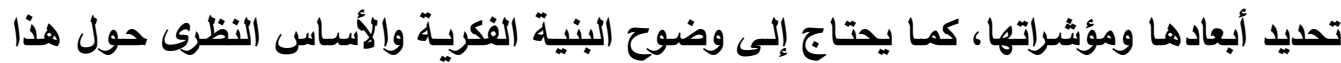
النوع من المجتمعات حتى يمكن تصميمها وبناؤها على النحو الأمثل داخل الجامعات.

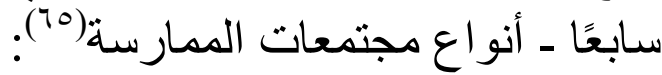

قدم أجريفوليو Agrifoglio ودوبى وآخرون Dube \& et al. وكومـار Kumar

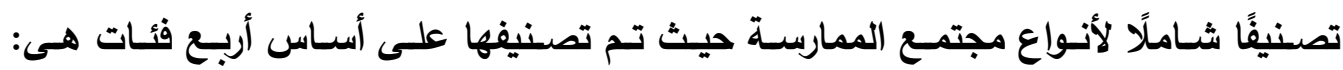


(الديموغرافيـة، والتنظيمية، وإلفرديـة، وإلتكنولوجية)، وشملت كل فئة من هذه الفئـات أنواعًا محددة من مجتمعات الممارسة.

ا - الفئة الديموغرافية: وقد اشتملت على ثلاثة أنواع من مجتمعات الممارسة وهى:

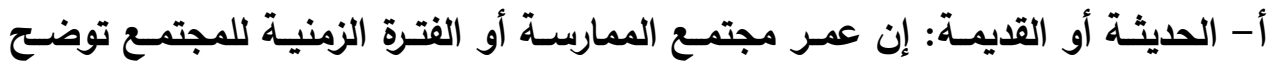
مستوى نضجه، فمجتمع الممارسة الحديث تكون مدتـه (أقل من سنة) بينما مجتمع الممارسـة القديم تكون مدتـه الزمنيـة (أكثر مـن خمس سنوات)، ولقد تمكن بعض العلماء من إيجاد العلاقة بين متوسط عمر مجتمـع ما ومستوى نضجه، فالمجتمعات

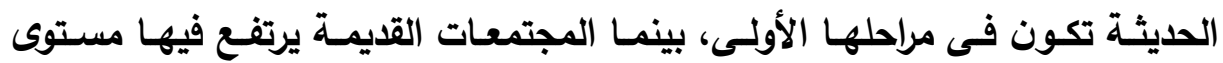
النضج وتكون فى مراحل متقدمة. ب- صغيرة أو كبيرة: يمكن القول أن حجم مجتمعات الممارسة صغير أو كبير طبقًا لعدد

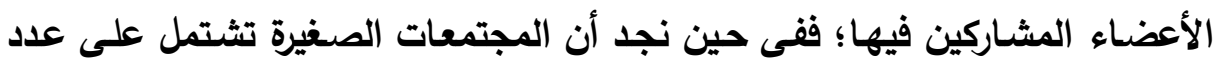
قليل من الأفراد، والمجتمعات الكبيرة يمكن أن تثتمل على مئات الأفراد إلا أن البعض

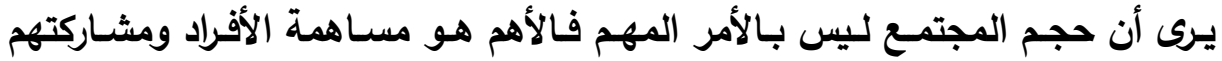
الفعالة داخل المجتمع، وعلى الرغم من أن البعض يرى أن المجتمعات الكبيرة يمكن

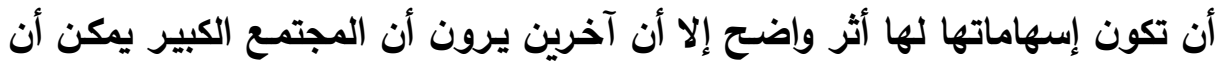
يشمل أفرادًا لهم مصـالح مشروطة كمـا يمكن أن تكون علاقات الأفراد عابرة وغير متعمقة. ج- قصيرة الأجل أو طويلـة الأجل: تختلف الفترة الزمنية لمجتمع الممارسـة من قصيرة الأجـل (مؤقتـة)، وطويلـة الأجـل (دائمـة)؛ فمجتمعـات الممارســة التـى تتعلق بمهن محددة تكون دائمسة وليس لها فترة زمنية محددة، بينما يتم إنشـاء مجتمعات أخرى لهول مؤقتـة إذا كـان لها غرض معين مثل المشـروعات المؤقتـة؛ لذا يُعرَف النوع الأول بطويل الأجل والنوع الثانى بقصير الأجل. 
r - الفئة التظيمية وتشتمل على ثلاثة أنواع من مجتمعات الممارسة وهى: أ- تلقائية أو مقصودة: قد يتم إنشـاء مجتمعات الممارسـة بطريقة مقصودة ويتم اختيار

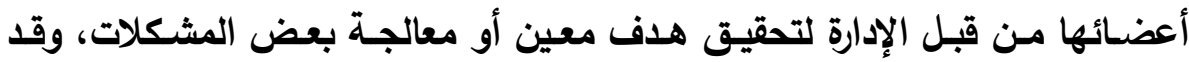

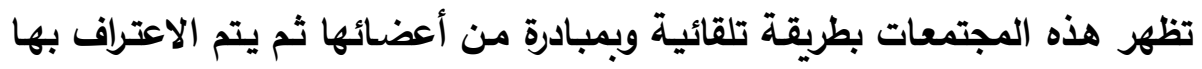
ويتم تقبُّلها من قبل الإدارة. ب- داخل الددود أو خارج الدود: قد توجد مجتمعات الممارسـة داخل المنظمات (داخل الحدود) أو خـارج الحـدود التظيميـة (خـارج الحدود)، وتلجـأ المنظمـات إلـى دعم مجتمعـات الممارسـة خـارج حـدودها التظظيميـة حتى تعـز التعـاون والعلاقـات الاجتماعية، حيث تسمح مجتمعات الممارسة خارج الحدود بانضمام أكبر عدد من الأفراد إليها ويساعد اجتياز الحدود على تبادل الأفكار ومشاركة المعرفة والتفاعل المستمر - المتر ج- غير معترف بها (غير رسـمية) أو ذات طـابع مؤسسـى (رسـمية): إن مجتمعـات

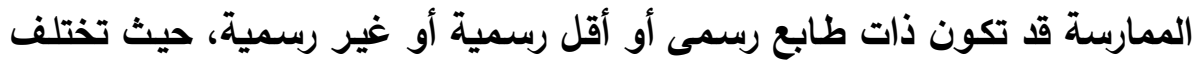
مجتمعات الممارسة فى درجة رسميتها، فهناك مجتمعات ممارسة غير رسمية وغير معترف بها وهى مجتمعات غير مرئية بالنسبة للمنظمـة، وهناك الأقل رسمية وهى

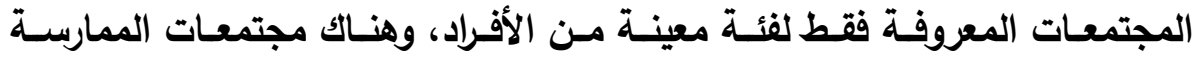

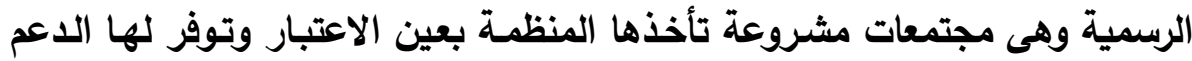
والإمكانـات الماديـة والبثربية اللازمسة وتعتبرهـا وحدة رسمية مثل الوحدات الأخرى الموجودة بالأقسام.

r- الفئة الفردية والتى تتعلق بتقارُب العلاقات والخلفيات الثقافية وتثتمل على نوعين هما: أ- المنتشـرة أو فـى موقـع وإحـد: مـن خـلال الموقـع الجغرافـى يمكن تمييز مجتمعـات

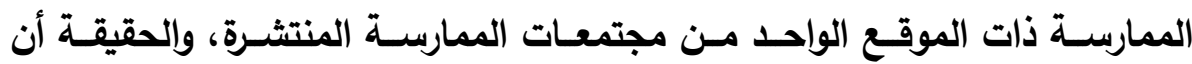

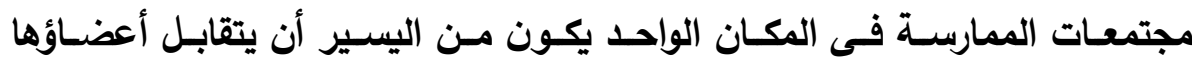
ويتفاعلوا معًا بثكل منتظم، وهذا على عكس مجتمعات الممارسـة المنتشرة حول العالم حيث يصعب تحقيق ذلك، فعلى سبيل المثال: مجتمعات الممارسـة لمجموعة مـن العلمـاء يعملـون لحسـاب منظمـات مختلفــة حـول العـالم يصـعب أن تكـون 
مقــابلاتهم بشــكل مسـتمر ولكـنهم يمكـن أن يتقــابلوا بشـكل دورى فـى النـدوات

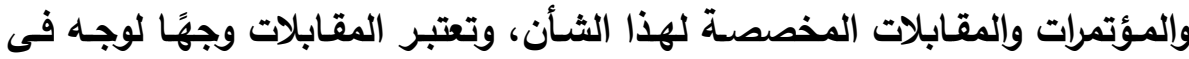

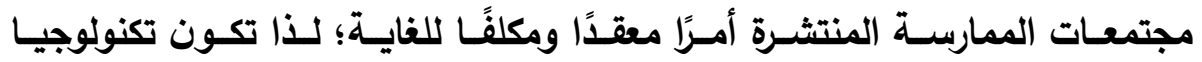
المعلومات والاتصالات هى الحل الأمثل لمثل هذا النوع من مجتمعات الممارسة. ب- متشـابهة أو غير متشـابهة: يمكن تمييز مجتمعات الممارسـة على أسـاس الخلفية

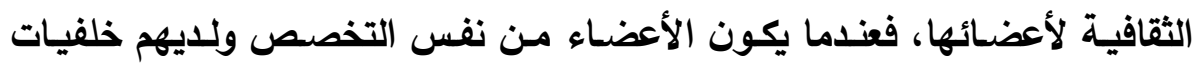
متماثلـة ناجمـة عن وجـودهم داخل المنظمـة أو منظمـات مختلفـة ولكن ذات ذات ثقافة متثـابهة لكونها في بلـ لـه ثقافة محلية قويـة، لذا يطلق على هذه المجتمعات مجتمعات الممارسة المتثابهة، وعلى صعيد آخر قد تكون مجتمعات الممارسة غير

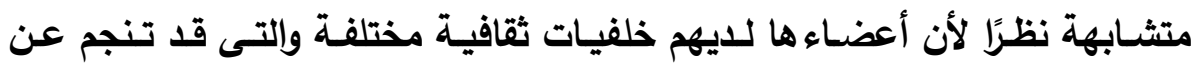
وجودهم في منظمـات مختلفـة فى بـلاد مختلفـة أو فى بلد وإحد يوجد بـه ثقافات متعددة. ـ - الفئـة التكنولوجيـة: وفى هذه الفئة يمكن التمييز بين المجتمعات التى يتقابل أعضاؤها وجهًا لوجــه وبـين المجتمعـات الافتراضـية التـى تعتمـــ علـى تكنولوجيـا المعلومــات والاتصالات وتثتمل هذه الفئة على النوع التالى: أ- مجتمعـات الممارسـة وجهًا لوجـهـ مقابـل مجتمعـات الممارسـة الافتراضـية: بفضـل التكنولوجيا الحديثة وتقنيات العصر الحالى فإن ذلك سـاعد على تقليص المسافات واجتياز عقبة الزمان والمكان وتمكين الأفراد من الاشتراك فى مثل هذه المجتمعات

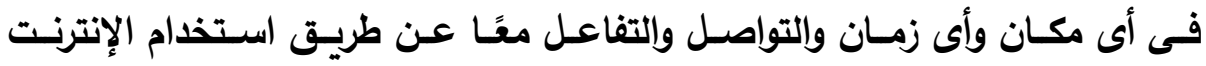
والتكنولوجيا الحديثة، ورغم أهمية المجتمعات التى يتقابل فيها الأعضساء وجهًا لوجه إنه

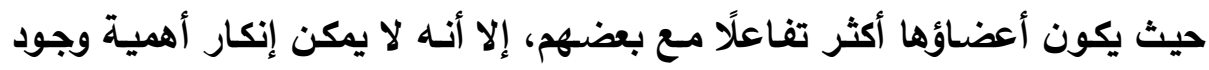
مجتمعات ممارسة افتراضية عندما لا يتوافر الوقت اللازم أو المكان الملائم. إن ما سبق يوضح أن مجتمعات الممارسة لها أنواع متعددة ومتنوعة، وعلى مستوى الجامعات يمكن اختيار النوع الذى يلبى احتياجاتها فى العصر الراهن، وقد اتضـح من الأنواع

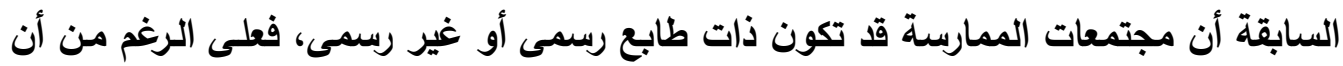
مجتمعات الممارسة فى بـايتها كان يغلب عليها الطابع غير الرسمى كما أوضحت الأدبيات 
من قبل إلا أن نجاح مثل هذه المجتمعات فى تحقيق الأهداف المرجوة منها أدى إلى اتجاه الجامعات إلى رعاية التفاعلات الاجتماعية الموجودة بها والموجهة نحو هدف محدد ووضعها فى إطار رسمى، وأصبحت الجامعات توفر لها الدعم الللازم وإلموارد المادية والبشرية اللازمـة لها واعتبرتها كوحدة رسمية من وحدات العمل الموجودة بها.

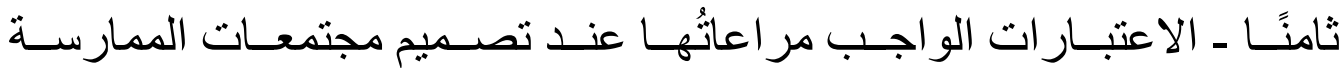

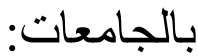

أكد إيتين فينجر أنه بدون طاقة التعلُّم يصبح المجتمع راكدًا، وبدون علاقات الانتماء القويـة يتحول المجتمع إلى أشـلاء، وبدون القدرة على التأمل والتفكر يصبح المجتمع أسيرًا لتاريخه، وبالإضافة إلى هذه الأمور أثشار فينجر إلى الاعتبارات الواجب مراعاتها عند تصميم مجتمعات الممارسة وهى (ب7):

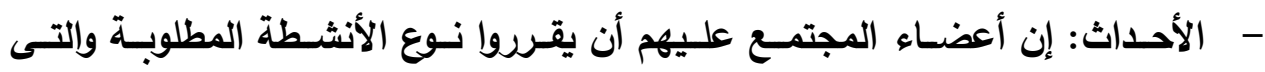
يحتاجها المجتمـع سـواء كانت اجتماعـات رسمية أو غير رسمية أو جلسـات لحل المشكلات أو استضافة متحدثين ومحاضرين مـع مراعاة التناغم بين تلك الأحداث، وإلمسئوليات الأخرى التى تقع على عاتق الأعضاء. - - القيادة: مجتمعـات الممارسـة تعتمد على القيادة الاخلية، فالقـادة عندما يقومـون بأدوارهم على أكمل وجه فإن ذلك يسـاعد على تنمية المجتمع وتطوِره، وعلى القادة

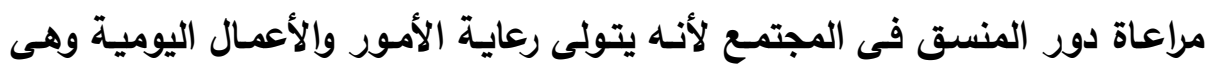

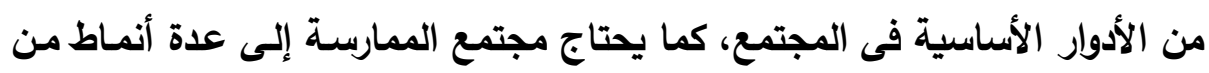

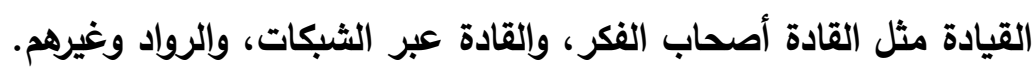
- التواصل: إن بنـاء مجتمع الممارسـة لا يعتمد فقط على تنظيم الأحداث وإنمـا يقوم على التواصـل الثرى بين الأفراد، وقد يتضمن ذلك وجـود وسطاء ، فالوسـاطة بين الأفراد الذين يحتاجون إلى التحدث أو بين الأفراد الذين بحاجة إلى مسـاعدة يعتبر

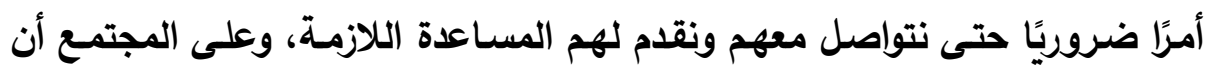
يحرص على وجود سبل متنوعة ليتواصل الأفراد معًا ويتفاعل بعضهم مع بعض.

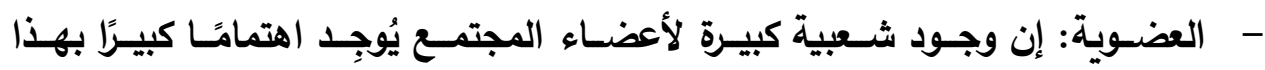

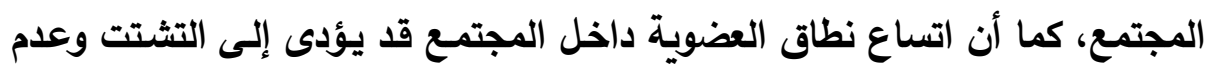
التركيز على الاتصال وإنتزاع هُويات الأفراد. 
- - مشروعات التعلم: إن مجتمعات الممارسـة تُعمِّق الالتزام لدى الأفراد خاصـة عندما

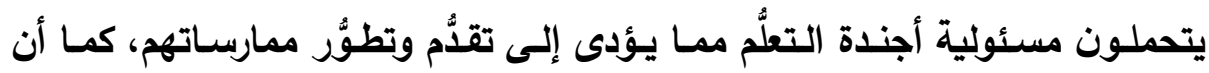
المشـاركة فى الأنثطة تسـاعد على تحقيق الهـف واكتثـاف المجال المعرفى من جميع جوانبه، والوقوف على الفجوات الموجودة فى مجتمـع الممارسـة، ويمكن بذألك

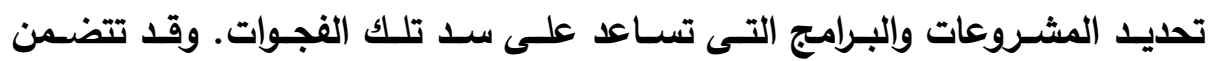

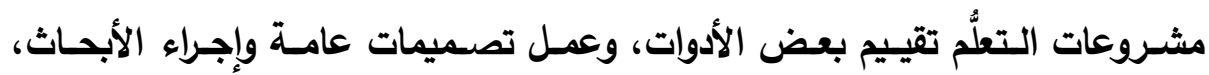
والتواصـل مـع الجامعـات التى تقوم بعمل أبحـاث فى نفس المجـال المعرفى وعقد مقابلات مع بعض الخبراء لعمل دليل إرشادى للأفراد الجدد.

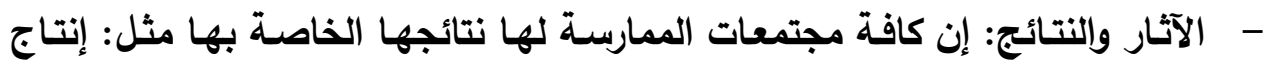
الوثائق والأدوات والقصص والرموز وغير ذلك، وعلى أعضاء المجتمع مراعاة هذه النتائج والآثار المرجوة منها، وتعديد من لايهم القدرة على الحفاظ على تلك النتائج للاستفادة منها فى المجتمع. وإذا كان إيتين فينجر قد حدد مجموعة من الاعتبارات عند تصميم مجتمعات الممارسـة

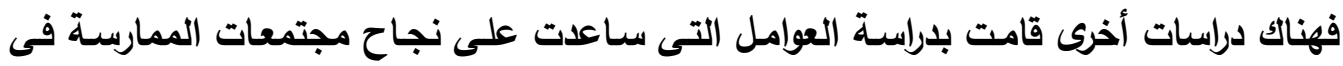
الجامعة كما فى دراسـة أخافان وآخرين .Akhavan \& et al والذين توصلوا إلى أن هناك ستة عوامـل أساسية لنجاح مجتمعـات الممارسـة فـى الجامعـات وهـى: التظيم، والتفـاعلات الهادفة، والبنية التحتية، وأدوات الدعم، والاستراتيجية والأهداف، واللدعم التنظيمى، وأكدوا أن هذه العوامل من شأنها التأثير على الطلاب وعملية بناء وتوليد المعرفة فى الجامعة، وأثشاروا إلى أن أعضساء الجامعة وطلابها يميلون إلى صنع المعرفة فى مجتمعاتهم، لكن لا يتوافر لايهم الدعم الكافى لتكوين المجتمعات الخاصة بهم لبناء تلك المعرفة وتبادلها فيما بينهم، ونظرًا للأهميـة المتزايـدة للمعرفـة فـى هذا العصر فقد تـم وضـع التظيم كـأول عامـل لنجـاح مجتمعات الممارسة لأنه يرتبط بالجها الجماعى، ويمتلك الخطط الملائمة، ويقدم الدعم التلازم

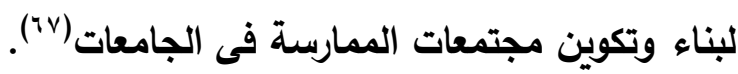

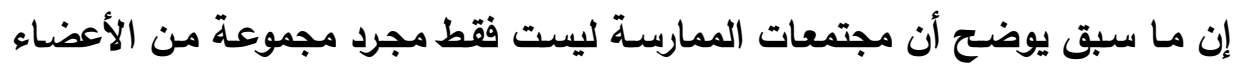

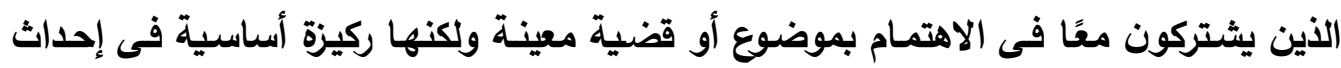

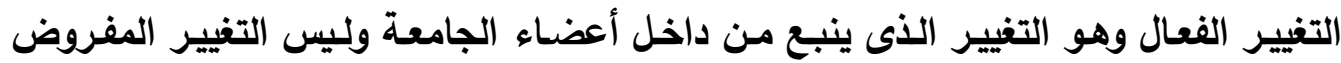


عليهم لأنـه تغيير نـابع من علاقات الأعضـاء وتواصلهم وارتباط بعضهم ببعض، وبنـاء مثل

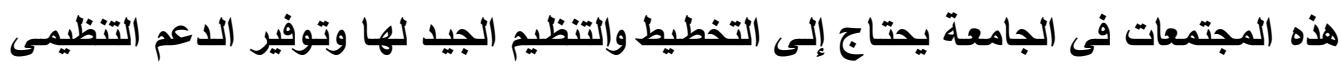
والقيادة الواعية القادرة على تكوين المناخ المناسب للإبداع.

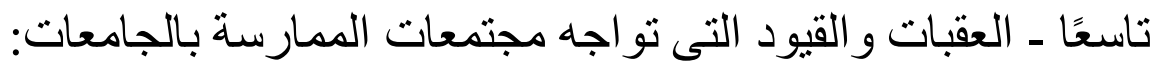
استطاع كيرنو Kerno أن يوضـح العقبات والقيـود التى تواجـه مجتمعات الممارسـة وأكد أن لفت الانتباه إلى هذه العقبات سيسـاعد المنظمـات على التعامل معها وتجاوزها حتى يُمكِن تشجيع وتنمية مجتمعات الممارسة، وحدد هذه العقبات على النحو التالى (^^ان): 1-عقبات تتعلق بقيود الوقت:

تعتبر العقبـة الأولـى التى تواجـه مجتمعـات الممارسـة هـى ضيق الوقت وعدم توافر

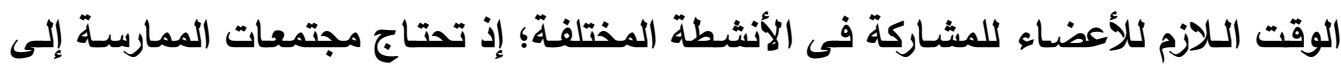

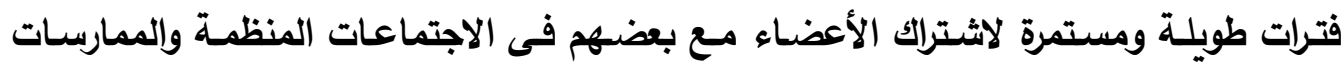
المختلفة وفى الحديث مع بعضهم، كما تحتاج إلى الظروف الملائمة التى تسمح بتشكيل هذه التهاع

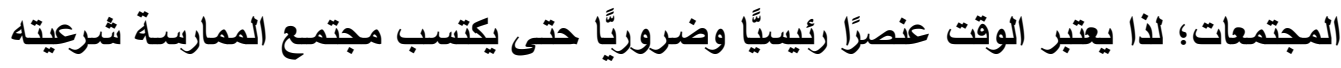
ويتاح لله الوقت اللازم لإنجاز الأنشطة. r - reقبات تتعلق بالتسلسل الهرمى التنظيمى: إن التسلسل الهرمى التظظيسى يثتمل على عدة مستويات للإدارة، وتقع الإدارة العليا فـى قـة هذا الهرم وتكون مسئولة عن وضـع السياسـات والأهداف والخطط واتخـاذ القرارات المرتبطة بالمؤسسـة، لذا يكون هناك مركزيـة نسبية بمـا تحملـه من سلطة وإصدار للأوامـر

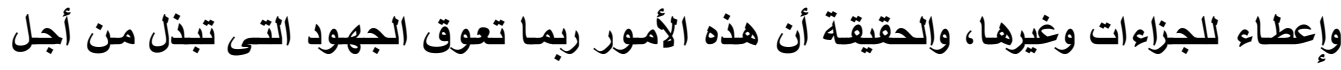
نجاح مجتمع الممارسـة نظرًا لكونها هياكل اجتماعية تكْمُن فائدتها فى ترابط أعضائها حتى إنى يتبادلوا أفكارهم وينشروا ممارساتهم.

r-عقبات تتعلق بالثقافة المحلية (البيئة الاجتماعية وإلثقافية): تختلف الثقافة من منطقة لأخرى تبعًا لقيم ومعتقدات كل منطقة؛ لذا فإنان المجتمعات

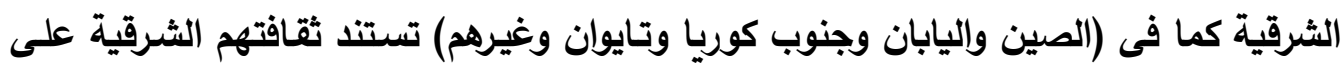

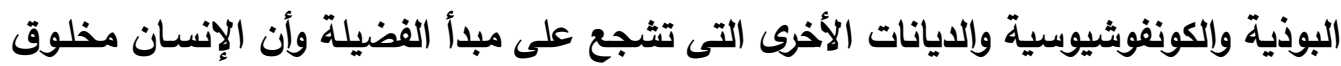

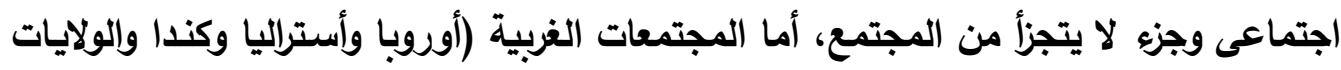
المتحدة الأمريكية) فإنها تختلف عن المجتمعات الثرقية فى تركيزها على الذات والتأكيد على الثى 
الفرديـة، ورغم أن المجتمعـات الغربيـة تقوم على الثقافـة الفرديـة إلا أنها استطاعت تطوير وكتابة أغلب الدراسـات المتعلقة بمجتمعات الممارسـة بل واستطاعت تطبيقها فى العديد من المنظمـات وربمـا لتتجـاوز بـذلك مشكلاتها عن طريـق التركيز على قيمـة المجتمـع والعمـل الجماعى، ورغم ذلك تستطيع المجتمعات الشرقية الاستفادة من مجتمعات الممارسـة، فالبيئة الاجتماعية والثقافية التى تقدر قيمة المجتمع هى البيئة المناسبة والأكثر فاعلية لنجاح مثل هذا النوع من المجتمعات.

وإذا كـان كيرنـو Kerno قد أوضـح العقبـات التـى تواجـه مجتمعـات الممارسـة والتـى تتعلق بالمنظمة وثقافة المجتمع ذاته فإن لندا سـى لى وآخرين .Linda C Li \& et al قد ركزوا على العقبات التى تتعلق بمجتمـع الممارسـة ذاته؛ فقد أشـاروا إلى أن العلاقات القويـة

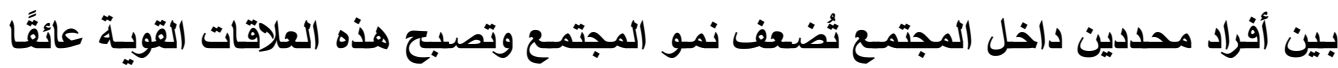
أمام دمج أعضاء جدد نظرًا لعدم قبولهم لوجود أفراد آخرين، كمـا أن العلاقات القويـة إذا زادت هده عن حد معين فإن ذلك يؤدى إلى تكوين زمرة أو عصبة من هؤلاء الأعضاء، وينتج عن ذلك مجموعة أخطار مثل الأفكار الناتجة عن هذه العصبة والفشل في استيعاب التغيير أو التنوع، ورفضهم للتعـاون الخـارجى ولإبـاعاعات الآخرين الموجـودين خـارج المجموعـة، وبـذلك يصبح المجتمع سـاكنًا وغير قـادر على جذب أعضـاء جدد، وهذا مـن شـأنه إعاقـة عمليـة تبادل المعلومات وعدم قدرة المجتمع على إظهار الأفكار الإبداعية والخلاقة (979).

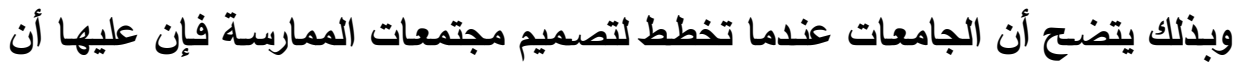
تراعى الوقت اللازم لها وتعمل على تهيئة الظروف الملائمة لبنائها، وهذا مـا أوضحته أوبرتى وبيريز Oberty \& Perez فقد أشـارتا إلى أن مجتمعات الممارسـة لا تحتاج إلى هياكل

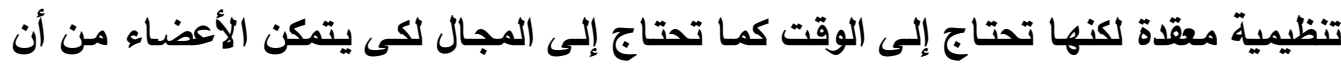
يتعاونوا معًا، كما أن مجتمعات الممارسة لا تحتاج إلى مزيد من الإدارة لكنها بحاجة إلى مزيــ

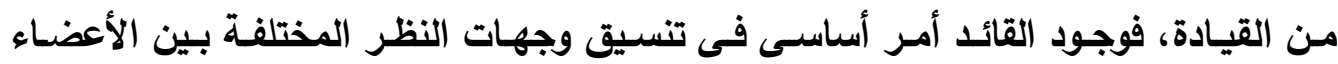

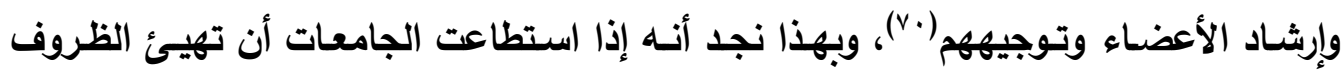
المناسبة وإزالة كافة العقبات التى يمكن أن تواجه بناء مثل هذه المجتمعات فإنها بذلك سوف

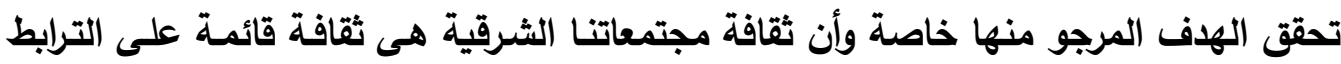
والتعاون ويتضح ذلك فى تعاليم الدين الإسـلامى الذى يحثنا على التآزر والتضـامن، قال الله 


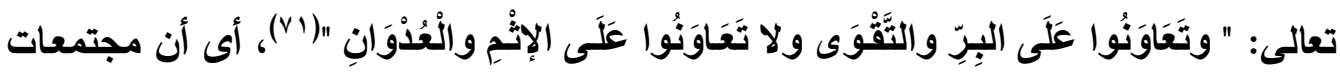

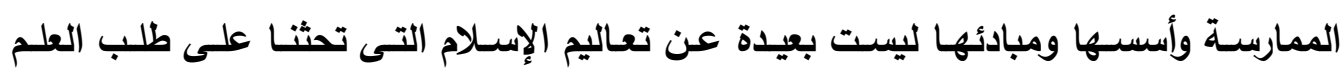
والسعى وراء المعرفة والاتحاد والتعاون على البر والتقوى. الخطوة الثالثة: طبيعة علاقة مجتمعات الممارسة بتطوير الجامعات:

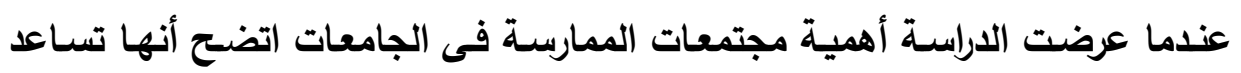
على تحسـين الأداء، وتحسين مهارات الأعضـاء، وتســاعد على تبـادل المعرفـة وتقاســها،

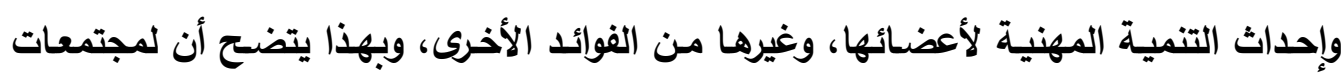

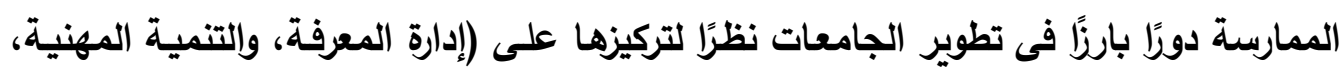

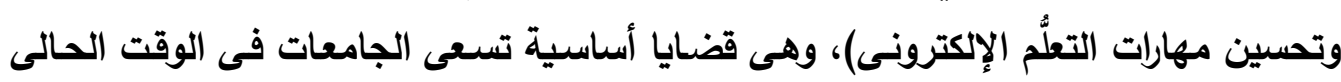

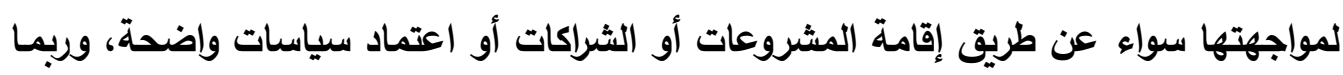
يكون التوجه نحو تصميم وبناء مجتمعات الممارسة هو ما يناسب هذا العصر بمـا يشمله من

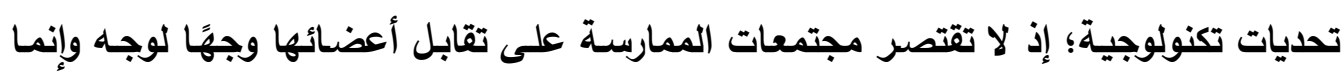

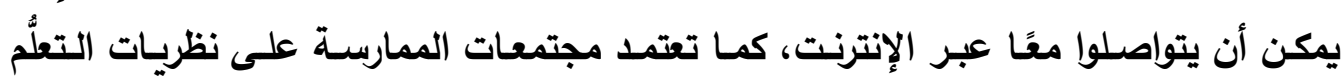
الاجتماعى، ولهذا استطاعت العديد من الدول الاستفادة منها فى مواجهة العديد من القضانسايا

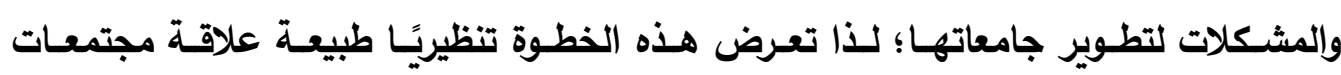

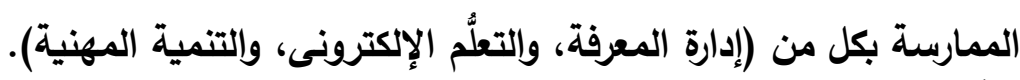

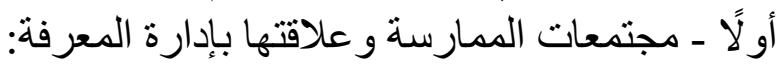

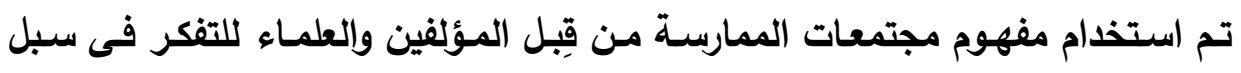

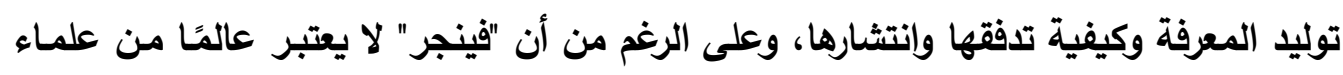

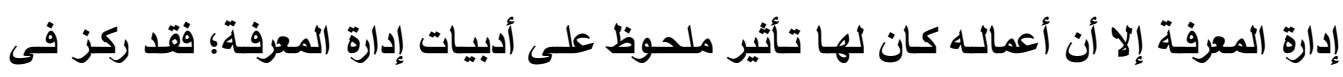

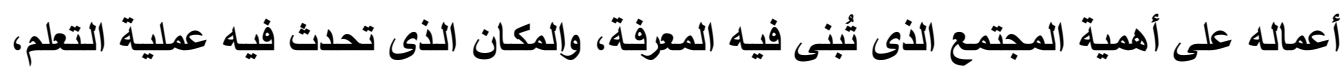

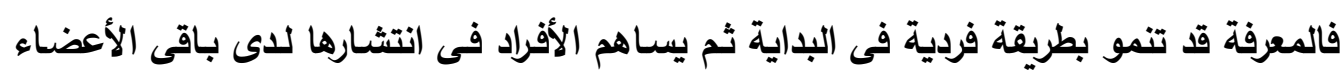
ومع الوافين الجدد(Vr). و"من مميزات مجتمع الممارسـة عدم نشر شكل محدد من المعرفة ولكن يتم تطويرهـا

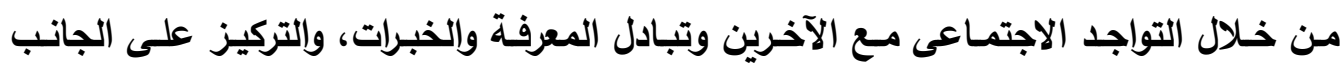

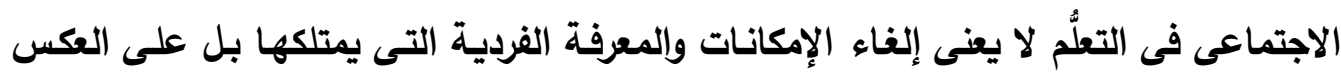

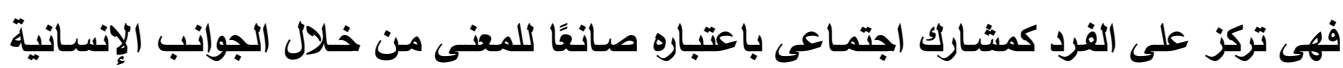


والتفاعل مع الآخرين، فهو ليس مجرد كيان معرفى بل هو كيان اجتماعى، فالمتعلمون فى

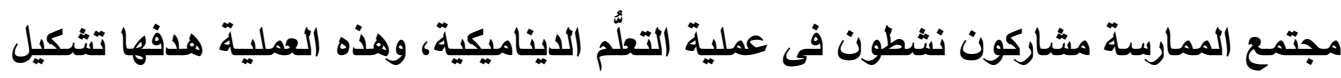
المعرفة وليس الحصول عليها وتلقيها بسهولة، فهناك حوار وتفاوض بثأن مشكلة معينة تتطلب حلولًا ابتكاريـة يتم فى إطار ذلك عرض الأفكار والخبرات ويمكن دمـج أكثر من فكرة حتى يتبلور الحل للأطراف المشـاركة فى عملية التعلم، وبالتالى يتمكن الشخص ذو المعرفة

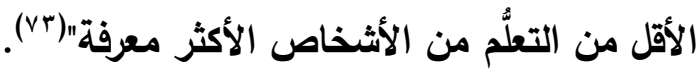
وهنـاك نوعـان مـن المعرفة، وهمـا: المعرفة الصـريحة، وهـى التى توجد فـى الوثائق والملفـات والســلات وتتعلـق بالبيانـات والمعلومــات الظـاهرة التـى يمكـن الحصــول عليهـا، والمعرفـة الضمنية وهـى المعرفـة المخفيـة والمتجسدة فـى تجارب الأفراد الثخصية. وعملية توليــا المعرفـة هـى عمليـة اتصـال بـين المعرفـة الصـريحة والمعرفـة الضــنية، وتظهـر قـوة

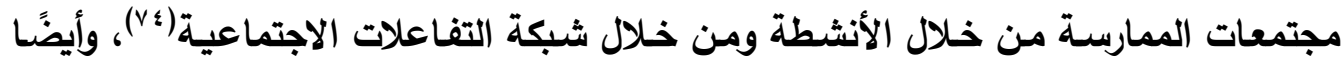
من خلال الأعضاء القدامى الذين يقومون بنقل خبراتهم إلى الأعضاء الجدد عن طريق سرد القصص ونشر ممارساتهم.

وقد أشار كلين وآخرون . Klein \& et al. إلى وجود اختلاف فى درجة المعرفة التى يمتلكها أعضـاء مجتمعات الممارسـة؛ فـالمجتمع الواحد قد يضـم بـاخلـه الخبراء والمبتـائين والأفراد أصـحاب المسـتويات المعرفيـة المتوسـطة، ولـيس مـن اليسـير أن تضـم مجتمعـات

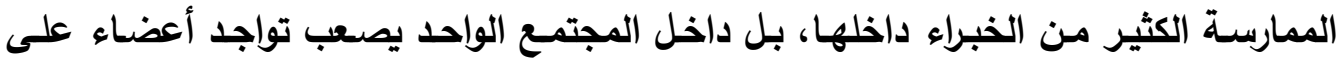
نفس القدر من الخبرة والمعرفة، ولا تقتصر مجتمعات الممارسـة على أفراد تتباين خبراتهم بل إن طريقة وهيكلة وتنظيم تلك المستويات من الخبرة يمكن أن تتباين أيضًا، فمن ناحية قد يُقر المجتمع بالخبرة المتباينة لأعضـائه ويتعامل مـع المستويات المختلفة للمعرفة سواء كان هذا الاعتراف بثكل رسمى أو غير رسمي، ويطلق على هذا المجتمع لقب "المجتمع المتدرج" وفى لهـ المجتمعات المتدرجة يتم تدفق المعرفة ونشرها من الأعضاء الأكثر خبرة إلى الأقل خبرة؛ أى الى

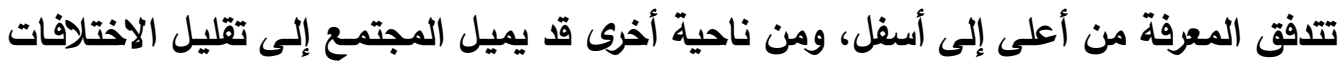

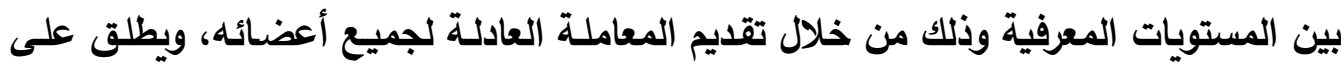
هذا النوع من المجتمعات لقب "المجتمع العادل" فعلى سبيل المثال قد يتألف مجتمـع الممارسـة من علماء فى البحث العلمى ولكن تتباين حالة العضوية مـا بين خبير (أستاذ)، إلى أن يصل 
إلـى المبتــئين مـن طلبـة البحثث العلمـى ومـع ذلـك يتعامـل الجميـع بـنفس المعاملـة، وفـى

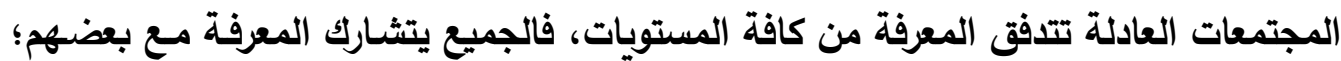
لذا فتتدفق المعرفة من أعلى وأسفل (vo) وكما تتباين مستويات المعرفة لاى الأعضاء تتباين أيضًا الأنثطة المرتبطة بالمعرفة

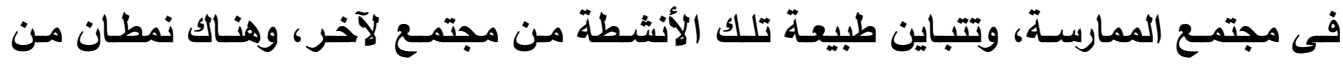
الأنثطة المعرفية لمجتمعات الممارسة، فمن ناحية هناك مجتمعات تجعل عملية نشر وتبادل المعرفة من خلال أنشطتها من أولوياتها، ويطلق على هذه المجتمعات لقب "مجتمعات نشر وتبادل المعرفة"، وفى هذه المجتمعات يتم إعداد الأعضساء على تبادل المعرفة ونشرها مـع ميع الأعضاء الآخرين كجزء من دورهم داخل المجتمع، والمعرفة التى يتثاركها الأعضاء قد تتباين

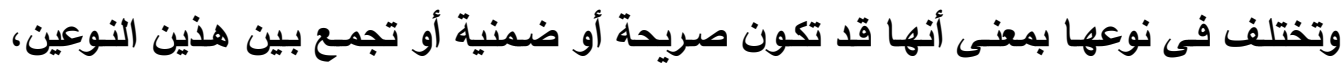
وعملية نثر المعرفة وتبادلها قد تكون سببًا من أسباب وجود المجتمع، وقد تكون نتيجة لـه له

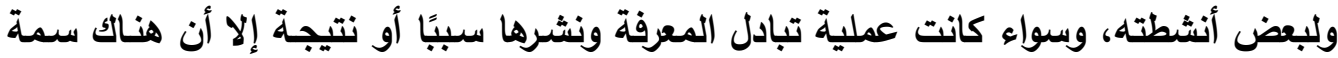

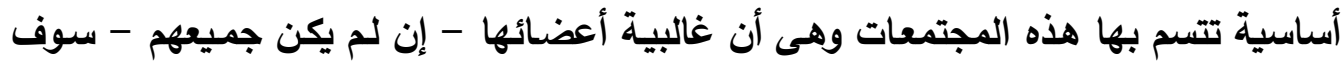
يكتسبون المعرفة من الآخرين ومن خلال أنشطة المجتمع، ومن ناحية أخرى يوجد نمط آخر من الأنشطة المعرفية وهى المجتمعات التى ترعى المعرفة ويطلق عليها لقب "مجتمعات رعاية الاهن المعرفة"، وهذه المجتمعات رغم تنوع أنشطتها إلا أنها لا تعزز عملية نشر المعرفة وتبادلها بشكل ظاهرى، ولكنها تتيح البيئة المواتية لرعاية هذه المعرفة داخل هذا المجتمـع وذلك من خلال خبرات الأعضاء فهذه الخبرات هى الأساس فى عملية تطوير المعرفة لاى هذا النوع من

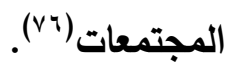




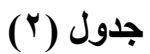

تصنيفات الأنشطة المعرفية داخل مجتمعات الممارسة

\begin{tabular}{|c|c|c|}
\hline نشاط المعرفة "الرعاية" & نشاط المعرفة "التبادل" & \\
\hline 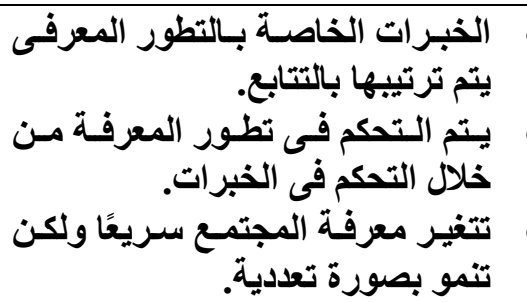 & 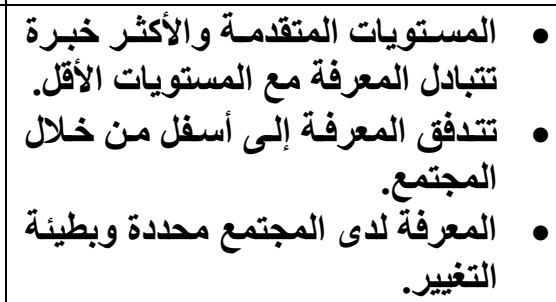 & الهيكل المتدر \\
\hline 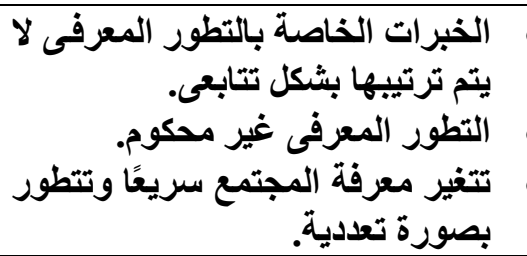 & 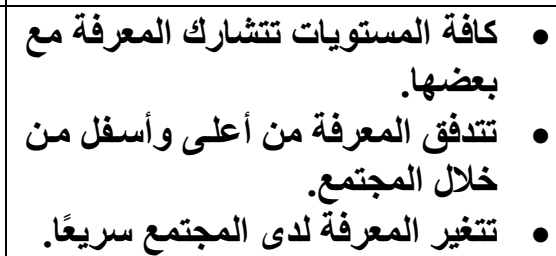 & دل \\
\hline
\end{tabular}

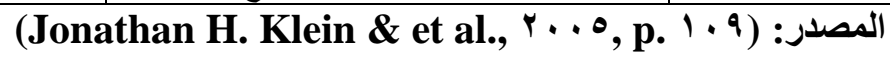

من خلال هذا الجدول يتضـح أن هناك تنوعًا سواء فى مستوى المعرفة التى يمتلكها

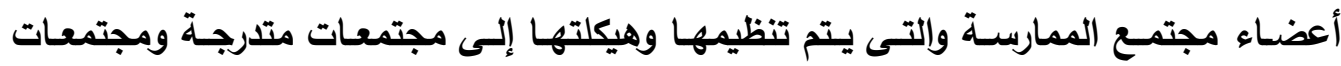

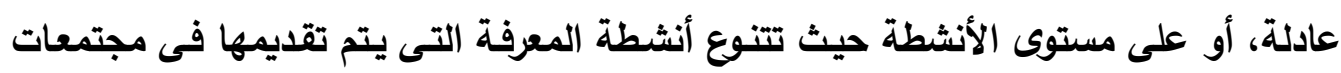

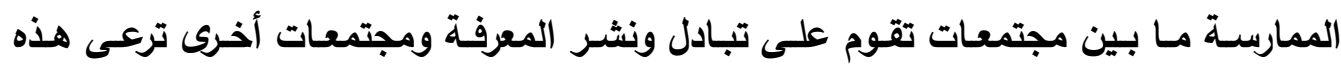
المعرفة من خلال توفير البيئة الملائمة لها والاستفادة من خبرات الأعضاء، ورغم هذا لهاد التنوع إلا أنه يمكن أن نلاحظ أن مجتمعات الممارسـة تركز على الأعضاء والمعرفة التى يمتلكونها، لذا قد يكون التساؤل هنا لماذا التركيز على الأفراد أكثر من التركيز على المعرفة ذاتها؟! وهذاء التهاء

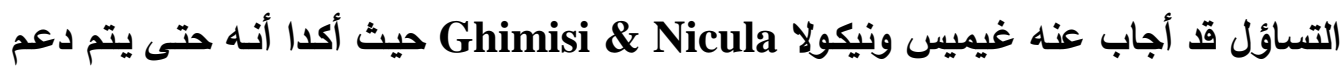
المعرفـة فإنـه يجب التركيز على المجتمـع الذَى يملكها والأفراد الذين يقومـون باستخدامها

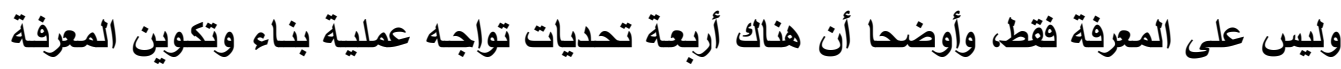

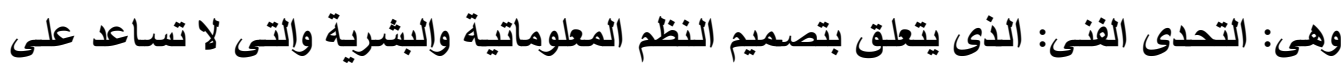
إتاحة المعلومات فقط وإنما تساعد أعضاء المجتمع على أن يفكروا معًا، وإلتحدى الاجتماعى:

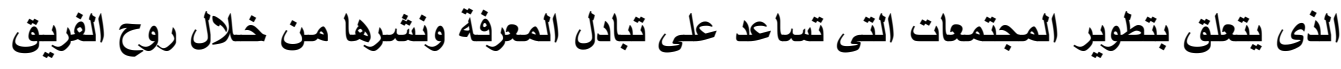

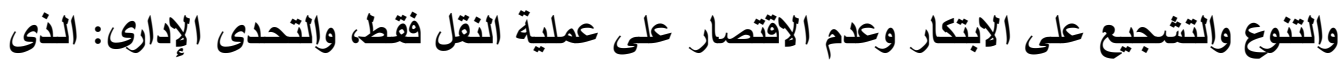

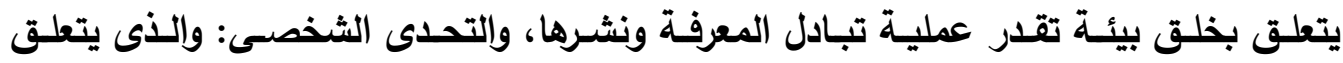

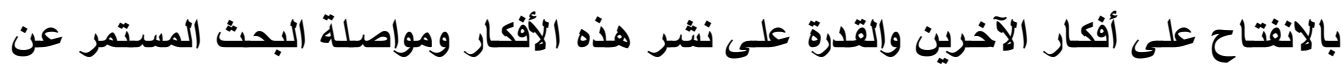


المعرفة الجديدة، ورغم هذه التحديات إلا أن مجتمعات الممارسـة سواء عبر الإنترنت أو التى تتطلب تفـاعلًا وجها لوجـه تعتبر من أفضل السياقات على الإطلاق لإدارة المعرفة، لذا يتم

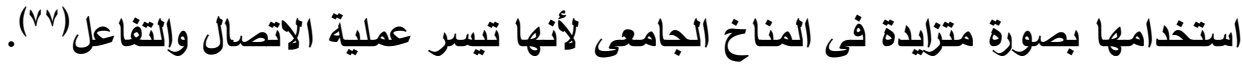

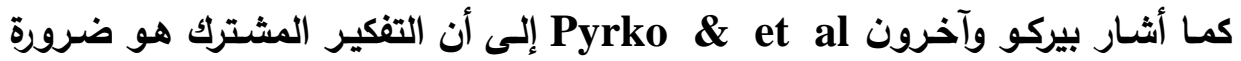

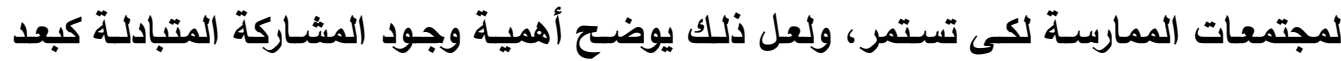
أساسى من أبعاد مجتمعات الممارسة؛ فالمعرفة لا تنتقل بالمعنى الحرفى كالأثشياء وإنما يعاد إحياؤها وبناؤها لاى من يمتلكونها، فالمعرفة تتحقق من خلال الممارسـة ومشـاركة الأعضاء وتفاعلات بعضهم مع بعض (v^)

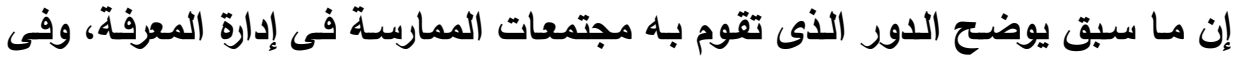
ظل تطور الاقتصاد القائم على المعرفة أصبحت الجامعات بحاجة إلى استخدام كافة السبل لبناء المعرفة ونقلها وتثاركها مع الآخرين، لكى تواكب التحديات المعرفية والتكنولوجية التى التى أصبحت سمة أساسية من سمات هذا العصر، لذا أصبح تصميم وبنـاء مجتمعات الممارسـة فى الجامعات ضرورة فرضتها تحديات هذا العصر، فهى قادرة على إدارة المعرفة فى ظل مناخ اجتماعى يشجع على العلاقات الإنسانية والتعاون واحترام الأات وإحترام الآخرين.

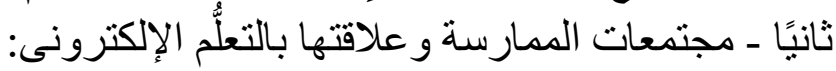
Communities of Practice of E- إن مجتمعات الممارسـة للتعلم الإلكترونسى بالإسى Learning الأفراد يتجمعون مع بعضهم ويتعاونون وينظمون أنفسهم من أجل تبادل المعلومـات والخبرات

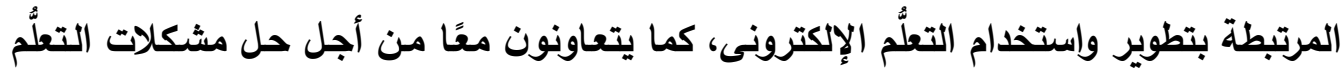
الإكترونى، وتكوين وبنـاء المعرفة التدريسية والتكنولوجية والوقوف على أفضل الممارسـات، ويتعلم بعضهم من بعض، ويطورون مهاراتهم فى مجال تكنولوجيا التعليم، ويعززون استخدام

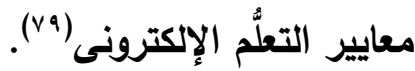
وهنـاك مفــاهيم وأدوار رئيسـية لمجتمـع الممارسـة للتعلم الإكترونـى يمكن توضـيحها كمــا يلى (•) 
(1) ممثلو مجتمعات الممارسة للتعلم الإلكترونى وأدوارهم:

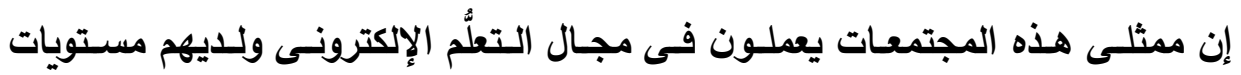

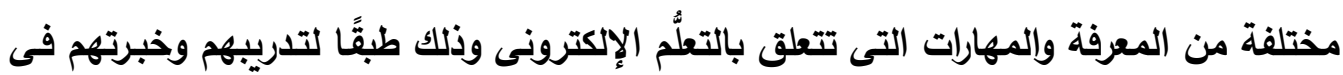

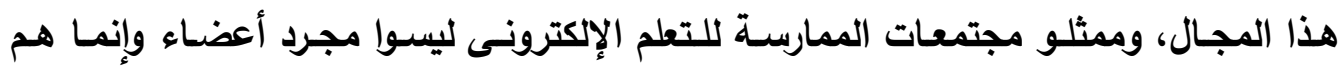

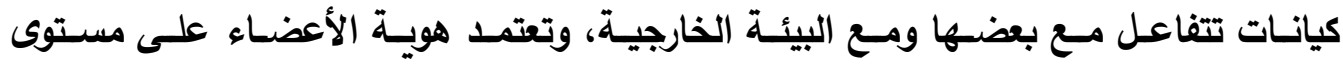

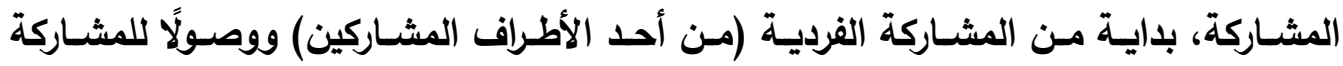
النشطة (التفاعل بين جميع المشاركين)، وإنتهاءً بالمشاركة فى جوهر المجتمع (المشاركة في المئ

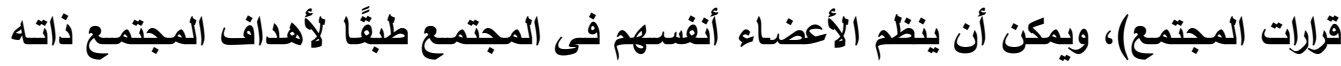
وجوانب الاهتمـام، لذا هناك نوعـان من الأعضـاء وهمـا: أ-العضو الداعم: وهو الذى يسهم بطريقة فعالة ومستمرة فى أعمال مجتمع الممارسة للتعلم الإكترونى كما يقوم ببعض الأدوار مثل: • دور المنسق: حيث يثرف ويحدد القضايا المهمة فى مجال التعلُّم الإكترونسى ويسـاعد فى تقييم ممارسات المجتمع. • دور الوسيط: حيث يرشد الأعضاء ويحفز عمليات التعلم. • دور الإدارى: حيث يساعد فى تحسين موارد المجتمع وإدارة الأعضاء.

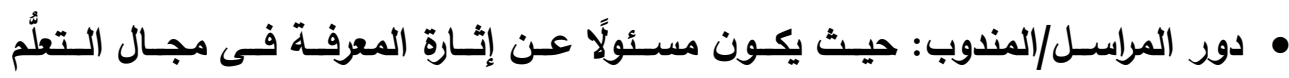
الإكترونى وتجميع نتائج المناقشات.

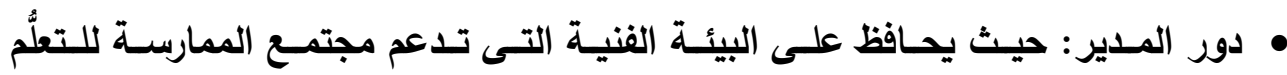
الإلكترونى ويساعد الأعضاء فى استخدامها والاستفادة منها. ب-العضـو المـتعلم: وهـو الـذى يسـهم فـى تنفيـذ أنثـطة مجتمــع الممارســة للتعلم الإكترونى، والعضو فى هذا المجتمع إما أن يكون مقدِّمًا للمعرفة، أو مستهلكًا لها، فالعضو

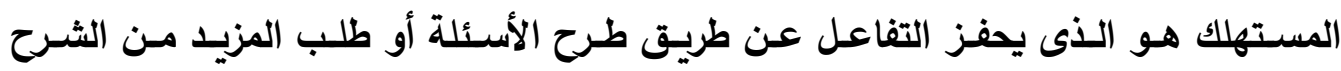
والتوضيح، أما العضو المُقدم للمعرفة فهو الذى يثـارك فى إيجاد إجابات عن طريق تحديد المشكلة وإيجاد الحلول لها بصورة مباشرة. 
هناك أربعة أنثطة تتم داخل مجتمعات الممارسة للتطلم الإكترونى وهى: مأنثطة التحليل: وتتمثل فى شرح الأهداف التدريسية، وتحديد مـا يتعلق باحتياجات التعلم، وما يتعلق بالهدف العام، والثروط، والاعتبارات التظظيمية والمالية.

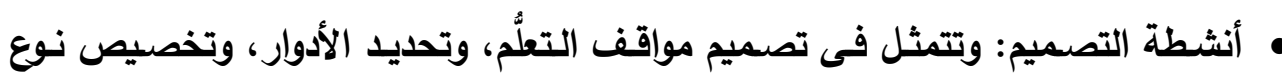

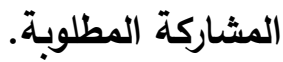

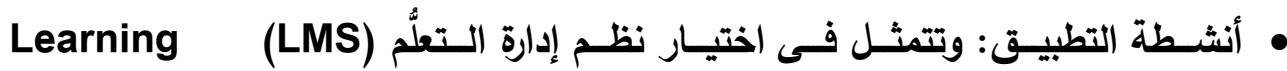
Management Systems • أنثطة الاستخذام: وتتمثل فى توجيه أنثطة التعلم.

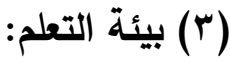

تتطلب مجتمعات الممارسة للتعلم الإكترونى بيئة فنية تدعم أنثطة التعلُم لأعضائها،

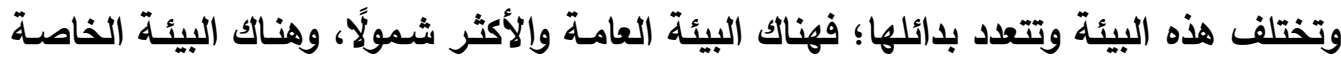

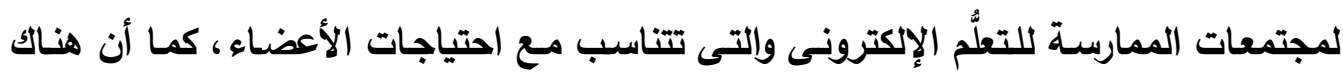

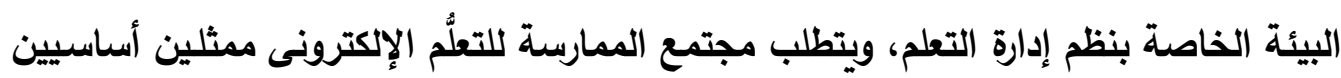

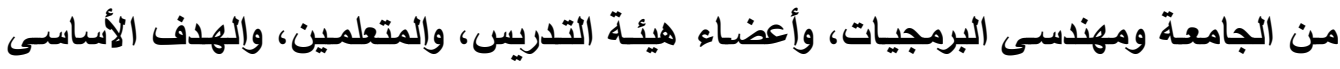

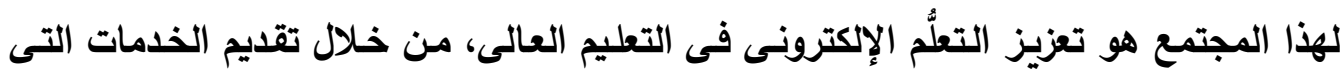

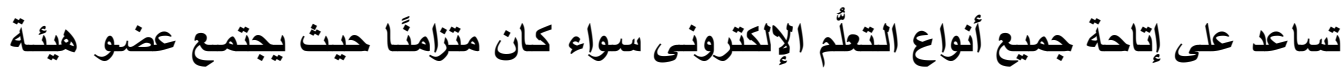

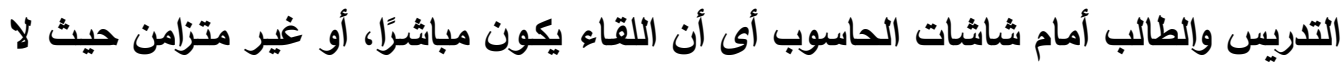

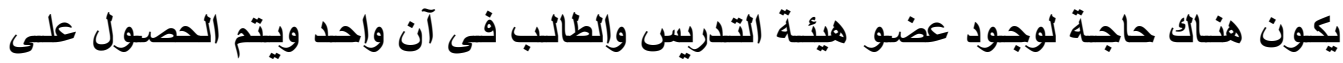

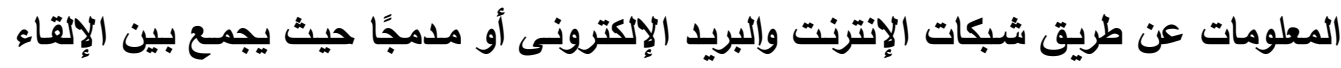
المباشر فى قاعة المحاضرات والتواصل عبر الإنترنت.

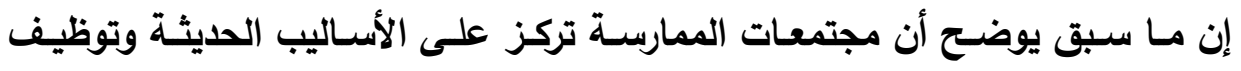

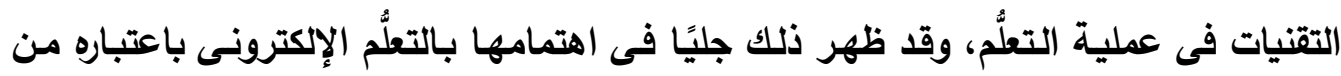

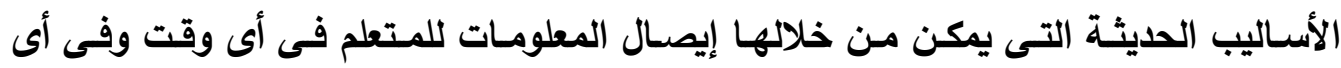

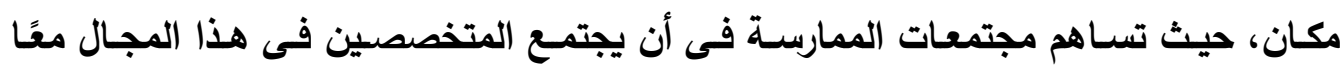

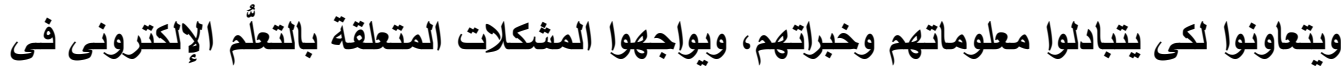


جامعاتهم، ويعملوا معًا على إتاحة الأنثطة الخاصـة بالتعلُّم الإكترونى وتوفير البيئة الفنية التى تدعم تلك الأنثطة.

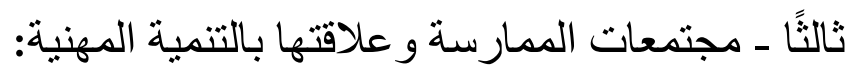
تعد تنمية أعضـاء هيئة التدريس جزعًا أساسيًا من التخطيط المؤسسى، وفى الوقت

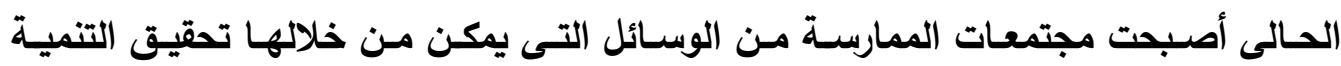

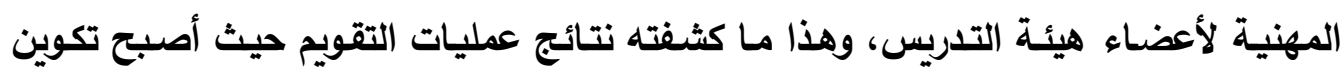
مجموعات من أعضاء هيئة التدريس بالجامعات لتحقيق هدف محدد أو علاج قضية محددة

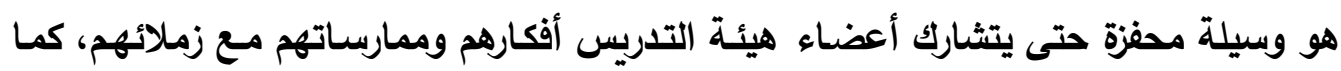
أنها طريقة فعالة لتلبية احتياجاتهم الفردية، ويمكن استخدامها كنهج مستدام لتحسين عملية

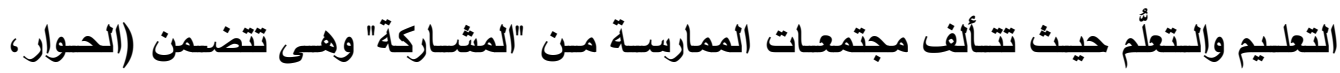
والأنثطة، والتفكر والتأمل)، كما تتألف من الأدوات والتىى تثتمل على (الوثائق، والعمليات،

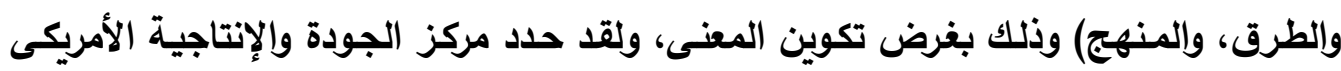
The American Productivity and Quality Center وراء بنـاء مجتمعات الممارسـة بالنسبة للمهنيين والمتخصصين وهـى: حل المشكلات التى

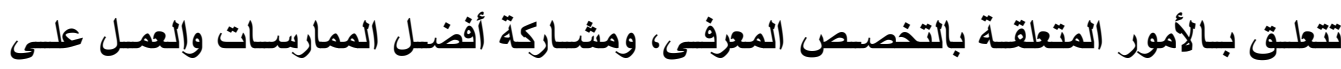
تطويرها، وخلق الأدوات والوظائف المساعدة، وأخيرًا الابتكار (1^). والحقيقة أن القوة الحقيقية لمجتمعات الممارسـة تكمن فى قدرتها على تخطى حاجز

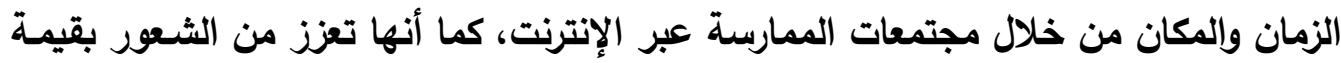

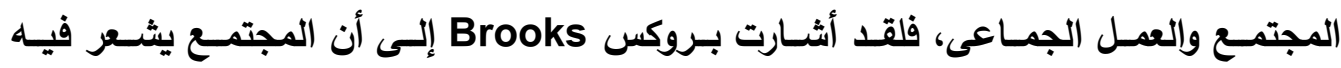
الأعضاء بأهمية بعضهم، ويكون لايهم إيمان مشترك بأن احتياجاتهم سيتم تلبيتها من خلال

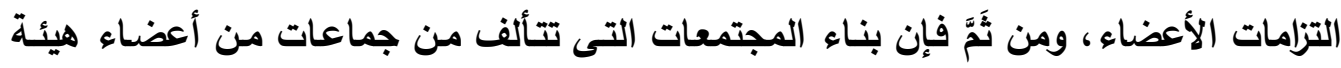

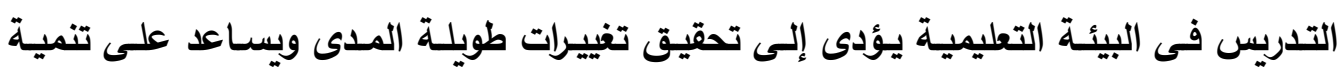

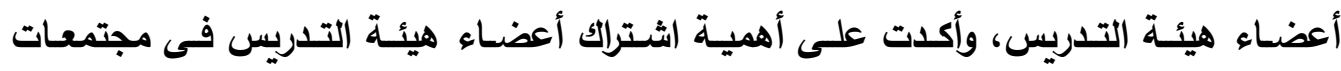

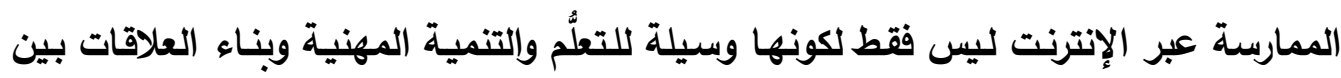
الأفراد ولكن أيضًا لكونها منتدى قائمًا على الحوار والتفاعل، فالحوار والمناقثشات التى تدور

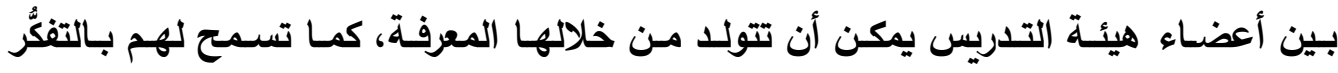


والتأمُّل، وأوضحت أنسه على الرغم من أن الاجتماعات التى تحدث في مجتمعات المعارسية وجهًا لوجها يمكن أن توفر لأعضاء هيئة التدريس التواصل الجاد والفعال، إلا أن مجتمعات التهات التهات

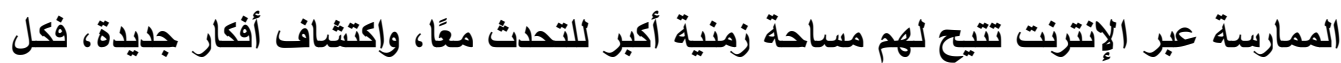
عضو من أعضاء هيئة التدريس لديه خلفية ثقافية واجتماعية مختلفة عن غيره وذلك طبقًا لعمره، وتاريخه، وهو ما يؤدى فى النهاية إلى تبادل الثقافات والخبرات المتنوعة (هr).

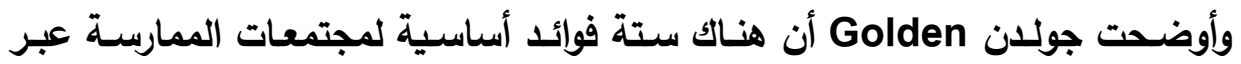
الإنترنت تتعلق بالتمية المهنية لأعضاء هيئة التدريس، وتصف الجوانب المختلفة للتفاعل

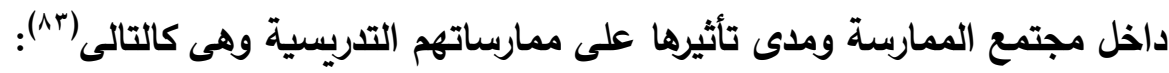
1-الممارسة المشتركة والنمو المهنى والتنمية المهنية: إن أعضاء مجتمعات الممارسة يسيطر عليهم الثعور بالرغبة فى العمل الأى يقومون

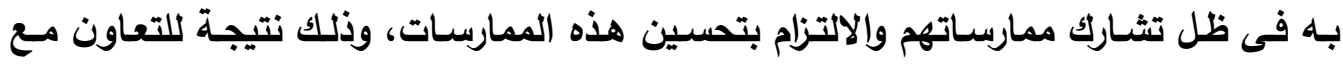

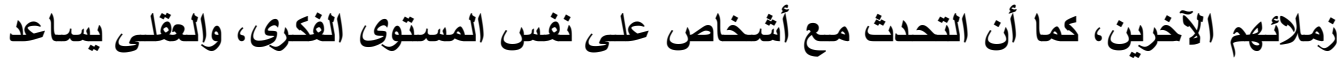

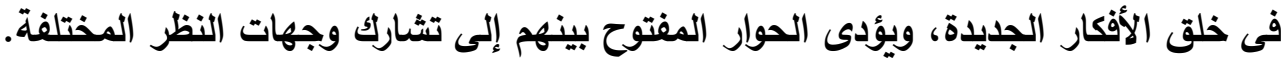
r-دعم وتثجيع التغيير وتعزيز المعرفة الذاتية والممارسة التأملية: إن المشـاركين فى مجتمـع الممارسـة عبر الإنترنت يتثـاركون فى عمليـات التفكير

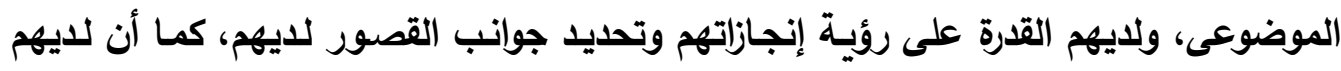

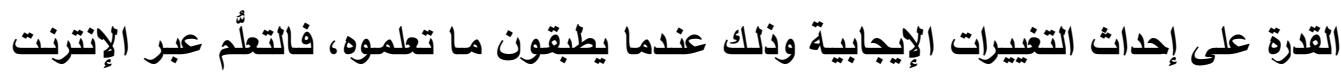
يساعدهم على الارتقاء من مستوى إلى مستوى آخر أعلى منـه، وعندما يتقدم أحد الأعضاء

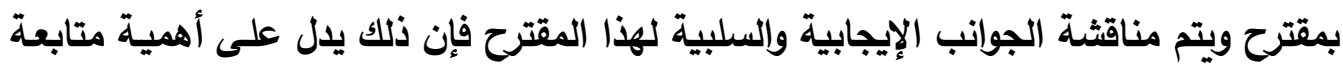

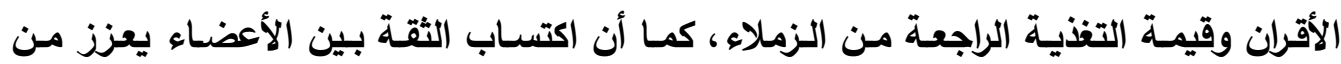

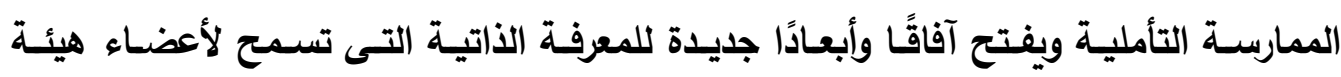

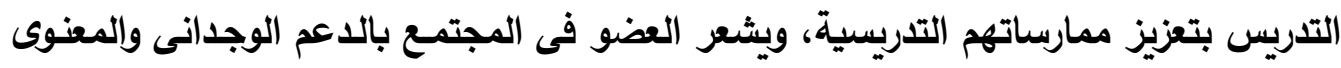
عذما يوافق الآخرون على أفكاره ويقرون بصلاحيتها ويتشاركونها معًا. 


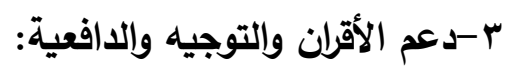

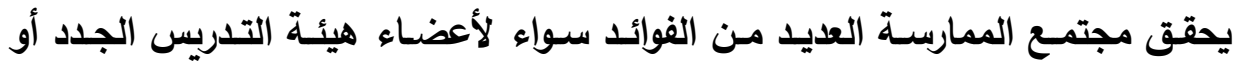

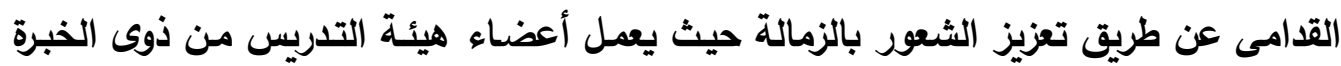

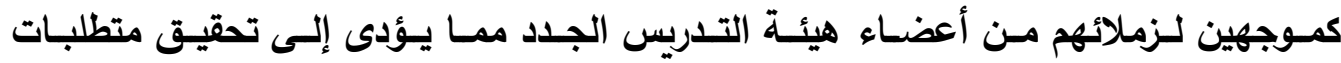
واحتياجات الزملاء وتظوير ممارساتهم، فالتوجيه والتعاون بين الأقران هو أحد السبل الأكثر إفادة فى تنمية أعضاء هيئة التدريس بالجامعات. ؛ - بناء الثقة والبيئة الآمنة:

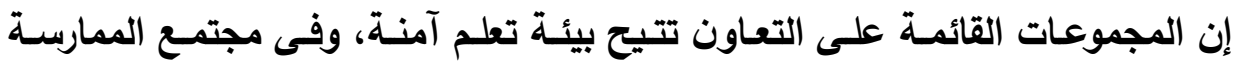

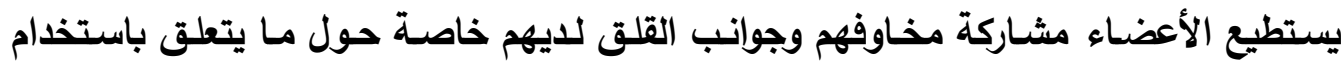

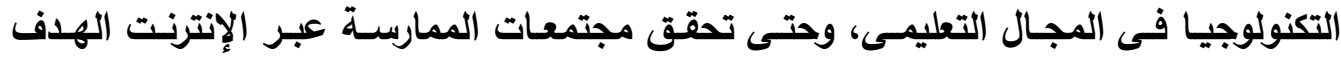

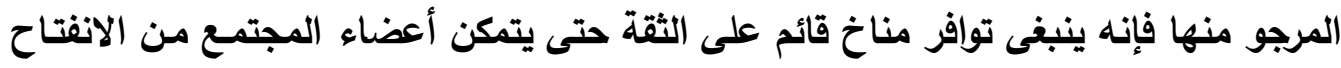

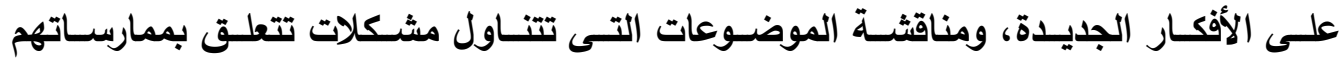

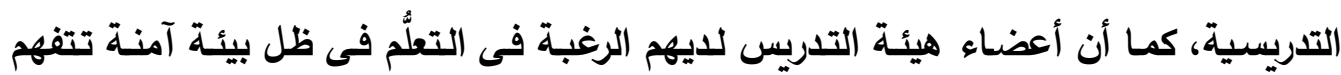
قدراتهم واحتياجاتهم، فهم ليسوا بحاجة إلى من يصدر عليهم الأحكام ويحد من قدراتهم. ه-بناء المجتمع والحد من العزلة: تعتبر العزلة فى المجتمع الجامعى من أكثر الجوانب المثيرة للقلق، فعندما يشعر عضو

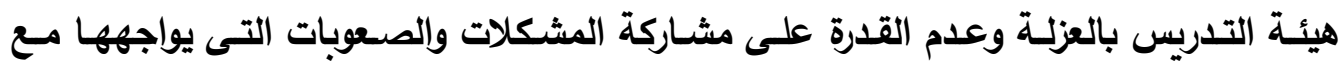

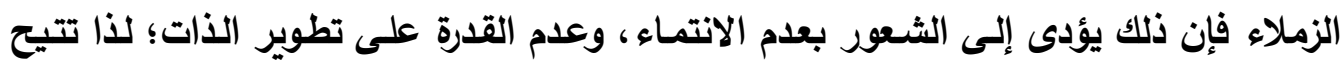

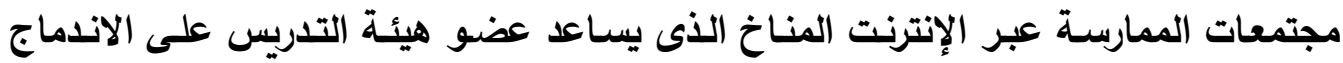

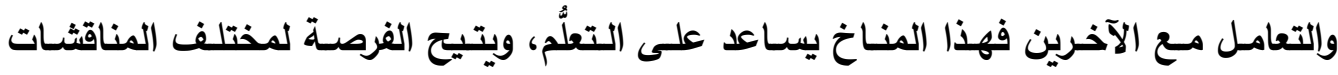
والحوارات، كما يساعد على بناء علاقات قوية بين الزملاء والثشعور بالهوية والانتماء. 1-تبادل الموارد وتقنيات النمذجة: إن أعضاء مجتمعات الممارسة لديهم أفكار مختلفة، ونظريات متباينة، وسبل مختلفة

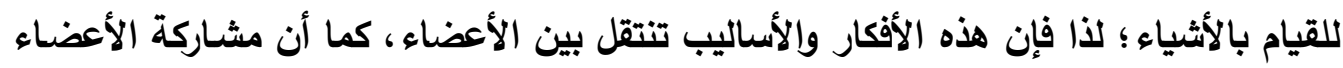

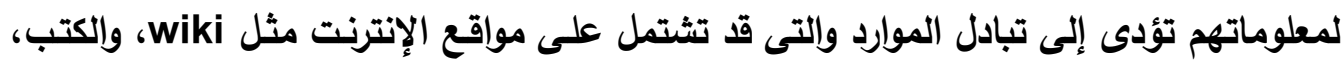


والقصص، وطرق التـدريس، ....، كمـا يتبـادلون معًا مختلـف تقنيـات النمذجـة فـى مجـال الحاسب الآلى.

يتضح مما سبق علاقة مجتمعات الممارسـة بإدارة المعرفة والتعلُّم الإكترونى والتنمية

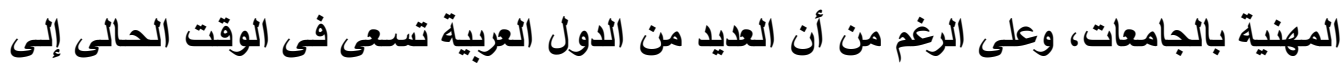
تطوير جامعاتها والتركيز على جودة التعليم والارتقاء بتصنيفها عالميًا من خلال إنشـاء مراكز لتطوير الأداء الجامعى ووحدات الجودة وإقامة العديد من مشروعات التطوير، إلا أن جامعات الدول المتقدمة لجأت بالإضـافة إلى كل مـا سبق إلى النظرة بجديـة إلى نظريـات التعلُّم وعلم الاجتمـاع، وركزت على التفاعلات الاجتماعية، فالتفاعل يعنى التأثير المتبادل بين الأفراد، وربما يكون لكل فرد منهم صفاته وثقافته وخبراته الخاصة ولكن يؤدى تفاعلهم مـع بعضهم إلى ظهور ثقافات وأفكار وخبرات جديدة وهو ما تتيحه لنا مجتمعات الممارسة؛ فبناء مثل هذا النوع من المجتمعات على مستوى الجامعات لن يقتصر تأثيره فقط على تحسين مهارات التعلُّم الإكترونى وإدارة المعرفة والتنمية المهنية كما سبق وذكرنـا، ولكنـه سيتعدى ذلك إلى شعور الأفراد بهويتهم وزيـادة شـورهم بالثقة وتخطى مخـاوفهم؛ فهناك زمـلاء متواجدون فى العمل ومتواجدون على شبكة الإنترنت ويمكن الاستفادة من خبراتهم فى أى وقت وفى أى مكان، وسوف تنصهر أفكار الطلاب وأعضاء هيئة التدريس فى بوتقة واحدة وينتج عنها فى النهاية أفكـار إبداعيـة والثـعور بالمسـئولية، والإصـرار، والمثـابرة، والثـعور بالقــــة علـى الإنجـاز ومواجهة العقبات والمشكلات وهو ما تحتاجه جامعاتنا فى الوقت الحالى.

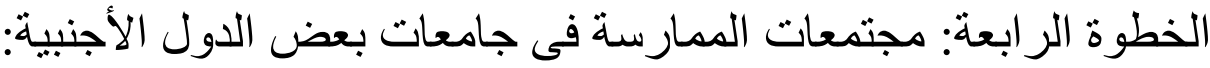
استطاعت جامعـات بعض الدول المتقدمسة أن تركز علـى بنـاء مجتمعـات الممارســة داخلها، وأصبحت إحدى أولويـات هذه الجامعات إقامـة مجتمـع هـادف يتبـادل فيـه الأعضـاء

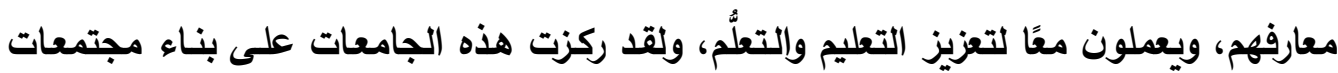
الممارسة تحديدًا نظرًا لحرص هذه المجتمعات على تبادل المعرفة ونشرها ليس فقط فى إطار

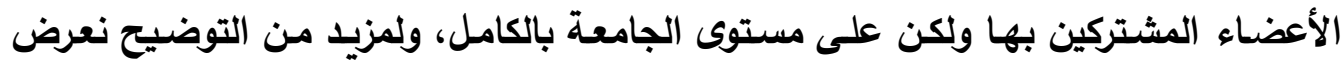
خبرات بعض الجامعات الأجنبية فى مجال مجتمعات الممارسة، وذلك فى الصفحات التالية: 


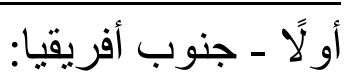

تقع جمهورية جنوب أفريقيا فى أقصى جنوب القارة الأفريقية ويحدها كل من ناميبيا،

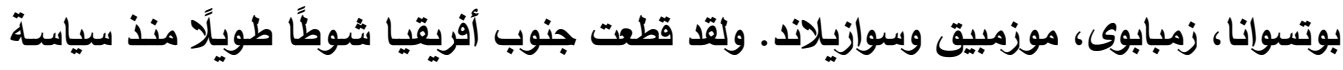
الفصل العنصرى (الأبارتايد) - والأبارتايد هو نظام الفصل العنصرى الذى حكمت من خلاله

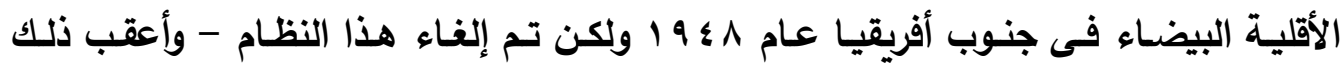
انتخابات ديمقراطية، ففى عام ؟9 9 التم تنظيم أول انتخابات متعددة تمثل جميع الأعرلق، ومنذ ذلك العام تحقق فى البلاد نظام برلمانى متعدد الأحزاب بسلطات تنفيذية ممنوحة لرئيس

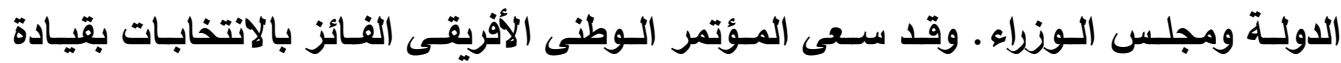
"تيلسون مانديلا"، إلى إنهاء إرث النزاع العرقى والعنصرى. وقد تلقى مانديلا لاحقًا جائزة نوبل

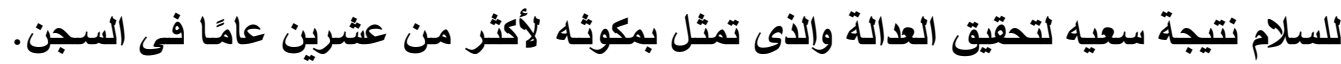

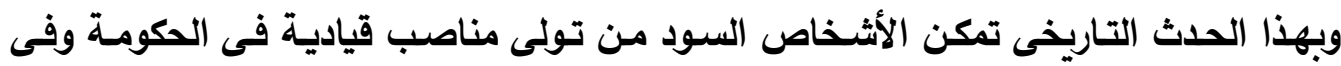
قطاعات مختلفة (^).

ومنذ عام ؟9 9 ا كان لإصلاح التعليم الأولوية فى جنوب أفريقيا لتعزيز المساواة بين الأعرلق المختلفة، ووضعت جنوب أفريقيا سياسات التعليم التى تعزز إتاحة الفرص التعليمية للمجموعات وإلفئـات المحرومـة، وشـهـت كل البنود الخاصـة بالتعليم تطورًا وتقدمًا كبيرًا مثل التشريعات التعليمية والسياسـة والتطوير وإصـلاح المنـاهج الدراسية وتطبيق الأنمـاط الجديدة فى مجال التعليم(^).

ورغم التقدم الحـادث الآن فى جنـوب أفريقيا فى العديد مـن المجـالات إلا أن جنـوب

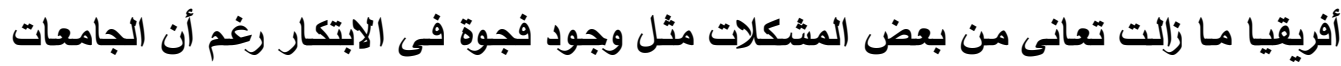

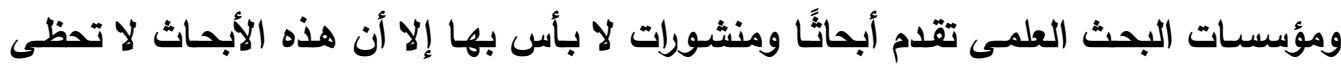

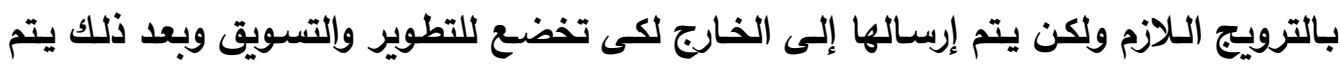
اسـتردادها إلى جنـوب أفريقيا مـرة ثانيـة بتكلفـة كبيرة على المستهلك، وتحـاول العديـ مـن المؤسسات والثركات التغلب على تلك الفجوة حيث قامت رابطة البحوث والابتكار فى جنوب أفريقيـا ووزارة العلـوم والتكنولوجيـا والجامعـات وقطـاع الصـناعة وإلتكنولوجيـة بالعمـل بثكل متآلف ومتكامل لمواجهة تلك المشكلة عن طريق بناء المجتمعات حتى يتم تعزيز التعاون بين

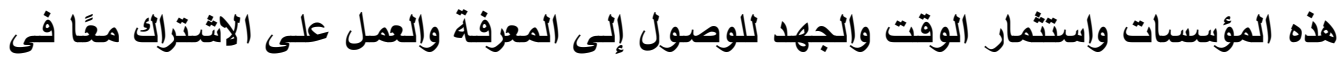
المشروعات التعاونية(ז^). 
Global Research كمـا اشـتركت جنـوب أفريقيا فى التحالف البحثى العـالمى Alliance (GRA)

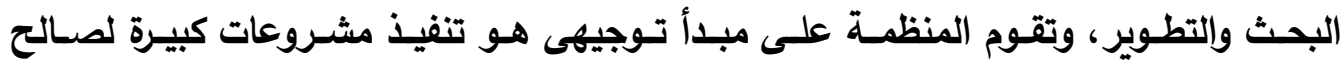
المجتمعات واستخدام العلوم والتكنولوجيا لمواجهة المشكلات فى الدول النامية، ولقد تشكل التحالف البحثى العالمى على أسـاس الثقة بين الدول الأعضاء المشتركين فى التحالف مثل

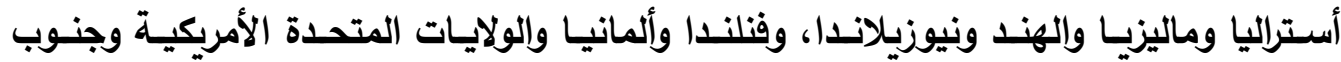
أفريقيا، ويعمل التحالف البحثى العالمى كمجتمع ممارسة تنظيمى؛ فهو يشمل مجموعة كبيرة من العلماء والخبراء والكفاءات من مختلف أنحاء العالم، وعلى الرغم من أهمية هذا التحالف كمجتمع للممارسة إلا أن هناك بعض المشكلات التى واجهته ترتبط بالتدرج الهرمى والطبقى مئى فى الإدارة وضرورة وجود رؤساء ونواب مما يعرقل عملية الابتكار (Av).

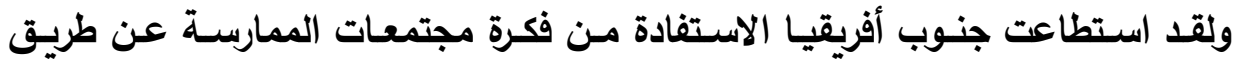

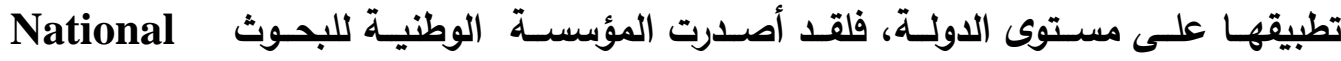
Research Foundation (NRF) واسـعة فـ مختلف المجالات البحثية، وتعتبر هذه الخبرات ثروة قوميـة يمكن ترجمتها إلى خطط عمل ملموسة وسياسات قابلة للتففيذ، ويمكن تحقيق ذلك من خلال مجتمعات الممارسة حيث يمكن تقديم حلول للعديد من المشكلات التى تواجه جنوب أفريقيا، وأوضحت الوثيقة أن

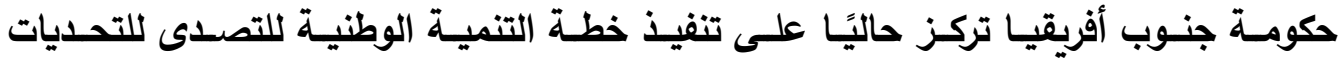
المجتمعية التى تواجه البلاد، وعلى الرغم من ذلك فما زالت الدولـة تعانى من بعض الأمور التى ينبغى مواجهتها مثل عدم المساواة الاقتصادية والذى لا يزال واضحًا على أسس عرقية

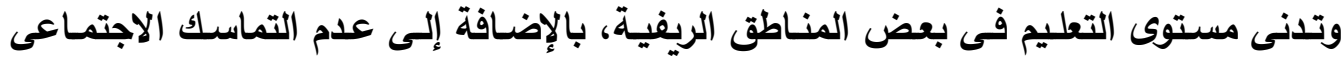
الناتج عن نظام الفصل العنصرى، ورغم جهود الدولة فى وضع مجموعة كبيرة من السياسـات والبرامج الإصـلاحية إلا أنـه لا يزال بالإمكـان القيـام بالعديـ مـن الأمسور مـن خـلال المشـاركة

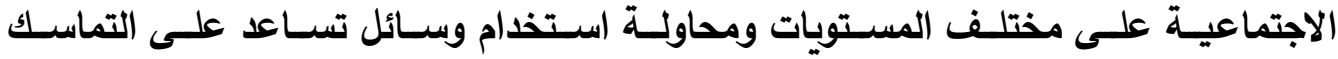
الاجتماعى مثل مجتمعات الممارسة؛ فهى الوسيلة التى ستحقق بها الاولة العديد من التدابير

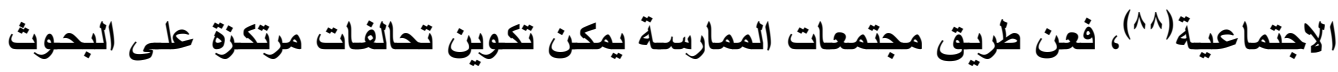
يتعاون فيها الباحثون للتوصُل إلى حلول إجرائية لمثكلة ما، والأهم من ذلك ينبغى أن تكون 
مجتمعات الممارسة متوافقة بثكل استراتيجى مع سياسات الحكومـة من خـلال تركيز الباحثين

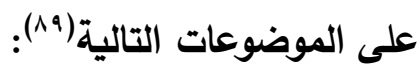
1 - التخفيف من حدة الفقر وعدم المساواة والتتمية. r - الاقتصاد الريفى الثامل والتوظيف. r- الطاقة وتغير المناخ والبيئة والتنوع البيولوجى. צ - التعليم وإلتدربب.

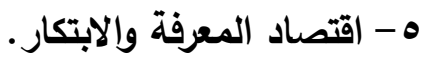
צ- إدارة الصحة والابتكار الصحى. V - المساءلة ومكافحة الفساد.

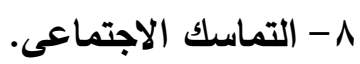
9 - وحَكمة البلديات وإدارتها. • 1 - الاتصالات السلكية واللاسلكية وإدارة البيانات والابتكار . 11 - التعدين وإغناء المعادن والسلامة.

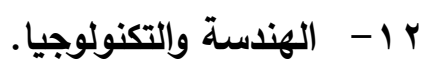
r ا - الثمول الاجتماعى للأشخاص ذوى الإعاقة وكبار السن.

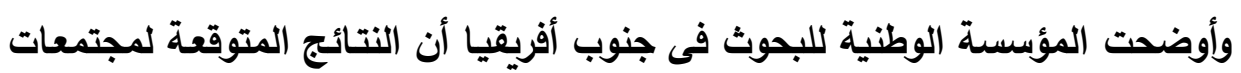

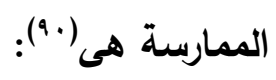

- ضمان أن كل مجتمع ممارسـة سـوف يصل إلى حلول للتصدى لتحديات معينـة فى

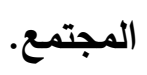

- -

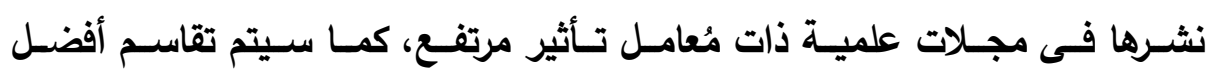
الممارسات من خلال المنتديات وشبكات مجتمعات الممارسة الأخرى.

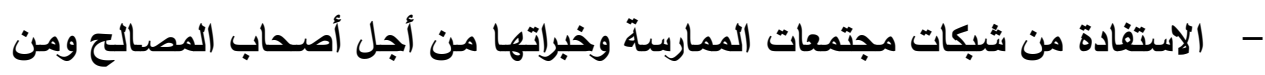
أجل المهام الاستشاريـة المحددة. 
- تقديم تقرير شامل لورش عمل مجتمعات الممارسـة يتم فيها شرح مسارات التنمية

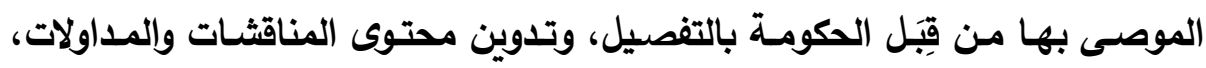
ومن المتصور تحويل هذا التقرير إلى وثيقة رسمية بعد ذلك.

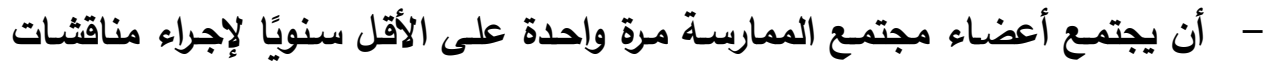
جماعية حول موضوعاتهم، وتهدف هذه الاجتماعات إلى إجراء مناقثـات تأملية اعنة

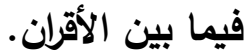

- - بناء القدات البحثية من خلال زيادة عدد الخريجين والإثراف على الطلاب ودعمهر.

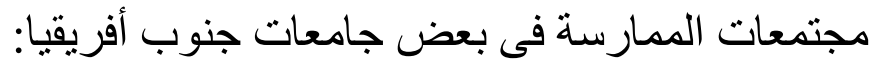

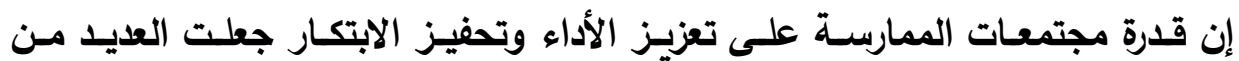

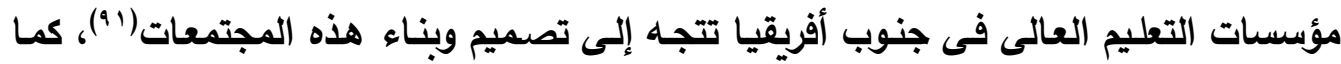
قامت بعض الجامعات ببناء مجتمعات الممارسـة لأغراض معينة، ومواجهة مشكلات محددة

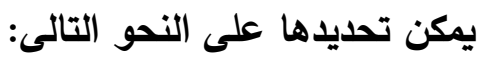

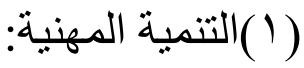

University of the Witwatersrand جامعة ويتواترسراند (r) قامـت كلية التجارة بجامعة ويتواترسراند بتصميم وبنـاء مجتمعات الممارسـة لتنميـة

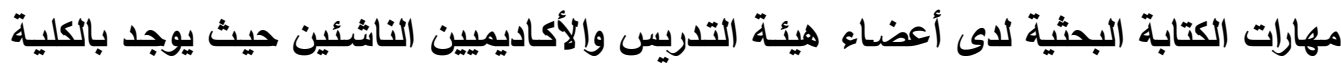
ما يقرب من • ^ أكاديميًا فى مختلف التخصصات، وقد تم تصنيف الكلية على أنها "دون الأداء" خاصة فى مجال الإصدارات البحثية، ولم تكن الكلية هى الوحيدة ذات الأداء المتدنى

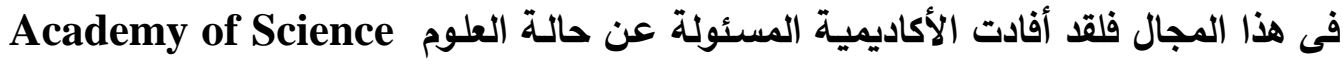
of South Africa العلمية تثير إلى ارتفاع أعمار الباحثين؛ فقد ظهر أن أكثر من نصف الإصدارات البحثية

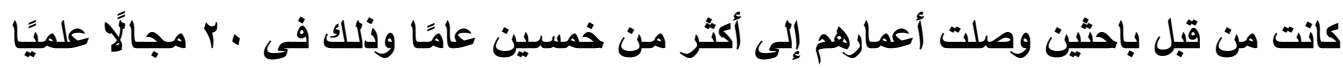

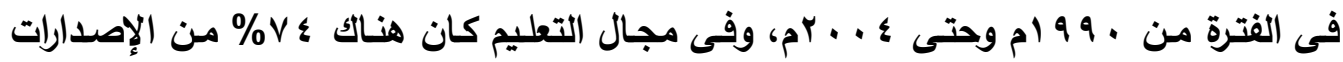
من قبل باحثين فى أعمار متقدمة؛ لذا تحتاج الجامعات إلى وسيلة فعَالة لاعم أعضاء هيئة

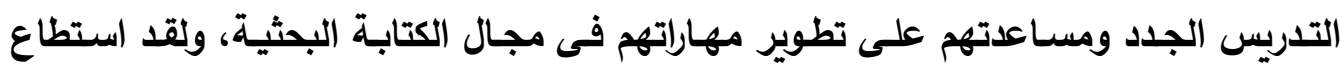
رئيس كلية التجارة بجامعة ويتواترسراند بطلب تمويل من الجامعة لزيادة معدل نثر البحوث

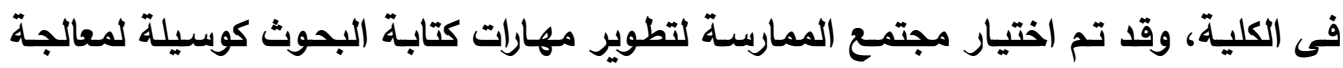


مشكلة الانخفاض فى معدلات الإصدار البحثى بالكلية ومحاولـة مواجهة الضغوط والعقبات التى تواجه أعضاء هيئة التدريس الجدد خاصة الذين لم يقوموا بنشر أبحاث من قبل ولديهم شعور بالضعف والقصور فى هذا الجانب على الرغم من قدراتهم الفكريـة العالية وجداراتهم

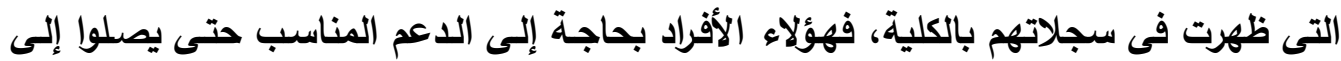
المستوى المرجو منهم؛ ولهذا اشترك فى مجتمع الممارسة بالكلية الخبراء فى المجال البحثى

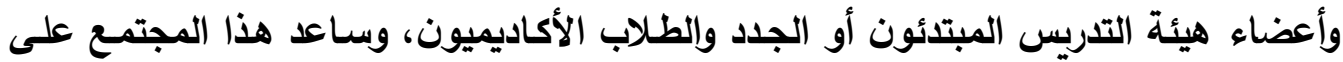
ربط احتياجات الأعضاء وكتابة الأبحاث باحتياجات الجامعة، وفى مجتمع الممارسة كان هناك ثلاث ممارسات أساسية مشتركة: - - الممارسة الأولى: "استعراض النظراء"، حيث يقدم الخبراء من أعضاء هيئة التدريس

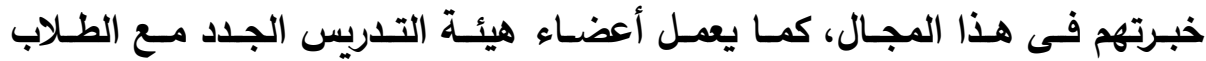
الأكاديميين والخبراء فى عملية أفقية لتطوير خبراتهم ومهاراتهم فى مختلف جوانب الكتابة البحثية كما يُكوّنون معًا شبكة من العلاقات الإنسانية. - - الممارسة الثانية: "الكتابة كعملية قابلة للصياغة والمراجعة"، فى هذه الممارسـة وجد الإسل أن أعضــاء هيئة التـدريس الجـدد بالكليـة يقـرأون فقـط المجـلات العلميـة الجيـدة

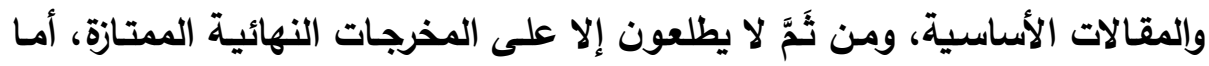
المراجعات السـابقة وحـالات رفض الأبحاث أو الأبحاث قبـل أن تصل إلـى التعديل

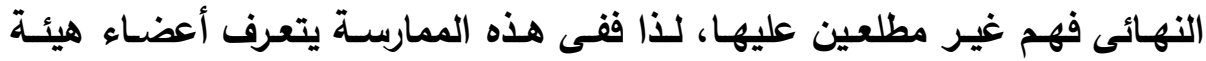
التدريس على أهمية النقد البناء وضرورة تحكيم البحوث من قِبَل الأسـاتذة، وكيف هيف يمكن أن يمر البحث العلمى بأكثر من مرحلة حتى يصل إلى الصورة النهائية.

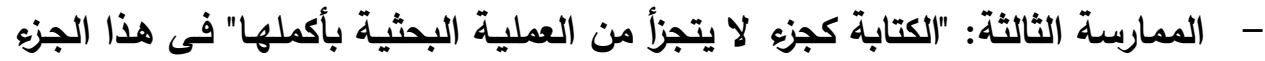

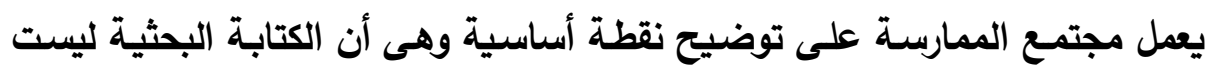

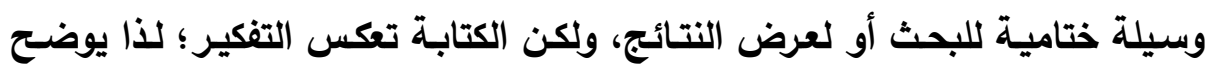
مجتمع الممارسة الطرق المختلفة للكتابة، كما يوضـح التقنيات والأسـاليب المختلفة مثل الكتابـة الحرة وتتطور الكتابـة مـن خـلال المسـودات حتى تصـل إلى الصـورة النهائية. 
ومن خلال الممارسات الثلاث السابقة يقوم أعضاء مجتمـع الممارسـة بتنمية مهاراتهم

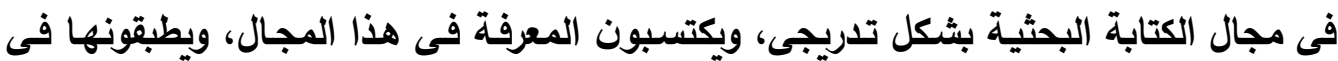

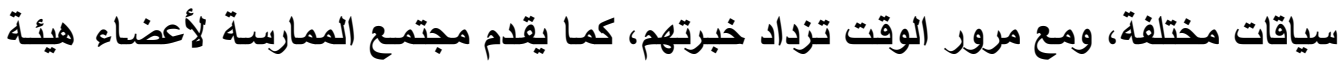

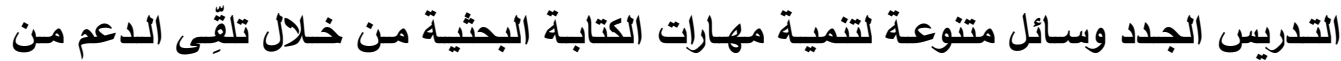
الخبـراء والميسـرين، هــا بالإضـافة إلـى الجلســات وورش العهـل الرســـية، والملاحظــات

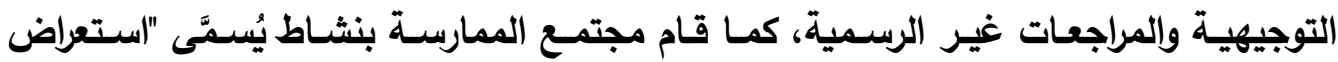
الأقران" حيث يقوم الأعضاء بكتابة أولق بحثية ويقوم أقرانهم بمراجعتها بينما يراقب الخبراء

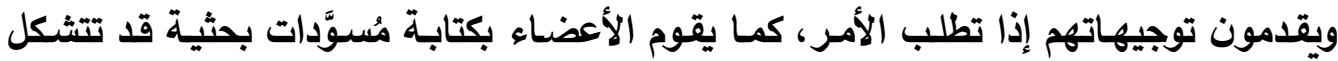
على مدى بضعة أيام ويتم مراجعتها من قِتِل الخبراء.

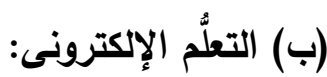

\section{University of the Western Cape}

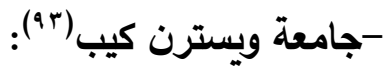

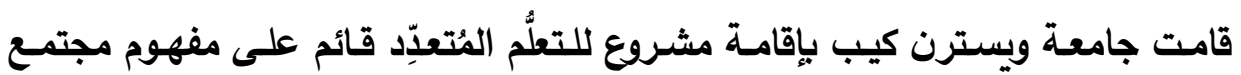
الممارسـة حيث يعتمد المشروع على قضية محددة وهى افتقار العليد من طلاب الجامعة

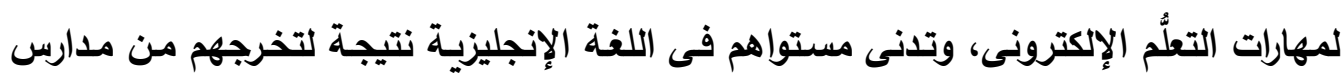

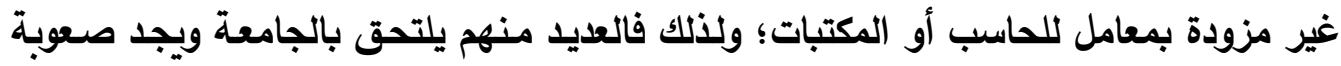

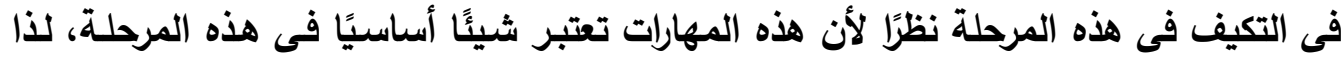

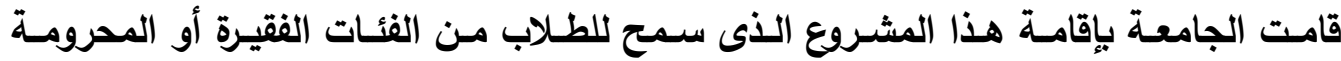

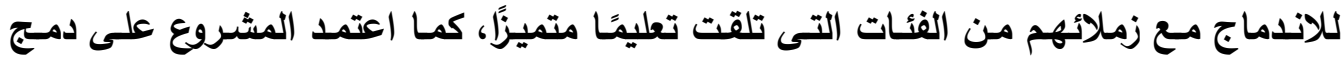

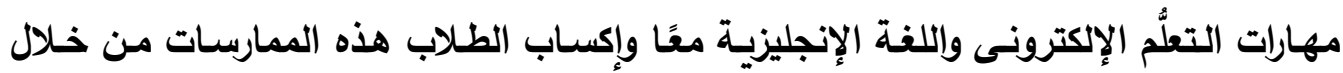

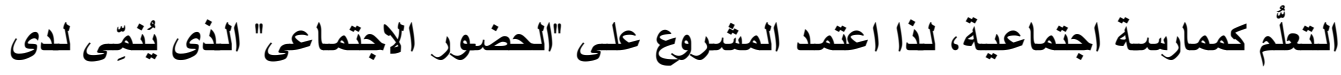

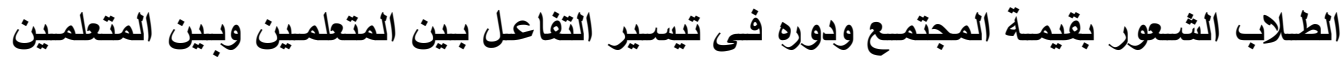
والمعلمين، ولقد تم تطبيق المشروع بكلية علوم الصحة والمجتمع فى جامعة ويسترن كئر كيب

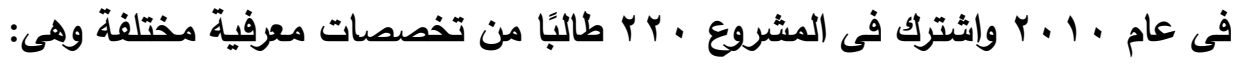




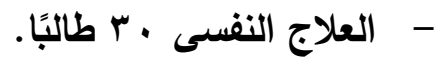

- - ملم النفس r ا طالبًا.

- الرياضة البدنية وإعادة التأهيل والعلوم هr طالبًا.

- - العلاج الوظيفى · ب طالبًا.

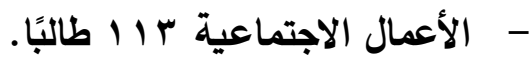

ورغم أن كل تخصص من تلك التخصصات المعرفية يقدم المحاضرات الخاصة بهه، إلا

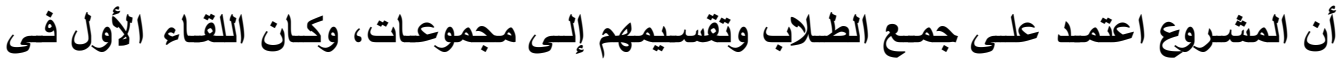
المشروع عبارة عن "حضور اجتماعى" حتى يتعرف الطلاب على بعضهم بطريقة أفضل مما يخلق الثـعور بالترابط والقدرة على الانـدماج، وحتى يتقبل الطـلاب أن يتواصلوا معًا عبر الإنترنت.

بعد ذلك كانت هناك جلسة "التعلُّم الإكترونى الأولى" ولقد تلقى فيها الطلاب التدريب اللازم حول كيفية الاخول إلى المواقع الإكترونية، واللاخول فى منتدى للمناقشـات، والرد على لإنى

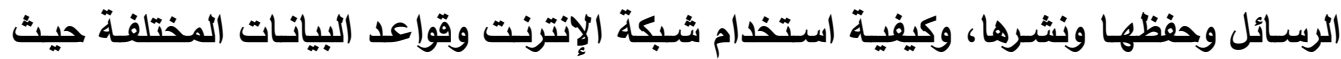

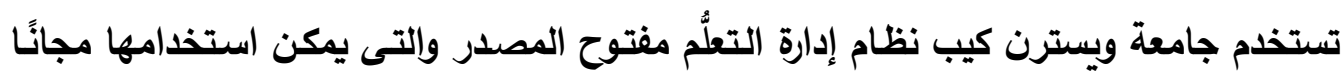
وإخضاعها للتطوير والتعديل. وفى جلسـة "التعلُّم الإكترونـى الثانية" قام المصمم التعليمى فى بدايـة الجلسـة بثرح مـوجز عن كيفيـة الـخول إلى المواقع ومنتـيات المناقثـة ومـن ثم طلب من الطلاب نثر

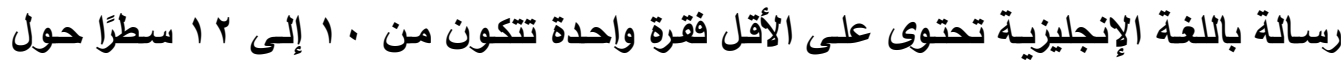

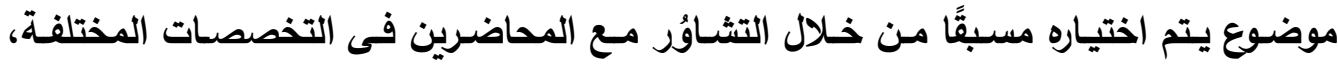
وربما تشمل الموضوعات مشكلات عامة تتعلق بأمراض معينة كالإيدز ونقص المناعة، ويعمل الطلاب فى مجموعات معًا ويناقشون معًا هذه الموضوعات، وهنـا يعى الطلاب أن "المهمـة

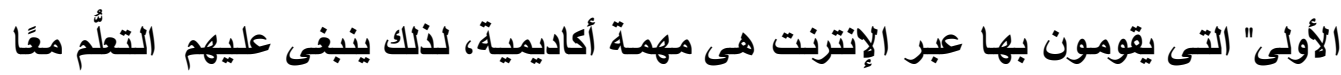
والاتفاق حول أصول الكتابة الأكاديمية. كما يعمل اثنان من المصممين التعليميين كميسرين للطلاب أثناء الجلسـات ويقدمان

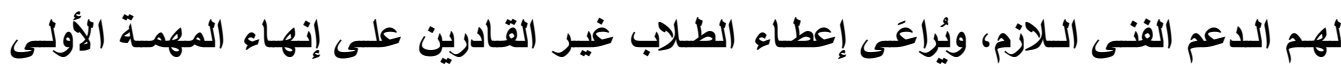


المسندة إليهم فترة أسبوع لإكمال المهمة، ولمساعدتهم فى ذلك يقوم المساعد الفنى والمصمم التعليمى ومحاضر فى اللغة الإنجليزية بتقديم الاعم اللازم لهم. وبعد أن ينتهى الطلاب من نشر الرسالة الأولى (المهمة الأولى)، يحضر الطلاب ثلاث

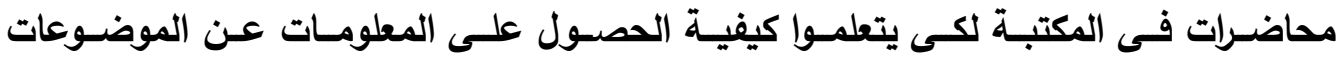
المطروحة عبر الإنترنت وقواعد البيانات المختلفة.

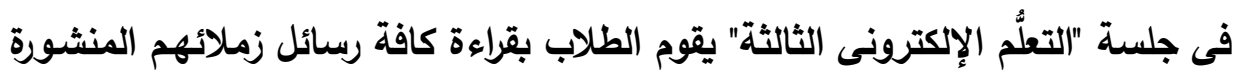
على الإنترنـت، ويقـوم كل طالب باختيـار رسـالة واحدة للـرد عليها فـى فقـرة واحدة باللغــة الإنجليزيـة "المهمـة الثانية"، وذلك حتى يتعرفوا على الموضوعات المختلفة التى قام أقرانهم بنشرها، كما تجرى مناقشات بين الأقران ومعهم محاضر اللغة الإنجليزيـة بهدف تنمية الطلاب فى اللفة الإنجليزية، وبمجرد إكمال الطلاب للمهمة الأولى والثانية يقومون بطباعة "الرسـالة الأولى" و"الرد على الرسـالة" المختارة لإدراجهم ضمن الملف الثخصى للطالب والتـى تشكل جزيًا أساسيًا فى هذا المشروع. قام المصـم التعليمس ومحاضر اللفـة الإنجليزيـة بتقييم المشـروع، وكـان مـن ضـمن أدوات التقييم مناقشات الطلاب فى الجلسات ومهاراتهم فى استخدام التكنولوجيا، والفقرات التى قام الطلاب بكتابتها، وإلمقابلات مـع الطلاب وخضعت التقييمات للتحليل من جانب المصمم التعليمى الذى يقوم بتقييم مهارات الطلاب فى استخدام الحاسب الآلى والإنترنت، ومحاضر اللغـة الإنجليزيـة يقـوم بتقيـيم رسـائل الطـلاب والبحـث عن الأخطـاء التـى تكررت كثيـرًا فـى النصوص. ولقد أوضحت نتائج التقييم أن اندماج الطلاب أدى إلى عدم وجود تفرقة فى معاملات الطـلاب فيم بيـهم سـواء بين الطـلاب مـن الفئـات الفقيـرة أو الفئـات الفتيـة، فـالجميع كـان متعاونين معًا بالإضافة إلى تعاون الميسرين معهم.

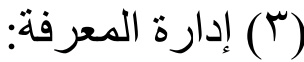
University of Pretoria جامعة بريتوريا (؛ 9): استطاعت جامعة بريتوريا بناء مجتمعات الممارسـة والتى كان لها دور أساسىى فى The إدارة المعرفـة بالجامعـة، فلقد تمكنـت خدمـة المعلومـات الأكاديميـة بالجامعـة Academic Information Service (AIS) 
بناء المعرفة ونقلها وتبادلها من خلال مجتمعات الممارسة التى تستخدم طرقًا مختلفة لتبادل المعرفة مثل السرد القصصى: حيث يتم نقل الخبرات السابقة للأعضاء فى شكل قصص واقعية مما يؤدى إلى فهم أفضل للقضية المعروضة ونقل المعرفة بسهولية إلى الآخرين، أو من خلال لعب الأدوار والسيناريوهات: وهو أسلوب يقوم فيه الأشخاص بـأدوار جديـدة أمـام بعضههم أو القيـام بمحاكـاة مواقـف حقيقيـة، أو مـن خـلال خرائط المعرفة وهـى عبارة عن مخطط يرسـم ويحدد مصسادر المعرفة وقواعدها، وأصسولها وكيفيـة تطورهـا، وطريقـة استخدامها، وخـرائط المعرفـة عبـارة عن صـورة أو مخطط توضح المعرفة الداخلية للجامعة أو المعرفة الخارجية المضافة من خلال تحديد المعرفة وتحديد ما الأى يعرفه الآخرون وما هى العلاقات بين مخزونات المعرفة. وخدمة المعلومات الأكاديمية بجامعة بريتوريا (AIS) هو الاسم الدارج لمكتبات جامعة بريتوريا وهى عبارة عن منظمة شبكية تتكون من عدد من الوحدات التى تهدف كل منها إلى تقديم خدمة شاملة لكل من (الطلاب، وأعضاء هيئة التدريس، والباحثين)، فـى العديــ مـن المجـالات مثل مجـال العلوم الإنسـانية، والاقتصـاد، وإلعلـوم الإداريـة، والعلوم البيطرية.

هذا بالإضـافة إلى وحدات الـعم وهـى عبارة عن كيانـات مثل الإدارة المالية

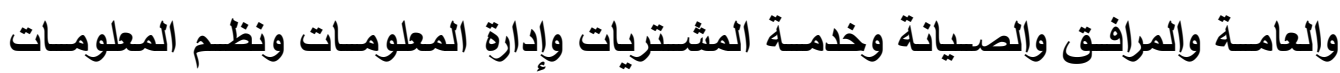
والتكنولوجيا.

ويمكن تمييز نوعين من مجتمعات الممارسة بجامعة بريتوريا وهما: (أ) مجتمعات الممارسة عبر الحدود التظظيمية: ويشترك فيها خدمسة المعلومـات الأكاديمية بالجامعة مع منظمات أخرى بها مهنيون يتشـاركون مـع الجامعة فى نفس ونس المجال رغم وجودهم فى منظمات مختلفة مثل: *مجموعة ممارسة إدارة المعرفة فى بريتوريا: ومجتمع الممارسـة هنـا يتكون من أعضاء من الدوائر الحكومية، والمؤسسـات الأكاديمية والمنظمات غير الحكومية المهتمة بإدارة المعرفة. 
Gauteng and Environs Libraries مجموعة اتحاد مكتبات غوتنغ وإنفيرون" Consortium (GAELIC) وهـى مجموعـة غير رسـية لتبادل المعرفـة فى مجال الفهرسـة؛ فالأفراد الذين يملكون خبرة فى هذا المجـال يتشـاركون خبراتهم فحى مجـال الفهرسـة مـع الأعضـاء الآخرين من مختلف المؤسسات الأخرى. "مجموعة علم الآثار البحرى: وهذه المجموعـة تركز على قضية علم الآثار البحرى وهو العلم الذى يـرس تفاعل الإنسـان مـع البحيرات والأنهار من خـلال دراسـة البقايـا الماديـة الموجـود فيى البحيرات، ولقد اشتملت هذه المجموعة على أعضاء من جامعة بريتوريـا وكيب تاون، ملان وإختصاصى معلومات. "المجموعة الافتراضية لأبحاث المياه: اشترك فى هذه المجموعة ^/ قسمًا بجامعة بريتوريا يعملون فى مجال البحوث المائيـة مثـل أقسـام العــوم الطبيعيـة، والزراعيـة، وإلهندسية، والبيئيـة، وتكنولوجيـا المعلومات، ومجموعة من المحاضرين المتخصصين فى هذا المجال، ولقد اشترك بعض الأعضاء من هذه الأقسـام فى مجتمـع الممارسـة الافتراضـى لمناقشـة القضـايا المتعلقة بأبحاث المياه.

*المجموعة الافتراضية فى الهندسة المعمارية: وتتكون هذه المجموعة من طلاب قسم الهندسـة المعماربـة بالجامعة، ومحاضر وأخصائى معلومات والأفراد المهتمين بمجال الهندسة المعمارية. "مجموعة المكتبة البيطرية الأفريقية: ولقد اشترك فى هذه المجموعة الخبراء والباحثون ومجموعة من المزارعين ولقد تواصلوا مع بعضهم عبر شبكة الإنترنت حول المشكلات التى تتعلق بالمـاعز وحيوانات المنطقة. 
(ب) مجتمعات الممارسة الااخلية بجامعة بريتوريا والتى تمثلت فى الآتى: *مجموعة متخصصى المعلومات: ويتكون مجتمع الممارسة من مجموعة من المتخصصين فى مجال المعلومـات من جميع الوحدات المكونة لخدمـة المعلومـات الأكاديمية بالجامعة وتجتمـع المجموعة وجهًا لوجه مرة واحدة كل شهر. *مجموعة المخزون الرقمى: بدأت هذه المجموعة بصورة غير رسمية لتمكين الأعضاء من تبادل المعرفة حول "المعرفة الرقميـة" ودورهـا فى الوصول إلى المعلومـات المطلوبـة مباشرة وبسرعة فائقة. *شبكة خبراء المعلومات الإلكترونية غير الرسمية: ولقد تـم إنشـاء هذه المجموعـة مـن خـلال متخصصسين فـى خدمسة المعلومـات الأكاديمية بالجامعة، وتتشاررك هذه المجموعة قضية المعلومـات الإلكترونية سواء من خلال المقابلات وجهًا لوجه أو من خلال الاتصال عبر البريد الإكترونى واللهاتف. ولقد تطورت مجتمعات الممارسة فى جامعة بريتوريا من خلال عدة مراحل هى: المرحلـة الأولـى: بدايـة تثكيل مجتمـع الممارسـة، ومحاولـة العثور على مجـال محدد لإيجاد أرضية مشتركة لربط الأعضاء، وينحصر دور أخصائى المعلومات أو أمين المكتبة فى هذه المرحلة فى تحديد المرشحين المناسبين لمجتمع الممارسـة، وتعريف الإدارة على مضمون مجتمـع الممارسـة للحصول على اللدعم الـلازم، وإجراء المقابلات وتسهيل الحوار الجماعى. المرحلـة الثانيـة: يجتمـع الأعضـاء معًا ويشـكلون مجتمـع الممارسـة ويضـعون مبادئه الأساسية، ويقوم أخصائى المعلومات فى هذه المرحلة بالقيام بدور الميسر من خلال إعداد وتيسير وتوثيق اجتماعات المجموعة وتيسير تواصل الأعضساء معًا من

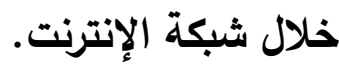


المرحلـة الثالثة: يبدأ أعضـاء المجتمـع فى تنفيذ أنثطة المجتمع وعملياتـه، ويقوم أخصـائى المعلومـات بتصـميم وعقد الندوات والمـؤتمرات وتحديد الـاعم الـلازم

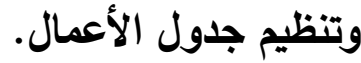
المرحلة الرابعة: تتضح فائدة المجتمع والتى تظهر فى صورة تبادل المعرفة بين الأعضاء من خلال العمل الجماعى والتعاون مـع بعضهـ، ويقوم أخصائى المعلومـات

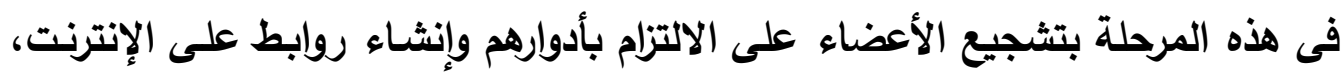

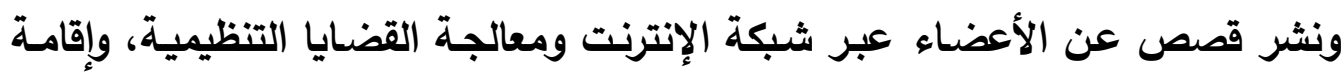

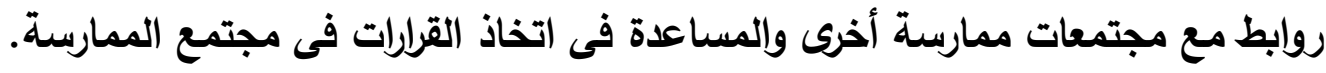

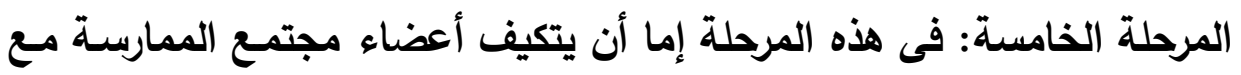

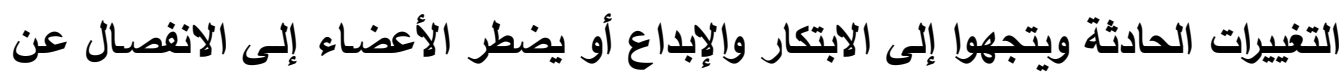

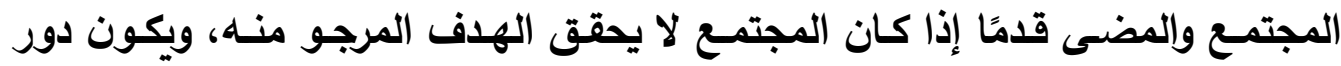

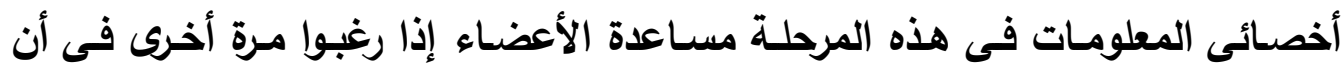
يجتمعو معًا. ولقد ساعدت مجتمعات الممارسة فى جامعة بريتوريا على تبادل المعرفة ونقلها

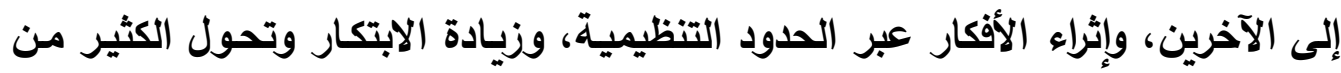

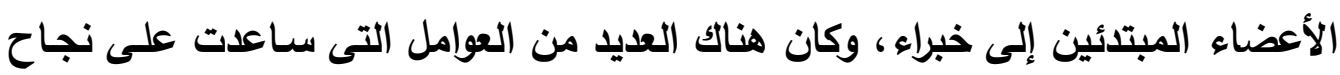
مجتمعات الممارسة بالجامعة تتمثل فيما يلى:

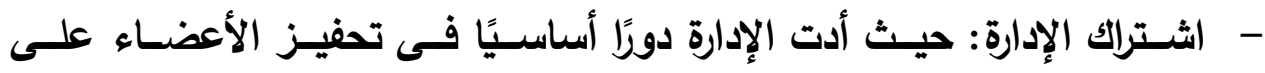
المشاركة فى مجتمعات الممارسة. - - توفير الوقت اللازم للأعضاء للمشاركة فى مجتمعات الممارسة.

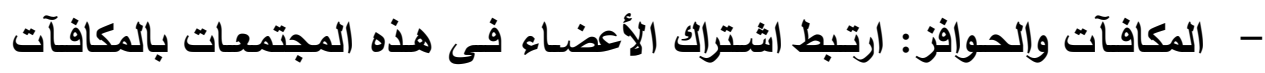
والحوافز المادية مما يحفز الأعضاء على الاهتمام بهذه المجتمعات. 
- حجم مجتمعات الممارسة: حيث وجلت الجامعة أن حجم مجتمعات الممارسة بهات

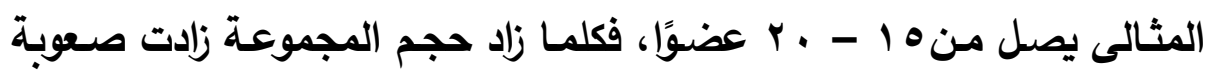

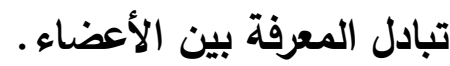
- دور الميسر فى مجتمع الممارسـة: حيث كان لدور أخصائى المعلومـات دور بارز فى تنظيم اجتماعات وأنثطة مجتمعات الممارسة.

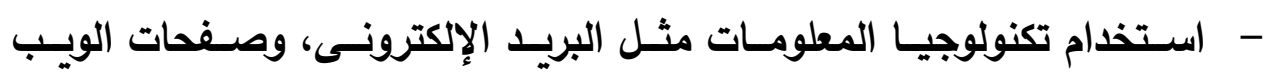
والمدونات وغيرها والتى ساعدت على استمرار تواصل الأعضاء مع بعضم.

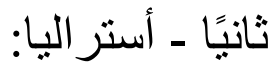
أستراليا هى الدولية الوحيدة التى تمثل قارة كاملة وتقع فى الجزء الجنوبى من الكرة

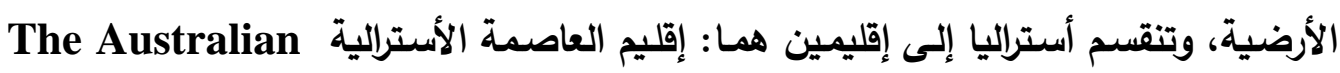
Capital Territory هي: نيوسـاوث ويلز New South Wales وكوينزلاند Queensland وجنسي

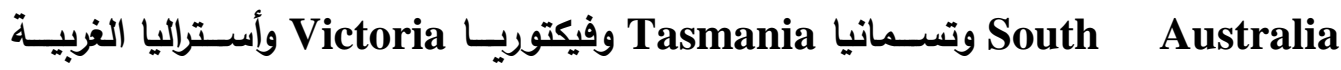
Western Australia

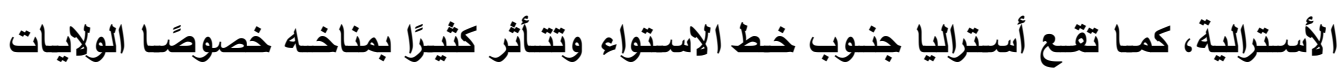

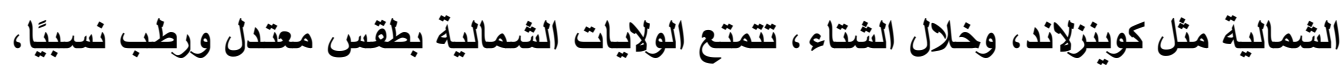

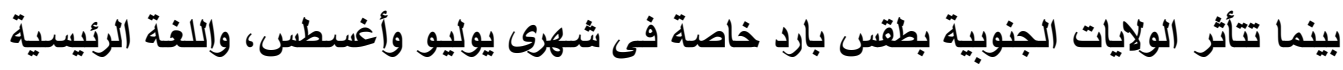

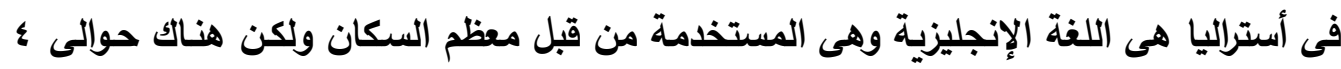
ملايين نسمة يتحدثون لغات أخرى(90). ونظرًا إلى كبر حجم دولة أستراليا والتى تمتد حوالى . . . ؛ كم من الثرق إلى الغرب،

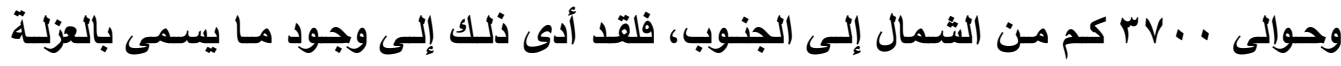

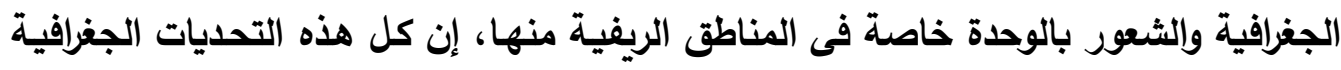

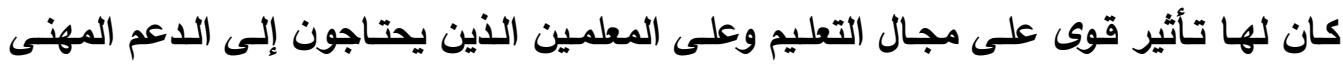

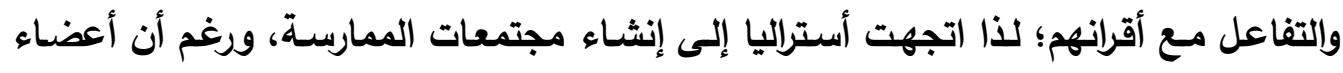

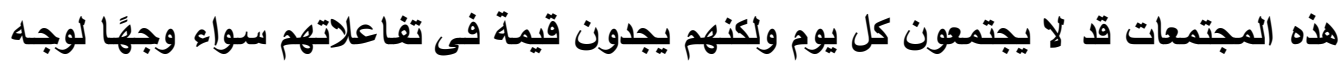


أو عبر الإنترنت ويتشاركون معًا معلوماتهم ويعملون معًا على حل مشكلاتهم ويناقشون معًا تطلعاتهم وطموحاتهم (49) كما اعتبرت أستراليا مجتمعات الممارسة استراتيجية أساسية فى تطبيق نظام التدريب القومى بقطاع التدريب والتعليم المهنى الأسترالى، حيث التزمست الدولـة بتوفير مـوارد هائلـة

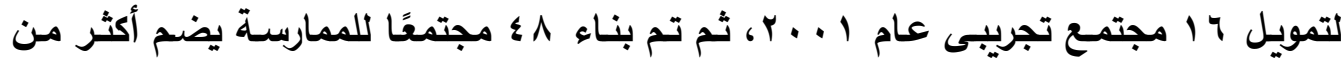

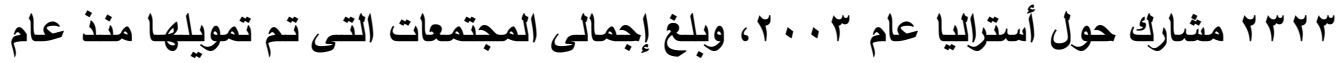

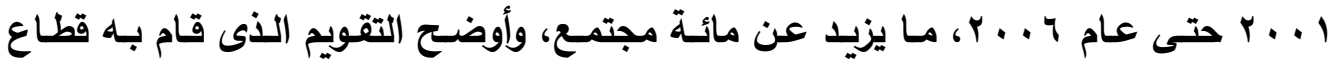
التـريب والتعليم المهنى الأسترالى أن مجتمـع الممارســة يتيح السبل المناسـبة لزيـادة رأس

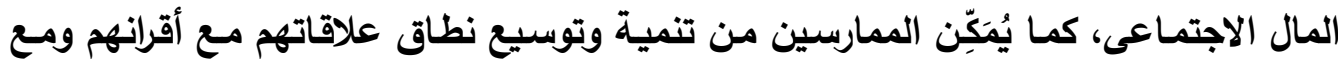
المسئولين فى قطاع الصناعة والتدريب والتعليم المهنى الأسترالى (av).

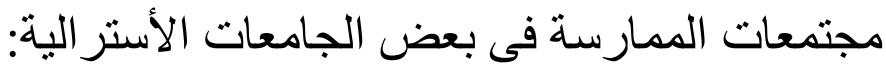
لقد أظهرت الاراسات الأسترالية أهمية العلاقات الاجتماعية بين الأكاديميين وضرورة التوصل إلى وسيلة تمكن الأكاديميين من الاتصال مـع بعضهم، وتعتبر مجتمعات الممارسـة

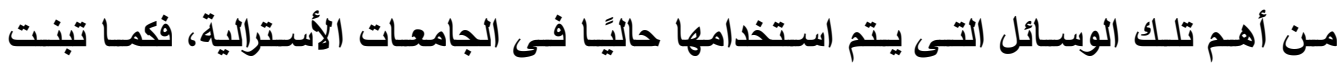

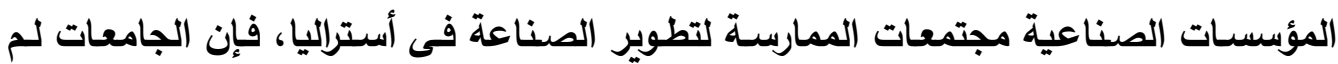
تختلف عن هذه المؤسسـات الصناعية فقد لجأت الجامعات إلى بنـاء مجتمعات الممارسـة لاكتساب المعرفة وتطبيقها وتبادلها ونقلها إلى الآخرين، وكانت هناك أمثلة عديدة على ذلك؛ فوثيقة سياسات جامعة جريفث Griffith University تقوم على دعم مجتمعات الممارسـة؛ إذ قد قامت الجامعـة بتصميم وبنـاء خمسـة مجتمعـات ممارسـة بالجامعة تعمل لمـدة خمسـة

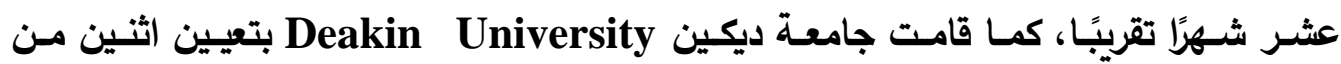

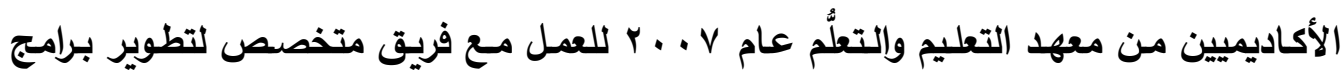
مجتمعات الممارسة، ولقد قامت جامعة ديكين بهذه المبادرة لدعم مسودة خطة الجامعة لعام 1 . . r والتى أشـارت إلـى ضرورة دعم وتشجيع اجتماعات أعضاء هيئة التدريس فى ضوه

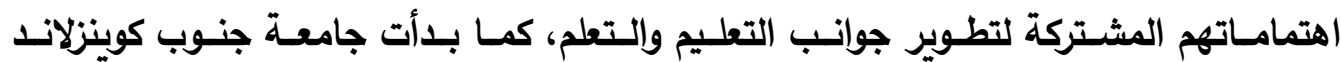
University of Southern Queensland

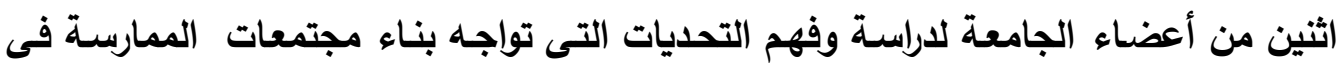

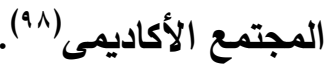


ولقد اختلف الهاف من بناء مجتمعات الممارسة من جامعة إلى أخرى طبقًا لسياسة الجامعة وأهدافها، وإلقضايا والمشكلات التى تسعى الجامعة إلى حلها ومن أهم هذه القضايا ما يلى:

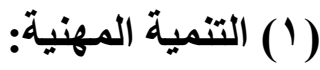
جامعة جنوب كوينزلاند (19): يواجه قطاع التعليم العالى الأسترالى تحديات كبيرة تتعلق بالمطالب الفردية والمؤسسية والمجتمعية، ولقد ساعدت مجتمعات الممارسة بعض الجامعات الأسترالية على تحسين جودة العالئ

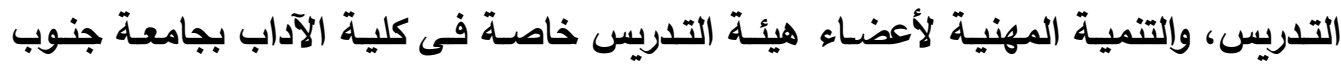

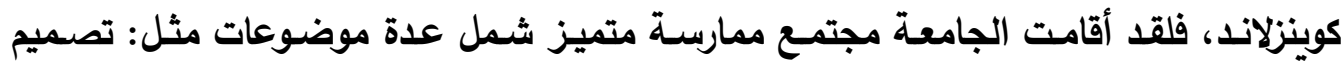
المقرر، ودمج القيم الأكاديمية، وسمات الخريجين، واستراتيجيات الاحتفاظ بالطلاب، كما تم فئرئ

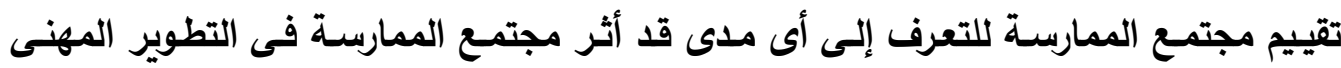

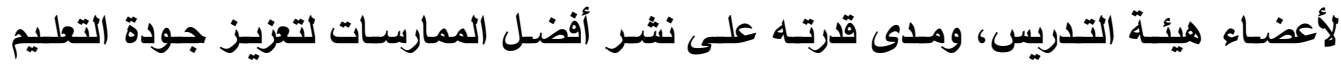
والتعلم.

ولقد نثأت فكرة مجتمعات الممارسة فى جامعة جنوب كوينزلاند بالتعاون بين كلية

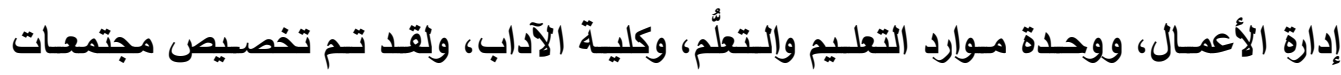

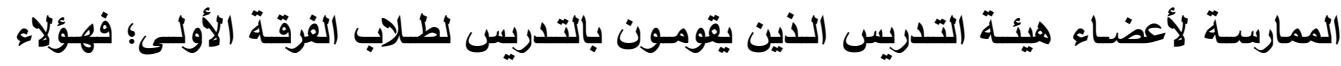

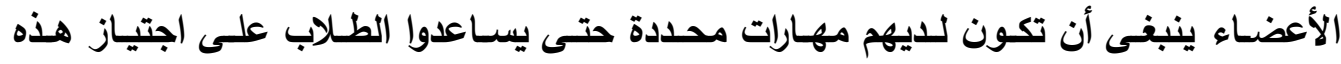
المرحلة الانتقالية؛ فالعديد من هؤلاء الطلاب يختبرون تحولات اجتماعية وشخصية وأكاديمية عند التحاقهم بالجامعات؛ لذا يكون على عاتق أعضاء هيئة التدريس مسئولية كبيرة تجاه هؤلاء الطلاب. وكانت بايـة مجتمعات الممارسـة عام ؟ +. ب، أمـا عن اجتماعات الأعضـاء فكانت تعقد فى كلية الآداب من شهر فبراير إلى نوفمبر، وتم الحصول على تمويل المجتمع من لجنة

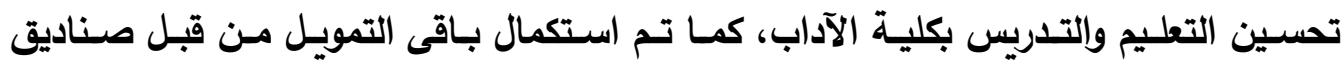

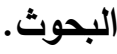

ولقد تألف مشروع مجتمع الممارسة من مرحلتين: - المرحلة الأولى: عبارة عن استطلاع عبر الإنترنت لأعضاء هيئة التدريس يحتوى

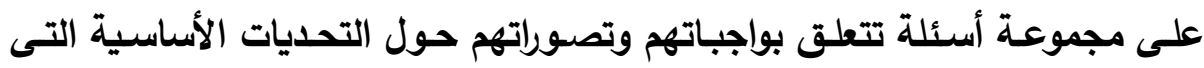


يواجهونها، ومـدى اسـتيعابهم لمبـادرات التعليم والتـدريس على مستوى الجامعـة، وكذلك رؤيتهم حول مدى إمكانية تطوير ممارساتهم.

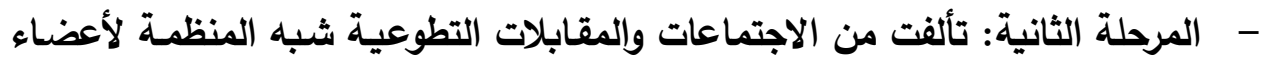
مجتمع الممارسة، وفى نهاية كل اجتماع كان هناك استطلاع رأى عبارة عن أسئلة مفتوحة موجهة لأعضاء هيئة التدريس عن مدى استفادتهم من الاجتمـاع، وتحديد المميزات وجوانب القصور ومقترحاتهم حول تطوير مجتمـع الممارسـة، ومدى تأثير موني مجتمع الممارسة على ممارسات أعضاء هيئة التدريس. وكان أعضاء مجتمع الممارسـة يتقابلون يوم الخميس من الأسبوع الرابع من الثـهر بين السـاعة الثانيـة مسـاءً وحتـى الرابعة مسـاءً، ويتكون المجتمـع مـن مُيَسر لأعضـاء هيئة التدريس، ومُيَسر من وحدة دعم التعليم والتدريس، ومجموعة أعضاء يصل عددهم من 7 -

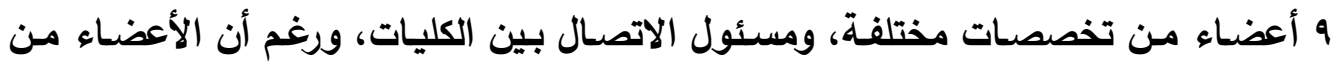
تخصصـات مختلفـة إلا أن الرابط المشترك بينهم هو أنهم يقومسون بالتدريس لطلاب الفرقة الأولى. وركزت موضوعات مجتمـع الممارسـة على قضايا أساسية مثل استراتيجيات الاحتفاظ بالطلاب، وتصميم مقررات الفرقة الأولى، والقيم الأكاديمية. تقييم مجتمع الممارسة: اعتمد تقييم المجتمع على مقابلات أعضاء هيئة التدريس، والتحليل النوعى للبيانات، وتوصلت نتائج التقييم إلى تطوير وتغيير ممارسـات أعضاء هيئة التدريس إلى الأفضل، ولقد اعتبر العديد مـن الأعضـاء أن مجتمـع الممارسـة قد سـاعد فـى تغيير ثقافـة أعضـاء هيئة التدريس رغم أن التغيير فى الممارسات التدريسية فى برامج التعليم الأسترالى يعتبر أمرًا نادر الحدوث حيث تستخدم معظم الجامعات نفس الطرق التدربسية التى تتبعها دائمًا. كمـا أظهرت النتائج أن اجتماعـات الأعضـاء فـى مجتمـع الممارسـة قد وفرت الفرصـة

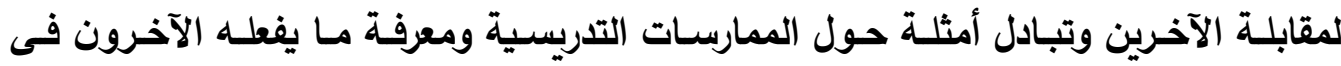

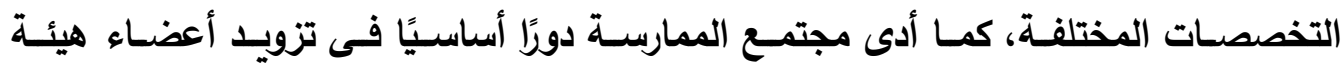

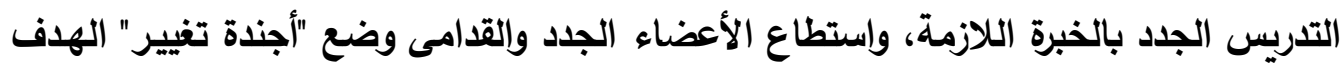

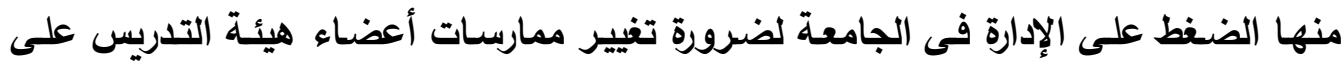


مستوى الجامعة بالكامل ورغبة الأعضاء فى الحصول على مزيد من التدريب وإقامة مزيـا من مجتمعات الممارسة، فلقد أقر غالبية الأعضاء الذين تمت مقابلتهم على قيامهم بإجراء العديد مسن التغييـرات المخططـة لممارســاتهم التدربسـية كنتيجـة مباشـرة لانضــامهم إلـى مجتمـع

$$
\text { (الممارسة. }
$$

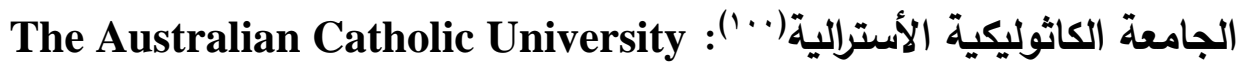

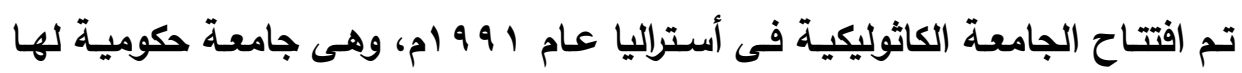
فروع فى جميع أنحاء أستراليا، والجامعة تحتوى على كلية العلوم والفنون والتربية، وعلوم

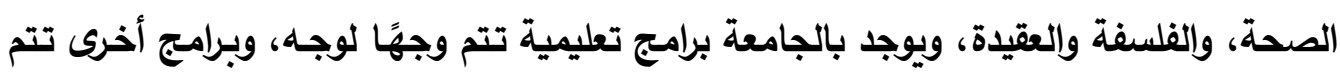
عبر الإنترنت، وهناك نمطان أساسيان للدراسة بالجامعة وهما:

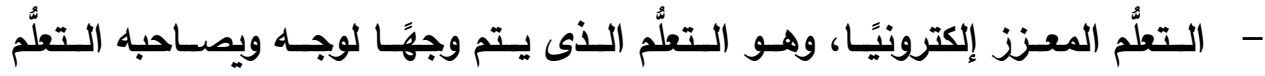

$$
\text { الإلكترونى. }
$$

- - التعلُّم الإلكترونسى بثكل كامل حيث يدرس الطلاب عن بعد من خلال الفيديوهات،

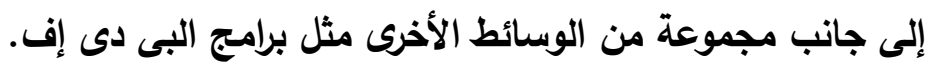
ولقـد استطاعت الجامعة أن تجمـع الأعضـاء مـن مختلف فروعها فـى جميع أنحاء

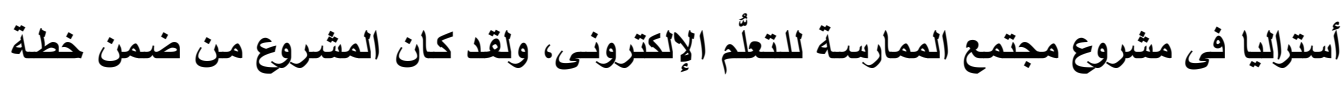

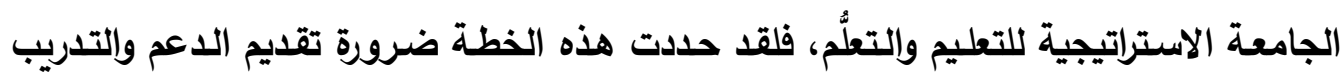

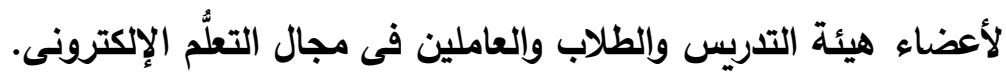

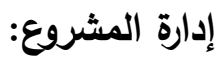

قـام نائسب رئسيس الجامعـة للشـئون الأكاديميـة برعايـة المشـروع، وكانـت هنـاك لجنـة المتابعة والمراقبة التى قامت بوضع خطة المشروع وكتابة دستور المشروع، كما كانت هناك لجنة الإدارة والقيادة والتى تألفت من نائب رئيس الجامعة، ومدير مركز التعليم والتعلُّم، ومدير إدارة التدريس المرن، ومدير قسم تكنولوجيا المعلومـات، ومدير المكتبات، كما تم التعاقد مـع مدير المشروع الذى يعمل على تحقيق أهداف المشروع وتم اختياره بحيث يكون ذا عقلية قادرة على فهم ما يسمى بالاثتباك الثقافى الناتج عن اختلاف ثقافات الأعضاء.

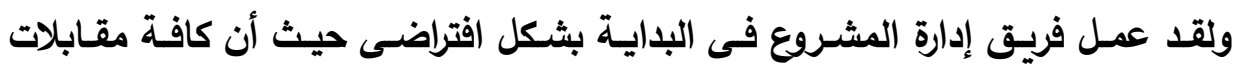
الفريق كانت تـتم عبر الفيديو كونفرانس وعبر الهاتف، وتمـت الموافقـة على سياسـة إدارة 
المشروع فى يوليو V. . . Y، والتزمت الجامعة بتطبيق كافة الاستراتيجيات الأساسية وتوفير

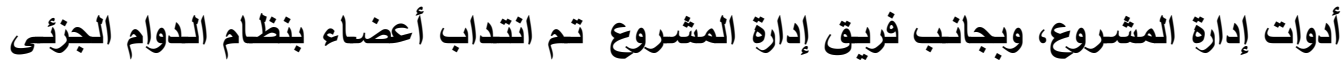
من قبل مجموعة من الوحدات تتضمن وحدة العاملين فى الهيئة الإرشـادية الأكاديمية عبر الإنترنت، وتم اختيار عضوين من أعضاء هيئة التدريس القدامى بها، كما تم اختيار عضوين

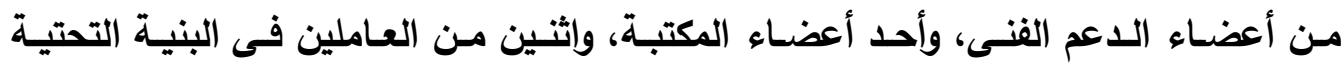
لتكنولوجيا المعلومات والاعم الطلابى. تنفيذ المشروع: - ت إن تجربة الفريق المختلط كانت أكثر إثارة للتحدى بسبب الطبيعة الافتراضية للمشروع وطريقة تنفيذه، فأعضاء الفريق منتشرون فى مختلف فروع الجامعة فى مناطق مختلفة فى لفى

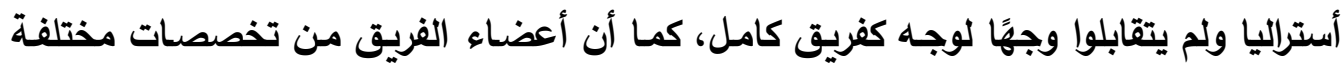
مما ساعد على تبادل المعرفة بينهم. ولقد قام أعضاء هيئة التدريس القدامى بأدوار متميزة حيث عملوا كمستثـارين عبر

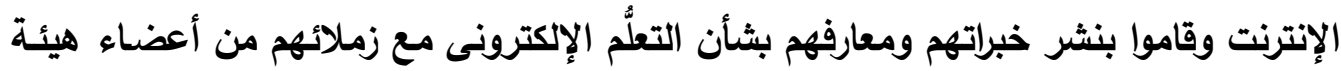
التدريس من خلال ندوات الفيديو كونفرانس الأسبوعية والتواصل عبر موقع بلاك بورد، كما

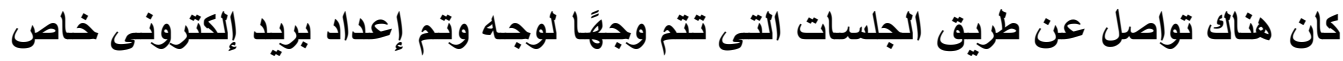

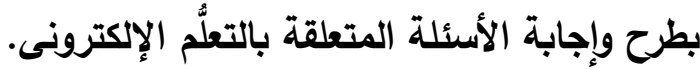

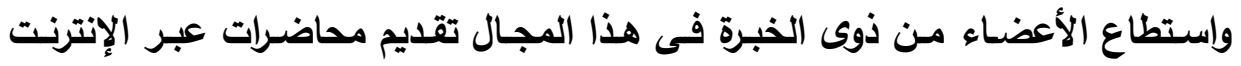
ودعم زملائهم من الأعضاء الجدد فى هذا المجال، ولقد قدرت إدارة المشروع جميع مسـاهمات الأعضاء، حيث كان هناك مجموعة من القرارات تتعلق بالمكافآت والحوافز ليثـعر الأعضاء بالتقدير الكلازم. أما عن مندوب أو مراسل المكتبة فقد قام بإعداد تقارير عن تطور المشروع وتم رفعها

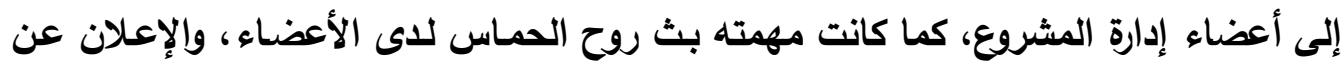
المصادر الجديدة للتعلم الإكترونى على الموقع المخصص للمكتبة، ومساعدة الطلاب فى حل

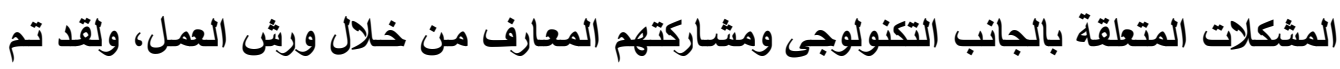
ربط خطة الجودة بالجامعة مـع خطة المشروع حتى يكون هناك تناست بين أهداف الجامعة وأهداف المشروع. 
أدوات التواصل فى المشروع:

عند بدايـة المشـروع تواصل الأعضـاء من خـلال موقع المشـروع، ومـؤتمرات الفيديو الجماعية، وخلال مرحلة تطوير المشروع كان هناتك اجتماعات منتظمـة بين مدير المشروع وبـاقى الفريق لتقديم تقرير عن المشروع، ومراجعة خطط المشروع، وتقديم التظذيـة الراجعة، كما كـان هناك سجل للمخاطر حتى يتمكن أعضـاء الفريق من إدارة المخـاطر فى المشروع كجزء لا يتجزأ من إدارة المشروع، وخلال مرحلة التففيذ كانت هناك أنشطة ترويجية للمشروع مثل الملصقات، وتم النشر عن المشروع فى مجلات ومقالات الجامعة.

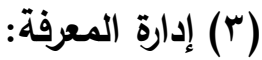

\section{Griffith University} جامعة جريفث(1) (1)

تتميـز مجتمعـات الممارسـة فـى جامعـة جريفـث بأنهـا تطوعيـة وتعتمــ على رغبـة الأعضاء فى المشاركة بهذه المجتمعات وتفاعلهم المستمر لتطوير مجال الممارسـة المختار، وتقوم مجتمعات الممارسـة فحى جامعة جريفث على تبادل المعرفة، وحل المشكلات، وتنمية أفضل الممارســات، وتعزيـز الابتكـار، كمـا تعمل كمنتدى استثـارى وقنـاة للمعلومـات، وبهـا

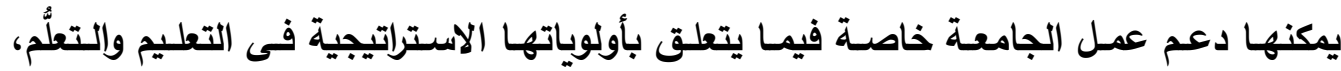
والمساهمة فى بناء المعرفة وتحسين النتائج. 1-الغرض من إنشاء مجتمعات الممارسة بجامعة جريفث: تم إنثـاء مجتمعات الممارسـة فى جامعة جريفث كاستراتيجية لبنـاء المعرفة ولتعزيز أفضل الممارسات؛ لذا تركز مجتمعات الممارسة على واحدة أو أكثر من الأولويات التالية: (أ) بناء المعرفة وتبادلها: يعتبر بنـاء المعرفة وتبادلها من المهام الرئيسية لمجتمعات الممارسـة؛ فبنـاء معرفة

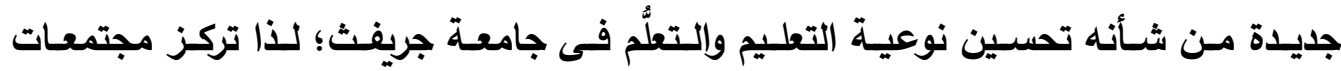

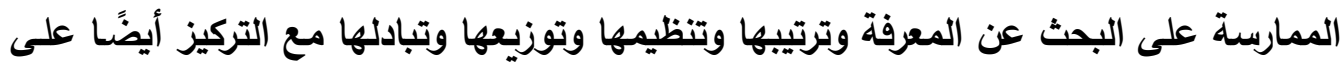
مله الفجوات المعرفية. (ب) حل المشكلات: (ب) معظم مجتمعـات الممارســة لـايها عنصـر مشـترك وهـو حل المشـكلات، حيث يقوم الأعضاء من ذوى الخبرة بالتعاون مع الأعضاء الآخرين لحل المشكلات الأساسية بالجامعة. 


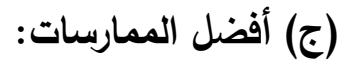

يركـز مجتــع الممارسـة علـى تطـوير الممارســات، ونشـرها، وقــــــــون مـن ضــن

مشروعات هذا المجتمع توثيق هذه الممارسات والعمل على نشرها داخل الجامعة.

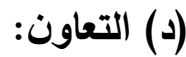

تقوم مجتمعات الممارسـة على تعاون الأعضـاء لأنها تستـد إلى قضـايا ذات أهميـة

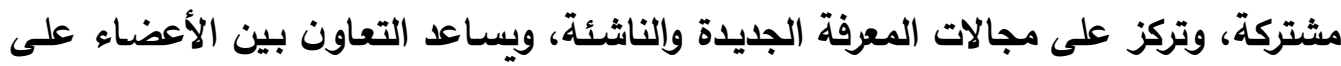
النشر السريع للأفكار والموارد الجديدة.

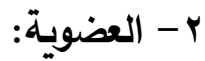

تخصـص مجتمعـات الممارسـة للأعضــاء بجامعـة جريفـث، ويمكـن الحصـول على العضوية من الجامعة، كما تعمل الجامعة على تحديد نطاق كل مجتمع ممارسـة وإلغرض منـه قبل دعوة الأعضاء للانضمام إليه. ب- أهداف مجتمعات الممارسة:

إن الهــف الأساســى لمجتمعــات الممارســة فـى الجامعـة هـــ تحقيـق الأولويــات الاستراتيجية للجامعة والمتمثلة فى تعزيز التعاون بين التخصصـات المختلفة من أجل بناء

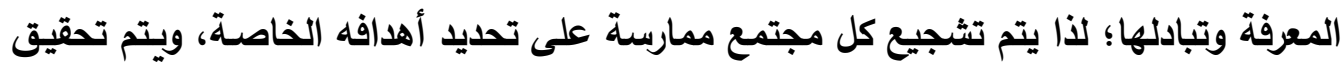
ذلك من خلال توقعات الأعضاء لأهداف هذا المجتمع، ويتم تقديم هذه النتائج والتوقعات فى مئ

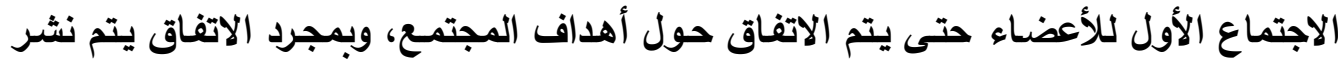
الأهداف على مستوى الجامعة، كما يتم مراجعتها بشكل دورى بالتشاور مع الأعضاء. ع - مبادئ تثغيل مجتمعات الممارسة: 
يتم تثغيل مجتمعات الممارسة فى جامعة جريفث مع مراعاة المبادئ التالية: أ- الإعلان عن مواعيد كل اجتماع قبل شهر واحد على الأقل.

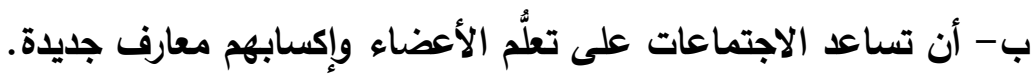
ج- مساهمة الأعضاء بانتظام فى أعمال وأنثطة المجتمع. د- تحديد جدول أعمال رسمى لكل مجتمع، وتحديد الموضوعات التى سيتم مناقثتها فى الاجتماعات وإحالة بنود هذه المناقثات إلى الرئيس والمنسق. هـ - تحديد سجل لكل عضو يشمل اختصاصه وخبراته. و - الحفاظ على الخصوصية والعرية داخل المجتمع. ى - توزيع ملذص خاص بالمناقثات على الأعضاء بعد كل جلسة. ز - تدوير منصب الرئيس كل ثلاثة أشهر.

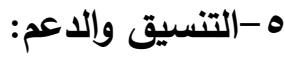

تـوفر جامعـة جريفـث منسـقًا عمليَّا لمجتمعـات الممارســة بهـا، كمــا تـوفر أمساكن

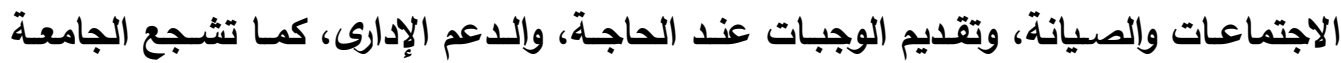

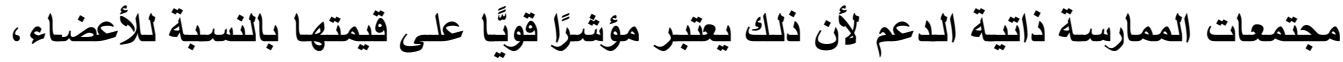

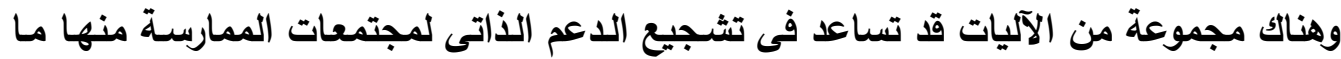
أ- يمكن تثجيع الأعضاء على القيام بدور المنثط والمحفز فى الاجتماعات، وغيرها من الأنثطة وذلك لتبادل المعرفة وإلخبرات. ب- خلال مرحلة التأسيس يقوم أعضـاء مجتمع الممارسـة بتوفير الدعم التشـيلى عبر الإنترنت من خلال الأنثطة التالية: - - تثجيع مثاركة الأعضاء على المناقثة عبر البريد الإكترونى. - - - يمكن إنثاء روابط عبر الإنترنت توفر معلومات حول مجتمعات الممارسة بالجامعة. 
צ - أعمال المنسق:

عندما ينضج مجتمع الممارسة يصبح قادرًا على الدعم الذاتى إلى حد كبير ويتناقص

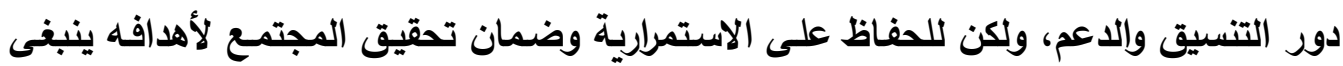
على المنسق القيام بالأنشطة التالية: - - تسجيل مشاركات الأعضاء عبر البريد الإكترونى وصفحة الويب. - - تحديث صفحة الويب. -

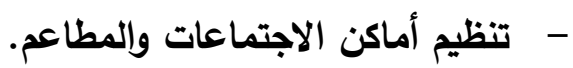
- - تحفيز الأعضاء على حضور الاجتماعات. - - إعداد مجتمع الممارسة بالمواد وإلمعلومات المفيدة. - - تبادل المعلومات حول الزائرين والخبراء والأحداث الأخرى ذات الصلة. - V - التقييم: - v يتم تقييم مجتمـع الممارسـة من خـلال تحليل مشـاركات الأعضاء وتعليقاتهم، كما يتم تقييم نتائج المجتمع بشكل دورى، كما يشمل التقييم ما يلى: - - مستوى المشاركة فى المناقشات. - - العروض التقديمية والاجتماعات. - - أنشطة وأعمال الأعضاء المشاركين. - - - نسبة حضور الاجتماعات.

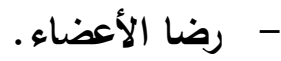
- - أفضل الممارسات. 1- إغلاق مجتمع الممارسة: قد يتم إغلاق مجتمع الممارسة فى أى من الحالات الآتية: - - توقف نشاط أعضاء المجموعة. - - - تحقيق المجتمع للغرض الرئيس منه. - إذا توصلت نتائج التقييم أن المجتمع لم يعد يخدم الغرض الذئى أنثئ من أجله. وعند إغلاق مجتمع الممارسة ينبفى التركيز على الآتى: - استشارة الأعضاء حول إغلاق مجتمع الممارسة. 


$$
\text { - - - مديد ونثر إنجازات المجموعة. }
$$

- -

$$
\begin{aligned}
& \text { إرسال الإخطارات عبر البريد الإكترونى. } \\
& \text { ثالثًا - الولايات المتحدة الأمريكية: }
\end{aligned}
$$

تقـع الولايـات المتحـدة الأمريكيـة فـى قـارة أمريكـا الثـمالية علـى مســاحة قــرها

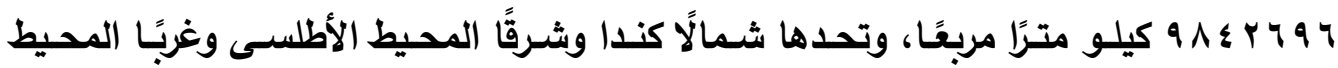
الهادى وجنوبًا المكسيك، وتتعدد صور المناخ فى الولايات المتحدة الأمريكية نتيجة لاتساع المساحة وامتدادها على دوائر عرض مختلفة؛ ولههذا فإنها تتميز باختلاف المناخ من منطقة إلى أخرى فمنها القارى والاستوائى والمعتدل وإلقطبى (البارد) (ץ- (1). و"يتكون المجتمع الأمريكى من مزيج من الأعرلق والأجناس، الذين هاجروا من كل

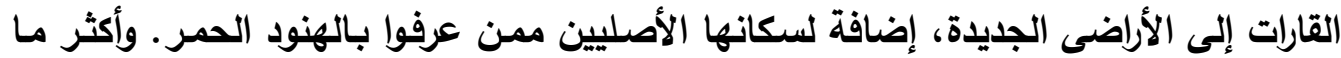
يميز المجتمع الأمريكى احترامسه للفرد الذى يكفل لـه الاستور والأعراف حربـة التعبير وإتخاذ القرارات، والحق فى حياة كريمة، والتعايش السلمى بين الأديان والثقافات. وبقدر مـا هو حق حقديز للفرد أن يتمتع بحريته فإن القوانين تردع مـن يسعى لاستفلال حريته فى التعدى على حريـة

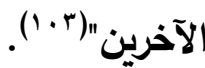

وعلى الرغم من التقدم الحادث فى الولايات المتحدة الأمريكية فى مختلف المجالات إلا أن العديد مـن الدراسـات قد توصلت إلى الدور البارز للعلاقات وإلتفاعلات الاجتماعيـة فـى

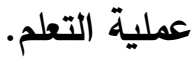

فلقد أشار مكتب الولايات المتحدة لإدارة شئون الموظفين United States Office of Personnel Management

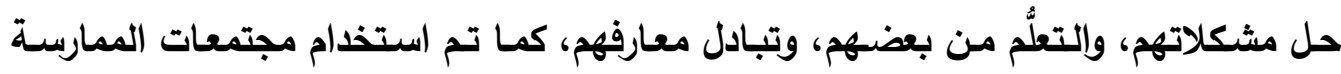

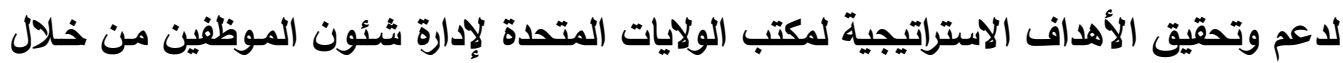

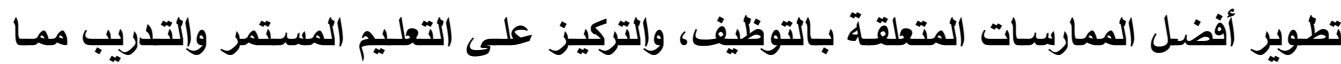
ساعد الموظفين على تحقيق أهداف العمل، كما أن إنثاء مجتمعات ممارسـة للموظفين الذين وصلوا إلى سن التقاعد ساعد على نقل خبراتهم إلى الموظفين الجدد (ء . (1). 
وفى مجال التعليم قبل الجامعى أثـار تقرير مكتب تكنولوجيا التعليم فى وزارة التعليم

The U.S. Department of Education Office of Educational الأمريكية Technology (OET) الإنترنت كانت لها أهمية كبيرة يمكن تصنيفها على النحو التالى (1. 1.): أ-أهمية مباشرة (تحدث من خلال المشاركة فى الأنثطة المجتمعية): - - - معور أقل بالعزلة. - - الانخراط فى محادثات مهنية مع المعلمين.

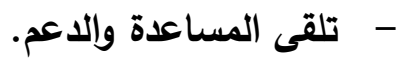
- - تقديم المشورة أو التشجيع. ب-أهمية محتملة (المعرفة والموارد والعلاقات التى يمكن أن تكون مفيدة فى المستقبل): - - تعميق المعرفة من خلال عمليات المشاركة المنظمة. - الحصول على منظور أوسع من خلال الممارسة. - - زيادة الثقة بالنفس والثعور بالهوية المهنية. - - ت توسيع شبكة الاتصالات المهنية. - - الوصول إلى الموارد والأدوات. - - ميادة الثقة فى الأفراد والجماعة. ج-الأهمية التطبيقية (التغييرات فى الممارسة): - - استطاع المعلمون ترجمة المعرفة إلى ممارسة. - ق قام المعلمون بتطبيق الأفكار والدروس المستفادة من المجتمع داخل قاعة الدرس. - - تغيير الممارسات داخل الفصل المدرسى. - - استطاع المعلمون تغيير الطرق التى تبادلوا بها المعرفة مع أقرانهم. - - بدء تجارب التنمية المهنية للمعلمين الآخرين. - - التعاون مع الأعضاء الآخرين لتقديم المؤتمرات والندوات. د- الأهمية المحققة (التحسينات فى النتائج الناتجة عن التطبيق): - - تحسين التواصل والتعلُّم داخل المؤسسة التعليمية. 
- - إنتاج المعرفـة التى تؤثر على السياسـة التعليميـة على مستوى المقاطعة والدولـة والمستوى الوطنى.

هـ-إعادة صياغة القيمة (التغييرات فى فهم النجاح): - - تسبب الحوار عالى الجودة فى إعـادة التفكير فى وجهات نظر المشـاركين حول الممارسات المختلفة وعدم التركيز فقط على القضايا الرئيسية فى التعليم ودوره فى

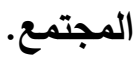

- تغيير رأى المعلمين الذين كانوا يعتقدون فى السابق أن مسئولياتهم المهنية تقتصر

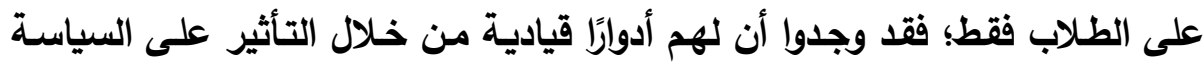

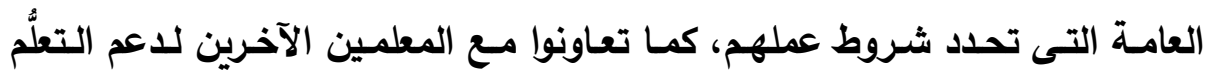
المهنى فى جميع مدارسهم. وبذلك يتضـح أن مجتمعات الممارسـة تسـاعد المعلمين والطلاب على تحقيق الأهداف المرجـوة مـنهم، فـالأفراد يتعلمون باستمرار مـن بعضهم ويتأثرون بشـبكة العلاقات والـروابط الاجتماعية التى يكونونها معًا، وهذا من شأنه أن يضيف إلى خبراتهم وينمى معارفهم ويحسن يُهن من عملية التواصل داخل المؤسسة التعليمية وخارجها. مجتمعات الممارسة فى بعض جامعات الو لايات المتحدة الأمريكية:

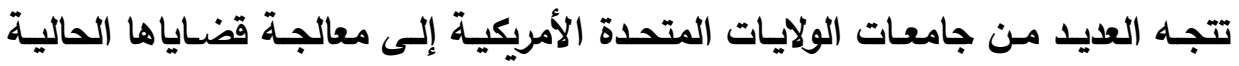

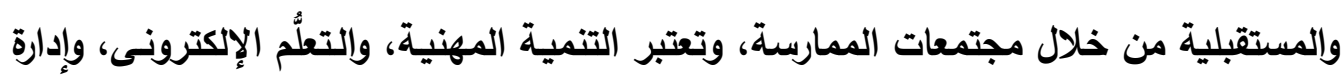
المعرفة من أهم هذه القضـايا، ويمكن عرض دور مجتمعات الممارسـة فى بعض الجامعات الأمريكية لمواجهة هذه القضايا على النحو التالى:

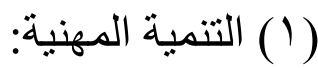

The University of Iowa

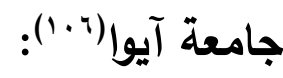

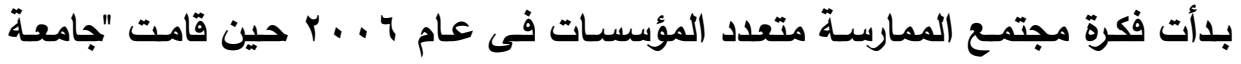
آيوا" بتنظيم اجتمـاع يضم V كليات للصيدلة من جامعات مختلفة ضمن فاعليات الاجتماع السنوى الأول للرابطة الأمريكية لكليات الصيدلة والذى عقد فى سـان دييجو San Diego،

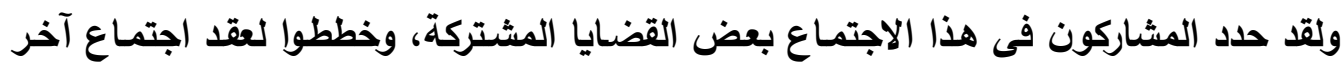

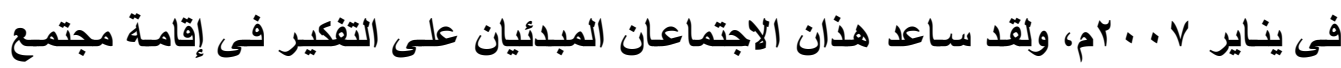
ممارسة يشمل العديد من كليات الصيدلة فى جامعة بوردو Purdue University، وجامعة ولاجئ 


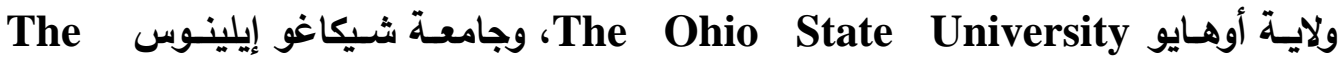
، The University of Iowa وجامعة آيوا، University of Illinois - Chicago The The University of Michigan وجامعة ميتثـجان The وجامعة مينسوتا The University of ون وجامعة ويسكونسـن (University of Minnesota Wisconsin

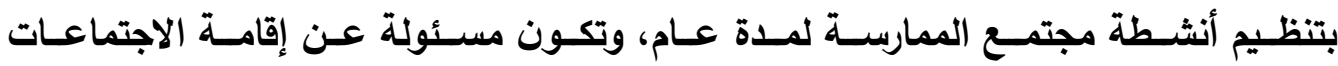

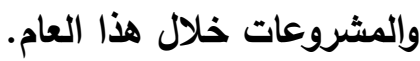

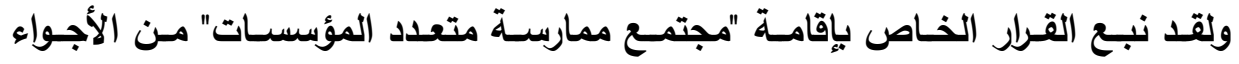

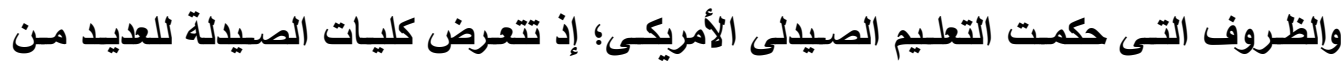
الضغوط لتطبيق مبادرات التعليم الجديدة والمبتكرة، لذا أصبح إقامة مجتمع ممارسة متعداد أمرًا حتميًا لمواجهة العديد من المثكلات مثل قضايا التنمية المهنية، وتقويم أداء أعضاء هيئة التدريس، كما أنه يقدم نمونجًا للمحاسبية لكافة كليات الصيدلة داخل الجامعات والمشاركة فى التى بناء هذا المجتمع.

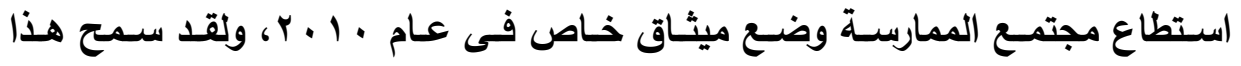

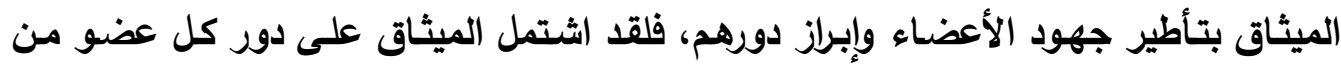

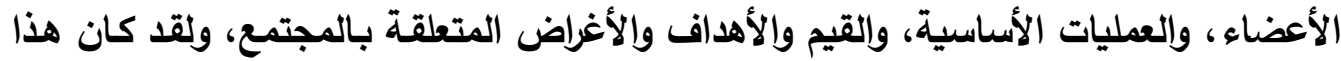
الميثاق بمثابة الباية الحقيقية لجهود اللجنة التعاونية لتقييم التعليم الصيدلى.

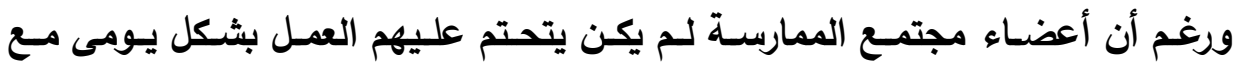

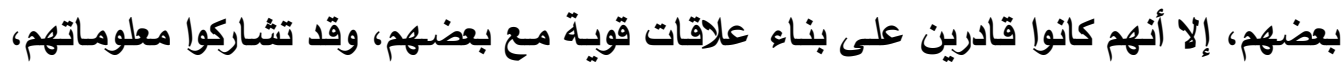

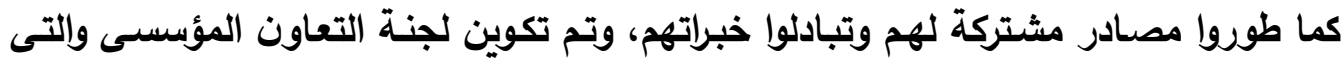

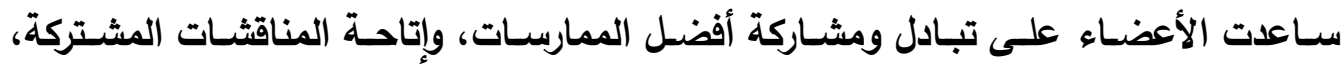
والأبحاث والمجلات والعروض التقديمية الرسمية مما ساعد على تنمية الأعضاء مهنيًا.

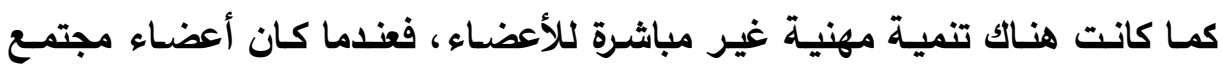

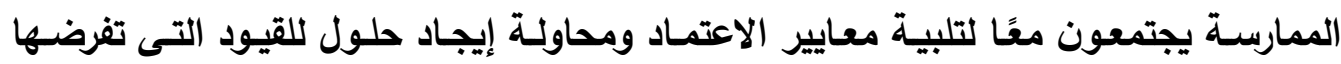

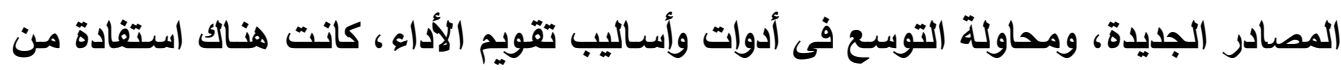


خبرات الأعضاء الآخرين؛ فالعديد من المشاركين كان لايهم قدر كبير من الخبرات فى مجال التقويم واستطاعوا تبادل خبراتهم مع الآخرين.

وبمرور الوقت استطاعت لجنـة التعاون المؤسسى بمجتمـع الممارسـة المتعدد إقامـة

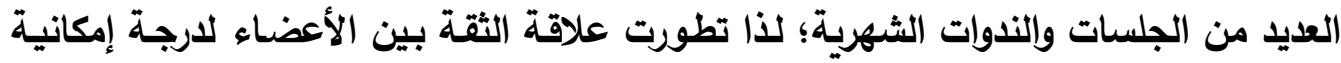

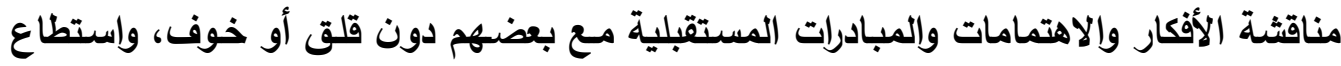

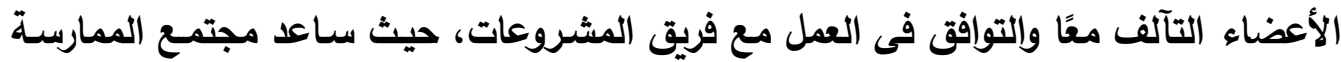

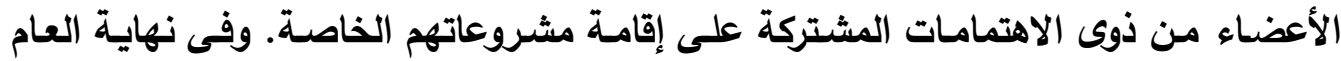
الأول ظهرت قيمة أخرى تمثلت فى قرة أى عضو على التقاط الهاتف ومحادثة أحد أعضاء المجتمع لطلب النصيحة بحريـة تامة؛ لذا كانت هناك تنمية مهنية مستمرة تحدث من خلافل فيلاك المشاركة والحوار.

وأصدرت لجنة التعاون المؤسسى مجلة تقييم شهرية لأعضاء مجتمع الممارسة، كما تم قراءة ملفات الإنجاز الثخصية للأعضاء ومناقشتها فى إطار الاجتماعات التى عقدات حول ذلك. كما كان الأعضاء يختارون قضية محددة ويتم مناقشتها على مدار ثلاثة أشهر الأرها

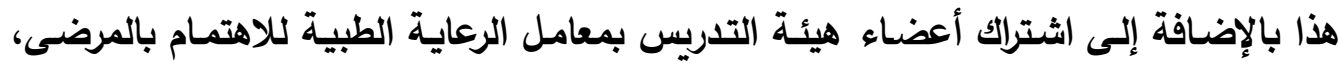
وكان المشاركون يقضون نصف اليوم فى الأمور المتعلقة بالمعامل. ولقد طورت اللجنة مبدأ الاتصال بين الكليات للاطّّلاع على اختبارات الكليات الأخرى الكئ والتقييم المتبادل فيما بينها، والاستفادة من طلاب الدارسات العليا المتميزين فى هذ المجال.

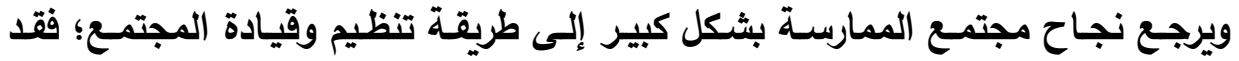

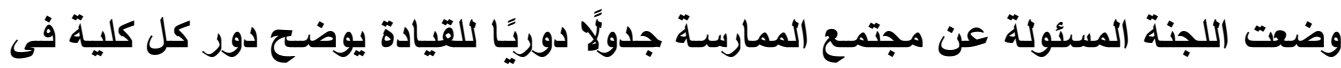

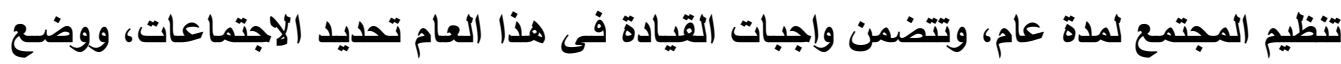

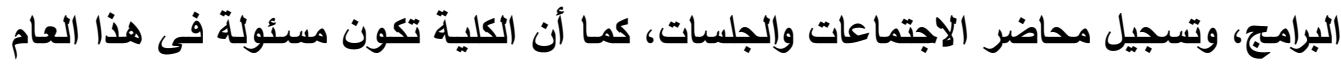
عن تكاليف ونفقات الاجتماعات، وحتى تكون هناك سهولة فى انتقال القيادة من كلية إلى أخرى يتشارك الرئيس الحالى للمجتمع مع الرئيس القادم (الذى تم تحديده مسبقًا فى الجدول) فى القيام بواجبات القيادة. وحرصت اللجنـة على تقديم تقرير سـوى يوضـح أعمـال المجتمـع على مـدار العام والأهداف التى حققها. 
جامعة إنديانا - جامعة بوردو فورت واين (v) (1):

Indiana University - Purdue University Fort Wayne (IPFW):

إن جامعة إنديانا - جامعة بوردو فورت وأين - هـ مؤسسة تعليمية عامـة تأسست

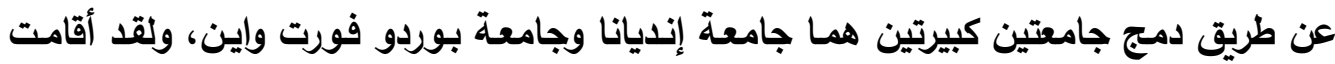

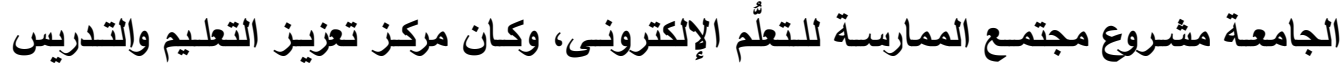
Center for the Enhancement of Learning and Teaching بالجامعة هو المسئول عن تنفيذ المشروع، وتم تحديد أهداف مشروع مجتمع الممارسـة للتعلم

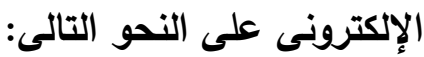

- - تعزيـز وتطوير التعـاون والتكامـل بين التخصصـات المعرفيـة مـن خـلال تكنولوجيـا الحاسوب.

- - زيادة الفاعلية والابتكار فى التدريس والتعلُّم ومشـاركة الطلاب بحيث يمكن قياسها وملاحظتها.

- دعم الابتكارات فى الأبحاث من خلال استخدام التكنولوجيا المحمولة. تطوير المشروع وتنفيذه:

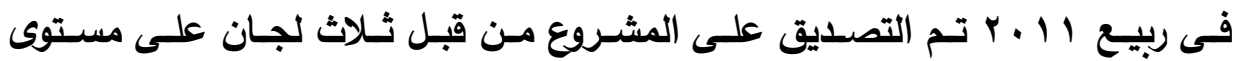
الجامعة، وتم تحديد قادة المشروع والفريق الاستثـارى، وتم تقسيم أعضـاء مجتمـع الممارسـة

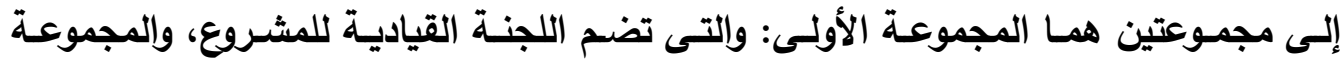
الثانية: وتضم باقى أعضاء مجتمـع الممارسـة، وتم اختيار جهاز التابلت لتقديمـه للأعضـاء، ، ولقد طلب من الأعضـاء المشاركين فى المجموعتين كتابة مقترحاتهم حول طريقة استخدام الأجهزة اللوحية (التابلت) فى عملية التدريس وإعداد الأبحاث وتقديم الخدمات المختلفة، وتم صرف بلل إنفاق زهيد مقابل شراء التطبيقات التى يحتاجها أعضاء هيئة التدريس. المشاركون:

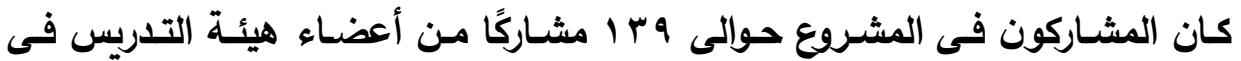
المجموعتين الأولى وإثانية، وكان هناك ممثلين لمختلف الكليات بالجامعة داخل المشروع. كما كان المشـاركون من مناصب ودرجات أكاديمية مختلفة منهم الأستاذ الجامعى والأستاذ المشارك والأستاذ المساعد والمدرسين والمعيدين إلى جانب رئيس المكتبة. 


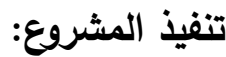

تم تنظيم مشروع مجتمع الممارسة بحيث يتقابل المشاركون معًا وجهًا لوجه حيث تعقد

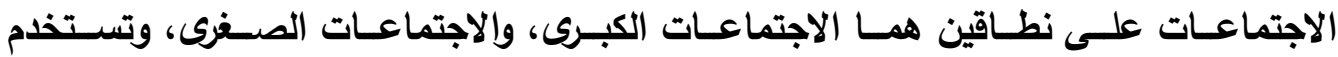

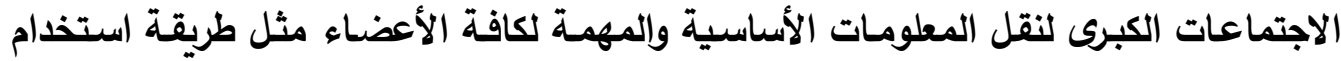
الأجهزة اللوحية فى التدريس، وطريقة الاستفادة من التطبيقات التى تقدمها الجامعة من خلال نظام (App Vault). أمسا الاجتماعات الصغرى فتتم بنـاءً على مقترحات الأعضـاء والمشروعات التى يتم

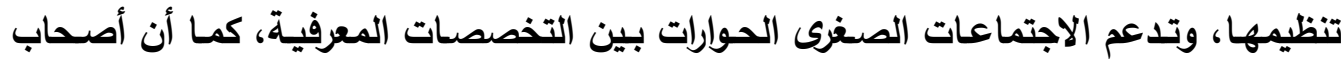

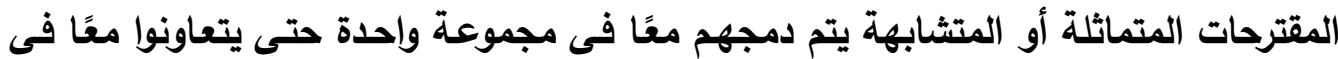
مشروعات تتماشسى مـع مقترحاتهم؛ وتعتبر الاجتماعات الصغرى هى السبيل لتقديم التغذية الراجعة حول مشروعات الأجهزة اللوحية وتطبيقاتها. وبالإضـافة إلى الاجتماعات التى كانت تعقد وجهُا لوجـهـ كـان المشـاركون يتبادلون

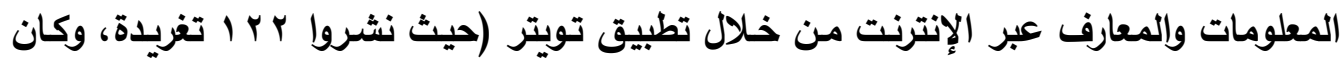

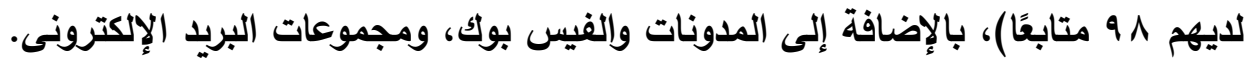

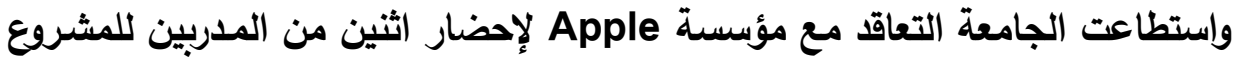

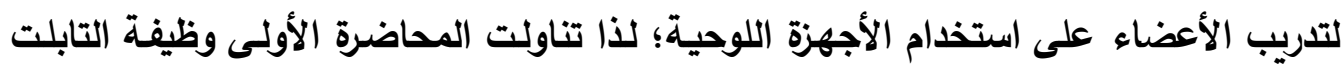

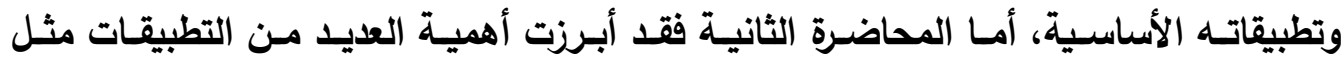
صفحات معالجة النصوص والكلمات الرئيسية فى برنامج العروض (الباوربوينت) إلى جانب التطبيقات التعليمية، كمـا تم تقديم الدعم الإضـافى من قبل العاملين فى مجال تكنولوجيا

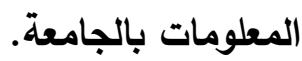
كمـا كانت هنـاك اجتماعـات خاصـة بالمجموعـة الثانيـة حيث يسر القائــ اجتماعـات

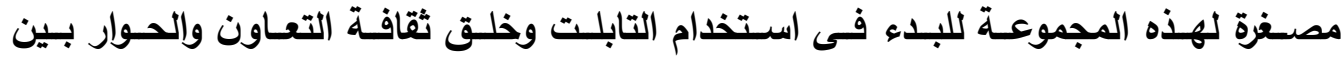
التخصصات المعرفية المختلفة، كما تم عقد ثلاثة اجتماعات كبرى ركزت على موضوعات التهات محددة مثل: الكتب الرقمية، وتطوير التطبيقات.

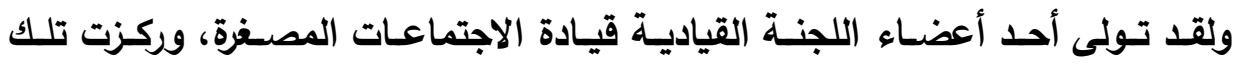

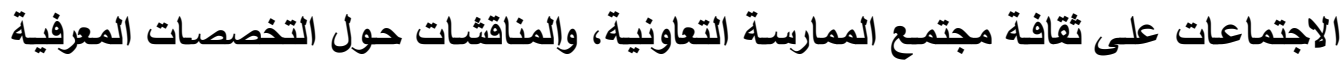


المختلفة، والفرص وإلتحديات التى تواجه استخدام الأجهزة اللوحية فى التدريس والبحث، كما قام أعضاء هيئة التدريس بتقديم مجموعة من العروض التوضيحية من استخدام التكنولوجيا فى التدريس، وكان هناك ورش عمل ركزت على استخدام التابلت واستخدام تطبيقات معينة مثل تطبيق Dropbox، وتطبيق Good Reader.

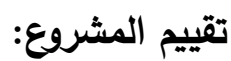

تم وضـع خطة لقياس نواتج المشروع، وتم تقديم هذه الخطة للجنة القيادية التابعة

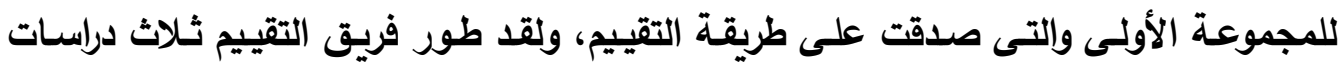

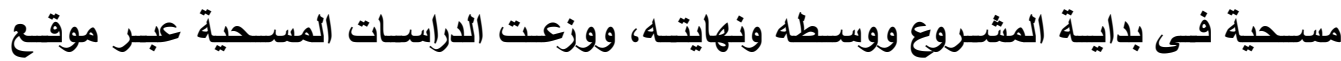
Qualtrics، وصممت الاراسـة المسحية الأولى لقياس الدوافع والخبرات المتعقة باستخدام التكنولوجيا فى التدريس، والتفاعلات الاجتماعية، أما الدراسة المسحية الثانية فكانت مختصرة وتضم أسئلة عن الوقت الذى يقضيه المشـاركون فى استخدام الأجهزة اللوحية داخل قاعة

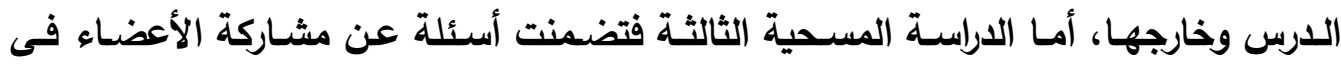
المشروع، وتصوراتهم، والقيمة الحقيقية من استخدام التكنولوجيا فى التدريس.

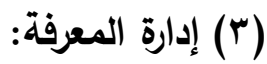

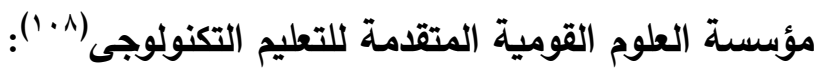
A National Science Foundation (NSF) Advanced Technological Education (ATE):

قامـت مؤسسـة العلـوم القوميـة المتقدمـة للتعليم التكنولـوجى بتمويـل مشـروع مجتمـع

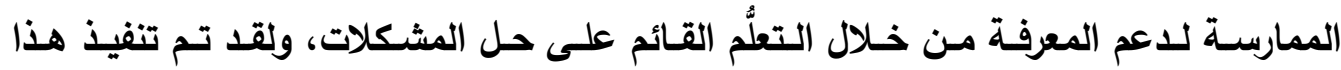

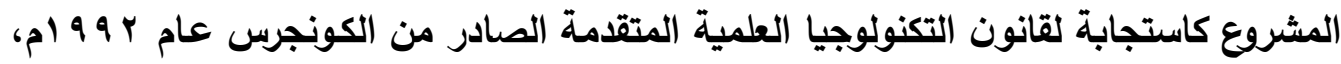
ولقد أقر هذا القانون أن مؤسسـة العلوم القومية هى الموكلة بتنفيذ المشروع والبرامج التى مانى

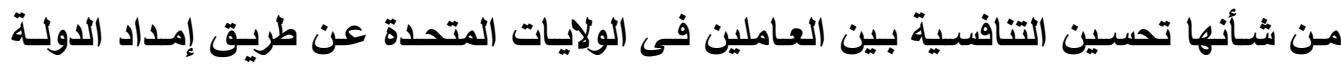
بالموارد البشربية الماهرة والمدربة. ولقد اشترك فى هذا المشروع العديد من أعضاء هيئة التدريس من مختلف الجامعات،

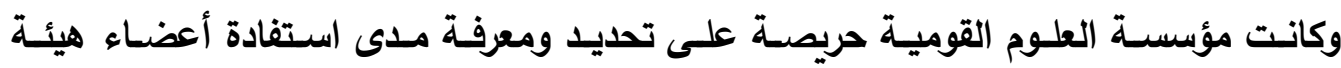

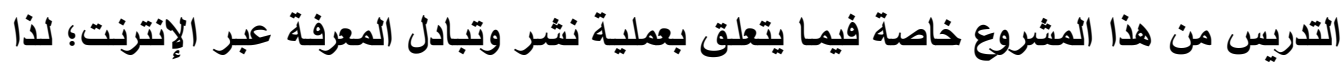


كانت هناك دراسة مسحية أمكن من خلالها التعرف على دور أعضاء هيئة التدريس فى نشر وتبـادل المعرفـة عبـر الإنترنـت داخـل مجتمـع الممارسـة، ومـدى ارتبـاط عوامـل مثل التكلفـة والفائدة بالمشاركة فى نشر المعرفة عبر الإنترنت.

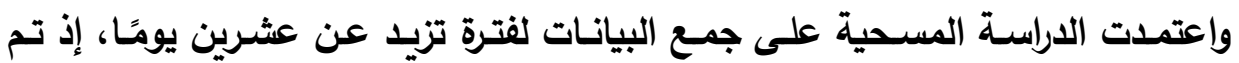

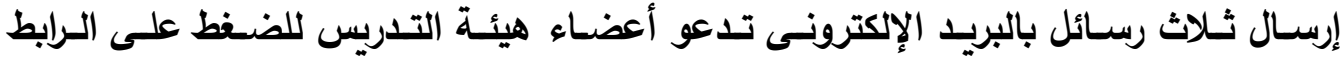
الإكترونى الموجود بالرسالة لإكمال الاراسـة المسحية والتى تُرسل عبر موقع سيرفى مونكى Survey Monkey لكافة أعضاء هيئة التدربس المشتركين فى المشروع والمسجلين فحى مؤسسـة العلوم القومية،

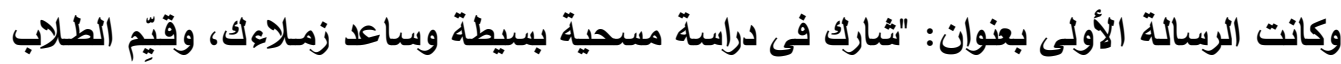
بدرجات"، أمـا الرسـالتان الثانيـة والثالثة فكانتا فـى يـوتى 9 أكتوبر و و 1 أكتوبر في نفس الثهر، وكانت الرسالة الثانية بعنوان: "ثـارك أفكارك وسـاعد زمـلاءك" وقد تلقى هذه الرسـالة

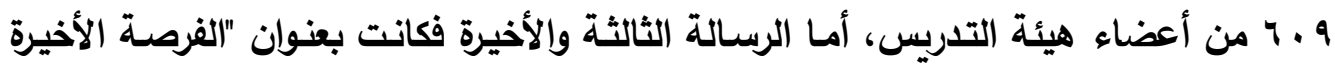
- دراسة مسحية قصيرة"، وتلقى هذه الرسالة بـه عضوًا من أعضاء هيئة التدريس. واستطاعت مؤسسة العلوم القومية متابعة الأعضاء بعد إرسال هذه الرسبائل، وتوصلت

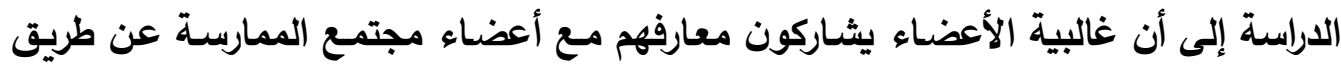
نشر مناقشاتهم وتبادل أفكارهم مع الأعضاء الآخرين عبر الإنترنت.

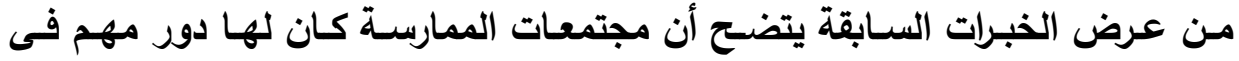

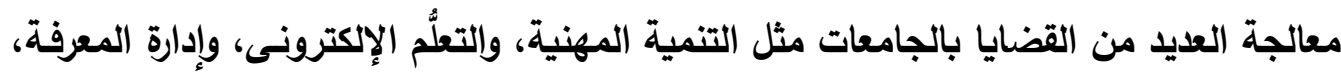

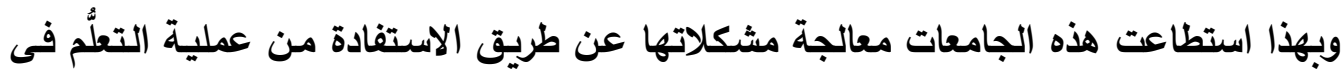
سياق من العلاقات الاجتماعية من خلال بناء المجتمعات داخلها، وتحديد مجال معين يمكن فى نطاقه معالجة قضايا أساسية وذلك فى إطار خبرات الأعضاء وأفكارهم ومواردهم المثتركة أو ما يمكن أن نطلق عليه الممارسة، وبهذا نجد أنـه إذا اجتمعت مجموعة من الأعضاء الاعهاء معًا

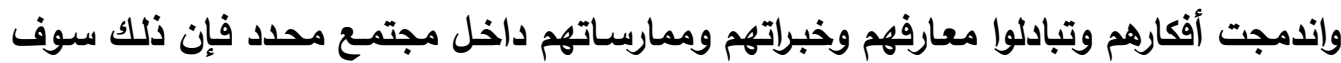
يساعد على تكامل رؤيتهم ووجهات نظرهم، وسوف تتحد إرادتهم لمعالجـة مشكلاتهم ومن ثَّمَّم يكونون قادرين على تحقيق أهدافهم. الخطوة الخامسة: التحليل المقارن: 
تأتى هذه الخطوة فى إطار المنهج المقارن، حيث يستدعى العرض السـابق لتطبيقات مجتمعات الممارسة فى جامعات بعض الدول الأجنبية وجود التحليل المقارن، وتوضيح أهم القـوى والكوامـل الثقافيـة المـؤثرة علـى الجامعـات فـى هذه الـدول، وتوضـيح أوجـه التثــابه والاختلاف بينها بغية الوصول إلى الهـف الرئيس لمدخل التحليل المقارن وهو الوصول إلى نتائج تساهم فى بناء الإجراءات المقترحة، وتسير تلك الخطوة على النحو المبين فى المحاور التالية:

1 - مجتمعات الممارسة والتنمية المهنية فى الجامعات: تتثـابه (جامعة ويتواترسراند بجنوب أفريقيا، وجامعـة جنوب كوينزلانــ فـى أستراليا، وجامعة آيوا فى الولايـات المتحدة الأمريكية) فى دواعى ومبررات بنـاء مجتمعات الممارسـة داخلها، ومن أهم هذه المبررات رغبـة هذه الجامعات فـى إحداث التنمية المهنية لأعضائها ليكونوا قادرين على مواجهة التحديات العلمية والتكنولوجية فى المستقبل، ولعل هذا راجع إلى إلى العامل الاقتصـادى فرغم الإصـلاحات وإلتقدم الحادث الآن فـى جنوب أفريقيا إلا أنها مـا زالت تعـانى مـن بعض المثـكلات الاقتصـادية، وقــ انعكس ذلـك علـى الجامعـات؛ ففى "جامعـة ويتواترسراند ارتفعت رسوم الالتحاق بالجامعة، وقد رجع ذلك إلى انخفاض الإعانات الحكومية

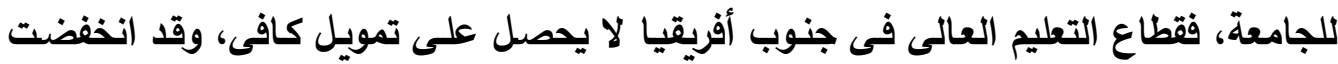

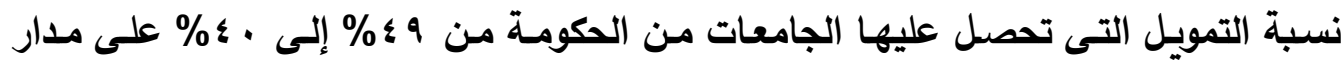

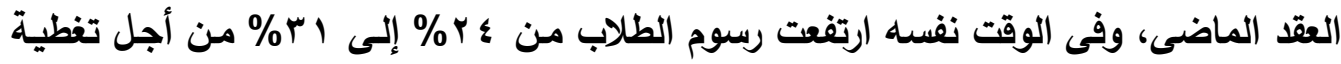

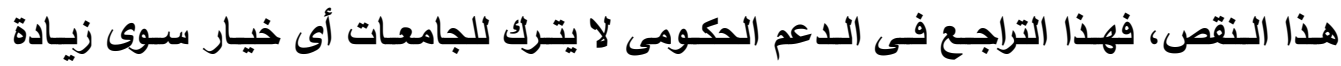

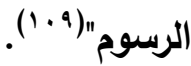

إلا أن ذلك لم يقف أمام عزيمة شعب جنوب أفريقيا فى إكمال مسيرة التطور من خلال

الاهتمام بالتعليم. لذا كانت هناك حملة فى شهر واحد مليون راند "Month I million

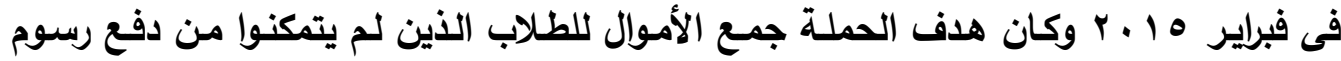

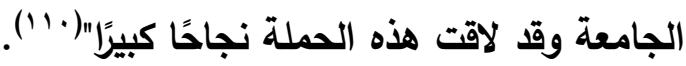
وجامعــة ويتواترســراند تقــع فــى المنــاطق الثــمالية مــن وســـ جوهانســـرغ

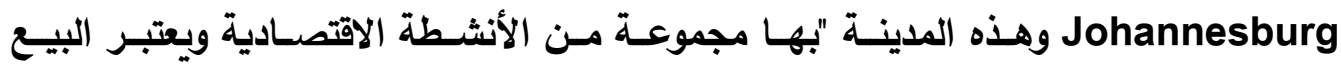
بالتجزئة من أهم هذه الأنشطة حيث يوجد بها أعمال تجاريـة متنوعة وشركات كبيرة توظف 
أعدادًا كبيرة مـن الأفراد، وتمتـاز بعدد مـن الصناعات مثل المواد الغذائية والنحت والحرف اليدوية وأعمال البناء والأعمـال الحرفية وغيرها، فلقد أوضحت دراسـة استقصائية عن جودة

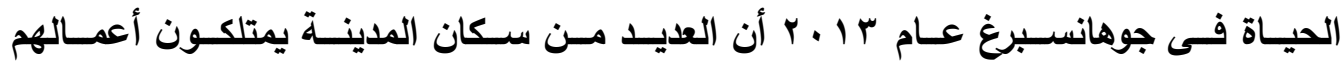
(الخاصة" (111).

وهذا يدل على أن هذه المدينة تحاول أن تواجه التحديات الاقتصادية التى تعانى منها

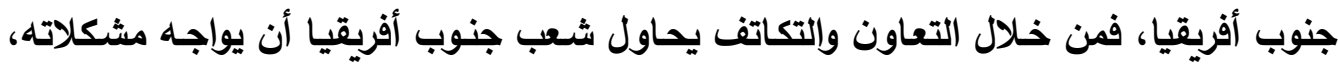
ولم تكن الجامعات بمعزل عن ذلك حيث تسعى جامعات جنوب أفريقيا إلى بنـاء مجتمعات الممارسـة لإحداث التنميـة المهنية لأعضـائها فى محاولـة منها للتطوير والتحديث ومواجهـة مختلف التحديات. وكان للعامل الاقتصادى أثر أيضًا فى أستراليا، "فلقد استطاعت أستراليا وضع أسس قوية لبناء اقتصاد مفتوح فى منطقة آسيا والمحيط الهادى وإنثـاء مناطق تجارة حرة"(r'l')، وجامعة جنوب كوينزلاند تقع فى منطقة توومبا، ولقد استطاعت هذه المنطقة أن يكون لليها اقتصاد ديناميكى متنوع؛ فعلى مدار تاريخها الطويل استطاعت منطقة توومبا تحويل قاعدتها الزراعيـة إلـى اقتصـاد متنـوع وقوى استطاعت مـن خلالـه تقديم فرص عمل متنوعـة ودعم

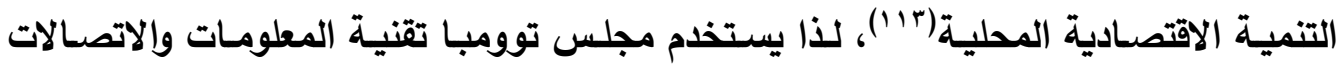
لتحسين الوظائف وتقديم الفوائد للمجتمع. كما أن من أهم الأهداف الرئيسية لهذه المنطقة هو تقديم نهج تعاونى للابتكار والتكنولوجيا واستخدام التكنولوجيا لتحسين تقديم الخدمات لسكان المنطقة(؛) 1)، ولهذا لم تكن الجامعة بعيدة عن هذا التطور الحادث في المنطقة حيث

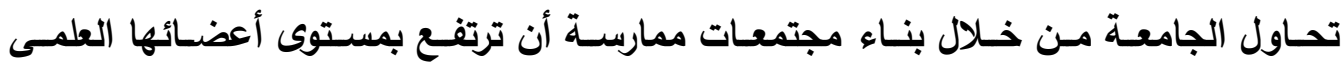
والتكنولوجى وأن تساهم فى تنميتهم مهنيًا، حتى تتماشى مع التطوير الحادث فى المنطقة.

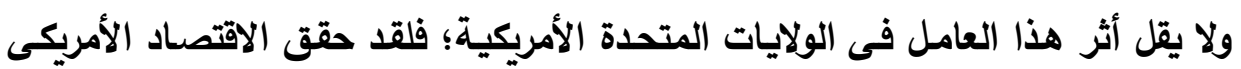

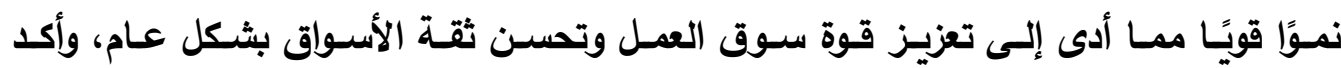

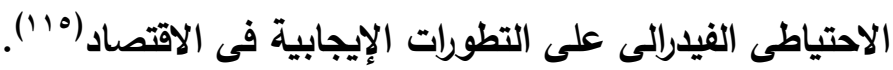
وتقع جامعة آيوا فى الولايات المتحدة الأمريكية فى ولاية آيوا، وهذه الولاية تعمل على الإنى

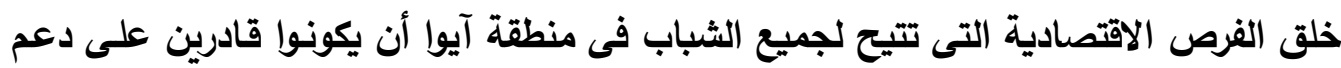
أسرهم والعيش بأمـان وكرامـة، لذا يقوم برنـامج تحسين الاقتصـاد فى آيـوا والذى تديره وزارة 
التنمية الاقتصادية بدعم هذه الوظائف، ويعتبر شباب آيوا محط اهتمـام كثير من صـانعى

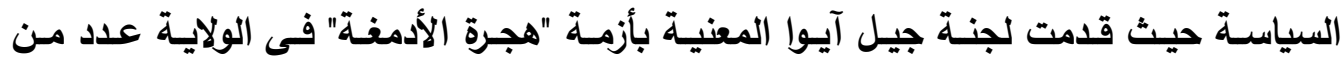

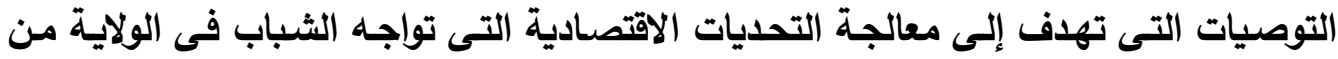

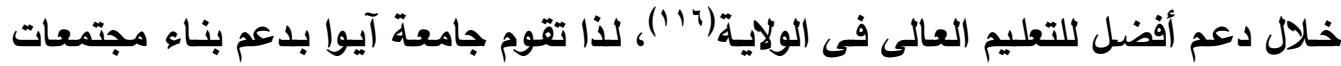

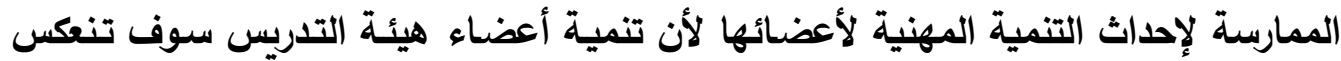
على طلاب الجامعة الذين يعتبرون الركيزة الأساسية للولاية ومحط اهتمامها لاعم اقتصادها. إن هذا التثابه فى مبررات ودواعى بناء مجتمعات الممارسة لإحداث التنمية المهنية لأعضاء هذه الجامعات راجع إلى رغبة هذه الدول فى الحفاظ على مكانتها الاقتصادية كما فى إدى

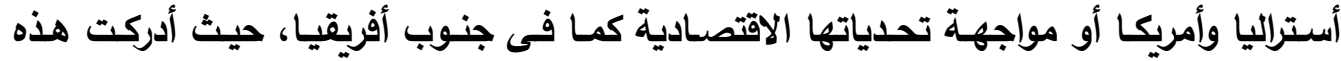

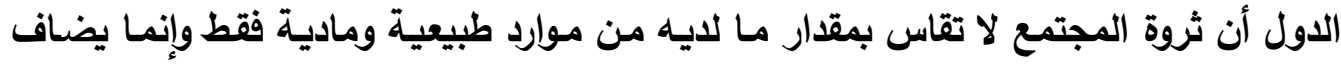
إليها أهم مورد وهو المورد البشرى أيضًا.

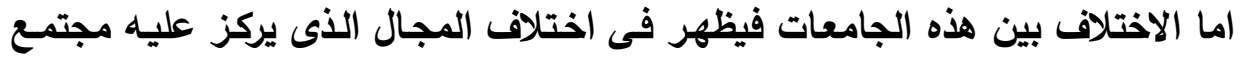
الممارسـة ففى حين تركز جامعة ويتواترسراند على المجال البحثى وتنمية مهارات الكتابـة

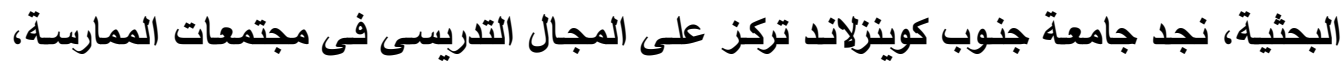

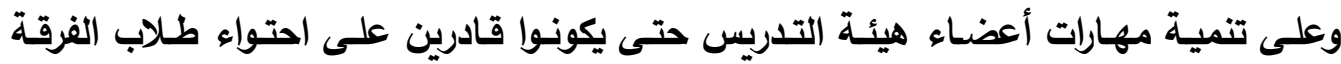
الأولى والتعرف على الاستراتيجيات المختلفة للاحتفاظ بالطلاب، بينما فى جامعة آيوا نجد أنساء

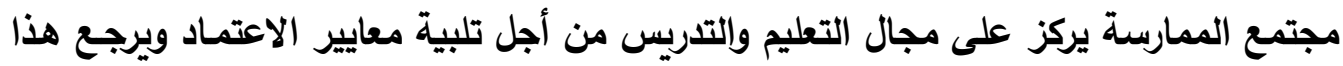

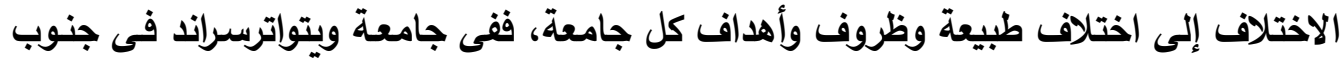

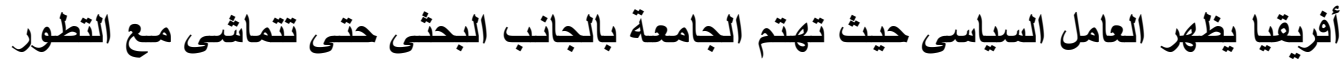

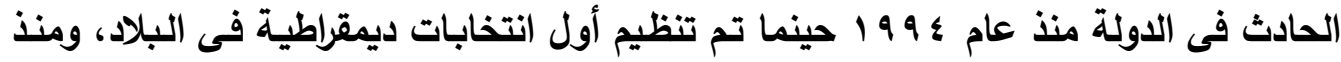
ذذلك العام تحقق فى البلاد نظام برلمانى متعدد الأحزاب بسلطات تنفيذية ممنوحة لرئيس الدولية

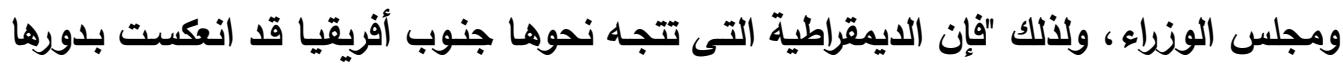

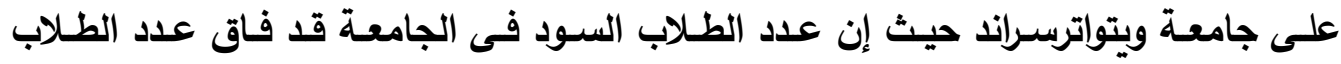

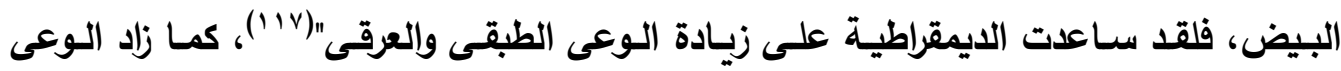
بأهمية البحث العلمى للارتقاء بالدولة. 
أما جامعة جنوب كوينزلاند فيظهر فيها أثر العامل الثقافي، وفى "أستراليا على وجها

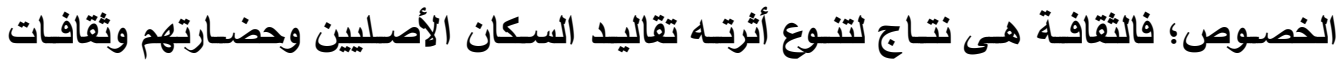
المهاجرين وعلومهم، وقد أثمر عن هذا المزيج حراكًا ثقافيًا مفعمًا بنشـاط متواصل ومتنوع

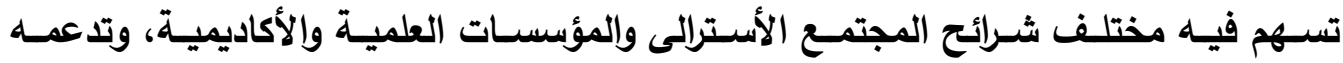

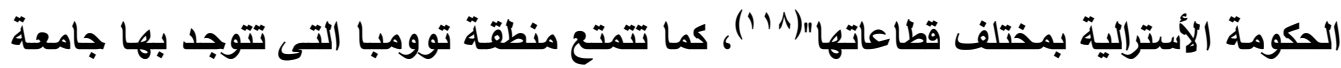
جنوب كوينزلاند بسمعة جيدة؛ فهى مجتمع حيوى وغنى ثقافيًا، كما أن بها نمط حياة لا مثيل لله حيث يُولى مجلس تومبا أولويـة قصوى لتشجيع رفاهية المجتمع ووضـع المعايير الثقافية

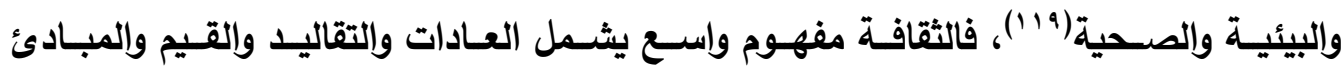
والمعارف والآداب، وهو يرتبط إلى حد كبيز بالتعليم؛ لذا فإن مجتمعات الممارسـة فى جامعة جنوب كوينزلاند تهتم بهذا الجانب؛ فعضو هيئة التدريس ينبغى أن يمتلك المهارات المختلفة التى تسـاعده فى التدريس، وأن يكون مدركًا لأهمية التعددية الثقافية حتى يستطيع احتواء الطلاب بمختلف قدراتهم وثقافاتهم. بينما تظهر أهمية العامل الاجتماعى فى جامعة آيوا بالولايات المتحدة الأمريكية حيث

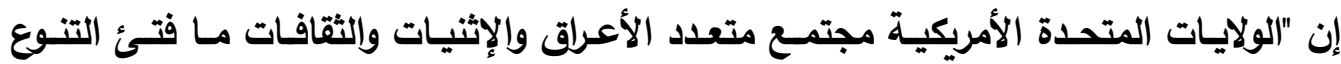
العرقى والإثنى فيه يتزيد باستمرار، إذ تكاد كل مجموعة قومية وعرقية وإثنية وثقافية ودينية

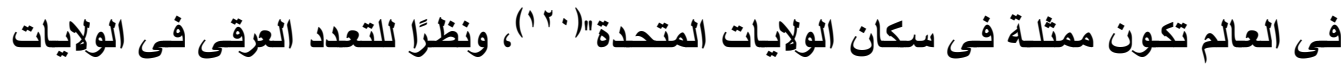
المتحدة الأمريكية أصبحت الدولة تسعى إلى جمـع هذه الأصول والأعرلق والثقافات المختلفة نحو هدف واحد وهو تنمية الدولة وإلحفاظ على تقدمها واستقرارها بغض النظر عن أصل الفرد

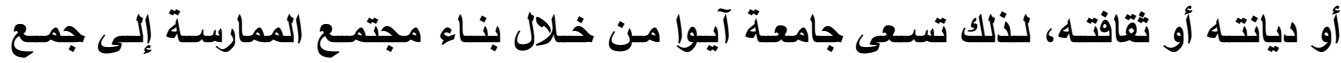
أعضاء هيئة التدربس من مختلف الأعرلق والثقافات والعمل على تنميتهه مهنيًا مـع التركيز على التعليم والتدريس لتحقيق الجودة فى الجامعة والحفاظ على تقدمها.

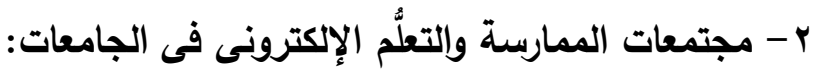
تتثابه (جامعة ويسترن كيب بجنوب أفريقيا، والجامعة الكاثوليكية الأسترالية، وجامعة واتهات

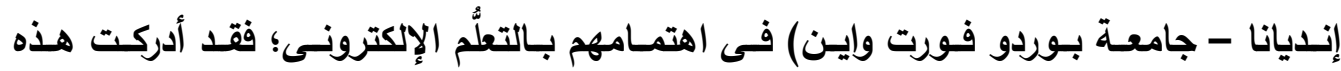

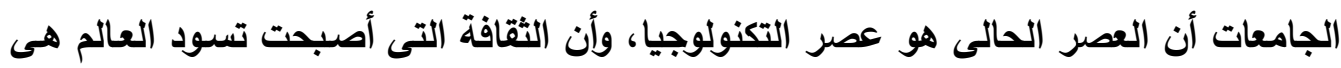
الثقافة الرقميـة؛ فلقد أصبحنا نعتمـ كليًا على المعرفـة فحى المجـال الإكترونسى فقد توغلت 
التكنولوجيا فى جميع جوانب الحياة الآن، وربما يرجع هذا التشـابه فى جامعة ويسترن كيب بجنوب أفريقيا إلى العامل السياسى فمن المعروف أن "جنوب أفريقيا قد عانت من الفصل العنصرى، وكان النظام متحيزًا عنصريًا حتى فى مكان العمل فكان البيض يشغلون المناصب العليا فـى حين لا يحصل السود إلا على مناصب أقل مسئولية وأقل مكانـة بسبب ظروفهر

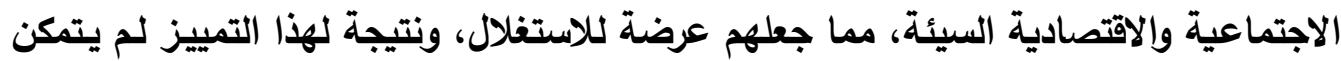

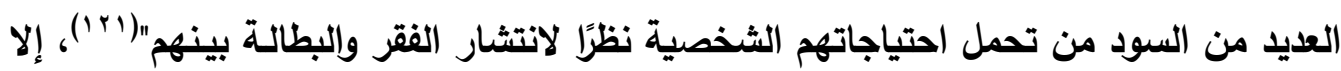
أن الوضع قد اختلف الآن فى جميع أنحاء جنوب أفريقيا عامـة - وفى كيب الغربية خاصة وهى المقاطعة التى توجد بها جامعة ويسترن كيب ومع "بداية إنشاء أول انتخابات ديمقراطية فحى جنوب أفريقيا، تم إنثاء نظام شبه اتحادى يتألف من حكومـة وطنية وتسـع مقاطعات تم منحها بعض السلطة، وكانت كيب الغربية من إحدى هذه المقاطعات، وتتميز كيب الغربية

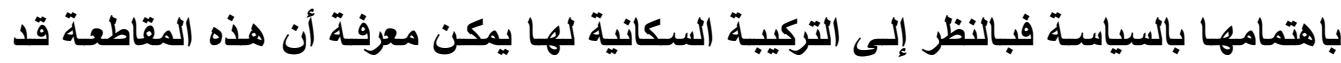
كافحت كثيرًا ضد الفصل العنصرى، لذا كـان بها منافسـة سياسية قويـة بين الأحزاب خـلال

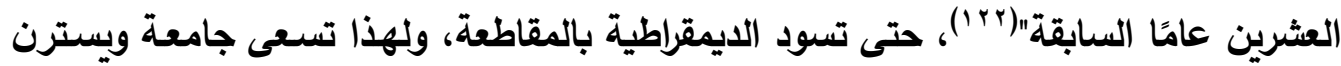
كيب إلى تبنى نهـج أفضـل الممارسـات، والاهتمـام بالتكنولوجيا مسن خـلال بنـاء مجتمعـات الممارسة داخلها حتى تتماشسى مع التطور الحادث فى الدولـة وتسـاعد فى القضساء على كل موروثات الفصل العنصرى.

وفى حين برز العامل السياسى فى جنوب أفريقيا نجد أن العامل الاقتصـادى قد برز فى الجامعة الكاثوليكية الأسترالية فهذه الجامعة توجد فى مدينة سيدنى كما أن لها فروعًا فى لهى

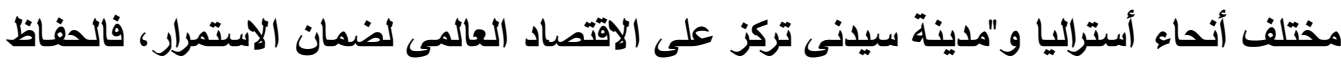

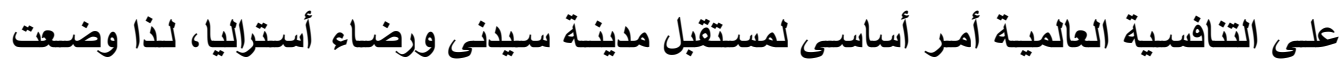
المدينة فى خطتها الاستراتيجية أن مدينة سيدنى مدينة تنافسية ومبتكرة على مستوى العالم،

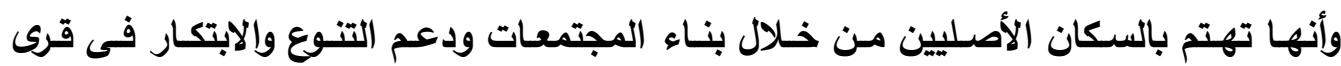
المدينة"("rr)، والواقع أن بناء المجتمعات لم يكن على مستوى المدينة فقط بل داخل جامعاتها أيضًا حيث حرصت الجامعة الكاثوليكية على بناء مجتمعات الممارسـة داخلها من أجل تطوير لبه

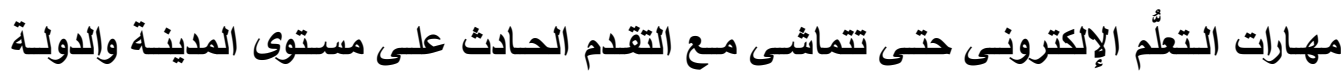
بالكامل. 
وفى الولايـات المتحدة الأمريكية وبالتحديد فـ فورت وايـن بولايـة إنديانا حيث تقع جامعة إنديانا - جامعة بوردو فورت واين يظهر أثر العامل الاجتماعى حيث "يسعى مجتمع الأعمـال فـى شـمال شـرق إنـيانا إلى إيجاد طرق متنوعـة لإشـراك قادة الجامعـة والإداريسين وأعضاء هيئة التدريس فى المجالس والوظائف الاجتماعية للمساعدة فى دمـج الجامعة فى لإسى حياة المجتمع"(ז')، ولم تختلف الجامعة عن المدينة التى تقع بها كثيرًا حيث تعمل الجامعة على إثراك أعضاء هيئة التدريس معًا وتساعد على بناء علاقات اجتماعية بينهم من خلال بناء مجتمع الممارسة للتعلم الإكترونى داخلها. أمـا الاختلاف بين هذه الجامعات فيظهر في طريقة تصميم مجتمع الممارسـة للتعلُّم الإكترونسى نظرًا لاختلاف الهـف المرجو منسه، ففى حين تركز جامعسة ويسترن كيب على ملى

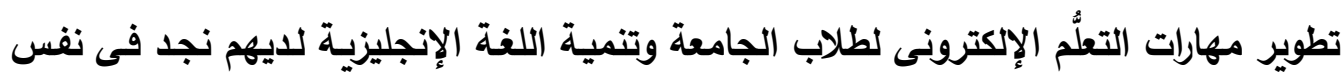
الوقت أن الجامعة الكاثوليكية فى أستراليا قد قامت بتصميم مجتمـع ممارسـة للتعلم الإكترونسى لإنى من أجل جمع أعضاء هيئة التدريس من مختلف فروعها على مستوى أستراليا ومن مختلف

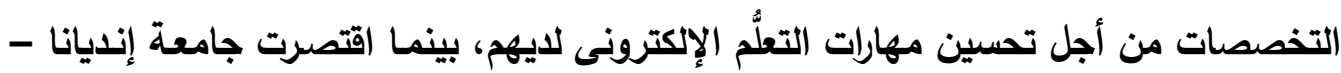

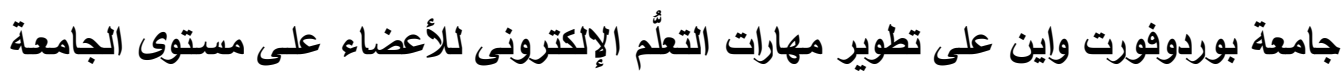
فقط، وربما يرجع ذلك الاختلاف إلى العامل الاجتماعى فى جنوب أفريقيا؛ فمما عانته جنوب أفريقيا "وكنتيجة عن الإرث الأى تركته الأغلبية البيضـاء الحاكمـة، برزت العاجية العديد من الأزمات

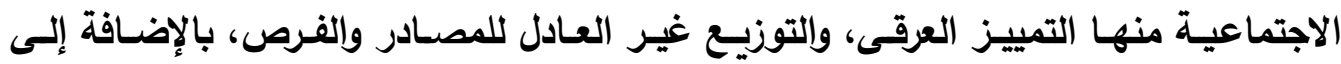

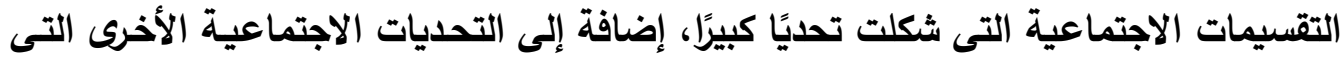
ظهرت مـا بعد حالة الانقسام وأصبحت بمثابة تحديات راهنة، منها الفقر المتجذر، والبطالة البها المنتثـرة بـين الأغلبيـة ذوى البثـرة الســوداء، وإحـدى أعلـى نسـب جريمـة فـى العـالم،

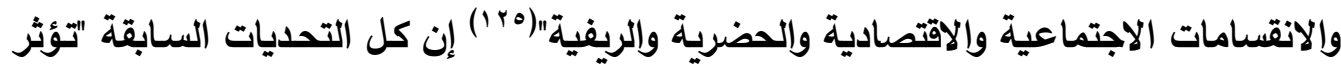
على الاستقرار الاجتماعى بطرق معقدة قد تؤدى إلى الانخفاض فى الاندماج الاجتماعى، كما

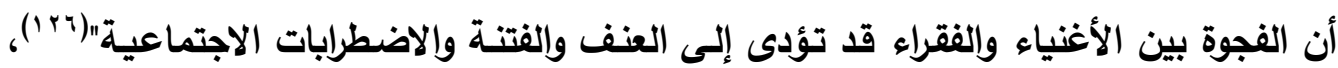
لذا اتجهت جامعة ويسترن كيب من خلال بناء مجتمع ممارسة للتعلّم الإلكترونى إلى تحسين

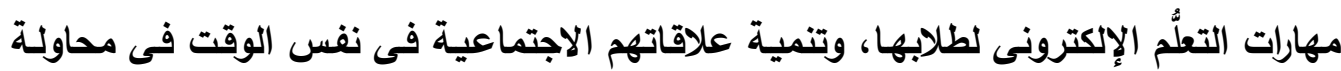
منها لتوجيه الطلاب إلى الاهتمام بالعلم والمعرفة بدلًا من التثتت والعنف. 
بينما فى أستراليا يظهر أثر العامل الجغرافى، فكما ذكرنا من قبل أن أستراليا قارة كاملة فكبر حجمها أدى إلى وجود ما يسمى بالعزلة الجغرافية، والثعور بالوحدة خاصة فى المناطق

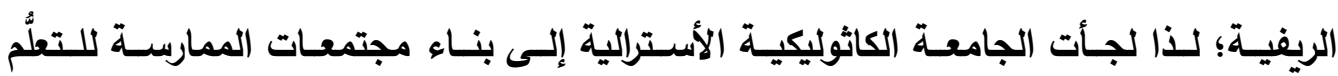

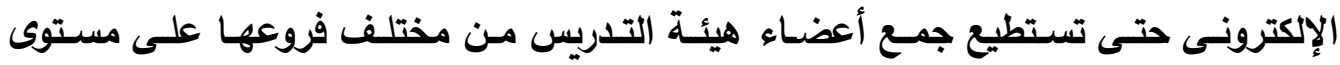
الدولة، فلقد أدركت أستراليا أن التكنولوجيا أصبحت هى السبيل الوحيد للقضـاء على العزلية الجغرافية داخلها. أمـا الولايـات المتحدة الأمريكيـة فيظهر فيها العامـل الاقتصـادى حيث يتمتـع الجزءء الثمالى الثرقى من ولاية إنديانا بتاريخ طويل من النمو الاقتصـادى منذ القرن الثامن عشر وذلك بالاثتراك مع مدينة فورت واين باعتبارها ركيزة أساسية للولاية، ولقد تطورت منوت المنطقة حيث أصبحت مركزًا للتجارة فى الجزء الأخير من القرن الثامن عشر، ثم سرعان مـا أصبح الاقتصـاد فـى فورت وايـن معتمـًا على التصنيع والزراعـة، ثم شـهـ القـرن العشـرون نمـوًا اقتصاديًا وبناء شركات صناعية كبرى، ثم تسارعت وتيرة النمو الاقتصادى فى القرن الحادى والعشرين؛ فقد وُجِتك خطط (قتصادية استراتيجية تعمل على تطوير الاقتصـاد بها، ولتحقيق أهداف الولاية تقوم المؤسسات التعليمية على جذب طلابها وذلك لتلبية احتياجات المنطقة من القُوَى العاملة، وتعتبر جامعة إنديانا - جامعة بورد فورت واين من أهم هذه المؤسسـات فهى

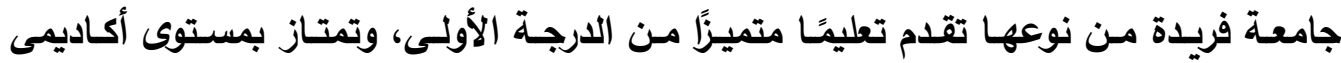

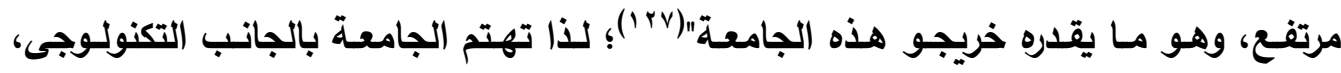

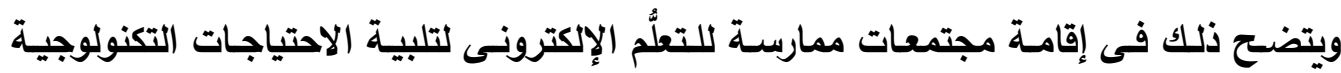

لأعضائها.

" - مجتمعات الممارسة و إدارة المعرفة بالجامعات: تتثابه دول الخبرات فى تركيزها على إدارة المعرفة فقد أدركت هذه الدول أن امتلاكها للمعرفة والمساهمة فى بنائها وتطويرها هو أسساس تقدمها، وأن استمراريتها ترتبط بمقدار مـا لمارها تملكهـ من هذه المعرفة، وفى جامعة بريتوريـا بجنوب أفريقيا يظهر أثر العامل الاقتصـادى، وهذه الجامعة تقع فى مدينة بريتوريا وفى الوقت الحالى تم تغيير اسم هذه المدينة إلى مدينة تثـوان Tshwane، ولقد "أثبتـت مدينـة تشـوان أنها رائدة فـى القـارة الأفريقيـة حيث تمتـاز بتوفير الصناعات المختلفة، والتعليم، والبحث، حيث يتم ، 9\% مـن مجمل الأبحاث وخطط التطوير فى جنوب أفريقيا فى مدينة تشوان بواسطة مجلس البحوث الطبية، ومجلس البحث 
العلمى والصناعى، ومؤسسة العلوم الإنسانية ومن أمثلة الجامعات فى تثوان جامعة جنوب

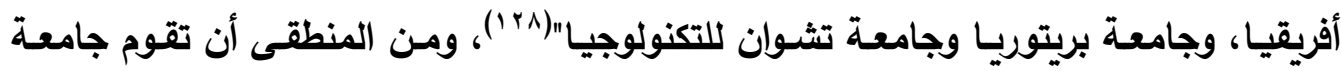
بريتوريا بإقامة مجتمعات ممارسة لإدارة المعرفة حتى تكون على غرار المدينة التى تقع فيها الجامعة والتى تمتاز بالاهتمام بالبحث والمعرفة. وفى جامعة جريفث بأستراليا يظهر أثر العامل الاجتمـاعى فإن "أول مَن سَكَن أستراليا هـم السـكان الأصـليون (الآبوريجينـال) وسكان جـزر مضسيق تـوريس، واللذين تعـد ثقــافتهم وتقاليدهم الفريدة من بين الأقدم فى العالم، ولقد كان معظم المهاجرين الأوائل من بريطانيا وأيرلندا، وكان لهذا التراث الأنجلو - كيلتى أثر مهم ومستمر على تاريخ أستراليا وثقافتها وتقاليـدها السياسـية. وأدت موجـات الهجرة اللاحقـة إلـى وصـول الأفراد مـن أفريقيـا وآسـيا والأمريكتين وأوروبا، الذين قدموا جميعًا مساهمات فريدة خاصة بهم إلى أستراليا وإلى أسلوب

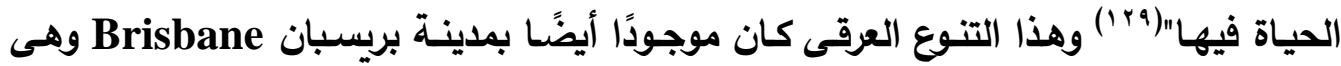
المدينة التى تقع فيها جامعة جريفث، فإن "بريسبان مدينة مزدهرة ومتعددة الثقافات، ولثها

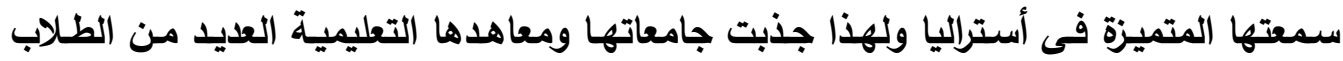
الذين تنوعوا فى اللغة ما بين متحدثين باللفات الإنجليزية أو متحدثين بلغات أخرى، ففى عام

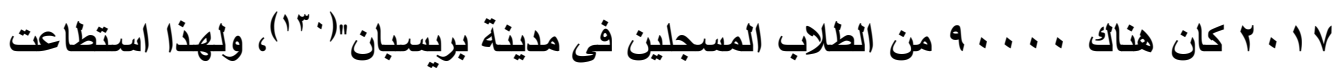

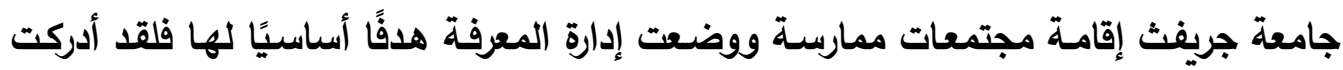
الجامعـة أن الوصـول للمعرفـة وتبادلها هو أسـاس التنميـة والتطوير مهمـا اختلفت الأصـول والأعراق.

بينما فى الولايات المتحدة الأمريكية يظهره أثر العامل الاقتصادى حيث أدركت أمريكا أن امتلاك المعرفة هو الأساس للحفاظ على مكانتها الاقتصادية بين دول العالم لذلك أنثأت مؤسسة العلوم الوطنية. وهذه المؤسسـة قد أنشـأها الكونجرس باعتبارهـا وكالـة اتحاديـة مستقلة عـام . 190 وهذه المؤسسة موجهة لتعزيز تقدم العلم والمعرفة والصحة فى جميع المجالات غير الطبية، فهي تهتم بمجالات معينة مثل علوم الكمبيوتر والبرامج التعليمية للعلوم ولتكنولوجيا والهندسة ولهية

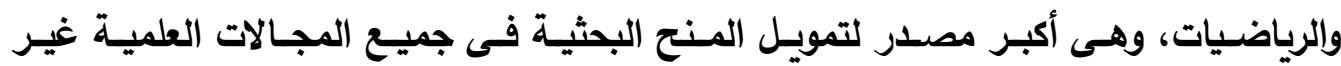

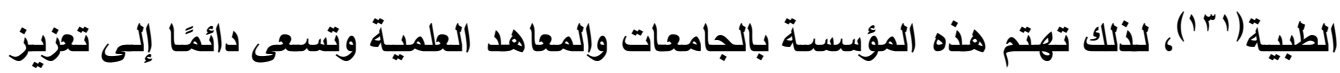


البحث والمعرفة فى جميع أنحاء الدولة، ولهذا قامت المؤسسة ببناء مجتمع ممارسـة لأعضاء هيئة التدريس حيث تحرص على إدارة المعرفة ونشرها وتبادلها، للاستفادة منها فى جميع المجالات.

أما الاختلاف بين دول الخبرات فيظهر فى اختيار كل مؤسسة تعليمية لنموذج مجتمع

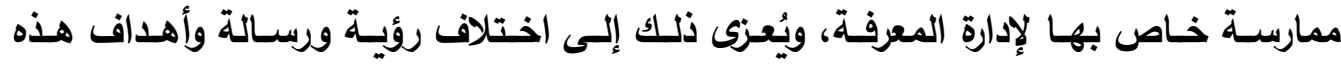
المؤسسة واختلاف إمكانياتها وظروفها، ففى جامعة بريتوريـا كان هناك نوعان من مجتمعات التهات

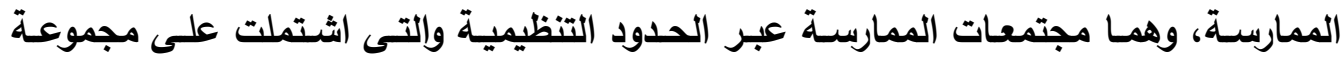
ممارسى إدارة المعرفة فى بريتوريا، ومجموعة اتحاد مكتبات غوتنـغ وإنفيرون، ومجموعة علم الآثـار البحـرى، وإلمجموعـة الافتراضسية لأبحساث الميـاه، والهندسـة المعماريسة والمجموعـة

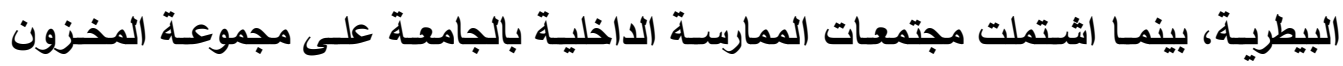
الرقمى، وشبكة خبراء المعلومات الإكترونية، وربما يوضح هذا التعدد فى المجالات المختلفة التى تتضمنها مجتمعات الممارسـة فى الجامعة أن الجامعة تسعى إلى بنـاء وتطوير المعرفة وتحسين سبل الوصول إليها وتبادلها وتثـاركها من خـلال التواصل مـع المنظمـات المختلفة، وربمـا يظهر هنـا أثر "العامـل الاقتصـادى"، وذلك "استتنادًا إلى التطـور الاقتصـادى لجنـوب أفريقيا، فإنها تعد كمركز حيوى للاخول إلى أسواق البلدان المحيطة المكونـة من مجموعة Southern African Development (SADC) التنميـة لأفريقيـا الجنوبيـة Community

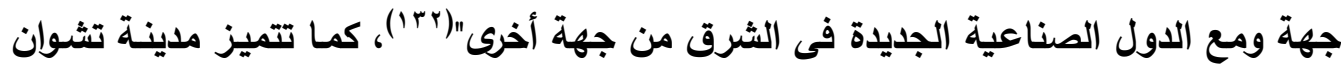

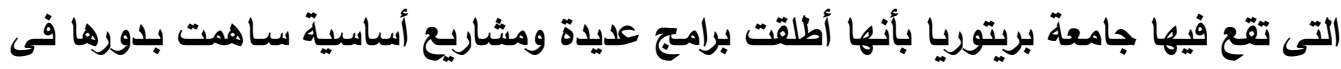
تخفيف وطأة الفقر وخلق فرص العمل فى محاولة منها لتحقيق أهداف الحزب الوطنى؛ فقد شرعت المدينـة فى إنثـاء العديلـ من المشـاريع لتحسين مستوى المعيثـة المحلى ومحاولـة

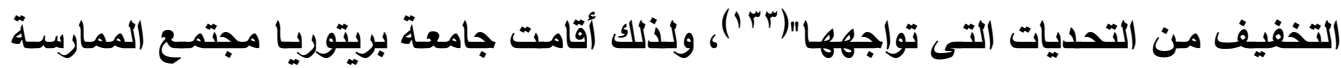
بهدف إدارة المعرفة وتبادلها وتشاركها مع مؤسسات ومنظمات المدينة.

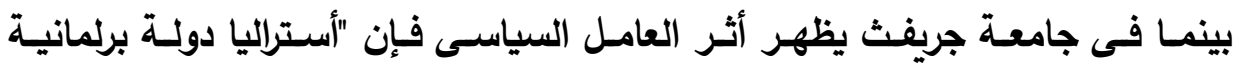
ديمقراطيـة، ممـا يعنى أن المـواطن الأسترالى يثـارك فـى كيفيـة حكم البلاد، وكيفيـة تمثيل

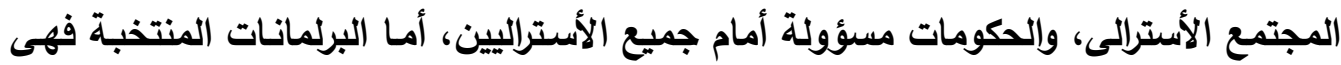


الهيئات الوحيدة القادرة على سن القوانين أو تفويض السلطة لسن القوانين فى أستراليا،

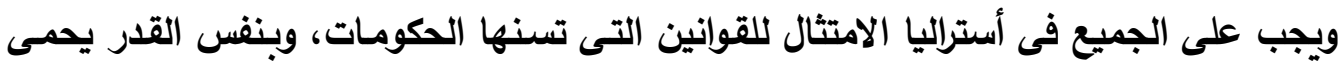

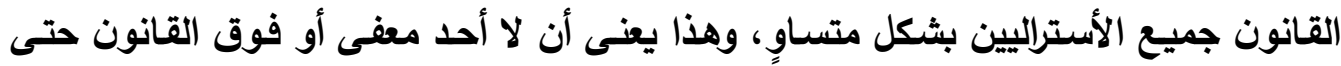

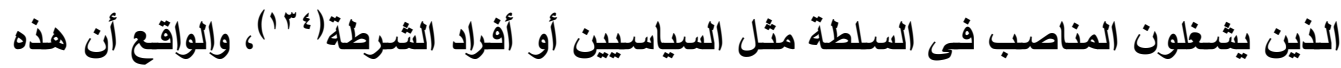

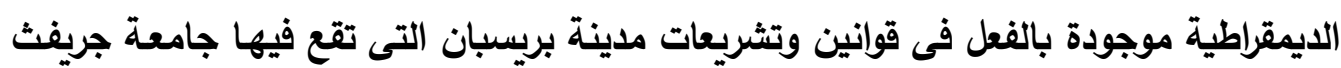

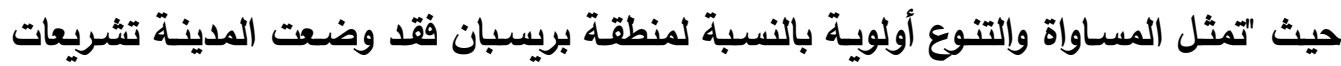

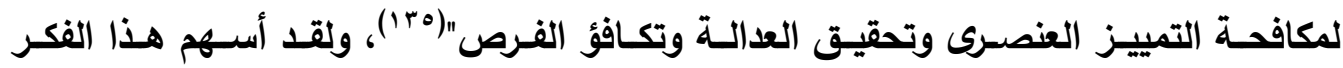

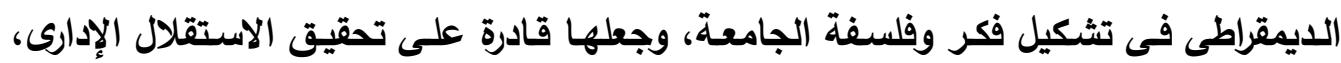
فعندما ارتأت الجامعة أن العصر الحالى هو عصر المعرفة اتجهت على الفي ولفور إلـى بنـاء مجتمعات الممارسة داخلها دون وجود قيود إدارية تحول دون تحقيق ذلك.

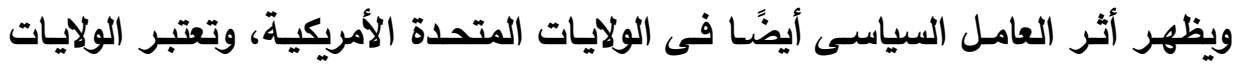

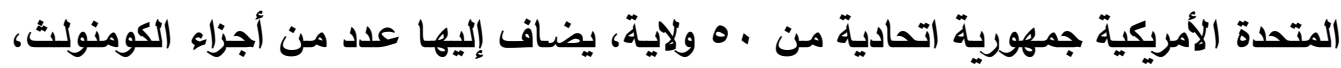

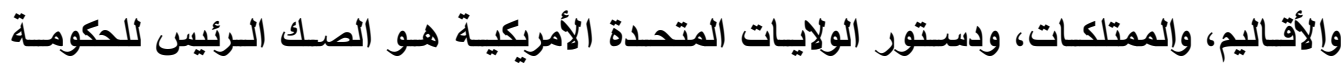

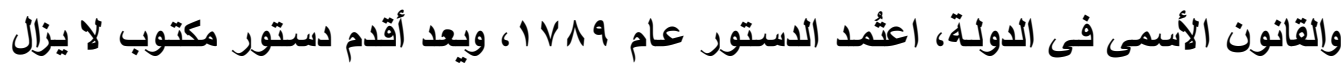

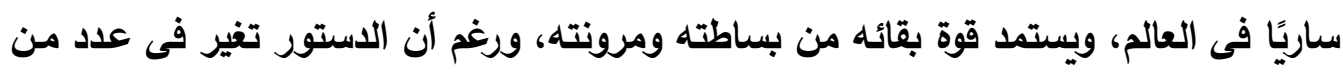

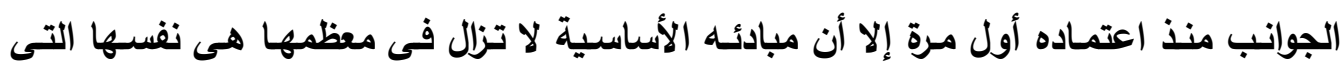

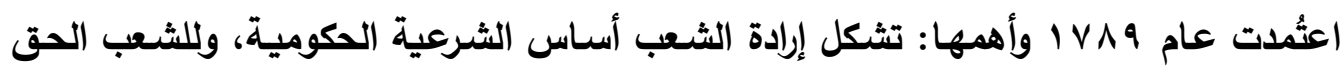

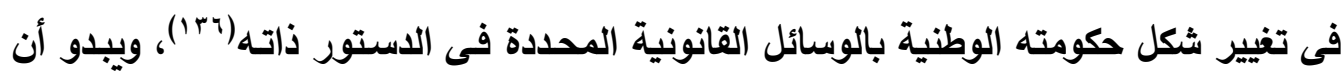
هذه الإرادة وتلك الحرية التى منحها الدستور للثعب قد انتقلت إلى الجامعات والمؤسسات

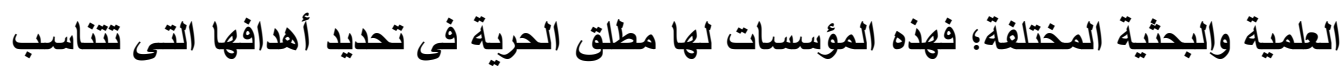

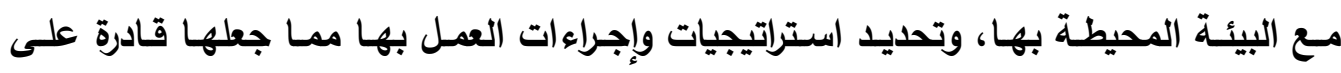

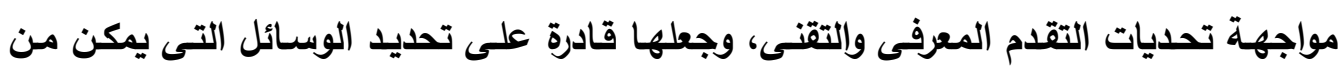
خلالها الوصول إلى المعرفة وتبادلها وتثـاركها مثل مجتمعات الممارسـة التى تعتبر وسيلة

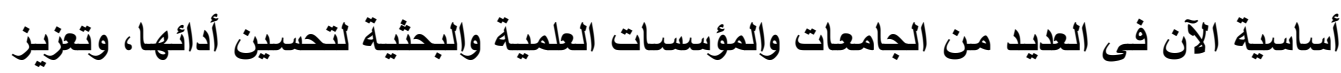

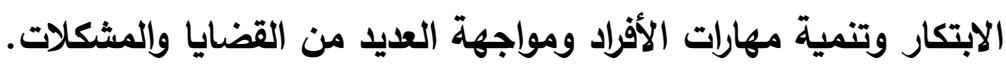

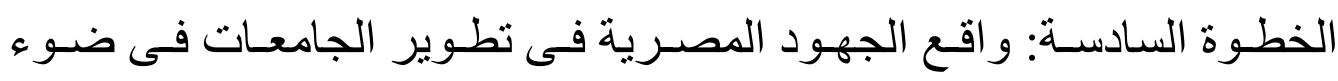

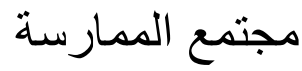


إن الجامعات تؤدى دورًا حيويًا فى تقدم الأمم، وفى تظور الثقافة والعلوم، وفى نشر العلم والمعرفة، ولها دور فاعل تجاه الثورة المعلوماتية والمعرفية، ونظرًا لأن الجامعة مـا هى إلا مؤسسة تعليمية تقع على قمة النظام التعليمى فى المجتمع، وتعتبر أداته للقيادة الفكرية

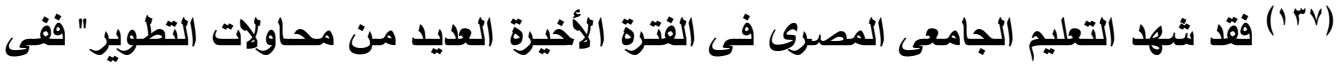
إطار البرنامج القومى لتحديث الدولة تأتى مشروعات تطوير التعليم العالى بمصر والتى تبناها

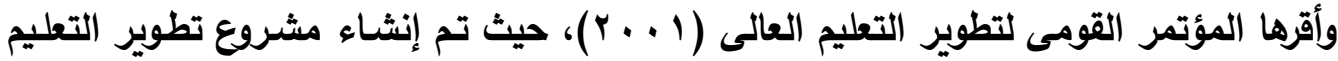

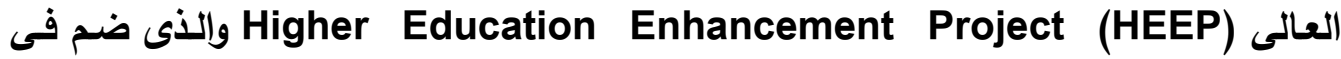

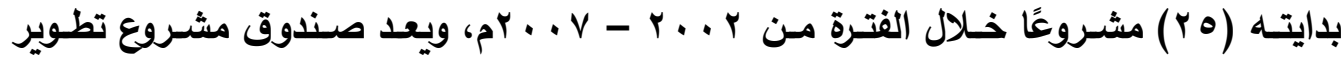
التعليم العالى (HEEPF) مس أوائلس المثروعات التى هدفت إلى تقديم المسـاعدة واللـاعم

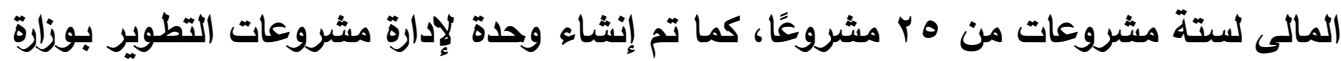
التعليم العالى، ثم قامت كل جامعة بتكوين وحدة لإدارة مشروعات التطوير ضمن الهيكل

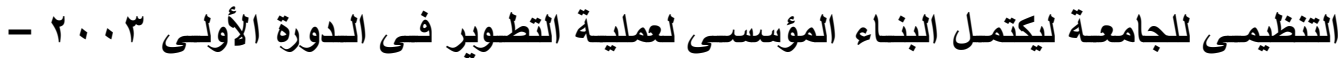

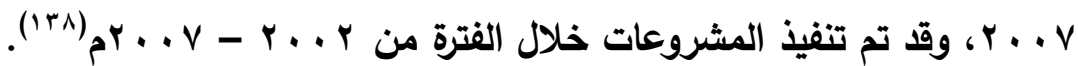

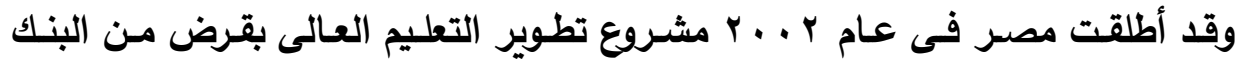
الدولى، بالإضافة إلى تمويل جزئى من الدكومة المصرية وبعض المصادر الأخرى يثمل هذا المشروع (آ) مشروعات فرعية هى: 1 - صندوق مشروع تظوير التعليم العالى (HEEPF) وهذا المشروع هو آلية دورية تنافسية، تم إنشاؤه لمساندة الجامعات ومؤسسات التعليم العالى

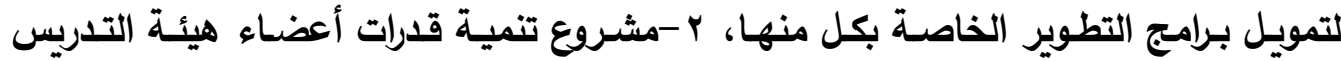

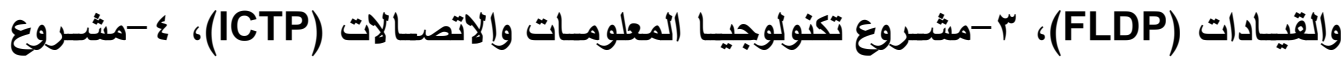

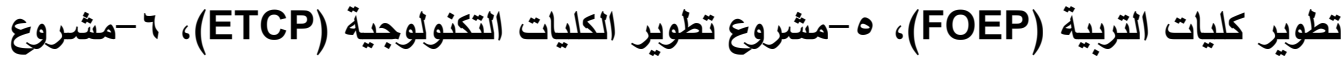
توكيد الجودة والاعتماد (QARP) بالإضافة إلى مشروعات تطوير البنية الأساسية للتعليم

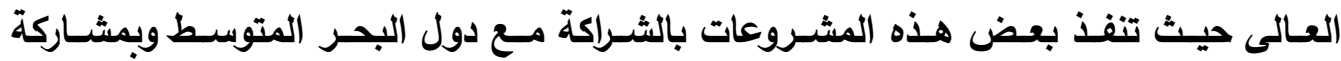

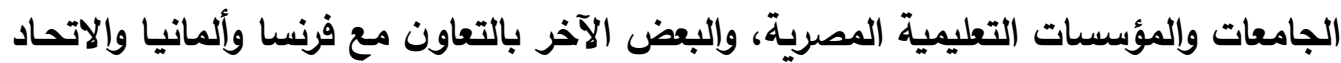

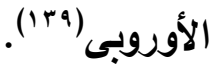
والحقيقة أن هذه المشروعات لم تكن لتتحقق أو تظهر على أرض الواقع إلا من خلال

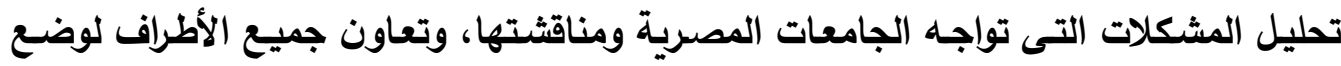


الحلول المناسبة لها، ومواجهة هذه المشكلات من خـلال إقامـة مشروعات محددة، وكل ذلك كان مصحوبًا بأفكار الأعضاء وجهودهم وممارساتهم حتى يتم تنفيذ هذه المشروعات، إن كل هذه الأمور عند تحليلها نجدها تندرج تحت مفهوم مجتمع الممارسـة، فعلى الرغم من أن هذاء

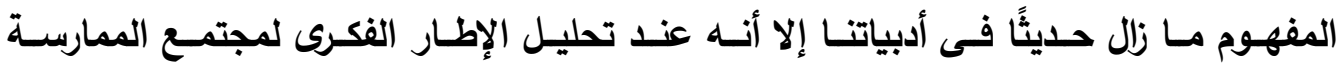
ومضاهاته بواقع تطوير جامعاتنا المصرية فسوف نجد أنتا لسنا بعيدين عن هذا المفهوم، ولكن جامعاتنا بحاجة إلى نشر ثقافة مجتمعات الممارسـة حتى يمكن وضع هذا المفهوم فى ئى إطاره الصحيح، فالجامعات المصرية رغم محاولات التطوير ما زالت تعانى من العديد من أوجه

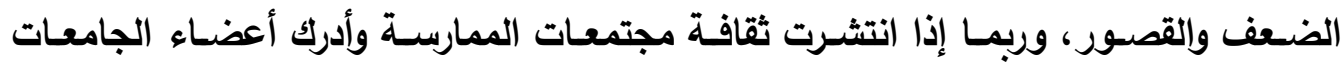
خصائصها وأبعادها ومؤشراتها وفوائدها ودورها فى استثمار العلاقات والتفاعلات الاجتماعية فَى مواجهة المشكلات، ربمـا حينها يمكنتا أن نحرز تقدمًا ملموسًا ونواجـه واقعنـا من خـلال تكاتفنا ومن خلال ممارساتنا الفعلية بلاًا من الاكتفاء بالدراسات والأبحاث النظريـة البعيدة عن

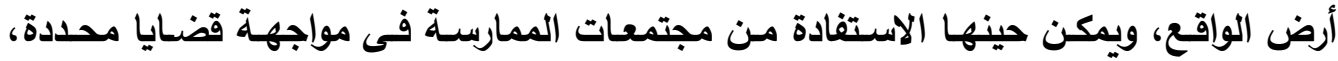
فهناك قضايا ما زالت تشغل الجامعات المصرية رغم الجهود المبذولة لمواجهتها ولعل من أهم هذه القضايا ما يلى: (1) التمية المهنية بالجامعات المصرية: لما كانت التنمية المهنية لأعضاء هيئة التدريس أحد المرتكزات الأساسية فى الإصلاح

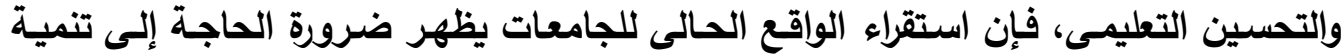
مهنية تعمل على الارتقاء بمستوى أعضاء هيئة التدريس داخل الجامعة، إضافة إلى إكسابهم

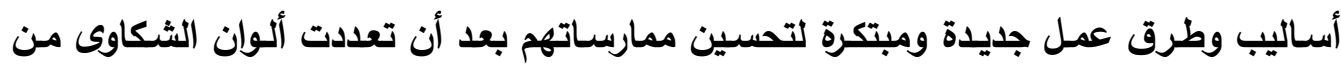
ضعف قدراتهم على التعامل بفهم ووعى مع متطلبات العصر الحاضر (• ؛ ( ). والحقيقة أن الجامعات فى جمهورية مصر العربية تقوم بدور كبير فى تنمية أعضاء

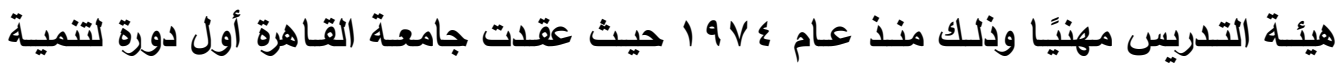

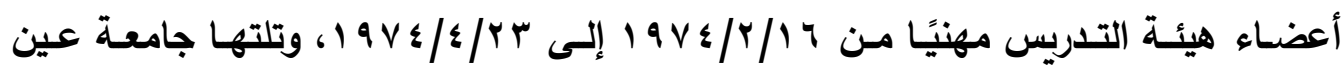
شمس ثم الأسكندرية وحلوان وبقية الجامعات الحكومية الأخرى( (1 أ)، وكان هناك العديد من هن

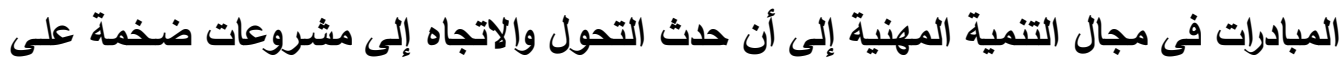

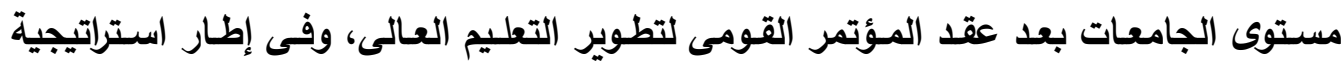
إصلاح التعليم العالى تم تنفيذ مشروع تنمية قدرات أعضاء هيئة التدريس والقيادات، و "يهدف 
هذا المشروع إلى تعزيز الإمكانات المؤسسية والمهنية فحى مؤسسـات التعليم العالى وتطوير

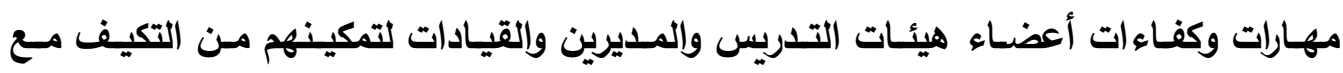
تطورات العصر الحديث ومـن مواجهة التنافسية، ناهيك عن زيـادة فاعلية مخرجـات التعليم العالى. وقد تجلت إنجازات المشروع من خلال: تحديد حاجات التدريب فى مؤسسـات التعليم العالى وقيام جامعات / معاهد التعليم العالى بتطوير استراتيجيات التدريب، وتنظيم ورش عمل مل مهل تدريبية للمدربين لتشكيل فرق أساسية من المدربين المعتمدين ضم كل جامعات ومؤسسات التعليم العالى، وإرسـاء آليات تدريب وتنمية مستدامة، ودعم تأسيس مراكز التدريب في كلى كل جامعة حكومية لضمان استدامة عملية التدربب المستمر "( ؟ ؟ ). ورغم حرص الجامعات على تنفيذ هذا المشروع وإجراء تقييم دورى لقياس أثر البرامج

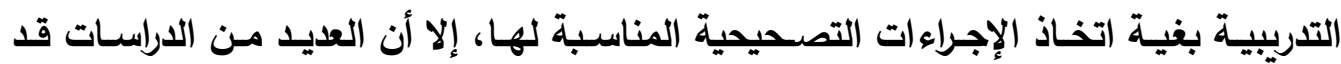
أشارت إلى أن هناك العديد من أوجه الضعف والقصور التى مـا زالت برامج التنمية المهنية فى الجامعات المصرية تعانى منها، ومن أهمها ما يلى:

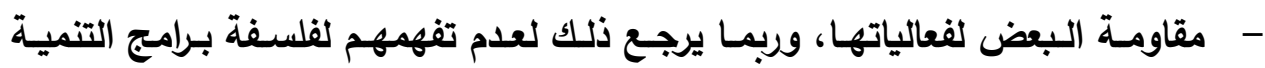
المهنية وأهد|فها، وقلة دافعيتهم نحو الالتحاق بها، نظرًا لبعدها عن احتياجـاتهم التدريبيـة، وكذلك اسـتخدام أسـاليب تقليديـة فـى تنفيذها، وضـعف معـايير اختيـار المدربين، وعدم توافر العدد الكافى منهم، بالإضافة إلى قصر مدة البرامج التدريبية،

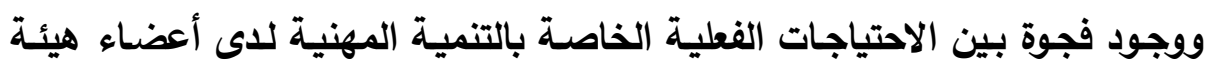
التدريس، وبين معدلات الأداء المطلـوب الوصـول إليها بعد تنفيذ البرامج، وعدم

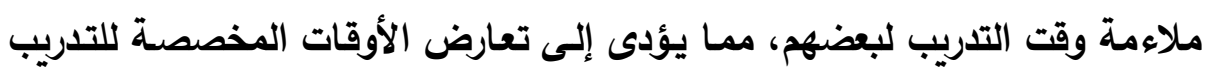

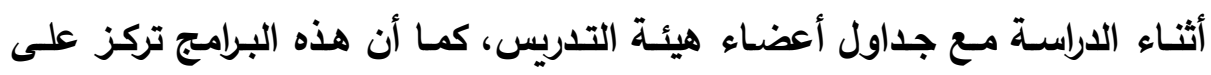
الجانب النظرى، وتهمل الممارسة العملية لأدوارهم المختلفة داخل الجامعة(ب ـ أباء ).

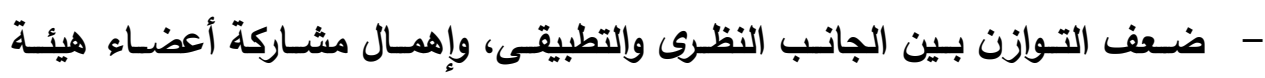
التدريس فى إعداد محتوى برامج التنمية المهنية، وافتقار بعض المدربين للتواصل

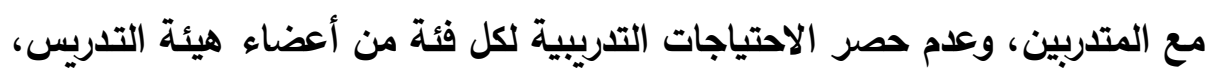
وحضور الدورات التدرببية كمطلب للترقية وليس للتعلم( ؛ ؛ 1). 
إن السـلبيات السـابقة تجعلنـا نتفكر فـى ضـرورة وجـود وسـيلة تمكن أعضــاء هيئة التدريس من أن يتواصلوا معًا دون أن يتقيدوا بمكان محدد، وأن يكون هذا التواصل والتفاعل ناتجًا عن رغبـة حقيقيـة نابعة من داخلهم وليس كمـا هو الحال الآن حيث يعتبر حضور التدريب مطلبًا أساسيَّا للترقية، فهم بحاجة إلى وسيلة تجعل من ممارسـاتهم العملية أساسًا لأدوارهم داخل الجامعة بلاًا من التركيز على الجانب النظرى، وأن يكون كل ذلك تحت مظلة

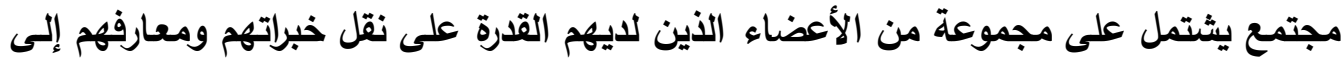
غيرهم، ولـايهم القدرة على وضـع بـائل لمشكلاتهم للوصـول إلـى أفضل الحلـول مـن خـلال

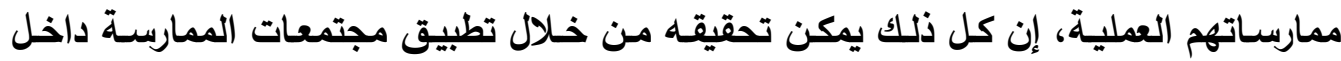
الجامعـات المصرية حتى يمكن تنميـة أعضـاء هيئة التـربس لمواجهـة التحديات المعرفيـة

$$
\text { والتكنولوجية الحالية والمستقبلية. }
$$

أصبحت التكنولوجيا لفةً العصر الحالى، ولههذا أصبحت الجامعات العربية تركز على لهى

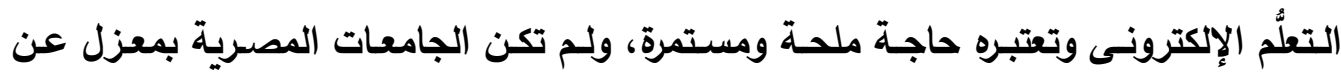
محيطها العربى حيث "قامت وحدة إدارة مشروعات تطوير التعليم العالى بتمويل مشروع لتطوير Information and Communication نظم وتكنولوجيا المعلومـات فى التعليم العالى Technology Project (ICTP) على إتاحة المعلومـات في الصورة الإلكترونيـة من خـلال شبكات معلومـات الجامعات بثكل مباشر وسريع، وإستحداث أنماط تعليمية جليدة، وتحقيق الميكنة المتكاملة للإدارة الجامعية، وتهيئة المجتمع الجامعى للتعامل معها من خـلال التدربب الموجـه والمستمر ـ وقد تم تقسيم محساور العمل بمشـروع ICTP إلى خمسـة محساور رئيسية هـى: محسور البنيـة الأساسـية

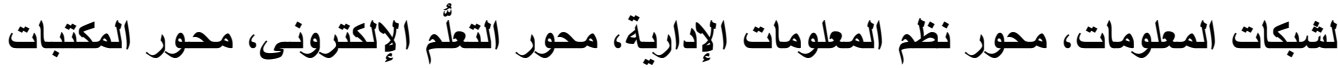

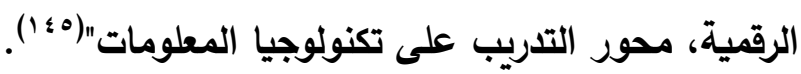
و"يقـوم مشـروع تطـوير نظـم وتكنولوجيـا المعلومــات (ICTP) بتمويـل عـدـ مـن المشروعات بالجامعات والمجلس الأعلى للجامعات بمـا يعمل على تظوير نظم وتكنولوجيا المعلومـات والاتصـالات بالجهـات المستفيدة وتفعيـل اسـتخد/مها بمـا يفيـ عمليـات التعليم 
وقد سـاهم مشروع تطوير نظم وتكنولوجيا المعلومـات ICTP فى التعليم العالى فى

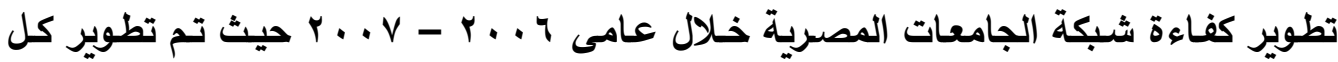
المكونـات الماديـة بشبكات الجامعات المصرية، وتم تطوير كافة مقوماتها بمـا يسـاعد على

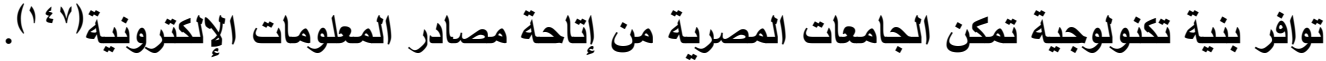

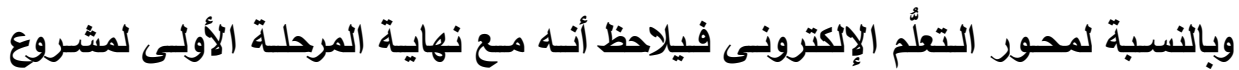
تطوير نظم وتكنولوجيا المعلومات فى التعليم العالى ICTP أصبح هناك المركز القومى للتعلم الإكترونى بالمجلس الأعلى للجامعات، ومركز لإنتاج المقررات الإكترونية بكل جامعة من

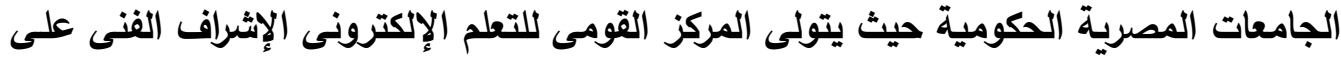

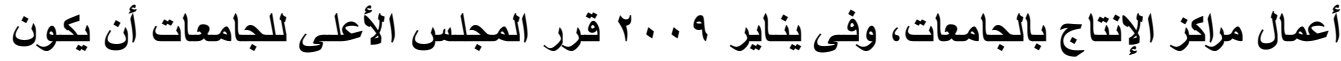
المركز القومى للتعلم الإكترونى هو الجهة المسئولة عن اعتمـاد المقررات الإكترونية داخل الجامعـات المصرية، وقد بـأت المرحلـة الثانيـة لمشـروع ICTP بتحديد مشـروعات محور

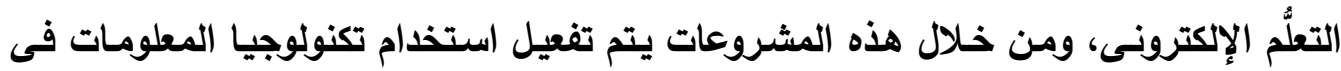

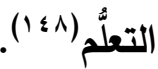

"ونظرًا لأهمية التعلُّم الإكترونسى فقد قامـ معظم جامعات مصر بالعمل على تحويـل

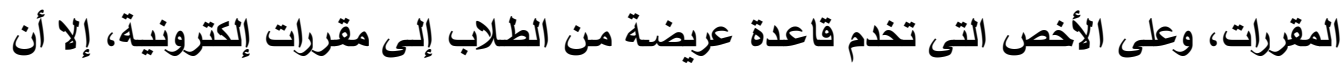
المقررات التى يتم نشرها حاليًا على شبكة الإنترنت تحتاج إلى مهارات للتعامل معها من قبل مُهريل

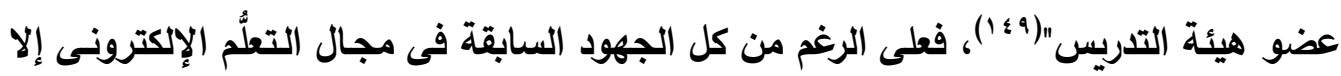

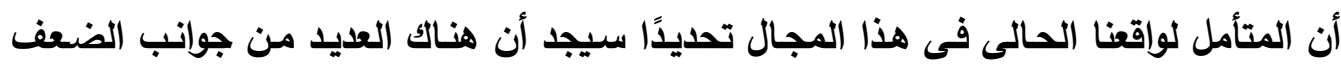
وإلقصور والتحى يمكن توضيحها فيما يلى: - - لم يحصل أعضاء هيئة التدريس ومعاونوهم على البرامج التدربية الكافية لإكسابهم كفايات تكنولوجيا التعليم الإلكترونى. - - لا يمتلك أعضـاء هيئة التـدريس ومعـاونوهم معظم الكفايـات لتحقيـق اسـتراتيجية الكليات للتعليم والتعلُّم الخاصة بتكنولوجيا التعليم التربن الإلكترونى. - غالبية أعضاء هيئة التدريس ممن تتوفر لديهم كفايات تكنولوجيا التعليم الإكترونى الإلى بالممارسة أو من خلال البرامج التدريبية يحتاجون إلى برامج صقل وتنمية للارتقاء بمستوى الكفايات لايهم. 
- لا يمتلك أعضاء هيئة التدريس ومعاونوهم كفايات تخطيط وتصميم وتطوير وتقويم وإدارة المقرر الإلكترونى(10.).

- عدم رغبة بعض أعضاء هيئة التدريس فى توظيف التعليم الإلكترونس فى العملية التعليمية.

- تصور بعض أعضساء هيئسة التدريس أن التعليم الإلكترونس غير مجدٍ فى العملية التعليمية. - ضعف وجود ثقافة التعلُّم الإكترونسى بين طلاب الجامعة وإلعاملين بها من أعضساء هيئة التدربس وغيرهم. - اعتمـاد أسـاليب التعليم وإلتعلُّم فـى البيئـة الجامعيـة علـى الطـرق التقليديـة دون الاهتمام الكافى بعمليات التطوير بتطبيق البعد الإكترونى فى التعلُّ.

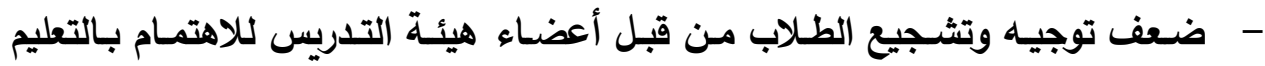
الإلكترونى والتعرُّف على خصائصه. - -

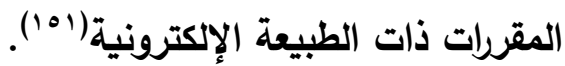
يتضـح مما سبق أنـه على الرغم من الجهود التى قامت بها الجامعات المصرية فى

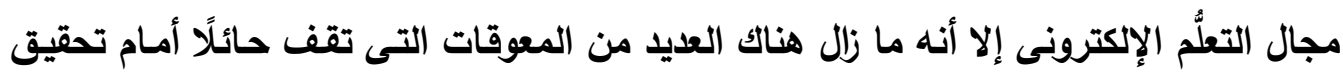

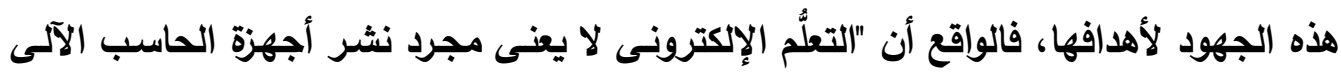

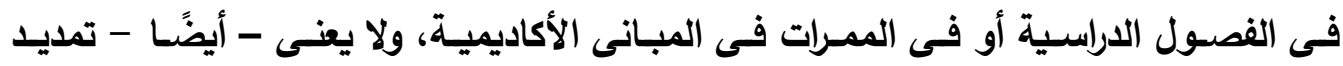

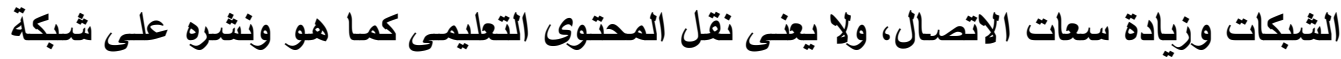

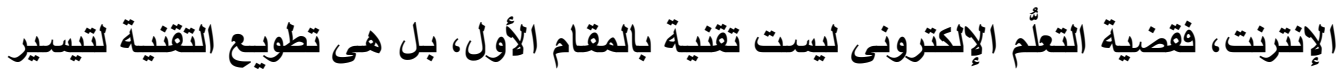

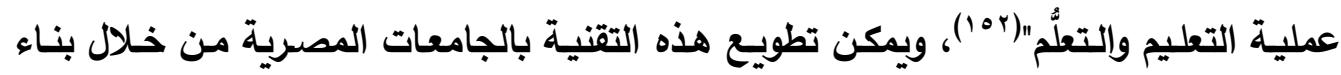

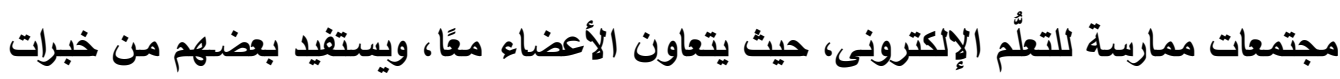
بعض فى هذا المجال، وينظمون أنفسهر، ويتبادلون معلومـاتهم المرتبطة بتطوير وإستخدام

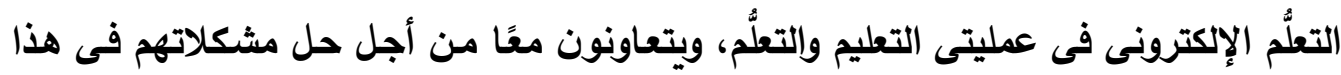

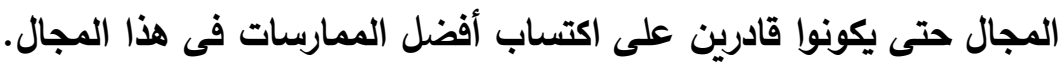

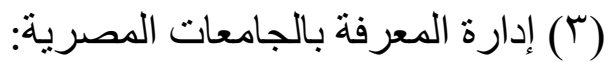


تعتبر الجامعة والمعرفة مفهومين متلازمين؛ فقد ارتبط مفهوم الجامعة خلال تاريخها

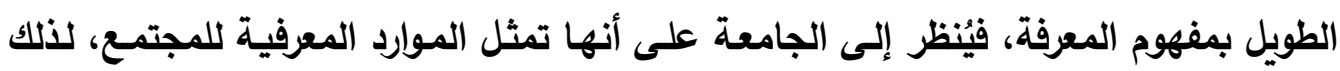
يقع على عاتق الجامعات مسئولية إثراء وتطوير وتنمية البناء المعرفى للمجتمع. وتتبع أهمية

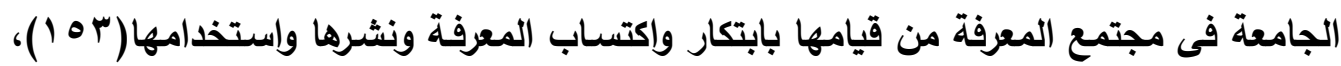
وفى ظل التحديات المعرفية والتكنولوجية والتسـابق العالمى فإن "الجامعات المصرية تسعى إلى أن يكون لها سمعة ومكانـة دولية تحتلها من خلال وجود ترتيب لها ضمن التصنيفات الإقليمية وإلعالميـة للجامعات، وخاصـة فيما يرتبط بأدائها البحثى، فمن مظاهر ذلك السعى ونى تطـوير بـرامج الدراســات العليـا، ووجـود العديــــــن المنشـورات العلميـة الدوليـة السـنوية والمشروعات البحثية الممولة"( ؛ ه 1). ومنذ أواخر السبعينات وأوائل الثمانينات بدأت حركة نشطة من التعاقدات بين جهات أجنبية وبعض الجامعات المصرية لإجراء مشروعات بحثية بتمويل أجنبى، ويأتى فى مقدمة هذه الهيئـات هيئة المعونـة الأمريكيـة، والبنـك الـولى، ومركز بحوث التنمية الدوليـة بكندا، وبرغم مـا حققته من إيجابيات فإنها ظلت قاصرة على تقديم إسـهام ملموس فى رفع كفاءة التعليم العالى وفى التنمية المجتمعية، ولقد سـاعدت هذه البحوث والمشروعات على تنثيط حركة البحث العلمى فى مصر، وعلى قدر من الاحتكاك المدود بجهات أجنبية، حيث لـ ينشأ عنها تفاعل حقيقى بين الجانب المصرى والأجنبى، كما أنه لم يترتب عليها فى الغالب الأعم علاقات بحثية متجددة(00 10 )، ومن جهة أخرى كانت هناك جهود لتطوير التعليم الجامعى المصرى لمواجهة تحديات مجتمع المعرفة منها: الأنشطة الاستراتيجية لوزارة التعليم العالى والبحث العلمى لتطوير التعليم الجامعى، وسَسَت بعض الجامعات إلى وضـع خطة استراتيجية لتحقيق الجودة والتميز فى الأداء الجامعى، كما أن هناك مشروعات تطوير التعليم الجامعى، ومن أهمها المشروعات الستة المدمجة التى تم اختيارها من بين الخمسة والعشرين مشروعًا

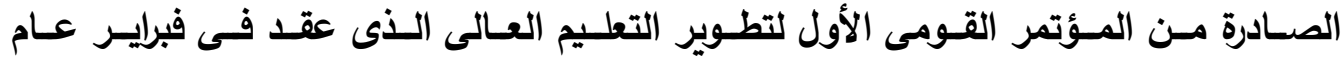

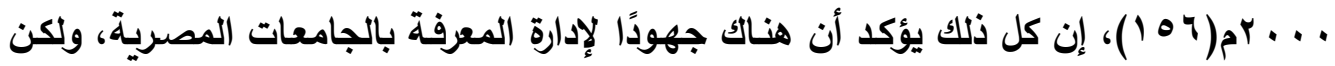
بالرغم من ذلك تثير العديد من الدراسات إلى وجود العديد من جوانب الضعف والقصور فى هذا المجال ومن أهمها ما يلى: - الثقافة الحالية لا تثجع مشاركة وتبادل المعرفة. 
- - نقص الوعى بالفوائد المتحققة من تطبيق إدارة المعرفة. - - الافتقار إلى التدربب المرتبط بإدارة المعرفة. - الافتقـار إلـى فهم إدارة المعرفة بشكل صـيح بسبب الاتصـال غير الفعـال وغير الكفء (l०V) - ضـعف صـور التعـاون العلمسى فـ حقـل البحوث واللاراسـات العليـا علـى المستوى المحلى بين الكليات بل وبين الأقسام الأكاديمية داخل الكلية الواحدة ممـا يؤدى إلى صعوبة تبادل المعرفة ونقلها والاستفادة منها ومن ثم يؤدى إلى إثرائها وتطويرها. - - افتقاد العمل بروح الفريق، وعدم تفرغ الغالبية العظمى من أعضاء هيئة التدريس للعمل فـى الجامعة، وتركيز أغلبهم على البحث لأغراض الترقية، ونــرة المشـاريع البحثيـة المشتركة، وإفتقـاد صـور التعـاون والتفاعل ممـا يحول دون ممارسـة إدارة

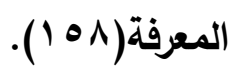

- ضـعف قنـوات الاتصـال بين الجامعة ومؤسســات المجتمع نتيجـة غيـاب السياسـات الموجهة للبحث العلمى الوجهة الصحيحة على مستوى الجامعات، ممـا ينتج عنهـ عدم ربط بحوث أعضاء هيئة التدريس بخطط التنمية، وعدم اهتمام جهات التنفيذ

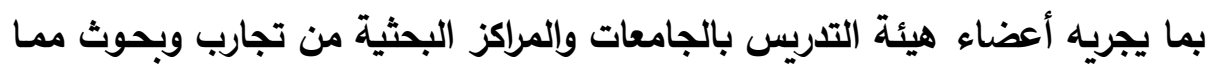

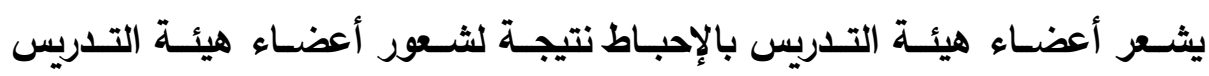
بمحدودية أثر بحوثهم وعدم جدواها فى تطوير المجتمع أو تنميته( 9 ه أ).

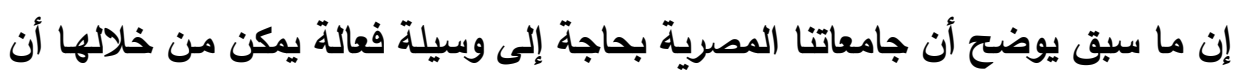

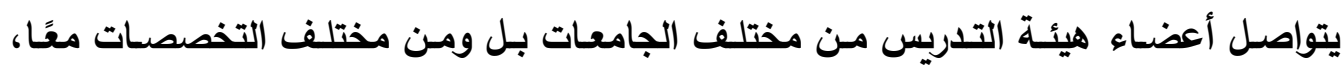

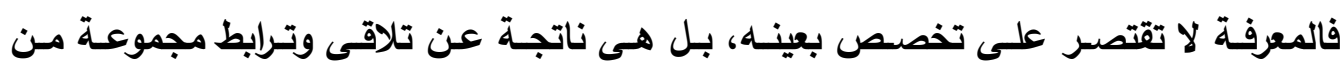

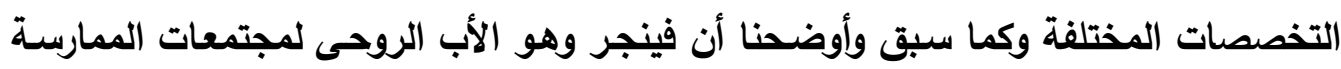

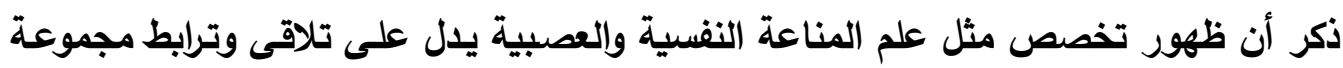
من الممارسات والتخصصات، لذلك فإنه يمكن عن طريق بناء مجتمعات الممارسـة أن يحدث أنه

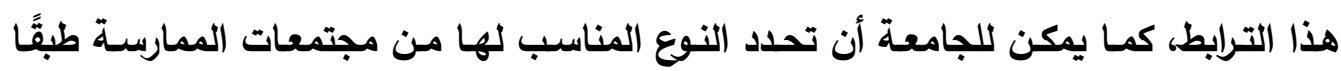

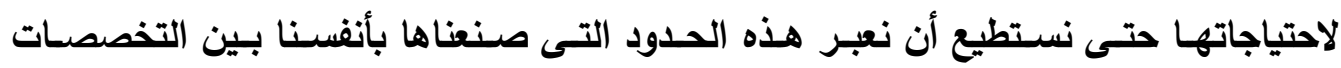

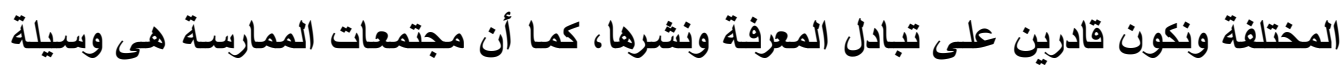


فعالة للاتصـال بين الجامعة ومؤسسـات المجتمع المدنى، ووسيلة فعالـة لغرس روح الفريق والتعاون بين أعضاء هيئة التدريس من خلال المشروعات المختلفة والتى تجعلنا نتعاون معًا لا من أجل الذات والتفكير فحى الترقية بل من أجل مواجهة المستقبل والتفلب على تحدياته القادمة من خلال تنمية البناء المعرفى.

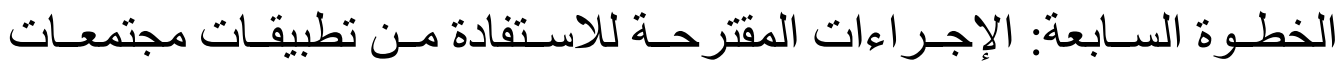
الممارسة فى جامعات بعض الدول الأجنبية فى جمهورية مصر العربية:

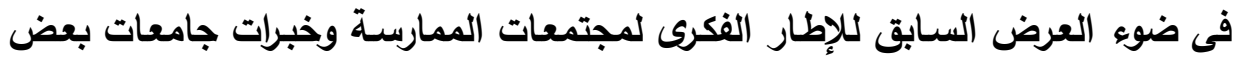
الداول الأجنبية فى هذا المجال، يمكن عرض أهـ النتائج التى توصلت إليها الاراسـة ثم توضيح الإجراءات المقترحة، والمعوقات التى يحتمل أن تواجه تطبيق مجتمعات الممارسـة فى لــ الجامعات المصرية وسبل التغلب عليها. أولًا - نتائج الدان المدرية وسئة

توصلت الاراسة إلى مجموعة من النتائج يمكن إيجازها على النحو التالى:

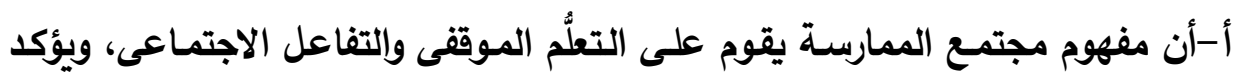
على ضرورة التثارك بين الأفراد لمعالجة قضايا محددة.

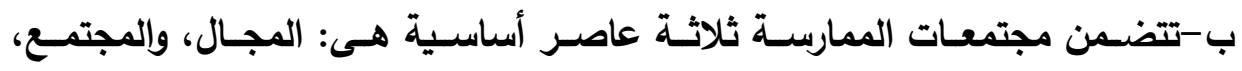
والممارسة، كما أن فينجر وضع أربعة عشر مؤشرًا لتحديد مجتمعات الممارسـة، وقام بتقسيم هذه المؤشرات فى ضوء ثلاثة أبعاد محددة.

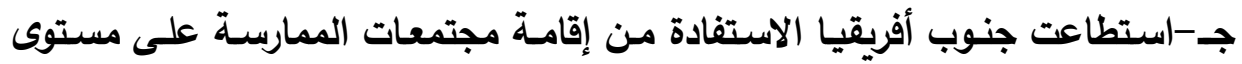
الدولـة لتحقيق استراتيجيات وسياسـات الحكومـة مـن خـلال التركيز على قضـايا محددة مثل منل

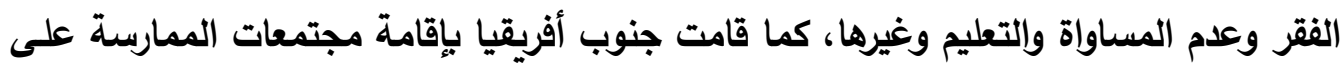

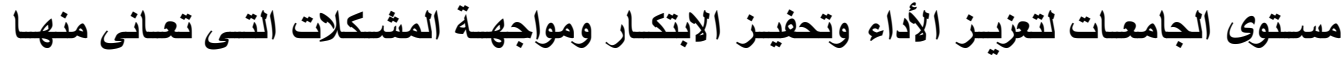
الجامعات.

د-اسـتطاعت أسـتراليا أن تسـتخدم مجتمعـات الممارسـة لمواجهـة مـا يســى بالعزلـة الاجتماعية بها والناتجة عن كبر مساحة الدولة؛ فقد حرصت أستراليا على إقامسة مجتمعات الممارسـة عبر الإنترنت لسـهولة التفاعل مـع الأقران وزيـادة الدعم المهنس، ولقد اعتبرت أستراليا أن مجتمعات الممارسـة استراتيجية أساسية فى تطوير نظام التدريب القومى بقطاع الإسرن التـدريب والتعليم المهنى الأسـترالى، وعلى مستوى التعليم الجـامعى فقــ لجـأت العديــ مـن 
الجامعات بها إلـى إقامـة مجتمعـات الممارسـة لتوليد المعرفة وتطبيقها وتبادلها ونقلها إلى الآخرين.

هـ-اتجهت الولايـات المتحدة الأمريكيـة إلى إقامسة مجتمعـات الممارسـة فى مختلف المجالات وكان ذلك ناتجًا عن توصل العديد من الدراسـات إلى أهمية الدور الذى تقوم بـه العلاقات الاجتماعية فى مواجهة العديد من المشكلات؛ لذا كان لمجتمعات الممارسـة دور مهم فـى التقليل مـن الثـعور بالعزلـة، وفى الانخراط فـى المحادثـات المهنيـة، وزيـادة الثقــة بين الأفراد، والوصول إلى أفضل الممارسات، وتحسين التواصل داخل المؤسسات التعليمية.

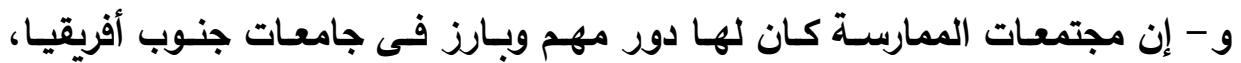
وأستراليا، والولايات المتحدة الأمريكية فى العديد من القضايا أهمها: التنمية المهنية، والتعلُّم الإلكترونى، وإدارة المعرفة.

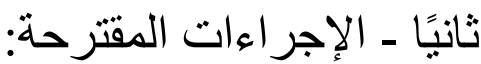
يمكن تصميم وبناء مجتمعات الممارسة بالجامعات المصرية من خلال المراحل التالية:

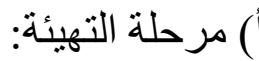

يعتبر مفهوم مجتمـع الممارسـة مفهومًا حديثًا نوعًا مـا على جامعاتنـا المصرية؛؛ لذا ينبفى فى البداية أن تحرص جامعاتنا على نشر ثقافة مجتمعات الممارسـة داخلها من خلال

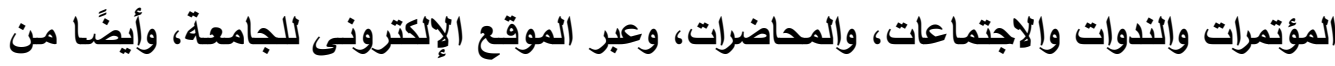
خـلال طبـع الإرشـادات وإلكتيبـات التـى توضـح معنى مجتمعـات الممارسـة، وإسـهاماتها فـى مواجهة تحديات ومشكلات الجامعة.

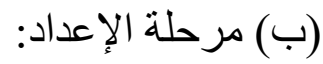

فى هذه المرحلة يتم تخصيص الاعتمادات المالية والتخطيط لوحدة مجتمعات الممارسـة بالجامعة والجهاز التنفيذى لها وتحديد أهداف هذه الوحدة والتى يمكن أن تكون على النحو التالى:

- - نشر ثقافة مجتمعات الممارسة على مستوى الجامعة. - رصد القضايا والمشكلات التى تواجه الجامعات المصرية. - - نثر المعرفة وتبادلها على مستوى الجامعات والمؤسسات المختلفة.

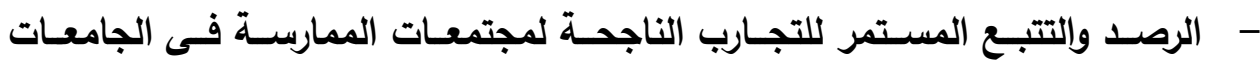
المتقدمة. 
- - التصديق على جدول الأعمال لكل مجتمع ممارسة.

- - تقييم مجتمعات الممارسة ومدى تحقيقها لأهدافها.

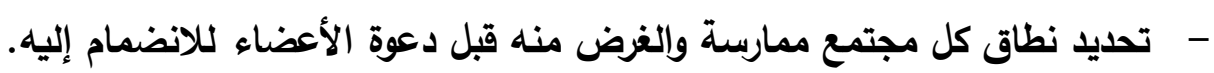
- تحديد الحوافز المادية والمعنوية للأعضاء.

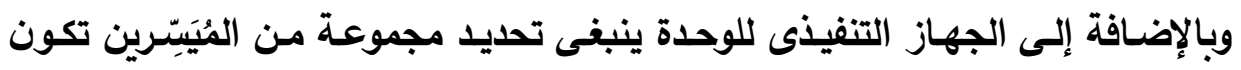

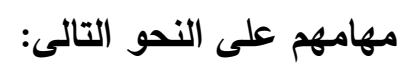

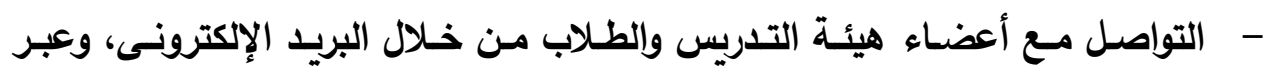
الموقع الإكترترونى للوحدة، وصفحات الويب والمُدَوَّنات. - - التواصل مع الجامعات الأخرى ومؤسسات المجتمع المدنى. - الإعلان عن مجتمعات الممارسة عبر الموقع الإكترونى للوحدة.

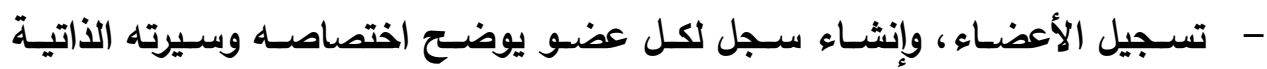
وإسهاماته داخل مجتمع الممارسة.

- - إعداد ونشر تقارير مستمرة حول أفضل الممارسات التى تم التوصل إليتها.

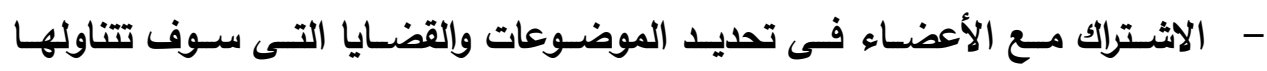

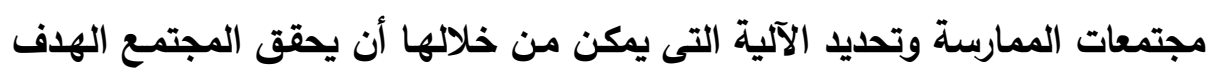

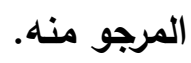
- فحص شكاوى الأعضاء والتوصل للحلول المناسبة لها.

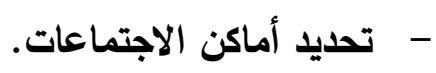

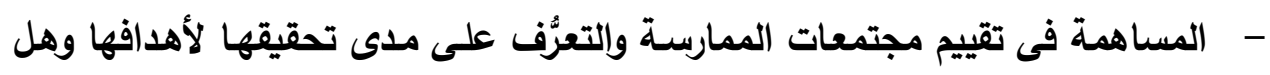
يتم استمرار المجتمع أم يتم إغلاقه إذا كان لا يؤدى الهافف المرجو منه؟

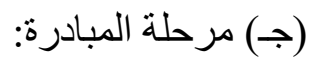
فى هذه المرحلة يقوم الجهاز التنفيذى لوحدة مجتمعات الممارسة بإجراء المقابلات

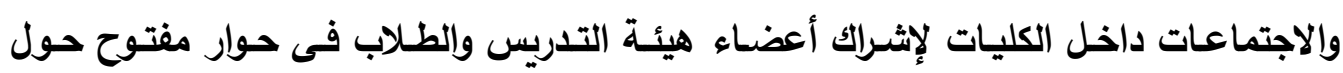

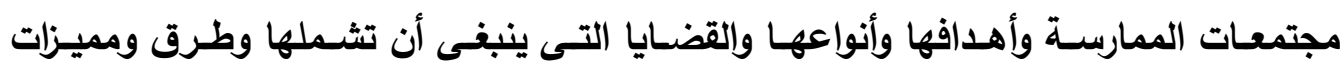
تطبيقها فى جامعات الدول المتقدمة.

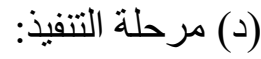


فى هذه المرحلة تقوم وحدة مجتمعات الممارسـة بالجامعـة بالإعلان عن القضـايا الرئيسية التى سوف تتناولها مجتمعات الممارسة، وعلى أعضاء هيئة التدريس الراغبين فى فئه الاثتراك فى إحدى هذه القضايا تسجيل بياناتهم عبر الموقع الإكترونى للوحدة، وفى ضواء

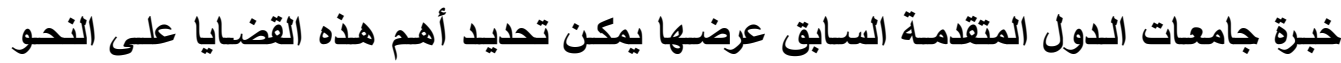

يمكن إقامسة مجتمعـات ممارسـة فـى الجامعـات المصـرية لتحسين وتعزيـز فعاليـة التدريس، وتنمية مهارات البحث العلمى، كما يمكن أن يتناول مجتمع الممارسة قضية "الكتابة

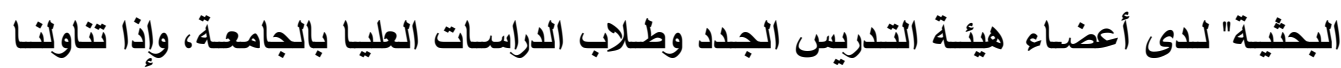

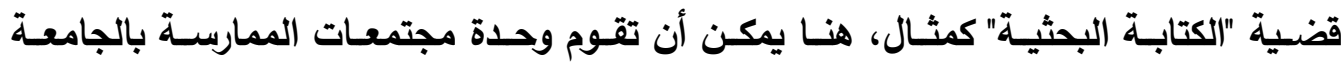
بالإعلان عن هذا المجتمع عبر موقعها الإكترونى وتحديد نطاق الأعضاء من كل كلية،

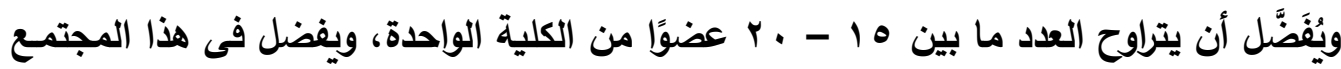

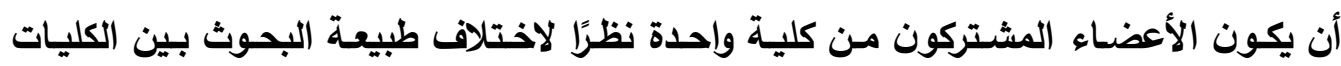

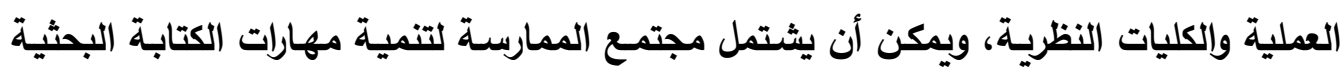

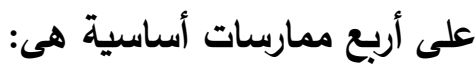
الممارسة الأولى "عرض الخبراء": حيث يقدم أعضاء هيئة التدريس القدامى خبراتها

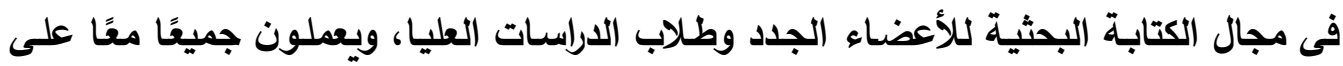
تكوين شبكة من العلاقات الاجتماعية التى تساعدهم على تبادل خبراتهم ومعارفهم معًا.

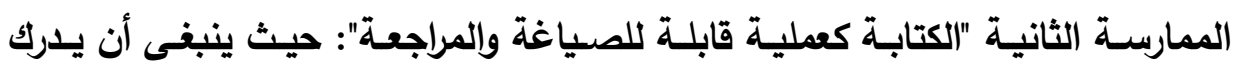
أعضاء هيئة التدريس الجدد أن الأبحاث التى تم نثرها بالفعل فى المجلات العلمية قد مرت التهابل

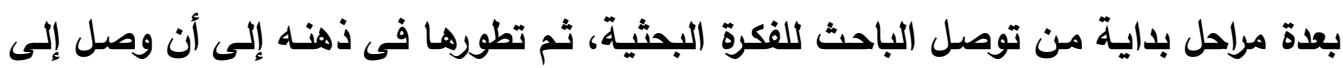

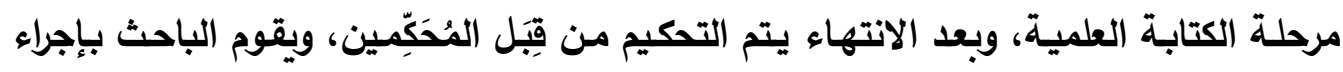
التعديلات المطلوبـة منـه حتى يصل البحث إلى صورته النهائية، وهذه المراحل ينبنى أنساء

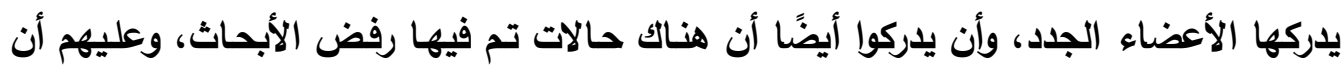

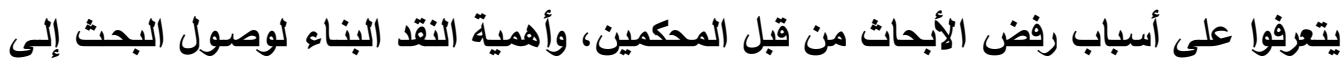

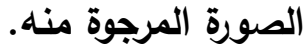


الممارسة الثالثة "الكتابة كجزء لا يتجزأ من العملية البحثية": فى هذه الممارسـة يعمل

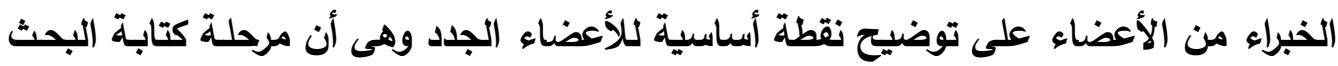

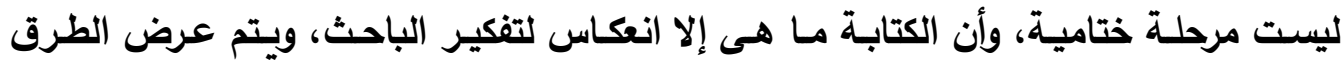
المختلفة للكتابة وكيفية كتابة مسودة البحث.

الممارسـة الرابعـة "عرض الأقران": حيث يقـوم الأعضــاء الجـد بكتابـة أورلق بحثيـة مصغرة، ويقوم أقرانهم بمراجعتها مع وجود الخبراء الذين يقدمون توجيهاتهم إذا تطلب الأمر، كما يقوم الأعضاء الجدد بكتابة مسودات بحثية، ويتم مراجعتها من قبل الأقران والخبراء. ومن خلال هذه الممارسات ينمـى أعضـاء مجتمع الممارسـة الجدد مهاراتهم فى مجال كتابة البحوث بشكل تدريجى عن طريق دعم الخبراء وإلميسرين والأقران فى الجلسـات وورش العمل.

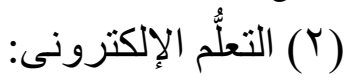
تعتبر قضسية التعلُّم الإكترونسى مـن أهـم القضـايا التى تواجـه الجامعـات فـى العصر الحالى، فالثقافة التى تسود العالم الآن هى الثقافة الرقمية، ولقد انتقلت المجتمعات من محو الآحو

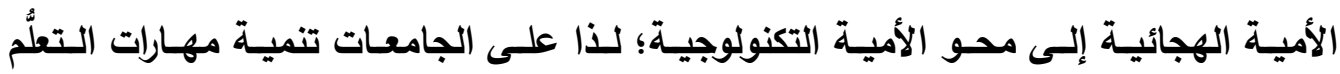

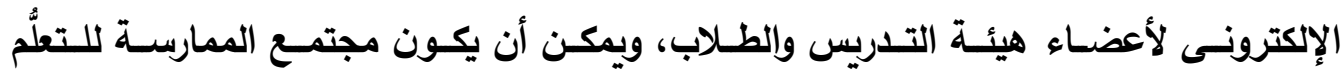
الإلكترونى على النحو التالى:

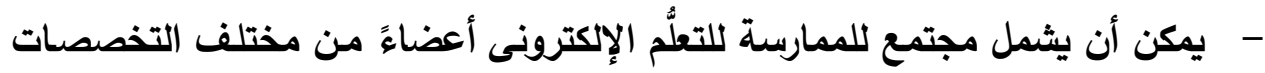

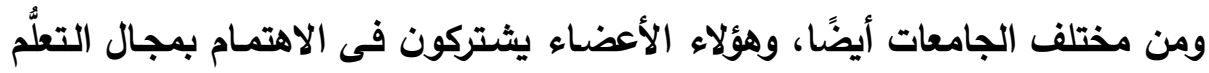
الإلكترونى. - - يـتم الإعـلان عـن المجتمـع عبـر وحـدة مجتمعـات الممارســة بالجامعـة، ويمكن أن يتقابل الأعضاء وجها لوجه أو عبر شبكة الإنترنت.

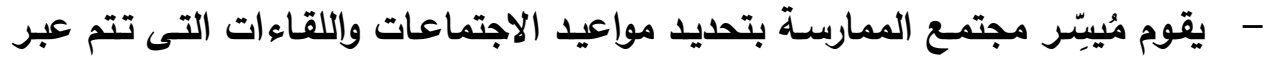
الإنترنت، ويمكن أن يتضمن المجتمع موضوعات أساسية مثل: أهمية التكنولوجيا فى التدريس، والتطبيقات الأساسية التى يمكن استخدامها فى مجال التدريس مثل برنـامـج العروض الباوربوينت، وطريقـة تصـميم المقررات الإكترونيـة، والتطبيقـات التعليمية. 


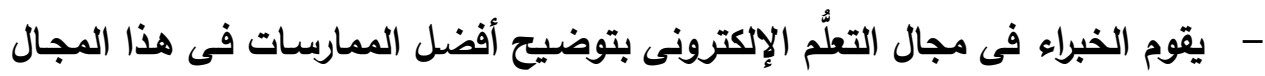

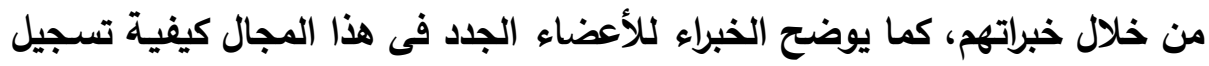
المحاضرات وبثها عبر شبكة الإنترنت، وطريقة تثـيل الفيديو كونفرانس، والبث

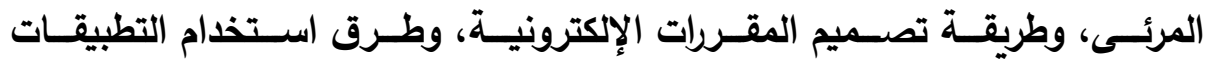

$$
\text { التكنولوجية المختلفة. }
$$

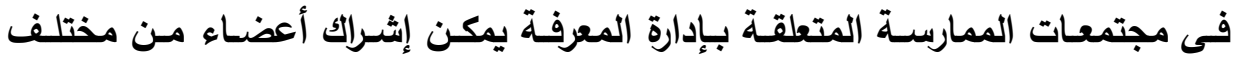
التضصصات ومن المؤسسات الأكاديمية والمنظمات غير الحكومية المهتمـة بإدارة المعرفة، وهنا يجب أن تركز مجتمعات الممارسة على إحداث التكامل والترابط بين العلوم المختلفة على التى نحو يسهم فى تكامل المعرفة حتى يمكن مواجهة التحديات التكنولوجية والمعرفية الحادثة

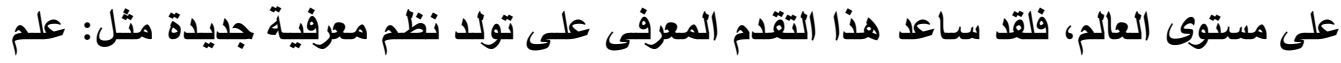

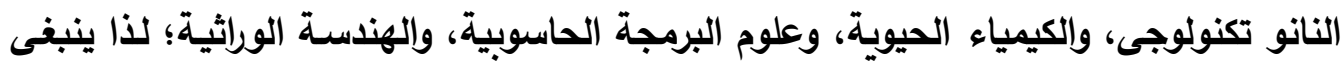
أن تحرص الجامعات من خلال مجتمعات الممارسة على تنظيم المفاهيم والأفكار المتعددة فى التى المجالات المختلفة بثكل مترابط ومتكامل، وهنا يمكن اقتراح مجتمعات الممارسة التالية: - مجموعة العلوم والتكنولوجيا والمجتمع: يمكن أن يشترك فى هذه المجموعة أعضاء من كليات العلوم، والكليات التكنولوجية،

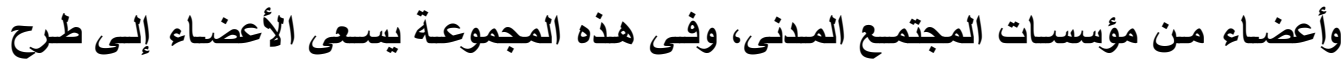

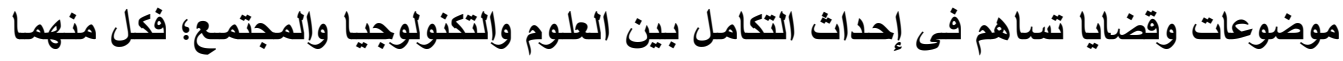
يؤثر على الآخر، فالعلوم الطبيعية ترتبط بالتطبيقات التكنولوجية وكل منهما يؤثر على البيئة

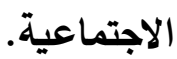

- مجموعة العلوم والتكنولوجيا والهندسة والرياضيات: وهذه المجموعة لها أهية كبيرة خاصة فى العصر الحالى الذى انتشرت فيه مدارس STEM فى جميع أنحاء العالم وفى مصر على وجه التحديد؛ فلقد انتشرت العديد من هذه الته

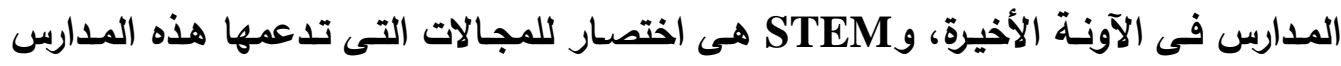
وتثـمل: Science, Technology, Engineering, Mathematics فالعلوم تتضمن المعارف وطرق التفكير العلى، والتكنولوجيا تتضمن التطبيقات العملية وعلوم الكمبيوتر، أما 
الرياضيات فتتضـمن قواعد وأساسـيات الرياضيات وحل المشكلات الرياضية، بينمـا تتضـمن الهندسـة كل مـا يتعلق بالتصميم الهندسى، وهذه المجالات الأربعة هـى أسـاس التقدام على واتى

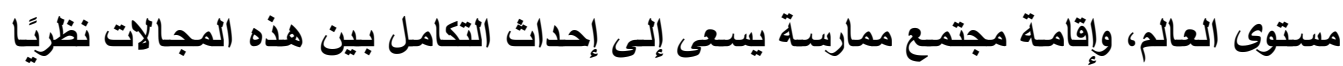
وعمليًا سـوف يـؤدى إلى توليد معرفـة جديدة يمكن نشـرها ونقلها وتبادلها على مسـتوى المؤسسات التعليمية المختلفة. -مجموعة "علم النفس": يتكون أعضاء هذه المجموعة من الأعضاء المتخصصين فى علم النفس من الكليات المختلفـة مثل الآداب والتربيـة وأيضًا مـن الأطباء النفسيين من كليـات الطب، فهنـاك ترابط وتكامل بين علم النفس والطب النفسى حيث يدرس علم النفس سلوك الإنسان بهذف فهم هذا السلوك وتفسيره والتنبؤ به، بينما يركز الطب النفسى على العقل ومنع الاضطرابات النفسية، وهذه المجموعة سوف تساهم من خلال القضايا التى تطرحها إلى إحداث التكامل والترابط بين العلاج النفسى وسلوك الإنسان للوصول إلى أفضل النتائج.

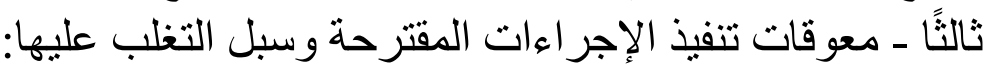
إن هناك معوقات يمكن أن تواجه تنفيذ الإجراءات المقترحة مثل مشكلة عجز ميزانية الجامعات المصرية؛ فإن نسب التمويل الضئيلة المخصصة للتعليم والبحث العلمى ربمـا تؤدى مأد إلى عدم توفير الإمكانيات والتجهيزات الللازمـة لتصميم وإقامـة مجتمعات الممارسـة، بالإضـافة

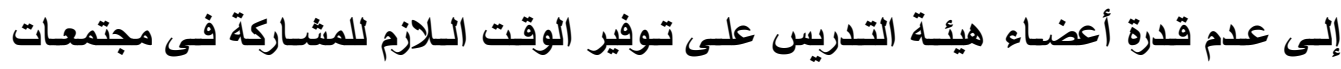

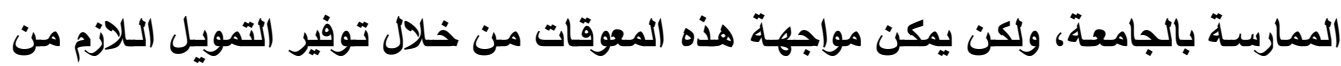
خلال صناديق الكليات ومؤسسـات المجتمع المدنى، كما أن الجامعة ينبغى أن تكون جامعة فونة منتجة وقادرة على زيادة مواردها من خلال إقامـة مشـاريع بحثية إنتاجية وتكوين علاقات مـع

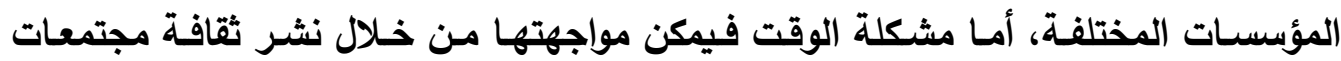

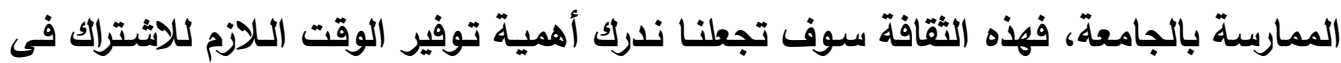
هذه المجتمعات نظرًا لأهميتها التى لا تقتصر على الجامعة فقط بل على المجتمع الخـارجى

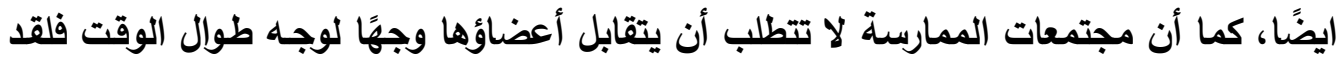
أسهمت التكنولوجيا الحديثة فى كسر حاجز الزمان والمكان؛ لذا يمكن أن يتواصل الأعضاء من خلال الثبكة العنكبوتية، وفى النهاية علينا أن ندرك جميعًا أن ممارسـاتنا لن يتم تطويرها 
دراسة مقارنة لجمتمعات الممارسة في جامعات بعض الدول الأجنبية .

إلا من خلال التعاون والعمل الجماعى، فالتفكير الجماعى ينتج عنـه أفكار إبداعية لا يمكن أن يصل إليها الفرد بمفرده.

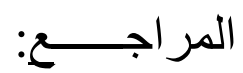

(1) Stefan Ghimisi \& Dana Nicula: "The Role of Communities of Practice in Higher Technical Education", Fiability \& Durability/Fiabilitate Si Durabilitate, Issue $r, r \cdot \mid \mathrm{V}$, p. $r \cdot$

( $r)$ Troy D. Sadler: Communities of Practice, Encyclopedia of Science Education, Springer Science + Business Media Dordrecht, January $Y \cdot 1 \leqslant$, pp. ${ }^{\prime}-$ r.

( $\ulcorner$ ) Maria Jakovljevic \& et al.: "Forming Communities of Practice in Higher Education: A Theoretical Perspective", Active Citizenship by Knowledge Management \& Innovation, Management Knowledge and Learning International Conference, $19-r)$ June, Zadar, Croatia, $r \cdot 1 r$, p. 11.9 .

( $\varepsilon$ ) Nicolae Nistor \& et al.: "Sense of Community in Academic Communities of Practice: Predictors and Effects", Higher Education, Vol. ${ }^{\uparrow}$, Issue. ${ }^{r}$, r. 10, p. roN. 
( $)$ Christine Van Winkelen: "Using Developmental Evaluation Methods With Communities of Practice", The Learning Organization, Vol. rr, No. $r / r, r \cdot 17, p^{\prime} 1 \leqslant r$.

(7) كمال عبد الحميد زيتون: تصميم البرامج التعليمية بفكر البنائية: تأصيل فكرى وبحث إمبريقى،

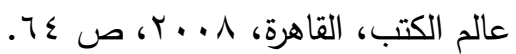

( $\vee$ ) Janet Resop Reilly \& et al.: "Faculty Development for E-Learning: A Multi-Campus Community of Practice (Cop) Approach", Journal of Asynchronous Learning Networks, Vol. 1 7 , Issue $r, r \cdot 1 r, p .1 \cdot r$.

(^) Joel O.Iverson \& Robert D. Mcphee: "Knowledge Management in Communities of Practice", Management Communication Quarterly,

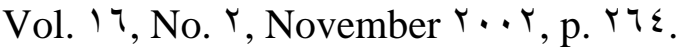

(9) Azeddine Chikh \& Lamia Berkani: "Communities of Practice of eLearning, an Innovative Learning Space for e-Learning Actors", Procedia Social and behavioral Sciences, Vol. $r$, Issue $r, r \cdot 1 \cdot$, p. $0 . r r$.

(1.) Aaron Bond \& Peter Macedo: "Building an e-Learning Faculty Community of Practice", $r^{\text {th }}$ Annual Conference on Distance Teaching \& Learning, Board of Regents of the University of Wisconsin System, $r \cdot 1 \cdot$, pp. $1-r$.

(1) Chery Hodgkinson Williams \& et al.: "Developing Communities of Practice within and Outside Higher Education Institutions", British

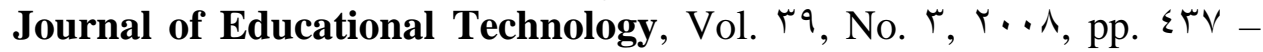
$\varepsilon$ «

(I T) Kristin Warr Pedersen: "Supporting Collaborative and Continuing Professional Development in Education for Sustainability Through a Communities of Practice Approach", International Journal of Sustainability in Higher Education, Vol. $\wedge$, No. ${ }^{\circ}, r^{\prime} \backslash \mathrm{V}, \mathrm{pp} .{ }^{\uparrow} 0^{0}-$ TAV.

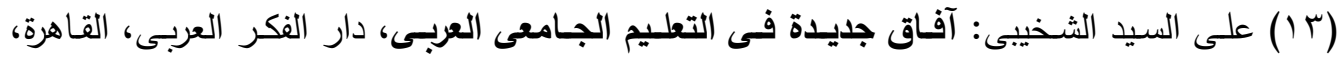

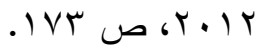

( ـ () محمد ناجح أبو شوشـة: "دور مشروعات تطوير التعليم العالى فى التنميـة المهنية لأعضـاء هيئة

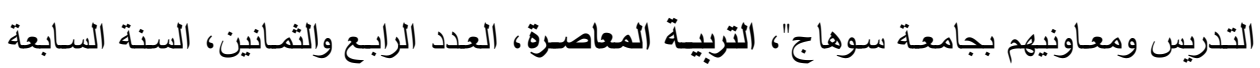

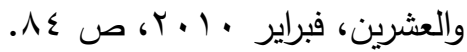

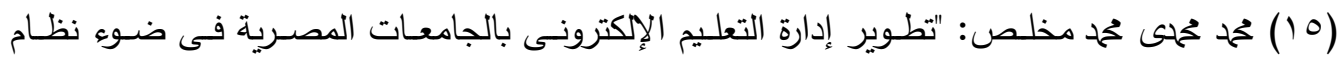

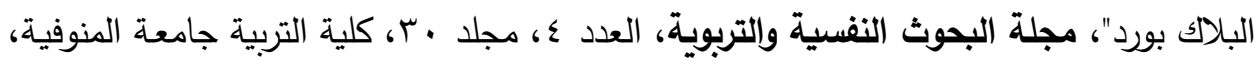

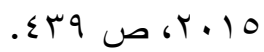




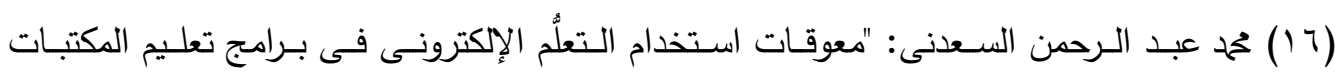

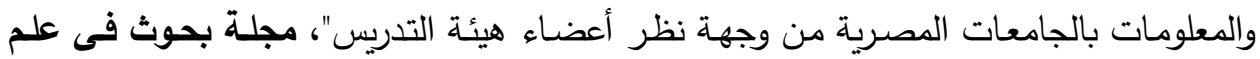

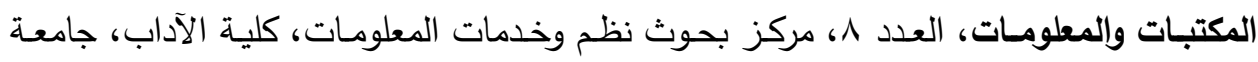

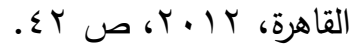

( IV) محمد محلى محمد مخلص: "تجربة الجامعة السعودية الإلكترونية فى التعليم المدمج والاستفادة منها

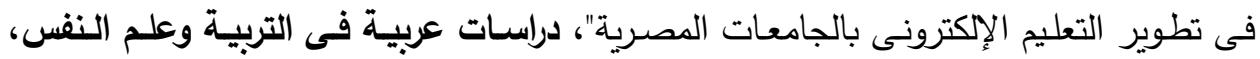

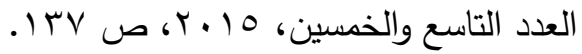
(1) داليا طه محمود يوسف: "تصور مقترح لتطوير أساليب التتمية المهنية لأعضاء هيئة التدريس

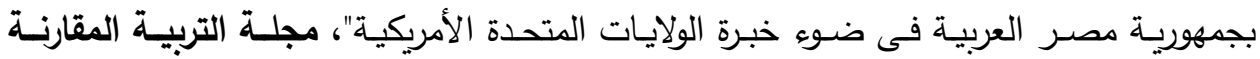

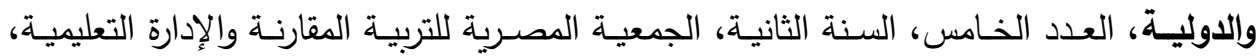
(177 ص .17 (9 (1) أشرف محمود أحمد محمود: "تصور مقترح لتطوير مراكز تتمية قدرات أعضـاء هيئة التدريس

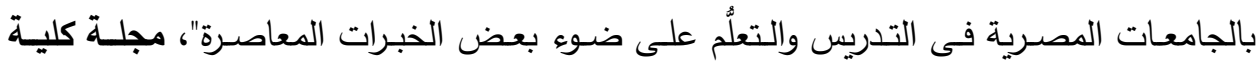

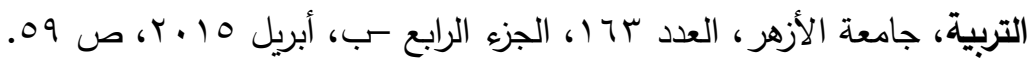

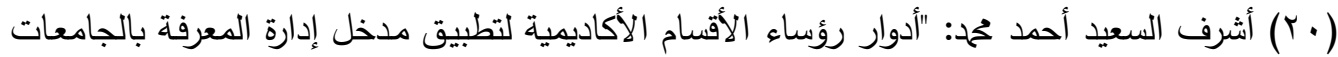

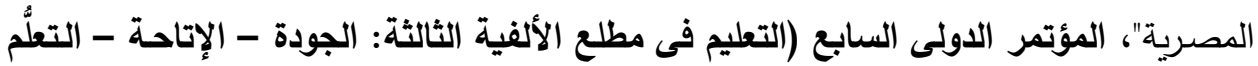

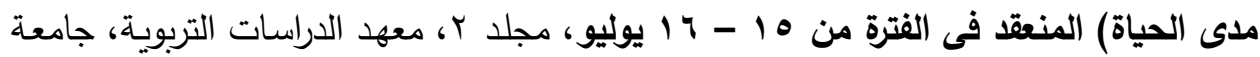

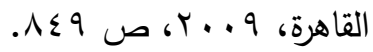
(Y) أميرة رمضان عبد الهادى: "إدارة المعرفة كمدخل لتحقيق الميزة التتافسية بالجامعات المصرية"، مجلـة الإدارة التربويـة، العدد السـابع، السنة الثانيـة، الجمعيـة المصـرية للتربيـة المقارنـة والإدارة

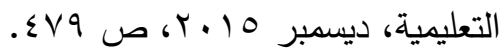

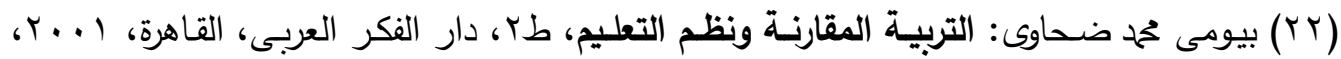

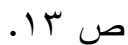
(YT) الملحقيـة الثقافيـة: الاراسـة بالولايـات المتحـدة الأمريكيـة: إرشــادات أوليـة للطلبـة المبتعثين،

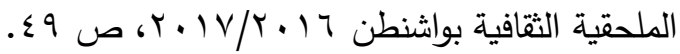

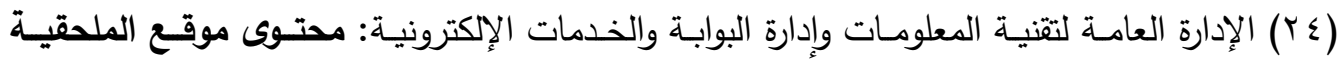

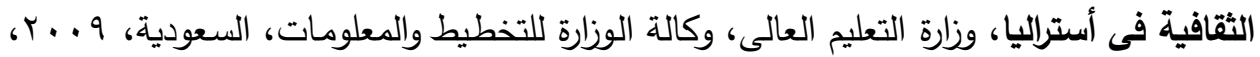


(Y0) بيومى محمد ضحاوى ورضا إبراهيم المليجى: "دراسة مقارنة لنظم الحوكمة المؤسسية للجامعات فى المئ

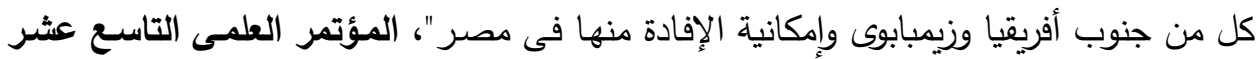

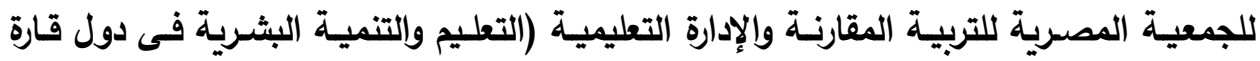

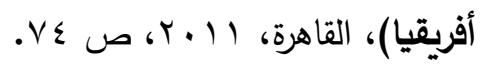

( $\Upsilon^{7}$ ) Olivier Serrat: Building Communities of Practice, Knowledge Solutions, Asian Development Bank, Phillippines, October $\uparrow \cdots \wedge$, p. '.

( $r v$ ) Sedef Uzuner Smith \& Suzanne Hayes and Peter Shea: "A Critical Review of the Use of Wenger's Community of Practice (COP) Theoretical Framework in Online and Blended learning Research, $\left.r_{\ldots} . .-r_{\bullet}\right) \leqslant "$,

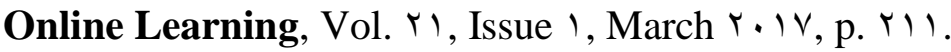

$(r \wedge)$ David H. Johnston: "Sitting Alone in the Staffroom Contemplating my Future': Communities of Practice, Legitimate peripheral Participation and Student Teachers' Experiences of Problematic School Placements as Guests", Cambridge Journal of Education, Vol. \{\urcorner , No. $\left\{, r^{\prime} / \uparrow\right.$, p. ort.

(Y9) بيومى محمد ضحاوى ورضا إبراهيم المليجى: توجهات الإدارة التربوية الفعالة فى مجتمع المعرفة،

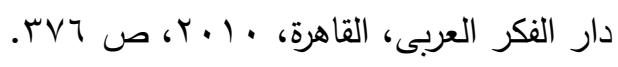

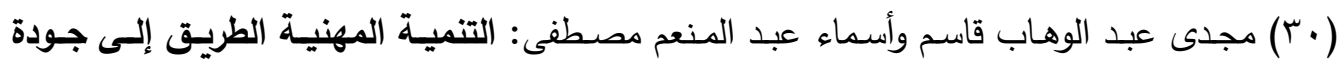

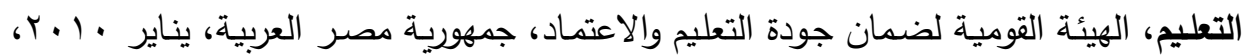
ص ص

( (T) نعمات عبد الناصر أحمد: "التخطيط لاستخدام الواقع الافتراضى كوسيط اتصالى للتعليم المفتوح

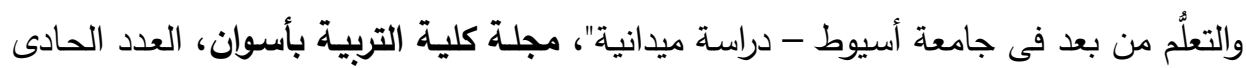

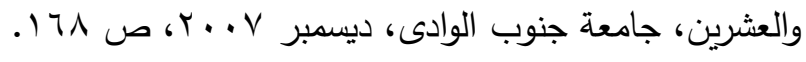

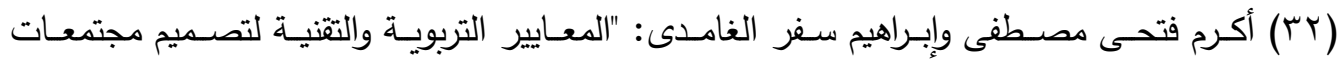

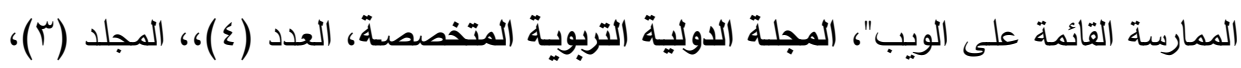

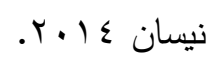

(Tr) نهلة سيد أبو عليوة: "دراسة مقارنة لبعض تطبيقات نظريـة مجتمع الممارسة فى التميـة المهنية

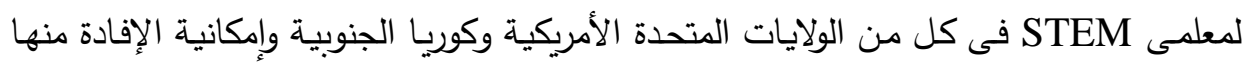

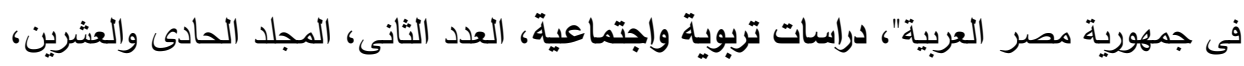

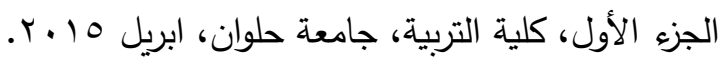


( $\longleftarrow$ ) David M. Carroll: "Collaborative Professional learning: Creating A Community of Practice Among School and University Partners in Teacher Education", Ph.D., Michigan State University, Department of Teacher Education, Y..l.

(ro) Catherine H. Monaghan \& Norina L. Columbaro: "Communities of Practice and Students' Professional Development", International Journal of Teaching and Learning in Higher Education, Vol. $r \cdot$, No. $r, r \cdots q$.

(чч) Charlotte Carey \& et al.: "Cross-University Enterprise Education collaboration as a Community of Practice", Education + Training, Vol. 01 , No. ^/9, r..9.

( $r v)$ Ismi Arif Ismail \& et al.: "Development of Educational Leadership in Research University Through Community of Practices Among Professors", Procedia Social and Behavioral Sciences, Vol.10, December $r .11$.

( $\wedge$ ) Aimée Lynn deChambeau: "Supported Student Success: communities of Practice in Higher Education", Ph.D., Prescott College, USA, r. 1 .

( 4 q) Sarah Bradbury \& Lucie Middlemiss: "The Role of Learning in Sustainable Communities of Practice", Local Environment, Vol. $r \cdot$, No. $\vee, Y \cdot 10$, p. $\vee 91$.

(\&•) Patricia Mccarver: "What a Learning Community Learns: A Cooperative Inquiry", Ph.D., The Graduate Faculty of the California Institute of Integral Studies, California, USA, $r \cdots r$, p. $\$.

(\&) Nicolae Nistor \& et al.: "Sense of Community in Academic Communities of Practice: Predictors and Effects", Higher Education, Vol. 19, Issue $r$, r. 10, p. ro9.

$(\leqslant r)$ Etienne C. Wenger \& William M. Snyder: "Communities of Practice: The Organizational Frontier", Harvard Business Review, Vol. v^, No. ', r..., p. 1 rq.

( $\leqslant r)$ Etienne Wenger, Richard McDermott \& William M. Snyder: Cultivating Communities of Practice: A Guide to Managing Knowledge, Harvard Business School Press, Boston, Massachusetts, United States of America, r..., pp. $\leqslant, 0$.

$(\varepsilon \varepsilon)$ Kay Cram \& Shona Gore: "Etienne Wenger and Communities of Practice - Who is in Your 'Village'?", International Journal of Birth \& Parent Education, Vol. $r$, Issue $1, r \cdot 1 \leqslant$, p. $r q$.

( $₹$ ) Linda $\mathrm{C} \mathrm{Li} \&$ et al.: "Evolution of Wenger's Concept of Community of Practice", Implementation Science, Vol. ₹, No. ' ', r.. q, p. ₹.

( ₹7) Mari Haneda: "Classrooms as Communities of Practice: A Reevaluation", Teachers of English to Speakers of Other Languages (TESOL)

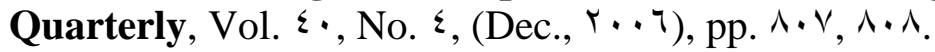


( $\vee$ \) Allan Macpherson \& Elena Antonacopoulou: "Translating Strategy in to Practice: The Role of Communities of Practice", Journal of Strategy

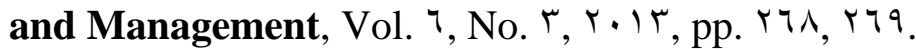

( $\_$) Christopher Koliba \& Rebecca Gajda: "Communities of Practice" as an Analytical Construct: Implications for Theory and Practice", International Journal of Public Administration, Vol. r $r$, Issue $r$, r.. q, pp. $1 \cdot 1,1 \cdot r$.

( ₹१)Linda $\mathrm{C} \mathrm{Li} \mathrm{\&} \mathrm{et} \mathrm{al.:} \mathrm{"Evolution} \mathrm{of} \mathrm{Wenger's} \mathrm{Concept} \mathrm{of} \mathrm{Community} \mathrm{of}$ Practice", Op. Cit., pp. $\varepsilon_{-}$.

(๑.) Norman Vaughan: "Investigating How a Blended leaning Approach Can Support an Inquiry Process within a Faculty Learning Community", Ph.D., University of Calgary, Alberta, Canada, $r \ldots \varepsilon$, p. $r \leqslant$.

(0) Etienne Wenger, Richard McDermott \& William M. Snyder: Cultivating Communities of Practice: A Guide to Managing Knowledge, Op. Cit., p. ${ }^{7}$.

(or) Ibid: p. 01 .

(or) Ettore Bolisani \& Enrico Scarso: "The Place of Communities of Practice in Knowledge Management Studies: A Critical Review", Journal of Knowledge Management, Vol. $\wedge$, No. r, r. I $\varepsilon$, p. rฯq.

$(\bullet \varepsilon)$ Etienne Wenger: "Conceptual Tools for Cops as Social Learning Systems:

Boundaries, Identity, Trajectories and Participation", Chris Blackmore (Editor), Social Learning Systems and Communities of Practice, Springer and The Open University, United Kingdom, $r_{\cdot} \cdot \cdot$, p. $1{ }^{\prime}$.

(00) Andrew Cox: "What are Communities of Practice? A Comparative Review of Four Seminal Works", Journal of Information Science, Vol.

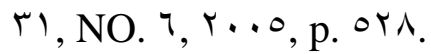

(07) Rocco Agrifoglio: Knowledge Preservation Through Community of Practice: Theoritical Issues and Empirical Evidence, Springer Briefs in Information Systems, New York, $r \cdot 10$, pp. ro, r .

( $\vee$ V) Patrick Ngulube \& Bongekile Mngadi: "Utilisation of Communities of Practice in the Humanities at The Universities of Kwazulu-Natal Zululand, South Africa", African Journal of Library, Archives \& Information Science, Vol. 19, No. ', r.. १, p. r.

(०^) Olivier Serrat: Building Communities of Practice, Op. Cit., pp. ' - $r$.

(०9) Joseph Bashouri \& Glen William Duncan: "Communities of Practice: Linking Knowledge Management and Strategy in Creative Firms", Journal of Business Strategy, Vol. ro, Issue $7, r \cdot 1 \leqslant$, pp. $0 \leqslant-00$.

( 7 . ) Catherine H. Monaghan: "Communities of Practice: A Learning Strategy for Management Education", Journal of Management Education, Vol. ro, No. r, r. Il, p. $\leqslant r \cdot$ 
(7) Kwok Wing Lai \& et al.: Literature Review and Synthesis: Online Communities of Practice, A Report Submitted to The Ministry of Education, New Zealand, Y.. `, p. $1 \cdot$.

(7r) Celia Zárraga-Oberty \& Petra De Saá - Pérez: "Work Teams to Favor Knowledge Management: Towards Communities of Practice", European

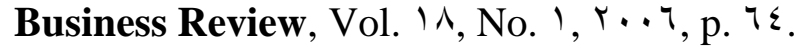

(7r) Jim Rogers: "Communities of Practice: A Framework for Fostering Coherence in Virtual Learning Communities", Educational Technology

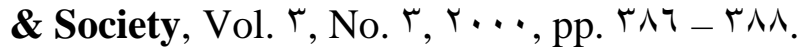

( $7 \varepsilon$ ) Mark Thompson: "Structural and Epistemic Parameters in Communities of Practice", Organization Science, Vol. 17, No. r, April r... , p. 10r.

(70) See:

- Rocco Agrifoglio: Knowledge Preservation Through Community of Practice: Theoretical Issues and Empirical Evidence, Op. Cit., pp. ${ }^{\top} \cdot-$ rะ.

- Line Dube, Anne Bourhis \& Réal Jacob: "Towards a Typology of Virtual Communities of Practice", Interdisciplinary Journal of Information, Knowledge and Management, Vol. ', ץ. . ', pp. $\vee_{0}$ ᄉ).

- Haradhan Kumar: "Roles of Communities of practice for the Development of the Society", Journal of Economic Development,

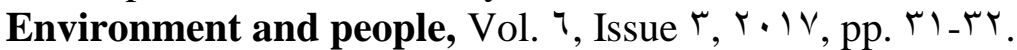

(7 ) Etienne Wenger: "Communities of Practice and Social Learning Systems", Organization, Vol. V, No. r, SAGE Social Science Collections, London, r..., pp. rr. - rrr.

(TV) Peyman Akhavan \& et al.: "Identifying the Success Factors of Communities of Practice (COPs): How do They Affect on Students to Creat Knowledge?", VINE Journal of Information and Knowledge,

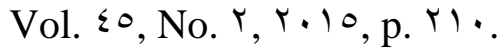

( $\uparrow$ ) Steven J. Kerno Jr.: "Limitations of Communities of Practice: A Consideration of unresolved Issues and Difficulties in the Approach", Journal of Leadership \& Organizational Studies, Vol. 10, No. ', August $r \cdots \wedge$, pp. $\vee r-V \tau$.

(79) Linda $\mathrm{C} \mathrm{Li} \&$ et al.: "Evolution of Wenger's Concept of Community of Practice", Op. Cit., p. r.

$(\vee \cdot)$ Celia Zarraga-Oberty \& PetraDe Saa-Perez: "Work Teams to Favor Knowledge Management: Towards Communities of Practice", Op. Cit., p. 77.

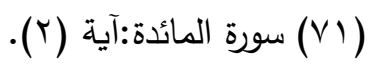


(Vr) Ettore Bolisani \& Enrico Scarso: "The Place of Communities of Practice in Knowledge Management Studies: A Critical Review", Op.Cit., p. rฯv.

نهلة سيد أبو عليوة: "دراسة مقارنة لبعض تطبيقات نظريـة مجتمع الممارسة فى التتمية المهنية لمعلمى STEM فى كل من الولايات المتحدة الأمريكية وكوريا الجنوبية وإمكانية الإفادة منها فى

$$
\text { جمهورية مصر العربية، مرجع سابق، ص الج. }
$$

$(\vee \varepsilon)$ Maria Jakovijevic \& et al.: "Forming Communities of Practice in Higher Education: A Theoretical Perspective", op.cit., p. $111 \cdot$.

(vo) Jonathan H. Klein \& et al.: "Knowledge Characteristics of Communities of Practice", Knowledge Management Research \& Practice, Vol. ץ, Issue $r, r \cdots 0$, p. $1 \cdot \wedge$.

(Vฯ) Ibid: pp. $1 \cdot \wedge-1 \cdot 9$.

$(\vee \vee)$ Stefan Ghimisi \& Dana Nicula: "The Role of Communities of Practice in Higher Technical Education, op.cit., pp.

$(\vee \wedge)$ Igor Pyrko \& et al.: "Thinking Together: What Makes Communities of

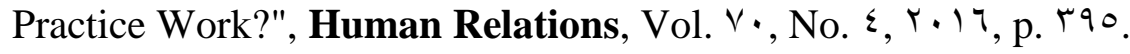

( $\vee$ q) Azeddine Chikh \& Lamia Berkani: "Communities of Practice of elearning, an Innovative Learning Space for e-learning Actors", op.cit., p. $0 . r \leqslant$.

(^•) Ibid: pp. $0 . Y \leq-0 . r \uparrow$.

(A) M. Aaron Bond \& Barbara B. Lockee: "Evaluating The Effectiveness of Faculty Inquiry Groups as Communities of Practice for Faculty Professional Development", Journal of Formative Design in Learning, Vol. r, Issue ', Association for Educational Communications \& Technology, r.ı^, p. ${ }^{\top}$.

(Ar) Catherine F. Brooks: "Toward 'hybridised' Faculty Development for the Twenty-first Century: Blending Online Communities of Practice and Face to Face Meetings in Instructional and Professional Support Programmes", Innovations in Education and Teaching International, Vol. $\leqslant v$, No. $r$, August $r \cdot 1 \cdot$, pp. r rr_r r

(^r) Julie E. Golden: "Supporting Online Faculty Through Communities of Practice: Finding The Faculty Voice", Innovations in Education and Teaching International, Vol. or, No. ', r. 17 , pp. 17 - ^9.

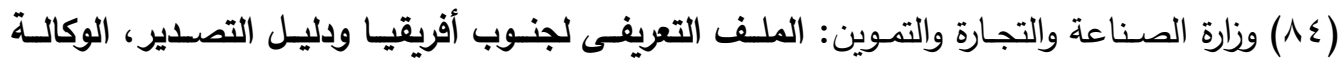

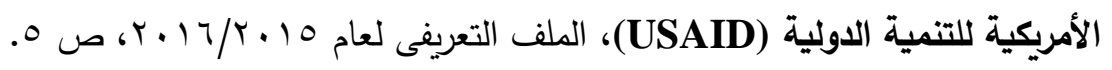

(^०) Emily Bagarukayo \& Billy Kalema: "Evaluation of E-Learning Usage in South African Universities: A Critical Review", International Journal of Education and Development Using Information and 
Communication Technology (IJEDICT), Vol. ' ', Issue r, r.10, p. 179.

(^५) Rene Erasmus: "The Impact of Communities of Practice (Cop) on Interfirm Alliance Research Terms", Doctorate of Business Leadership (DBL), University of South Africa, South Africa, ${ }^{\prime} \cdot{ }^{\circ}$, p. $9 \cdot$.

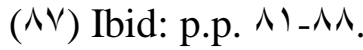

$(\wedge \wedge)$ National Research Foundation: Framework Document: Communities of

Practice - South African Research Chairs Initiative (SARCHI),

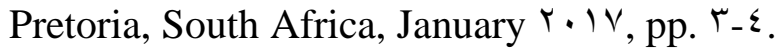

(^१) Ibid: p. ${ }^{\circ}$

(१•) Ibid: p. $\vee$.

(9) Patrick Ngulube \& Bongekile Mngadi: "Utilisation of Communities of Practice in the Humanities at the Universities of Kwazulu - Natal Zululand, South Africa", Op.cit., p. ${ }^{r}$.

(9r) Susan Benvenuti: "Pedagogy of Peers: Cultivating Writing Retreats as Communities of Academic Writing Practice", South African Journal of

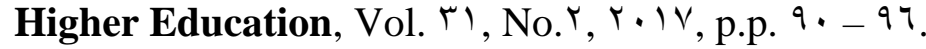

(१५) Sharita Bharuthram \& Carolynn Kies: "Introducing e-learning in a South African Higher Education Institution: Challenges arising from an Intervention and Possible Responses", British Journal of Educational Technology, Vol. « «, Issue $r$, April r. $r$, p.p. ${ }^{r}-\vee$.

( $q \varepsilon)$ Johann Van Wyx: Communities of Practice in an Academic Library: A run on the Wild Side?", oth $^{\text {th }}$ International Conference of Animal Health Information Specialists, \& $-\vee$ July, University of Pretoria, $\gamma . .0$, pp. $9 \vee_{-}$ $1 \cdot 1$.

(90) وزارة التعليم العالى، وكالة الوزارة للتخطيط والمعلومـات: محتوى موقـع الملحقيـة الثقافيـة فى

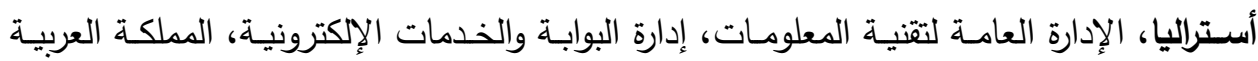

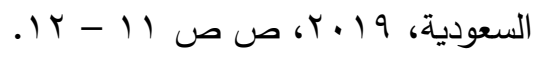

(97) Ria Hanewald: "Teachers' learning in Online Communities of Practice: Two Case Studies from Australia", International Conference on Educational Technologies, International Association for Development of the Information Society, $r_{\bullet} \mid r$, pp. $9 \vee_{-} q \wedge$.

( $\vee$ ) Jacquelin McDonald \& Cassandra Star: "Designing the Future of Learning Through a Community of Practice of Teachers of First Year Courses at an Australian University", In the First International LAMS Conference: Designing the Future of learning, $\uparrow-\wedge$ December,

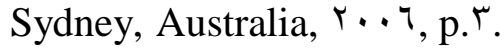

( $१$ ^) Judy Nagy \& Tony Burch: "Communities of Practice in Academe (Cop iA): Understanding Academic Work Practices to Enable Knowledge 
Building Capacities in Corporate Universities", Oxford Review of Education, Vol. ro, No. r, April r.. q, pp. r ro-rrч.

(१९) Jull Lawrence \& Michael Sankey: "Communities of Practice: Asphere of Influence Enhancing Teaching and Learning in Higher Education", ANZC A $\cdot \wedge$ Conference, Power and Place, Wellington, July $\uparrow \cdots \wedge$, pp. $1-1$ r.

( $\cdots)$ Ruth Laxton \& Andrelyn C. Applebee: "Developing Communities of Practice Around e-learning and Project Management", Journal of Distance Education, Vol. $r \leqslant$, No. $1, r_{\bullet} 1 \cdot$, pp. $1 r V_{-} \mid r \tau$.

(1.1)Griffith University: "Guidelines for Establishing Communities of Practice", Available at: http://policies.griffith.edu.au/pdf/Establishing

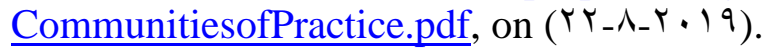

(r • ( ) وزارة التعليم العالى بالمملكة العربية السعودية: دليل المبتعث السعودى للدراسـة فـى الولايات

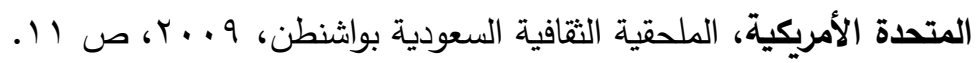

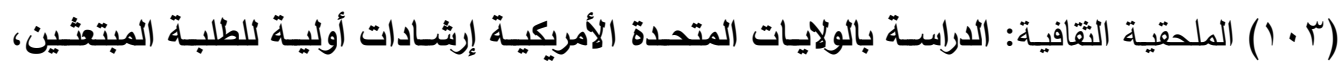

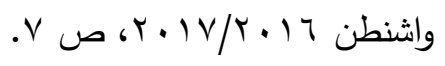

$(1 \cdot \varepsilon)$ United States Office of Personnel Management: Learning and Knowledge Sharing Strategy, Version $1 . \cdot$, June $r \cdot 1$ ', pp. $1-r$.

$(1 \cdot 0)$ U.S. Department of Education, Office of Educational Technology: Exploratory Research on Designing Online Communities of Practice for Educators to Create Value, U.S. Department of Education, U.S.A, r.l $\varepsilon$, p. $r$.

$(1 \cdot 7)$ Kristin K. Janke \& et al.,: "Building a Multi-Institutional Community of Practice to Foster Assessment", American Journal of Pharmaceutical

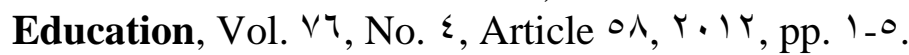

$(1 \cdot \vee)$ Michelle Drouin \& et al.: A Community of Practice model for Introducing Mobile Tablets to University Faculty", Innovative Higher Education, Vol. rq, No. r, June $r \cdot 1 \leqslant$, pp. $r$ ro- $r \leqslant r$.

$(1 \cdot \wedge) J a n e$ Christina Ostrander: "Costs, Benefits, and Participation in Online Knowledge Sharing in Communities of Practice for Faculty", Ph.D.,

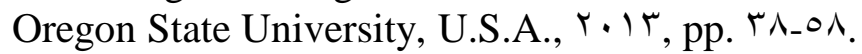

(1.9)Malose Langa: \#Hashtag: An analysis of the \# FeesMustfall Movement at South African Universities, Centre for the Study of Violence and Reconciliation (CSVR), Johannesburg, South Africa, r. IV, p. Irr.

(1).)Ibid: Irr.

(1) Sally Peberdy: International Migrants in Johannesburg's Informal Economy, SAMP Migration Policy Series, No. $\vee$, Southern African Migration Programme: Waterloo and Cape Town, r. I ', p. 9. 
( 1 ) r)Alan Oxley \& et al.,: Australia's Place in the World, Committee for Economic Development of Australia (CEdA), Melbourne, Australia, r. IV, p. rq.

( $/ \mathcal{Y}$ )Paul Antonio \& et al.,: Toowoomba Region: Annual Report $r \cdot \mid V / r \cdot 1 \wedge$, Toowoomba Regional Council, Australia, $r \cdot 1 \wedge$, p. $r \tau$.

(1) $\varepsilon$ )Ibid: p. $r \cdot$.

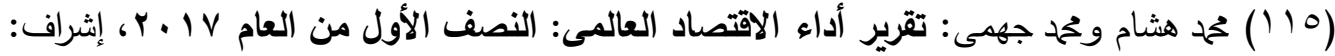
رائد الخضر وجوراف كاشايب، إيكويتى جلوبال ماركت Equiti Global Markets، لندن،

$$
\text { . } V \text { ص }
$$

( 117$)$ Beth Pearson \& Colin Gordon: Young Workers and The Iowa Economy: The State of Working Iowa $r \ldots \wedge$ Part $r$, The Iowa Policy Project, Iowa City Office, USA, September $r \cdots \wedge$, p. ${ }^{\circ}$.

( $1 \mathrm{~V}$ )Malose Langa: \#Hashtag: An analysis of the\# FeeMustfall Movement at South African Universities, op.cit., pp. 1 1 Tr.

(111) الملحقية الثقافية السعودية فى أستراليا: أصداء الحالـة الثقافية فى أستراليا - تقريـر الحالـة

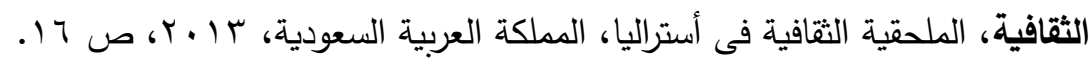

( 119 )Paul Antonio \& et al.,: Toowoomba Region: Annual Report r.।V/r.1^, op.cit., p. 11.

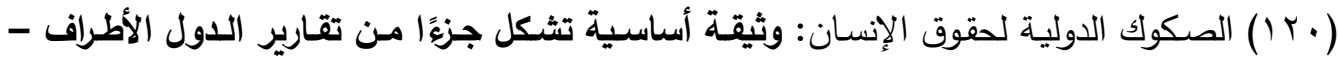

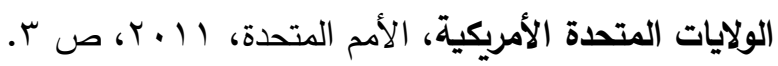

( 1 Y) Mohlapamaswi Mokgohloe Lorraine \& Rachidi Richard Molapo: "South Africa's Challenges of Realising her Socio-Economic Rights", Mediterranean Journal of Social Sciences, Vol. ${ }^{\circ}$, No. $r v$, MCSER Publishing, Rome, Italy, December $r \cdot 1 \leqslant$, p..$\cdot r$.

(I r r) Brian Levy \& et al.,: The Politics and Governance of Basic Education: A Tale of Two South African Provinces, Oxford University Press, Oxford, $\uparrow \cdot 1 \wedge$, p. ^^.

( Yr $^{2}$ Clover Moore \& et al.,: City of Sydney Annual Report: Statutory Returns r. I Y/r. IV (Sydney r.r.), Sydney, Australia, r. IV, p..

( $r \varepsilon) W i l l i a m$ Sheldrake \& John Stafford: IPFW Roles and Governance Report: An Analysis of the Issues and Opportunities Surrounding the Roles and Governance of IPFW, Presented to: Northeast Indiana Regional Partnership, Policy Analytics, Indiana University - Purdue University Fort Wayne USA, August Y. I \&, p. 7.

(1 ( ) وزارة الصناعة والتجارة والتموين: الملف التعريفى لجنوب أفريقيا ودليل التصدير ، مرجع سـابق، 


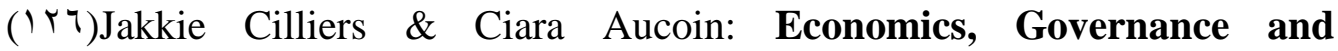
Instability in South Africa, Institute for Security Studies (ISS), ISS Paper $r q r$, June $r \cdot 17$, pp. $\varepsilon_{-} 0$.

(I rv) William Sheldrake \& John Stafford: IPFW Roles and Governance

Report: An Analysis of the Issues and Opportunities Surrounding the Roles and Governance of IPFW, op.cit., p. $\vee$.

(I YA)Shaakira Karolia \& et al.,: Capital Economic Outlook, Economic Intelligence Unit, Office of Executive Mayor, City of Tshwane, South Africa, $r^{\circ} 17$, p.. .

( (1 Y) الحكومة الأسترالية، قسم الهجرة وحماية الحدود: الحياة فى أستراليا: القيم والمبادئ الأسترالية،

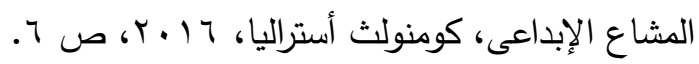

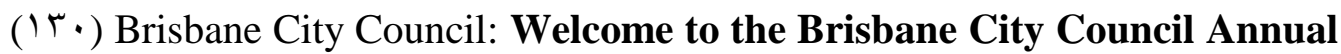
Report $r \cdot \mid \vee / r \cdot 1 \wedge$, Brisbane, Australia, $r \cdot \mid \wedge$, p. .

( 1 r I) Heather B. Gonzalez: The National Science Foundation: Background and Selected Policy Issues, Congressional Research Service, CRS Report Prepared for Members and Committees of Congress, June r. I , p. .'.

(r (1) وزارة الصناعة والتجارة والتموين: الملف التعريفى لجنوب أفريقيا ودليل التصدير ، مرجع سـابق، ص ص

( IT) Shaakira Karolia \& et al.: Capital Economic Outlook, op.cit., p.p. 9_l· (ع ז ا) الحكومة الأسترالية، قسم الهجرة وحماية الحدود: الحياة فى أستراليا، القيم والمبادئ الأسترالية، مرجع سابق، ص V V

(I ro) Brisban City Council: Welcome to the Brisbane City Council Annual Report $r \cdot \mid v / r \cdot 1 \wedge$, op.cit., p. $\leqslant r$.

(דr (1) الصكوك الدولية لحقوق الإنسان: وثيقة أساسية تثكل جزءًا من تقارير الدول الأطراف: الولايات

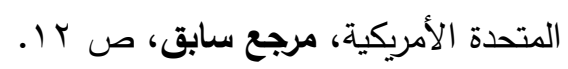

(ITVV) رحاب فايز أحمد سيد: "بوابات مشروعات تطوير الجامعات المصرية الحكومية: دراسة تحليلية

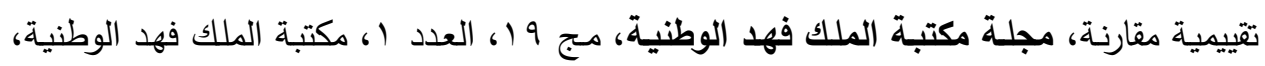
tritr

(1 ا ( أشرف محمود أحمد محمود: "تصور مقترح لتطوير مراكز تتمية قدرات أعضاء هيئة التدريس

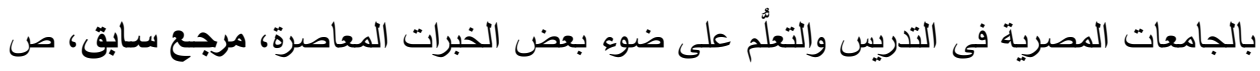


(1 (1) ثروت عبد الحميد عبد الحافظ والسيدة محمود إبراهيم سعد: "رؤية مقترحة لأدوار قادة مشروعات

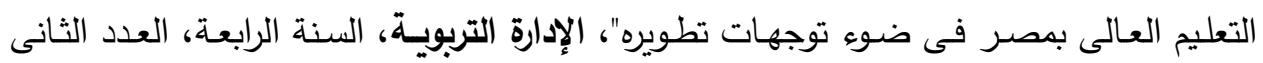

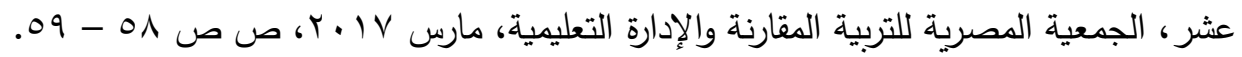

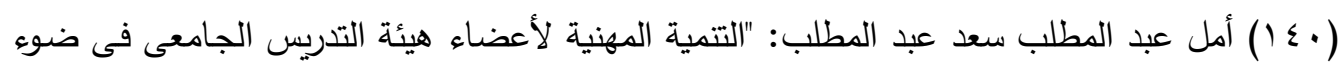

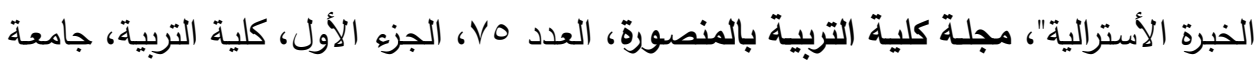

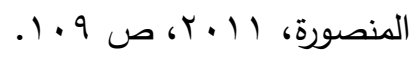
(1) (1) أمانى السيد غبور : "دراسـة تقويمية لبرامج التتمية المهنية لأعضاء هيئة التدريس بالجامعات

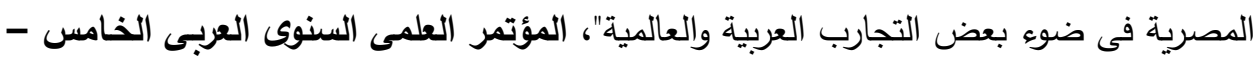

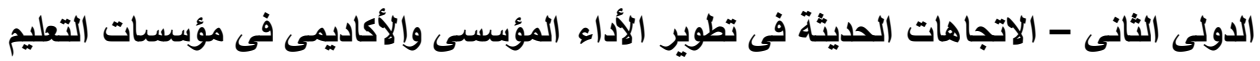

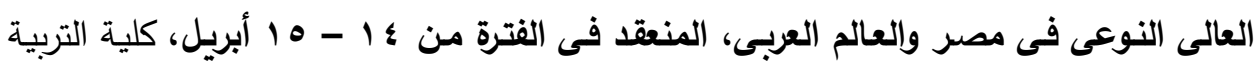

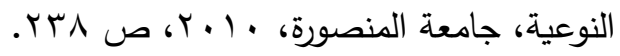

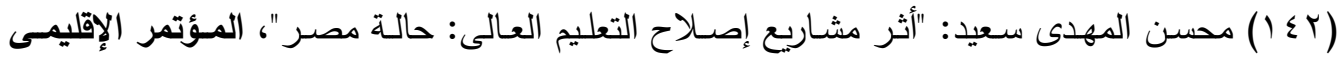

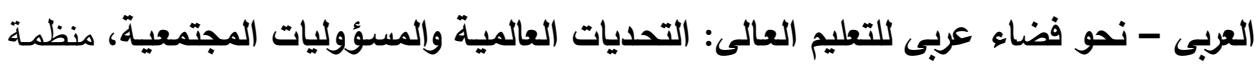

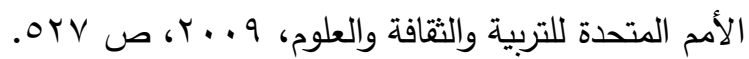
(T ( ) رضا إبراهيم المليجى: "التتمية المهنية المستدامة لأعضاء هيئة التدريس بالجامعات المصرية

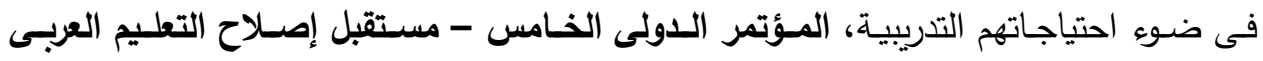

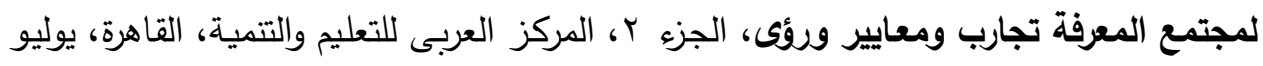

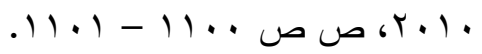
( § ( ) أمانى السيد غبور : "دراسـة تقويمية لبرامج التتمية المهنية لأعضـاء هيئة التدريس بالجامعات

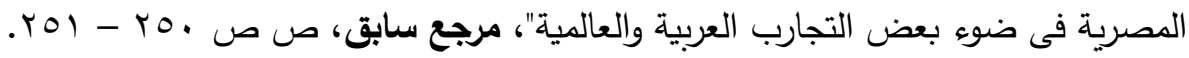

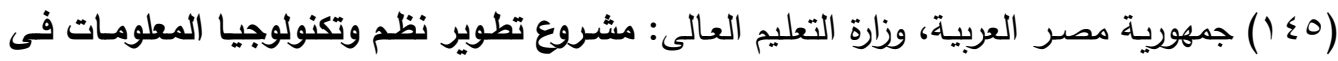

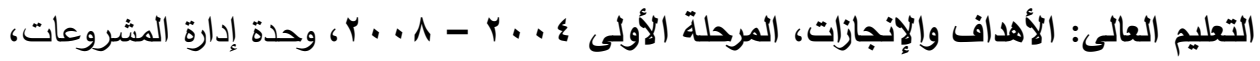
ص i i.

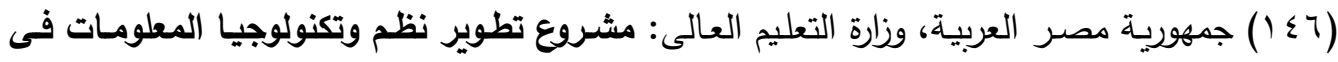

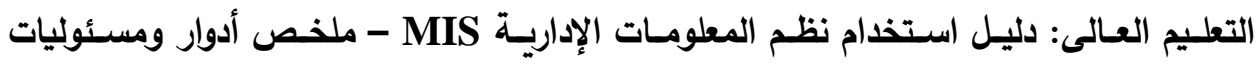

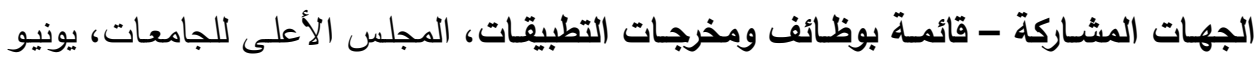


( IVV)

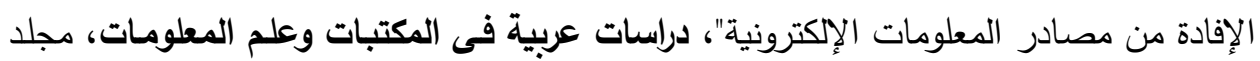

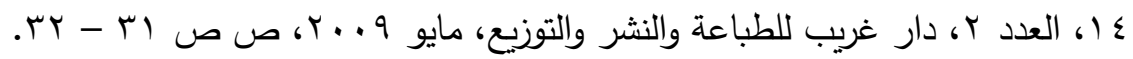

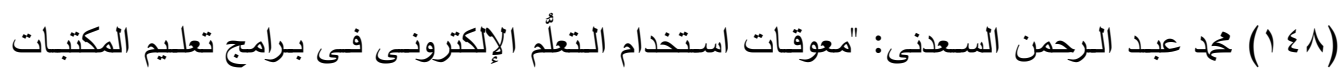

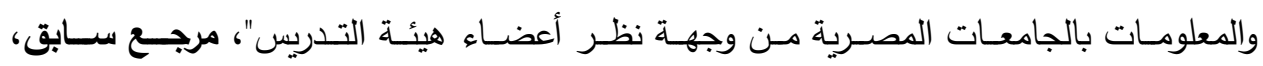
ص می . (9 ( ) محمد محمد عبد الهادى بدوى: "برنامج تدريبى مقتزح قائم على نظم إدارة التعلُم الإلكترونى عبر الثبكات

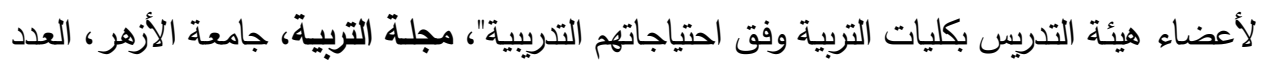

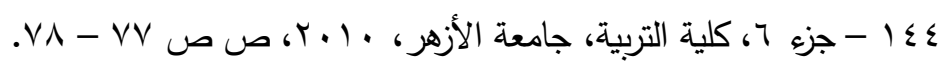

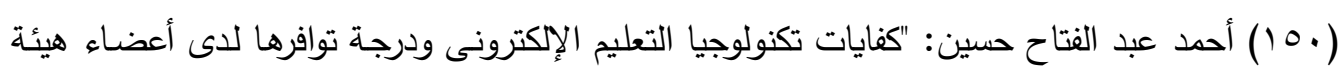

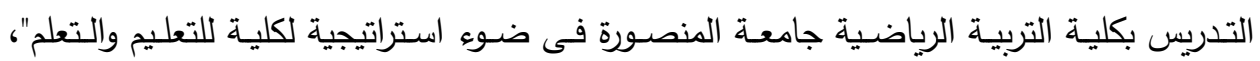

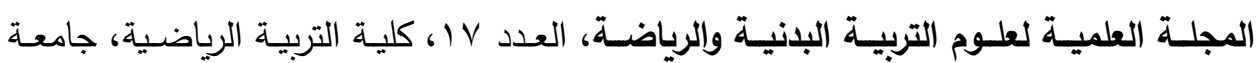

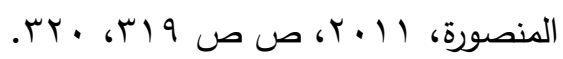
(101) محمد فوزى أحمد بدوى: "معوقات استخدام أعضاء هيئة التدريس بجامعة المنوفية لأنظمة إدارة

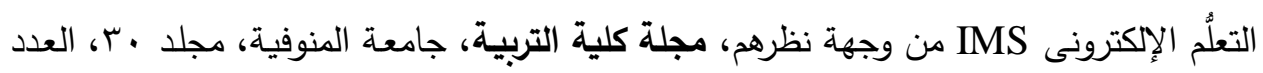

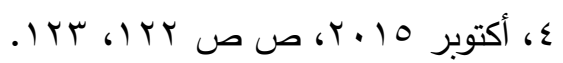

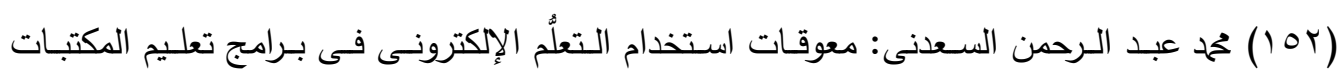

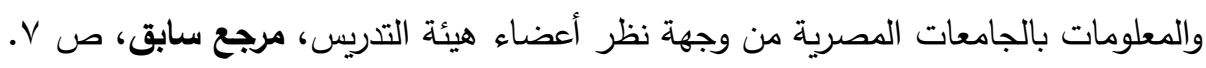

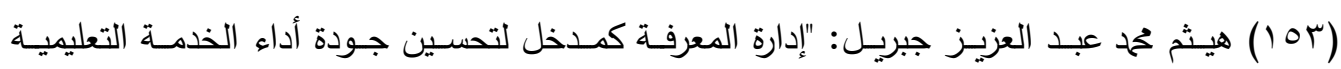

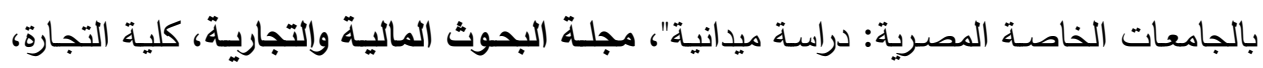

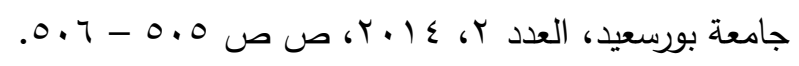

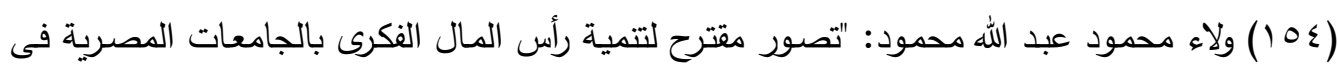

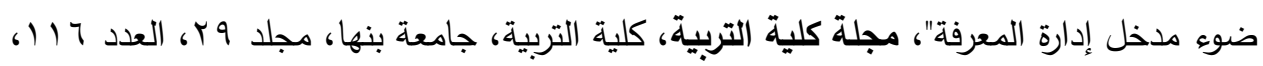

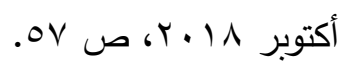

(100) نهلة عبد القادر هاشم: "إدارة المعرفة مدخل للإبداع التتظيمى فى الجامعات المصرية"، مستقبل

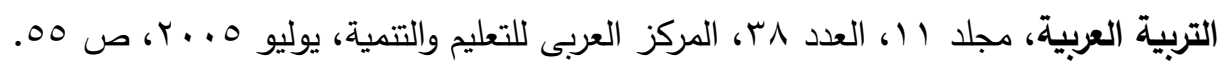

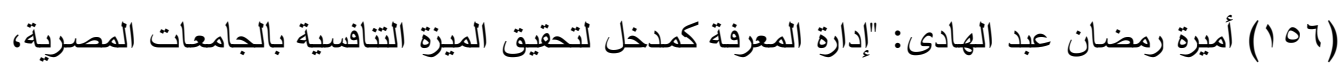

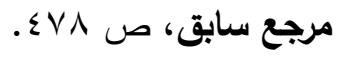




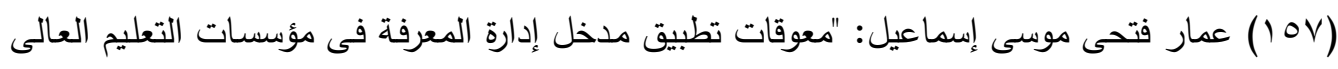

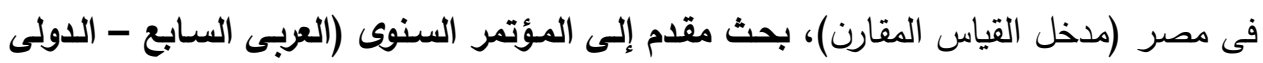

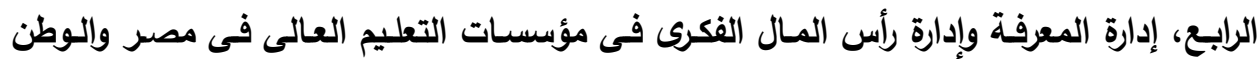

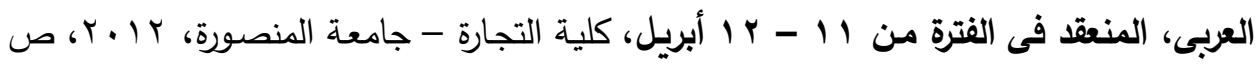
.. (101) محمد عبد الحميد لاشين ونهلة سيد أبو عليوة: "دراسة مقارنة لتطبيقات إدارة المعرفة فى بعض

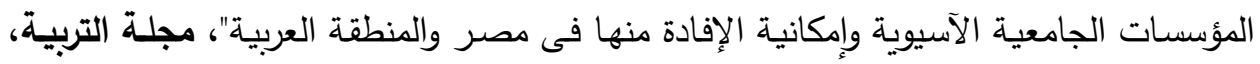

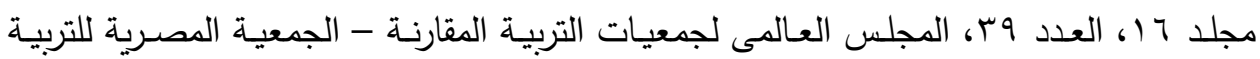

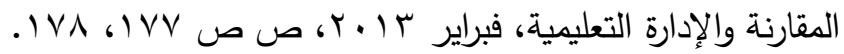
(109) أميمة حلمى عبد الحميد مصطفى: "تحسين الإنتاجية العلمية لأعضاء هيئة التدريس بالجامعات

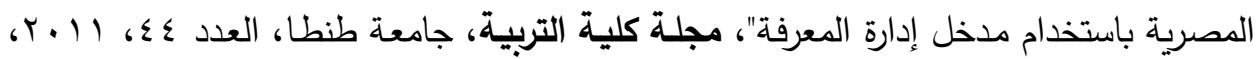

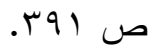

